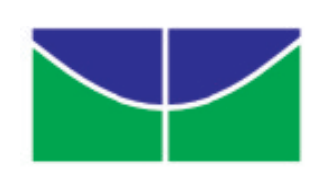

Universidade de Brasília - UnB

Faculdade de Ciências da Saúde

Programa de Pós-Graduação em Ciências da Saúde

Nível: Doutorado

\title{
EDUCAÇÃO EM SAÚDE NAS BIBLIOTECAS PÚBLICAS DO DISTRITO FEDERAL: UMA NOVA INTERLOCUÇÃO PARA QUALIDADE DE VIDA, PROMOÇÃO DA SAÚDE E EPIDEMIOLOGIA.
}

Tema de pesquisa: epidemiologia

Linha de pesquisa: epidemiologia, saúde e educação

Área de concentração: saúde coletiva

Orientador: Prof. Dr. Edgar Merchan Hamann 


\author{
UNIVERSIDADE DE BRASÍLIA - UNB \\ FACULDADE DE CIÊNCIAS DA SAÚDE \\ PROGRAMA DE PÓS-GRADUAÇÃO EM CIÊNCIAS DA SAÚDE
}

JACQUELINE RAMOS DE ANDRADE ANTUNES GOMES

\title{
EDUCAÇÃO EM SAÚDE NAS BIBLIOTECAS PÚBLICAS DO DISTRITO FEDERAL: UMA NOVA INTERLOCUÇÃO PARA QUALIDADE DE VIDA, PROMOÇÃO DA SAÚDE E EPIDEMIOLOGIA.
}

Tese apresentada como requisito parcial para a obtenção do Título de Doutora em Ciências da Saúde pelo Programa de Pós-Graduação em Ciências da Saúde da Universidade de Brasília.

Orientador:

Prof. Dr. Edgar Merchan Hamann

BRASÍLIA/DF 
G613p Gomes, Jacqueline Ramos de Andrade Antunes

Educação em saúde nas bibliotecas públicas do Distrito Federal: uma nova interlocução para qualidade de vida, promoção da saúde e epidemiologia / Jacqueline Ramos de Andrade Antunes Gomes. Brasília: 2015.

XVIII, 263p.; il.

Tese de Doutorado apresentada ao Programa de Pós-Graduação em Ciências da Saúde da Faculdade de Ciências da Saúde da Universidade de Brasília, como requisito para a obtenção do título de Doutor - 2015. Possui bibliografia, figuras, fotografias coloridas, tabelas, quadros e anexos com documentação específica.

Orientador: Prof. Dr. Edgar Merchán Hamann.

1. Saúde Coletiva 2. Educação em Saúde 3. Epidemiologia 4. Qualidade de Vida.

CDU 613.2

CDD 613

Bibliotecária Responsável: Profa. Dra. Walda de Andrade Antunes CRB-1/697 


\title{
EDUCAÇÃO EM SAÚDE NAS BIBLIOTECAS PÚBLICAS DO DISTRITO FEDERAL: UMA NOVA INTERLOCUÇÃO PARA QUALIDADE DE VIDA, PROMOÇÃO DA SAÚDE E EPIDEMIOLOGIA.
}

\begin{abstract}
Tese apresentada como requisito parcial para a obtenção do Título de Doutora em Ciências da Saúde pelo Programa de Pós-Graduação em Ciências da Saúde da Universidade de Brasília.
\end{abstract}

Aprovado em 03 de Março de 2016

\author{
BANCA EXAMINADORA \\ Presidente: Prof. Dr. Edgar Merchán Hamann \\ Universidade de Brasília \\ Prof. Dr. Pedro Sadi Monteiro \\ Universidade de Brasília
}

Profa. Dra. Maria Margarita Urdaneta Gutierrez Universidade de Brasília
Prof. Dr. Rafael Mota Pinheiro
Universidade de Brasília

Profa. Dra. Nidia Maria Lienert Lubisco

Universidade Federal da Bahia

Suplente: Prof. Dr. Natan Monsores de Sá

Universidade de Brasília 
1 - Identificação do Aluno Secretaria de Administração Acadêmica - SAA

Nome

Matrícula

Jacqueline Ramos de Andrade Antunes Gomes

10/0154417

Curso

Ciências da Saúde

Área de Concentração

Saúde Coletiva

Código

Departamento

2 - Sessão de Defesa de Tese

Título

"Educação em saúde nas bibliotecas públicas do Distrito Federal: uma nova interlocução para qualidade de vida, promoção da saúde e epidemiologia."

\begin{tabular}{l|l|l|}
\hline 3- Comissão Examinadora & Função & $\begin{array}{l}\text { Membro Interno vinculado ao programa (Presidente) } \\
\text { Departamento de Saúde Coletiva }\end{array}$ \\
\hline Nome & $\begin{array}{l}\text { Membro Interno näo vinculado ao programa } \\
\text { Departamento de Saúde Coletiva }\end{array}$ \\
\hline MARIA MARGARITA URDANETA GUTIERREZ (Doutor) & $\begin{array}{l}\text { Membro Interno não vinculado ao programa } \\
\text { Departamento de Enfermagem }\end{array}$ \\
\hline PEDRO SADI MONTEIRO (Doutor) & $\begin{array}{l}\text { Membro Interno não vinculado ao programa } \\
\text { Direção da Faculdade de Ciências da Saúde }\end{array}$ \\
\hline RAFAEL MOTA PINHEIRO (Doutor) & $\begin{array}{l}\text { Membro Externo não vinculado ao programa } \\
\text { Universidade Federal da Bahia }\end{array}$ \\
\hline Nídia Maria Lienert LubisCo (Doutor) & $\begin{array}{l}\text { Membro Interno não vinculado ao programa (Suplente) } \\
\text { Departamento de Saúde Coletiva }\end{array}$ \\
\hline NATAN MONSORES DE SÁ (Doutor) &
\end{tabular}

4 - Resultado

A Comissão Examinadora, em 03/03/2016 após exame da Defesa de Tese e argüição do candidato, decidiu:

X Pela aprovação da Tese $\square$ Pela aprovação da Tese, com revisão de forma, indicando o prazo de até 30 dias para apresentação definitiva do trabalho revisado.

Pela reprovação da Tese

Pela reformulação da Tese, indicando o prazo de versão. para nova

Preencher somente em caso de revisão de forma:

$\square$ O aluno apresentou a revisão de forma e a Tese foi aprovada.

Autenticação

Presidente da Comissão Examinadora

O aluno apresentou a revisão de forma e a Tese foi reprovada.

O aluno não apresentou a revisão de forma.

Autenticação

Coordenador do Curso

$03 / \frac{03}{\text { Data }} 16$ Assinatura/Carimbo

Ciente

Aluno

Data Assinatura/Carimbo

\section{$03,03,16$}

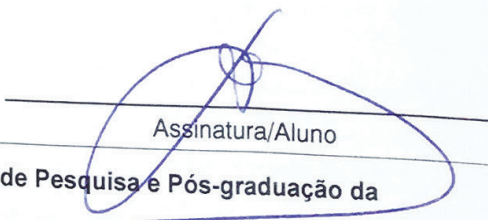

Universidade de Brasilia.

Aprovação do Decanato de Pesquisa e Pós-Graduação

Decisão:

Homologar

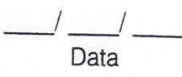

Assinatura do Decano 
Dedico este trabalho à minha professora de Educação, Moral e Cívica, que corajosamente, em meio ao Regime Militar vigente no Brasil à época, ensinou-nos o Método Científico de René Descartes, o que contribuiu para que nos tornássemos estudantes reflexivos, nascendo em mim o espírito investigativo. 


\section{AGRADECIMENTOS}

Aos meus pais, irmãos, sobrinhos, cunhadas, esposo, e sobrinha-neta. Minha eterna família adorada.

Ao Prof. Dr. Edgar Merchán Hamann, pelo apoio incondicional em todos os momentos.

À Profa. Dra. Maria Margarita Urdaneta Gutierrez, sempre ao meu lado.

Ao Prof. Dr. Pedro Sadi Monteiro, por acreditar em mim.

Ao Prof. Dr. Rafael Mota Pinheiro, por acreditar nesse projeto desde a Qualificação.

Ao Prof. Dr. Natan Monsores de Sá, meu primeiro orientador na Pós-Graduação.

À Profa. Dra. Nídia Maria Lienert Lubisco, que há muito tempo está presente e junto conosco.

Ao Exmo. Senador da República Cristovam Buarque, por viabilizar a realização deste projeto.

Aos Professores Doutores Antonio Miranda e Maria das Graças Pimentel de Menezes, pelo apoio incondicional.

À Madrinha, minha outra mãe, ao Tio Aristeu, Juliana, Guilherme e Vitória.

Aos meus avós maternos e paternos (In memorian)

Vó Lacy e Vovô Walter, a gente só morre quando é esquecido!

Ao incansável Erinaldo Vieira, sem palavras.

Aos meus gatos, cachorros e jabutis, peço desculpas por minhas ausências.

Ao Dr. Aloysio Campos da Paz Júnior (In memorian), eterna fonte de sabedoria que continua a inspirar-me.

Ao Dr. Marco Rolando Sainz Quiroga, essencial para dar-me tranquilidade com relação a minha mãe em um momento tão difícil nesta jornada.

Aos Residentes de Enfermagem em Centro Cirúrgico do HBDF que ingressaram de 2014 em diante.

Ao Dr. Jamil Ribeiro Elias, obrigada pela minha primeira mesa de trabalho.

Ao Dr. José Tadeu dos Santos Palmieri, pelas oportunidades valiosas.

Aos servidores da Subsecretaria de Atenção Integral à Saúde - SAIS/SES/DF.

Às queridas Lina e Tatiana, obrigada pela amizade, companheirismo e apoio.

À Dona Dirce, Dona Nancy, Rute e Márcia, do Hospital Sarah. Inesquecível gratidão!

A Dra. Vanessa Dalva Guimarães Campos, por acreditar junto comigo em um mundo melhor.

Aos servidores do Centro Cirúrgico do HBDF.

Aos servidores da Unidade de Anestesiologia e Medicina Perioperatória do HBDF.

Aos funcionários da Secretaria do Programa de Pós-Graduação em Ciências da Saúde - FS/UnB. Aos estimados membros da Banca, todo o meu agradecimento pela disponibilidade. 
"Prefiro afrontar o mundo para agradar a minha consciência do que afrontar a minha consciência para agradar o mundo". Humberto de Campos. 


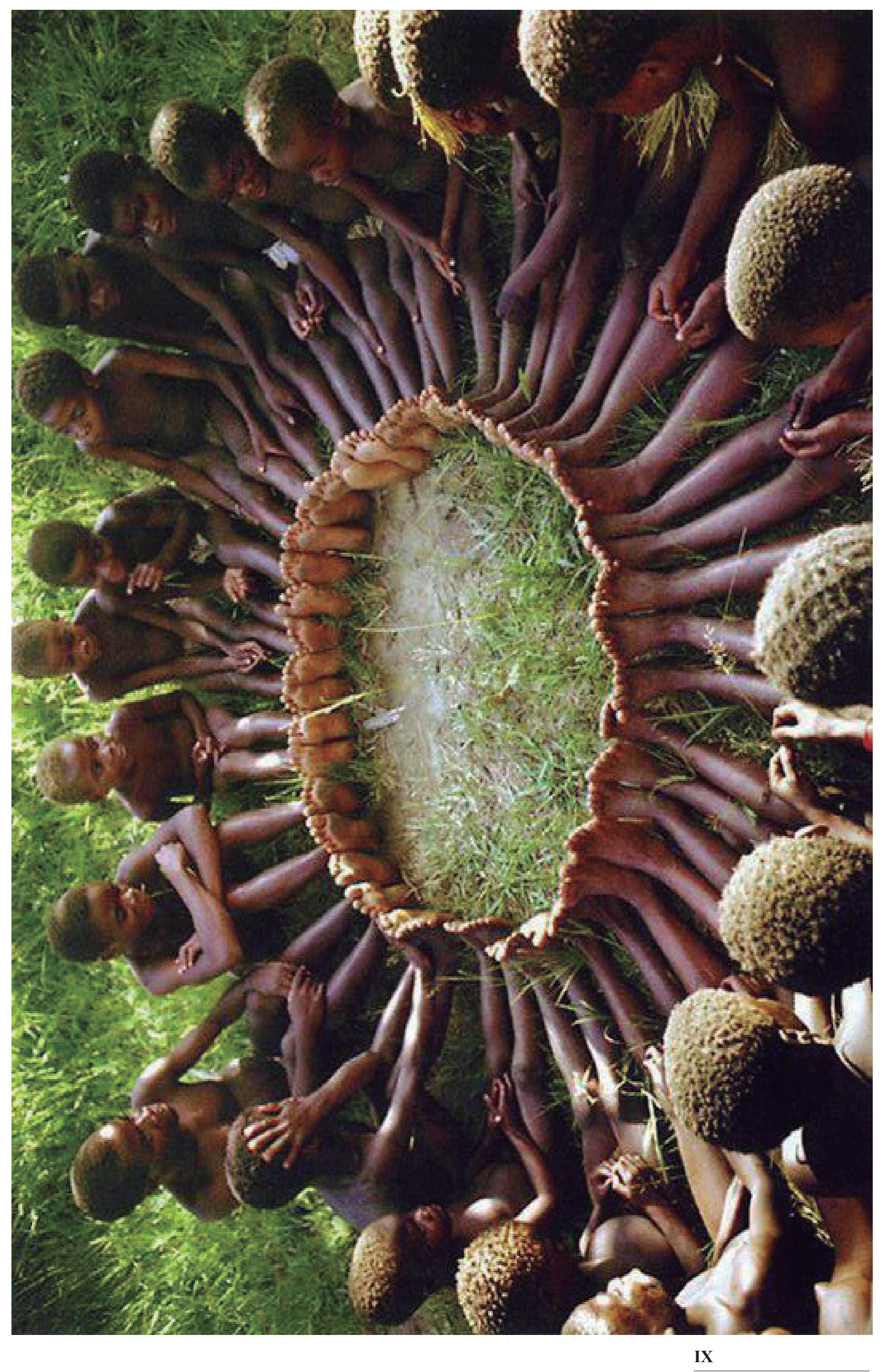




\section{“UBUNTU”, O QUE A ÁFRICA TEM A NOS ENSINAR}

Ubuntu é uma palavra existente nas línguas zulu e xhosa, faladas na África do Sul, que exprime um conceito moral, uma filosofia, um modo de viver que se opõe ao narcisismo e ao individualismo tão comuns em nossa sociedade capitalista neoliberal. Pode ser uma alternativa ecopolítica para uma convivência social e planetária pautada pelo altruísmo, fraternidade e colaboração entre os seres humanos.

Um antropólogo estava estudando os usos e costumes da tribo Ubuntu e, quando terminou seu trabalho, teve que esperar pelo transporte que o levaria até o aeroporto de volta pra casa. Como tinha muito tempo ainda até o embarque, ele propôs, então, uma brincadeira para as crianças que achou ser inofensiva. Comprou uma porção de doces e guloseimas na cidade, colocou tudo num cesto bem bonito com laço de fita e colocou debaixo de uma árvore. Aí ele chamou as crianças e combinou que quando ele dissesse "já!", elas deveriam sair correndo até o cesto e a que chegasse primeiro ganharia todos os doces que estavam lá dentro. As crianças se posicionaram na linha demarcatória que ele desenhou no chão e esperaram pelo sinal combinado. Quando ele disse "Já!" instantaneamente todas as crianças se deram as mãos e saíram correndo em direção à árvore com o cesto. Chegando lá, começaram a distribuir os doces entre si e a comerem felizes. $O$ antropólogo foi ao encontro delas e perguntou porque elas tinham ido todas juntas se uma só poderia ficar com tudo que havia no cesto e, assim, ganhar muito mais doces. Elas simplesmente responderam: - Ubuntu, tio. Como uma de nós poderia ficar feliz se todas as outras estivessem tristes? Ele ficou pasmo.

Meses e meses trabalhando nisso, estudando a tribo e ainda não havia compreendido, de verdade, a essência daquele povo. Ou jamais teria proposto uma competição, certo? Ubuntu significa: "Eu sou porque nós somos" ou, em outras palavras "Eu só existo porque nós existimos". "Como uma de nós poderia ficar feliz se todas as outras estivessem tristes?" A resposta singela da criança, é profunda e vital pois está carregada de valores como respeito, cortesia, solidariedade, compaixão, generosidade, confiança - enfim, tudo aquilo que nos torna humanos e garante uma convivência harmoniosa em sociedade. Ubuntu exprime a consciência da relação entre o indivíduo e a comunidade. É, ao mesmo tempo, um conceito moral, uma filosofia e um modo de viver que se opõe ao narcisismo e ao individualismo tão comuns em nossa sociedade ocidental capitalista. Enquanto a ideia europeia sobre a natureza humana baseia-se na ideia de liberdade, de que os indivíduos têm o poder da livre escolha, a ideia africana do ubuntu repousa sobre a ideia da comunidade, de que pessoas dependem de outras pessoas para serem pessoas. Segundo o espírito de ubuntu, as pessoas não devem levar vantagem pessoal em detrimento do bem-estar do grupo. Para que uma pessoa seja feliz será preciso que todas do grupo se sintam felizes. Estamos conectados uns com os outros e essa relação estende-se aos ancestrais e aos que ainda nascerão.

Ubuntu é, assim, um sistema de crenças, uma ética coletiva e uma filosofia humanista espiritual pautada pelo altruísmo, fraternidade e colaboração entre os seres humanos. Do ponto de vista político, o conceito de ubuntu é usado para enfatizar a necessidade da união e do consenso nas tomadas de decisão. É a síntese de um conhecido provérbio xhosa da África do Sul que diz o seguinte: "Umuntu Ngumuntu Ngabantu", que significa "Uma pessoa é uma pessoa por causa das outras pessoas". 


\section{Resumo}

\section{EDUCAÇÃO EM SAÚDE NAS BIBLIOTECAS PÚBLICAS DO DISTRITO FEDERAL: UMA NOVA INTERLOCUÇÃO PARA QUALIDADE DE VIDA, PROMOÇÃO DA SAÚDE E EPIDEMIOLOGIA}

Introdução: o conceito de saúde aproxima-se da noção de qualidade de vida e ao grau de satisfação em vários enfoques, com foco central na promoção da saúde. A prevenção das doenças não contempla a dimensão histórica e social, de políticas públicas saudáveis e intersetoriais, nem propicia o empoderamento das comunidades e a valorização de seus potenciais, bem como a melhoria de suas condições de vida e de trabalho. A promoção da saúde está mais vinculada a uma visão holística e socioambiental, atingindo limites extramuros das instituições de saúde tradicionais. A educação em saúde é uma ferramenta importante para se promover a saúde, no entanto, é importante interagir com o saber popular, pois dele se pode extrair subsídios para o processo educativo. Ademais, a educação em saúde pode ser feita na comunidade em vários locais, dentre os quais, as bibliotecas públicas, que são espaços privilegiados, caracterizando-se como núcleos comunitários de aprendizado, intervenção e promoção da saúde. Aliado a isso, a epidemiologia através de suas bases teóricas e metodológicas somada a princípios éticos e justificativas morais, direciona esforços para entender e contribuir na redução das desigualdades na saúde e melhoria da qualidade de vida dos indivíduos. A epidemiologia também é subsídio fundamental para fomentar as políticas públicas efetivamente saudáveis, demonstrando os melhores caminhos e alternativas para a efetividade da promoção da saúde. A aferição da qualidade de vida é uma ferramenta de extrema importância, pois sinaliza pontos que necessitam ser trabalhados para se alcançar efetividade nas políticas de saúde e, consequentemente, subsidiar estratégias para se alcançar patamares mais elevados de saúde nas populações. Existem vários instrumentos que foram desenvolvidos para medir a qualidade de vida, com destaque para o WHOQOL, da OMS. Esta pesquisa teve como linha de base o estudo diagnóstico de situação de saúde e de qualidade de vida de usuários de bibliotecas públicas do Distrito Federal e Região do Entorno, desenvolvido pela aluna durante o Mestrado, no período de 2006 a 2008. Objetivo: realizar uma intervenção de educação em saúde no âmbito de bibliotecas públicas do Distrito Federal para promover a saúde, melhoria da qualidade de vida e prevenir doenças, bem como verificar os efeitos dessa intervenção. Métodos: O tipo de estudo foi longitudinal do tipo estudo de painel para avaliação de intervenção antes-depois em um grupo de usuários. Também foi feito um emparelhamento artificial de pessoas com características semelhantes em determinados aspectos de um grupo amostral de indivíduos do Mestrado para comparar com grupo semelhante do Doutorado para averiguar diferenças no espaço temporal. Resultados: verificou-se que, com a intervenção, as mulheres acima de 25 anos tiveram melhoria em sua qualidade de vida em níveis mais elevados do que os homens. Na comparação entre o grupo do Mestrado e o grupo do Doutorado, observou-se piora na qualidade de vida. Projetos extramuros das bibliotecas foram desenvolvidos a partir da intervenção de educação em saúde. Conclusão: a intervenção de educação em saúde propicia a promoção da saúde nas comunidades e o empoderamento dos sujeitos no sentido de buscarem melhor qualidade de vida a partir dessas ações, bem como auxilia no desenvolvimento social e cultural dessas comunidades. As bibliotecas públicas necessitam fazer parte, efetivamente, dos aparelhos do Estado para a promoção da saúde, pois são frequentadas por pessoas formadoras de opinião e multiplicadoras de informações para a sociedade.

Palavras-chave: saúde coletiva, educação em saúde, epidemiologia, qualidade de vida. 


\section{Abstract}

\section{HEALTH EDUCATION IN PUBLIC LIBRARIES IN THE FEDERAL DISTRICT: A NEW DIALOGUE RELATED TO QUALITY OF LIFE, HEALTHCARE, AND EPIDEMIOLOGY}

Introduction: The concept of health touches on the concept of quality of life and degree of satisfaction in various approaches with a central focus on promoting health. Disease prevention does not address the historical and social dimensions of health and intersector public policies, is not conducive to empowering communities and appreciating their potential, neither in improving their conditions of life and work. Promoting health is more closely linked to a holistic, environmental vision, reaching the boundaries of traditional health institutions. Health education is an important tool for promoting health; however, it is important to interact with popular knowledge, because it can prove useful to the educational process. In addition, health education can be carried out in various places within a community, such as public libraries, which are well-known as community centers for learning, intercession, and health promotion. Allied to this, epidemiology, through its theoretical and methodological bases, coupled with ethical principles and moral justification, directs efforts to understand and contribute to reducing health inequalities and improving one's personal quality of life. Epidemiology is also instrumental to fostering public health policies, pointing out the best ways and alternatives to effective health promotion. Gauging quality of life is an extremely important tool because it indicates areas that need to be worked on to achieve effective health policies and therefore help develop strategies for achieving better levels of health within populations. There are several tools that have been developed to measure quality of life, especially the WHOQOL, from the World Health Organization. This base line of this research is a diagnostic study of the health status and quality of life of public library users in the Federal District and Surrounding Region, developed by the student during a Master's program from 2006 to 2008. Objective: conduct health education intercession within public libraries in the Federal District to promote health, improve quality of life, and prevent disease, and confirm its effects. Methods: A longitudinal panel study was used to assess before-after intercession in a group of users. There was also an artificial pairing of individuals with similar characteristics in certain aspects of a sample group of Master's students to compare with a similar group of Doctoral students to ascertain differences in the timeline. Results: It was found that, with the intercession, women over 25 showed improvement in their quality of life at higher levels than men. In the comparison between the Master's and Doctoral groups, a deterioration in quality of life was observed. Projects outside of the libraries were developed from this intercession. Conclusion: health education intercession provides health promotion in communities and empowers individuals to seek a better quality of life from these actions, as well as assisting in the social and cultural development of these communities. Public libraries need to be part of the system through which the state promotes health as they are frequented by opinion shapers and multipliers of information to society.

Keywords: public health, health education, epidemiology, quality of life. 


\section{LISTA DE FIGURAS E QUADROS}

Figura 1. Distribuição geográfica dos locais de realização da pesquisa no DF 33

Figura 2. Distribuição geográfica dos locais de realização da pesquisa no Entorno 33

Figura 3. Desenho do estudo

Figura 4. Documento UnB de liberação de verba de Emenda Parlamentar para a pesquisa

Figura 5. Estrutura operacional da RAS 111

Quadro 1. STROBE 40

Quadro 2. Variáveis Qualitativas Pré-Intervenção. 64

Quadro 3. Variáveis Qualitativas Pós-Intervenção. 69

Quadro 4. Sistema de Classificação de Risco de Manchester. 112

Quadro 5. Sistematização da Realização da Pesquisa 114

Quadro 6. Concepções de saúde e diferentes visões da promoção da saúde 131 


\section{LISTA DE TABELAS}

TABELA 1. Distribuição dos usuários de quatro bibliotecas públicas do DF segundo a QV, Domínio 1 (Físico), WHOQOL - Bref no momento pré-intervenção. 75 TABELA 2. Distribuição dos usuários de quatro bibliotecas públicas do DF segundo a QV, Domínio 2 (Psicológico), WHOQOL - Bref no momento pré-intervenção............ 76 TABELA 3. Distribuição dos usuários de quatro bibliotecas públicas do DF segundo a QV, Domínio 3 (Relações Sociais), WHOQOL - Bref no momento pré-intervenção. 77 TABELA 4. Distribuição dos usuários de quatro bibliotecas públicas do DF segundo a QV, Domínio 4 (Meio Ambiente), WHOQOL - Bref no momento pré-intervenção .....78 TABELA 5. Distribuição dos usuários de quatro bibliotecas públicas do DF segundo a QV, Questões W1/W2, WHOQOL - Bref no momento pré-intervenção. 79

TABELA 6. Distribuição dos usuários de quatro bibliotecas públicas do DF segundo a $Q V$, Domínio 1 (Físico), WHOQOL - Bref no momento pós-intervenção 80 TABELA 7. Distribuição dos usuários de quatro bibliotecas públicas do DF segundo a QV, Domínio 2 (Psicológico), WHOQOL - Bref no momento pós-intervenção. 81 TABELA 8. Distribuição dos usuários de quatro bibliotecas públicas do DF segundo a QV, Domínio 3 (Relações Sociais), WHOQOL - Bref no momento pós-intervenção. 82 TABELA 9. Distribuição dos usuários de quatro bibliotecas públicas do DF segundo a QV, Domínio 4 (Meio Ambiente), WHOQOL - Bref no momento pós-intervenção .... 83 TABELA 10. Distribuição dos usuários de quatro bibliotecas públicas do DF segundo a QV, Questões W1M2, WHOQOL - Bref no momento pós-intervenção. 84

TABELA 11. Associação entre a prevalência da QV $<70$ e os momentos pré e pós-intervenção 85

TABELA 12. Associação entre a prevalência da QV $<70$ nos momentos pré e pós-intervenção e gênero feminino. 86

TABELA 13. Associação entre a prevalência da QV $<70$ nos momentos pré e pós-intervenção e gênero masculino

TABELA 14. Associação entre a prevalência da QV $<70$ nos momentos pré e pós-intervenção e idade menor ou igual a 24 anos 88

TABELA 15. Associação entre a prevalência da QV $<70$ nos momentos pré e pós-intervenção e idade maior que 25 anos

TABELA 16. Associação entre os escores de QV mínimos e máximos dos Domínios e os momentos pré e pós-intervenção 90

TABELA 17. Distribuição dos Tutores de quatro bibliotecas públicas do DF segundo a QV, Domínio 1 (Físico), WHOQOL - Bref..... 91

TABELA 18. Distribuição dos Tutores de quatro bibliotecas públicas do DF segundo a QV, Domínio 2 (Psicológico), WHOQOL - Bref. 
TABELA 19. Distribuição dos Tutores de quatro bibliotecas públicas do DF segundo a QV, Domínio 3 (Relações Sociais), WHOQOL - Bref .....

TABELA 20. Distribuição dos Tutores de quatro bibliotecas públicas do DF segundo a QV, Domínio 4 (Meio Ambiente), WHOQOL - Bref.

TABELA 21. Distribuição dos Tutores de quatro bibliotecas públicas do DF segundo a QV, Questões W1/W2, WHOQOL - Bref 95

TABELA 22. Associação entre variáveis preditores e QV < 70, no Domínio 1 (Físico), no Grupo 1 - Mestrado (2008) e no Grupo 2 - Doutorado (2015) 96

TABELA 23. Associação entre variáveis preditores e QV < 70, no Domínio 2 (Psicológico), no Grupo 1 - Mestrado (2008) e no Grupo 2 - Doutorado (2015).

TABELA 24. Associação entre variáveis preditores e QV < 70, no Domínio 3 (Relações

Sociais), no Grupo 1 - Mestrado (2008) e no Grupo 2 - Doutorado (2015). 98

TABELA 25. Associação entre variáveis preditores e QV < 70, no Domínio 4 (Meio Ambiente), no Grupo 1 - Mestrado (2008) e no Grupo 2 - Doutorado (2015). 99 TABELA 26. Associação entre variáveis preditores e QV < 70, Questão W1, no Grupo 1 - Mestrado (2008) e no Grupo 2 - Doutorado (2015) 100 TABELA 27. Associação entre variáveis preditores e QV < 70, Questão W2, no Grupo 1 - Mestrado (2008) e no Grupo 2 - Doutorado (2015) 101 TABELA 28. Caracterização do acervo, atendimento e serviços de quatro bibliotecas do DF pelos Tutores 102

TABELA 29. Grau de satisfação dos Tutores quanto aos recursos estruturais e de equipamentos de quatro bibliotecas do DF 103 TABELA 30-A. Graus de satisfação dos Tutores quanto ao atendimento aos usuários de quatro bibliotecas do DF 104 TABELA 30-B. Graus de satisfação dos Tutores quanto ao atendimento aos usuários de quatro bibliotecas do DF 105 TABELA 31-A. Frequência de atividades desenvolvidas junto a comunidade em quatro bibliotecas do DF. 106 TABELA 31-B. Frequência de atividades desenvolvidas junto a comunidade em quatro bibliotecas do DF. 107 


\section{LISTA DE ABREVIATURAS E SIGLAS}

OMS - Organização Mundial de Saúde

SUS - Sistema Único de Saúde

QVRS - Qualidade de Vida Relacionada à Saúde

QV - Qualidade de Vida

WHOQOL - 100 - Word Health Organization Quality Of Life Assesment

WHOQOL - Bref - Word Health Organization Quality Of Life Assesment Abbreviated Version of the WHOQOL - 100

DF - Distrito Federal

PROCON/DF - Fundação de Proteção e Defesa do Consumidor do Distrito Federal RAS - Redes de Atenção em Saúde

APS - Atenção Primária em Saúde

ABRASCO - Associação Brasileira de Pós-Graduação em Saúde Coletiva 


\section{SUMÁRIO}

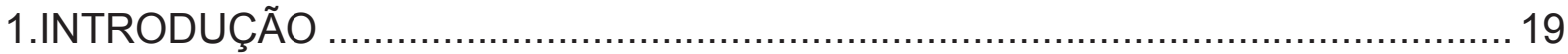

1.1 Referencial Teórico

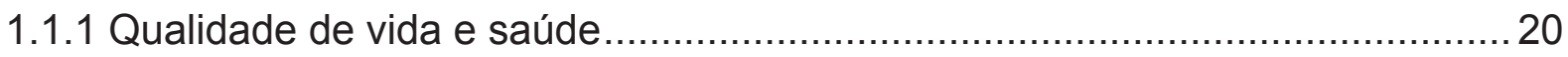

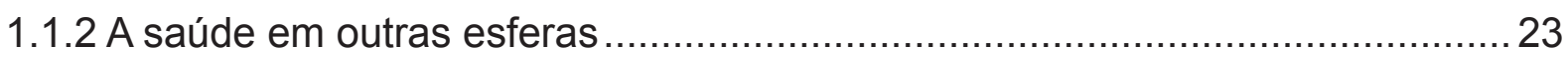

1.1.3 Educação em saúde, inclusão social e cidadania ........................................25

1.1.4 Interlocução entre qualidade de vida, promoção da saúde e epidemiologia ..............26

1.1.5 Bioética de Intervenção, corpo, meio ambiente e saúde .............................. 28

1.1.6 Qualidade de vida: instrumento de medida WHOQOL e WHOQOL-Bref ............... 31

1.1.7 Caracterização da Região Integrada de Desenvolvimento do Entorno RIDE-DF. .... 32

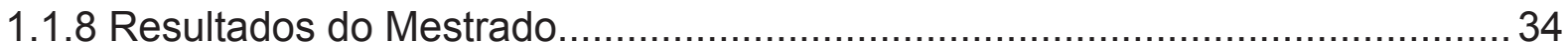

2.JUSTIFICATIVA

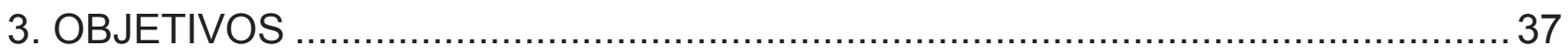

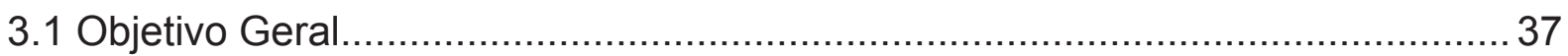

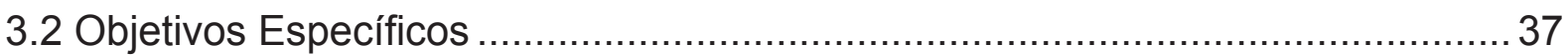

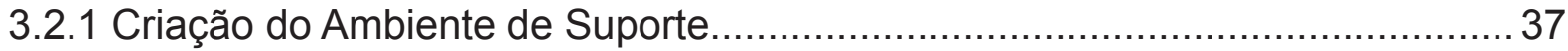

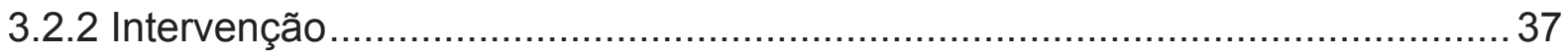

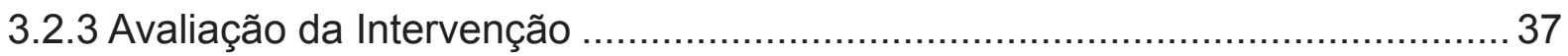

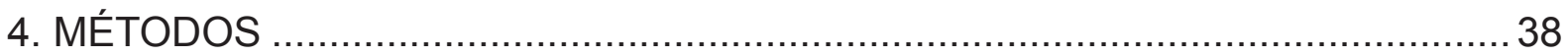

5. RESULTADOS

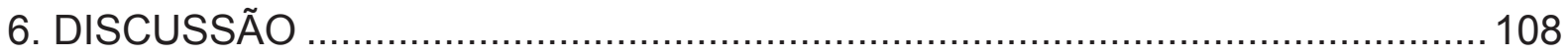

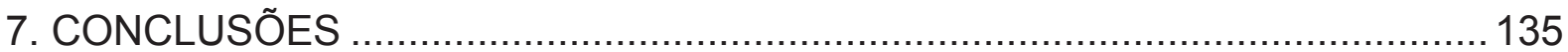

REFERÊNCIAS

ANEXOS

ANEXO 1 - QUADRO DOS RESULTADOS DO MESTRADO …........................... 142

ANEXO 2 - APROVAÇÃO DO CEP/FS/UnB e outros documentos ......................153

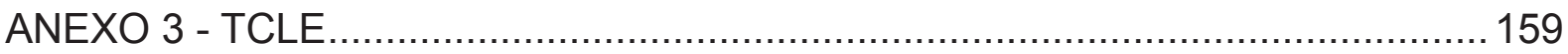


ANEXO 5 - QUESTIONÁRIO PERCEPÇÃO ACERCA DO AUTO-CUIDADO COM O CORPO E SAÚDE FÍSICA E MENTAL NA PERSPECTIVA DA PROMOÇÃO DA SAÚDE 166

ANEXO 6 - PRODUÇÃO LITERÁRIA QUE INTEGROU O KIT DE APOIO À INTERVENÇÃO PROPOSTA:

6.1 Coleção para gente grande: Cuidando dos Dentes 176

6.2 Coleção para gente grande: Cuidando da Higiene 176

6.3 Coleção para gente grande: Como se Organizar. 176

6.4 Coleção maçã verde: A festa dos dentes .... 176

6.5 Coleção maçã verde: Isadora e a turma do banho 176

6.6 Coleção maçã verde: Cada coisa no lugar certo 176

ANEXO 7: DEMO DO VÍDEO PRODUZIDO PARA INTEGRAR O KIT DE APOIO À INTERVENÇÃO PROPOSTA 178

ANEXO 8: ORIENTAÇÕES PARA OS CÁLCULOS DO WHOQOL-Bref 180

ANEXO 9: CARTA E BILHETE DO SENADOR CRISTOVAM BUARQUE 198

ANEXO 10: CERTIFICAÇÃO DO CURSO DE DINAMIZAÇÃO E USO DA BIBLIOTECA PÚBLICA FORNECIDO AOS PARTICIPANTES 201

ANEXO 11: LISTAS DE PRESENÇAS REUNIÃO COSE 203

ANEXO 12: CERTIFICADO DE AGRADECIMENTO. 205 ANEXO 13: DADOS UTILIZADOS NOS CRUZAMENTOS DAS TABELAS 207 


\section{INTRODUÇÃO}

\subsection{Referencial Teórico}

Quando se fala em saúde, não é possível defini-la apenas como a ausência de doença. A saúde envolve diversos aspectos relacionados entre si como, por exemplo, condições de saneamento, acesso à educação, a hospitais e postos de saúde, emprego, meio ambiente saudável, dentre outros. Portanto, a concepção de saúde aproxima-se da noção de qualidade de vida. Esta última tem estreita relação com o grau de satisfação encontrado na vida familiar, social, ambiental, dentre outros, tendo no quesito promoção da saúde seu foco central.

Segundo Ferreira e Buss (1), na década de 1960 houve um grande debate entre vários países do mundo sobre as condições econômicas e sociais da saúde, cujo desfecho propiciou uma reflexão sobre a orientação da saúde centrada na doença. Com a abertura da China Nacionalista para o mundo, a Organização Mundial de Saúde - OMS realizou uma missão de observação onde foi verificado que havia um elenco de atividades voltadas para a melhoria da saúde, especialmente no ambiente rural, cuja implementação havia se iniciado desde 1965.

Os mesmos autores (1) relatam que foi observado que as atividades na China voltadas para a saúde eram desenvolvidas por Comitês Comunais, propiciando um empoderamento dos indivíduos à época. dessa forma, houve o aproveitamento dessas ideias para a proposição de uma nova forma de atenção primária em saúde cujo desfecho deu-se na Conferência de Alma-Ata, em 1978.

Historicamente, o modelo assistencial hegemônico das políticas públicas de assistência à saúde, caracterizado pela ênfase no atendimento individual e em atos médicos especializados, foi um dos fatores preponderantes para a realização da Conferência de Alma-Ata, em 1978 (2). Durante a mesma, a Organização Mundial de Saúde apresentou o tema "Saúde para Todos no Ano 2000", com o objetivo de estimular a revisão de práticas assistenciais e estabelecer uma agenda para reformar o setor saúde no mundo, enfatizar a oferta de cuidados primários de saúde e introduzir princípios da medicina integral e preventiva. Foi estabelecida uma concepção de promoção da saúde, onde a valorização da mesma constitui-se como componente central do desenvolvimento humano, com especial enfoque nos fatores necessários para assegurar a qualidade de vida e o direito ao bem estar social.

Após Alma-Ata, foi realizada a primeira Conferência Internacional sobre Promoção da Saúde, realizada em Ottawa, em 1986, onde foi elaborada uma Carta de Intenções (3), com a proposta de estabelecer as diretrizes para uma nova saúde pública, e na promoção desta com a adoção de políticas públicas voltadas para o reforço de ações comunitárias, desenvolvimento de capacidades pessoais, criação de ambientes favoráveis e reorientação dos serviços de saúde.

Na Carta de Ottawa, a promoção da saúde não é responsabilidade exclusiva do setor saúde, está contextualizada na direção do bem estar global. Ademais, a mesma apóia o desenvolvimento pessoal e social através da divulgação da informação, educação para a saúde e intensificação das habilidades vitais, com uma ação coorde- 
nada entre todas as partes envolvidas: governo, setor saúde e outros setores sociais e econômicos, organizações voluntárias e não governamentais, autoridades locais, indústria e mídia (3).

A Declaração de Sundsvall propôs ambientes favoráveis à saúde e a Declaração de Jacarta foi uma atualização da discussão sobre o reforço da ação comunitária, ou seja, a Conferência reconheceu que os métodos em promoção da saúde baseados no emprego de combinações das estratégias de Ottawa são mais eficazes que os centrados em um único campo. Diversos cenários como cidades, comunidades locais, escolas oferecem oportunidades práticas para a execução de estratégias integrais com a promoção da responsabilidade social para a saúde e aumento da capacitação da comunidade pela educação e parcerias. Ademais, aprender sobre saúde fomenta a participação social (4).

Em nosso país, nos anos setenta, houve uma crise na previdência, que culminou em um processo impulsionado no sentido de buscar soluções que privilegiassem a equidade e o direito de acesso à saúde, o qual levou a um movimento de reforma sanitária, com a criação do Sistema Único de Saúde (SUS), que teve sua aprovação na Constituição de 1988 (5).

Desde então, foram implementados vários programas de assistência no Brasil, como estratégia para consolidação do Sistema Único de Saúde. Destaca-se o Programa Saúde da Família (PSF), que foi implantado desde 1994 pelo Ministério da Saúde, e alterou o modelo hegemônico de assistência à saúde na atenção básica. Suas ações constituem a porta de entrada dos sistemas locais de saúde, com o objetivo de promover a atenção integral da população residente nas suas áreas de atuação e reorganizar as ações e os serviços dos demais níveis de atenção (6).

Porém, apesar de todos os aspectos acima descritos, observa-se que, com a globalização, aumentou o abismo existente entre países centrais e periféricos. Enquanto os países centrais buscam legitimar sua ideologia e moral, com a desconsideração das diferenças morais e priorização dos mercados e do lucro, nos países periféricos essa busca está calcada na conquista de acesso à saúde e a outros itens indispensáveis para uma vida humana digna.

Conforme Alma Ata (2), "a atenção primária de saúde é, ao mesmo tempo, um reflexo e uma conseqüência das condições econômicas e das características socioculturais e políticas do país e de suas comunidades", onde a promoção e proteção da saúde são indispensáveis ao desenvolvimento socioeconômico, com melhora na qualidade de vida. A condição biossocial, permeada por condições mentais, ambientais e culturais ideais, mediada pela promoção da saúde, deve fazer parte de um programa ideológico, para orientar o sentido real e positivo da qualidade de vida.

\subsubsection{Qualidade de vida e saúde}

A qualidade de vida é um conceito complexo, que tem merecido cada vez maior atenção da literatura científica e tem recebido vários significados e enfoques. Pode permear várias outras áreas do saber, como na sociologia, educação, medicina, enfer- 
magem, psicologia e outras especialidades. Além disso, está presente nos meios de comunicação, campanhas publicitárias e até em discursos políticos, e estabelece-se como um tema em destaque na sociedade atual. Porém, devido ao fato de merecer diversas possibilidades de enfoque, é ponto de inúmeras controvérsias teóricas e metodológicas.

$\mathrm{Na}$ história da humanidade é possível encontrar referências às tentativas de definição de qualidade de vida até mesmo antes da Era Cristã. Nos escritos Ética a Nicômaco, Aristóteles (384-322 a. C) mencionava que diferentes pessoas concebem boa vida ou bem-estar como sendo o mesmo que felicidade, e que o significado de felicidade torna-se uma questão de contestação, pois alguns afirmam ser uma coisa, outros dizem ser outra e, de fato muito frequentemente o mesmo homem lhe dá atribuições diferentes, de acordo com a situação que vivencia: quando adoece concebe saúde como sendo felicidade e, quando empobrece, concebe a riqueza e prosperidade como sinônimo de felicidade $(7,8)$.

Sócrates já se referia à qualidade de vida, quando ao encarar a pena de morte na corte ateniense, afirmou temer coisas piores além da morte, porque não era a vida que contava e sim a qualidade de vida. Para o filósofo, o mérito moral determinava essa qualidade (9). Dessa forma, há muito tempo a qualidade de vida é compreendida como um conceito baseado em percepções individuais, que pode variar conforme a experiência da pessoa em um dado contexto ou momento.

Podemos encontrar na literatura que a menção à qualidade de vida foi feita pela primeira vez por Pigou em 1920, onde esse autor relacionou qualidade de vida com o suporte do governo oferecido às classes menos favorecidas (10). Seidl et al referem que, após a Segunda Guerra Mundial, o conceito de "boa vida" foi usado para descrever a posse de bens materiais como casa própria, carros e outros bens de consumo. Com o passar do tempo, o crescimento econômico e industrial ampliou esse conceito, integrando as áreas da saúde, educação, moradia, transporte, lazer, trabalho, crescimento individual, segurança e diminuição da morbi-mortalidade infantil. Os autores ainda colocam que, em meados dos anos 1970, Campbell tentou demonstrar as dificuldades na conceituação de qualidade de vida, onde várias pessoas tentam definir, mas não sabem ao certo do que se trata (11).

Dessa forma, a definição de qualidade de vida, seus conceitos e suas propostas foi baseada em diferentes fundamentações teóricas e práticas até que, após a II Guerra Mundial, a Organização Mundial de Saúde redefiniu saúde, ao incorporar a noção de bem-estar físico, emocional e social e desencadeou uma discussão considerável a respeito da possibilidade de medir o bem-estar. Sendo assim, o termo qualidade de vida ressurgiu e iniciou um ciclo de formação do seu conceito que, apesar de parecer difícil de ser completado, permite uma reciclagem técnico-científica de acordo com a área profissional (12).

Nos dias atuais a qualidade de vida é conceituada conforme a área de aplicação, sendo dividida em dois conceitos: um genérico que não faz referência aos agravos à saúde, e outro, a Qualidade de Vida Relacionada à Saúde (QVRS), que engloba aspectos relativos às enfermidades, às disfunções e às necessárias intervenções terapêuticas em saúde, e identifica o impacto destes na qualidade de vida $(11,12)$. 
Qualidade de Vida Relacionada à Saúde (QVRS) é o valor atribuído à duração da vida quando modificada pela percepção de limitações físicas, psicológicas, funções sociais e oportunidades influenciadas pela doença, tratamento e outros agravos, tornando-se o principal indicador para a pesquisa avaliativa sobre o resultado de intervenções (13). Outra definição para QVRS é o valor atribuído à vida, ponderado pelas deteriorações funcionais, as percepções e condições sociais que são induzidas pela doença, agravos, tratamento e a organização política e econômica do sistema (14).

Minayo et al (14), ressaltam que "o patamar mínimo e universal para se falar em qualidade de vida diz respeito à satisfação das necessidades mais elementares da vida humana: alimentação, acesso a água potável, habitação, trabalho, educação, saúde e lazer; elementos essenciais que têm como referência noções relativas de conforto, bem-estar e realização individual e coletiva. No mundo ocidental atual, por exemplo, é possível dizer também que desemprego, exclusão social e violência são, de forma objetiva, reconhecidos como a negação da qualidade de vida. Trata-se, portanto, de componentes passíveis de mensuração e comparação, mesmo levando-se em conta a necessidade permanente de relativizá-los culturalmente, no tempo e no espaço."

Diniz et al (12) referem que o tema qualidade de vida é muito abrangente, pois interliga diversas abordagens e problemáticas, com ênfase para três âmbitos complementares que são fundamentais para a análise da qualidade de vida. O primeiro trata da distinção entre os aspectos materiais e imateriais. Os materiais dizem respeito às necessidades humanas básicas, como condições de habitação, abastecimento de água e sistema de saúde, ou seja, os aspectos de natureza física e infraestrutural e, as questões imateriais, mais ligadas ao ambiente, ao patrimônio cultural e ao bem-estar. O segundo âmbito faz a distinção entre os aspectos individuais e os coletivos, onde os individuais são relativos à condição econômica, pessoal e familiar e os coletivos estão diretamente ligados aos serviços básicos e públicos. O terceiro âmbito é baseado na diferença entre os aspectos objetivos da qualidade de vida, definidos pelos indicadores de natureza quantitativa, e os aspectos subjetivos, relativos à percepção subjetiva que os indivíduos têm sobre a qualidade de vida, que varia conforme a pessoa e o estrato social.

Devido aos avanços observados nas questões sociais, políticas, econômicas, ambientais e também nos campos da saúde pública e da medicina, é possível dizer que tem havido uma melhora nas condições de vida e de saúde em geral em vários países. Isso também pode ser observado na região da América Latina, segundo relatórios da Organização Mundial de Saúde (15) sobre a saúde mundial e da Organização Pan-americana de Saúde sobre a região das Américas (16). No entanto, as mesmas organizações não deixam de ressaltar que, apesar dessas melhorias, é evidente a permanência de profundas desigualdades nas condições de vida e de saúde entre países subdesenvolvidos, em determinadas regiões e grupos sociais.

Buss (17) refere a relação entre saúde, qualidade de vida, condições inadequadas e doenças. Uma boa saúde influencia favoravelmente a qualidade de vida; já a doença dificulta vários aspectos da vida humana; diminui a produção, aumenta os gastos e o número de pessoas empobrecidas. Dessa maneira, a promoção da saúde, através de ações preventivas é capaz de influenciar positivamente na qualidade de vida e constitui uma ferramenta para enfrentar os problemas que afetam as 
populações. Para isso, é importante a soma de saberes populares e científicos, além do auxílio através de recursos institucionais e comunitários, públicos e privados, para enfrentar e resolver os problemas das comunidades menos assistidas.

Ao se levar em conta o "viver saudável", mesmo na ocorrência de situações de doença, faz-se necessária a mudança de paradigmas para outros, que possibilitem novas formas de pensar-fazer o mundo, especialmente rever nossos conceitos de qualidade de vida, percebendo a saúde como processo e produto desta. A proposta é repensar nas nossas formas de cuidar da vida individual e coletiva, seja em casa, no trabalho, na comunidade e na sociedade de uma maneira geral (18).

O desenvolvimento do conceito de qualidade de vida poderá resultar em mudanças nas práticas assistenciais e na consolidação de novos paradigmas do processo saúde-doença, o que pode ser essencial para a superação de modelos de atendimento eminentemente biomédicos, que negligenciam aspectos sócioeconômicos, psicológicos e culturais importantes nas ações de promoção, prevenção, tratamento e reabilitação em saúde (11).

Assim, a qualidade de vida é um atributo da coletividade, um bem social, de felicidade e satisfação global. Por isso, a saúde de uma população depende de ações preventivas como boa alimentação e condições de higiene, fácil acesso a bens públicos e serviços, saneamento, educação dentre outros benefícios, do que da quantidade de leitos disponíveis em hospitais. No quesito promoção da saúde, as ações educativas são as que propiciam troca de informações e permitem evidenciar as necessidades e as melhores escolhas de uma população, além de estreitar laços entre a comunidade e os profissionais da saúde.

\subsubsection{A saúde em outras esferas}

A promoção da saúde pode ser feita na comunidade a partir de outras esferas, outras instituições. Citamos assim as escolas, associações comunitárias, organizações religiosas, postos de saúde, bibliotecas, dentre outros. Destes, a biblioteca "é a instituição cultural mais comum, ou seja, que está presente no maior número de municípios, e serve de lugar para a comunidade se encontrar, conversar, trocar informações, discutir problemas, saciar suas necessidades de informação, ampliar conhecimentos, ler livremente, recrear-se e criar. A biblioteca pública é do público e por ele deve ser frequentada livremente" (19). Portanto, a biblioteca pode ser um espaço privilegiado e potencial não apenas para se diagnosticar o perfil dos usuários que a frequentam, mas especialmente quanto ao conhecimento em saúde, além de poder se estabelecer como um núcleo comunitário de aprendizado, intervenção e promoção da saúde.

No Brasil existe um projeto onde a informação em saúde é disseminada em uma biblioteca. Trata-se do projeto Informação em Saúde e Cidadania (20), desenvolvido na Biblioteca Monique Bourget, em São Paulo, dentro do Programa Saúde da Família Santa Marcelina. Nele, as equipes fazem o cadastramento de famílias e visitas, e levantam dados relacionados à saúde e qualidade de vida e, identificam as necessidades para posterior seleção de materiais didáticos junto à biblioteca, com o objetivo de estimular a população para os cuidados com a saúde. 
O Ministério da Saúde, através do Projeto Biblioteca Virtual em Saúde - Estação BVS, busca democratizar o acesso às informações em Saúde Pública, onde qualquer usuário pode ter entrada livre às informações geradas pelas instituições federais do Sistema Único de Saúde - SUS e pelo Setor Acadêmico. Nas Estações BVS os usuários têm dicas de prevenção e eventos, conhecem seus direitos e são informados sobre a rede de serviços e atendimento em saúde. Cada Estação BVS é integrante da Rede de Bibliotecas e Unidades de Informação Cooperantes da Saúde (Rede BiblioSUS), e tem o objetivo de disseminar o conhecimento, incentivar o debate, a pesquisa e a promoção de saúde no Brasil (21).

Nos Estados Unidos, em Ohio, existe um projeto voltado para cidadãos das zonas rurais, onde diversas instituições, dentre elas as bibliotecas públicas, participam na disponibilização de informações sobre saúde para a população (22). Isso reforça o potencial que outros espaços sociais possuem para multiplicação de informações importantes, que resultem em melhores condições de vida.

Outro estudo desenvolvido em Wilmington, também nos Estados Unidos, verificou o impacto das informações sobre saúde promovidas por bibliotecas para pessoas da comunidade. Foi evidenciado que o valor de informações sobre saúde para os usuários tem grande impacto na aquisição de conhecimentos, ações e atitudes relativas à saúde pelas pessoas. $O$ estudo verificou também que, ao adquirir conhecimentos sobre saúde, as pessoas se sentiam assistidas e melhor preparadas para optarem por tratamentos médicos e melhoraram as relações com profissionais da saúde, dentre outras vantagens (23).

É essencial capacitar as pessoas para aprender durante toda a vida, preparando-as para as diversas fases da existência, o que inclui, por exemplo, o possível enfrentamento de doenças crônicas. Esta tarefa deve ser realizada nas escolas, nos lares, nos locais de trabalho e em outros espaços comunitários. Para alcançar a equidade em saúde, um dos focos da promoção da saúde, são necessários diversos recursos, dentre os quais o acesso à informação e a ambientes favoráveis ao aprendizado. Destaca-se o papel das bibliotecas, como espaços comunitários já existentes que podem ser utilizados nas ações promotoras de saúde. A exemplo disso, Hicken (24) refere, em um artigo sobre as bibliotecas públicas e as pessoas socialmente excluídas, que as bibliotecas precisam ser mais pró-ativas, pois não estão voltadas para as necessidades das pessoas, como as relacionadas à inclusão social.

A consciência da necessidade do cuidado com o corpo e com a saúde em geral leva o indivíduo a buscar outras conquistas essenciais para manutenção e evolução de seu bem estar, como o saneamento básico, a educação, a conquista de meios dignos de subsistência, e o trabalho como forma de prazer e desenvolvimento social. O ponto essencial é que, a busca por melhores condições de cuidado com o corpo se estabelece como alavanca e estímulo para o crescimento humano. Existe mais valorização de uma conquista quando o ser humano participa efetivamente dela. E esse impulso é dado através da auto-valorização, do respeito próprio e mútuo, da educação e da cultura, pontos essenciais que podem ser desenvolvidos nos espaços das bibliotecas públicas. 
Nesse contexto, a presente pesquisa utilizou a biblioteca como ponto de partida para um trabalho de intervenção de educação em saúde com os usuários de bibliotecas públicas, onde era almejado que, após a sua realização, fosse impulsionada a formação de grupos de cuidados com a saúde nas comunidades onde o trabalho foi executado.

\subsubsection{Educação em saúde, inclusão social e cidadania}

As ações de promoção de saúde e prevenção de doenças são fundamentais para melhorar a vida das pessoas. A educação em saúde é uma ferramenta importante para se obter estes resultados. É importante interagir com o saber popular, pois dele se pode extrair subsídios para o processo educativo.

Valla (25) relata que os saberes da população são elaborados sobre a experiência concreta a partir de suas vivências, que são distintas daquelas dos profissionais de saúde. Na realidade, o saber da população não seria insuficiente, porém é apenas diferente. Dessa maneira, não deve haver incompatibilidade entre o saber científico e o saber popular, ou seja, a educação e a saúde devem caminhar juntas, sendo que vários são os atores responsáveis pela transmissão desses conhecimentos, especialmente os profissionais de saúde.

Dentre os quesitos fundamentais que permeiam a educação em saúde, inclusão social, cidadania e qualidade de vida, conceitua-se o apoio social. Este é definido, segundo Minkler (26), como qualquer informação ou auxílio material oferecido por grupos ou pessoas, que teriam contatos sistemáticos e que resultariam em efeitos emocionais e/ou comportamentos positivos. Seria um processo recíproco, que gera efeitos positivos para quem oferece e para quem recebe apoio.

Valla (25) coloca ainda que, o debate em torno da questão do apoio social é baseado em investigações que apontam para o seu papel na manutenção da saúde, na prevenção contra doenças e como forma de facilitar a convalescença. Além disso, o apoio social exerceria efeitos diretos sobre o sistema imunológico, agindo como um tampão, no sentido de aumentar a capacidade das pessoas de lidar com o stress e como contribuição para criar uma sensação de coerência na vida e de controle sobre a mesma, o que afeta o estado de saúde das pessoas de forma benéfica.

O apoio social é ferramenta para promoção da inclusão social e cidadania, desta forma, promove o empoderamento dos indivíduos, que passam a ganhar mais controle sobre seus próprios destinos. Segundo Valla (25), um envolvimento comunitário pode ser um fator psicossocial significativo no aumento da autoconfiança, da satisfação com a vida e com a capacidade de resolução e enfrentamento de problemas, o que seria uma maneira de reforçar o sistema imunológico do corpo e diminuir a suscetibilidade à doença.

Com o fenômeno da globalização, o conceito de cidadania transcendeu fronteiras, ou seja, como referem Arnaud e Capeller (27), uma nova cidadania pode ser fundada sobre uma reivindicação de direitos oriundos da escala global. Esses autores colocam ainda que essa nova cidadania esteja vinculada a uma nova forma de exercer a democracia, que traz transformações na administração dos assuntos públicos, 
com a contestação e participação dos cidadãos nas tomadas de decisões sobre políticas públicas.

O constante crescimento no que tange à disseminação de informações e produção do conhecimento impõe que se busque a aproximação de áreas que, embora distintas, permitam a identificação de interfaces capazes de somar especificidades, na busca de resultados que contribuam na melhoria de questões emergentes, como a qualidade de vida. No contexto da globalização da informação e do conhecimento, um dos grandes desafios da sociedade é garantir que essas possibilidades sejam acessíveis aos cidadãos, independente de segmentação social, o que garante aos indivíduos, uma verdadeira inclusão, propiciando uma participação na sociedade tanto intelectual, cultural como economicamente.

Através dessa inclusão social e do uso das informações e conhecimentos, é previsível que surjam cidadãos informados, zelosos de sua saúde e detentores de uma qualidade de vida digna. Ademais, o conhecimento do perfil dos indivíduos e a utilização de suportes educacionais com materiais, conteúdos e linguagem adequados para cada contexto constituem ferramentas de grande utilidade para a promoção da saúde nos diversos espaços sociais, como as bibliotecas públicas das comunidades.

Segundo Delduque e Oliveira (28) , a conquista do direito à saúde não se encerrou com a Constituição Federal de 1988, que apesar de representar um grande avanço, não foi suficiente para expandir esse direito a toda população, pois ainda permanecem indicadores sociais que demonstram injustiças, desigualdades e quadros epidemiológicos não favoráveis. Dessa forma, o direito à saúde ainda permanece em construção e, paradoxalmente, a saúde é sempre uma obra inacabada, pois está sempre em transformação.

\subsubsection{Interlocução entre qualidade de vida, promoção da saúde e epidemiologia}

Barreto (29) coloca que as vinculações entre os profissionais da saúde incluem a construção de afinidades em torno de tudo que diga respeito à prevenção. Assim, a epidemiologia reconstitui suas bases teóricas e metodológicas, a partir de princípios éticos e justificativas morais que direcionem seus esforços para entender e contribuir na redução das desigualdades na saúde, melhoria da qualidade de vida dos indivíduos e das populações e seleção das tecnologias de saúde, evitando a exposição indiscriminada dos indivíduos e das populações a intervenções com baixa efetividade. Dessa forma, a qualidade de vida pode ser usada, potencialmente, como indicador que apoie a promoção da saúde.

Segundo Paim e Almeida Filho (30), a epidemiologia como disciplina científica, que estuda a saúde, a doença e os seus determinantes, com a elaboração de teorias, desenho de estudos e análise de dados, produz informações e conhecimentos. Como campo profissional de saúde coletiva, ela desenvolve tecnologias e estratégias de prevenção, produz novos conhecimentos, delineamentos de estratégias e concretização de ações. No primeiro enfoque, podem existir erros de ordem teórica e metodológica. No segundo, os erros significam vidas, doenças, sofrimentos, ou ainda, custos sociais, econômicos ou políticos. 
O reencontro da epidemiologia com o ambiente e a qualidade da vida e, a atualização desses vínculos com os conhecimentos acumulados e as necessidades das sociedades contemporâneas é uma tarefa que tem como consequência não somente reforçar a disciplina, quanto às suas preocupações com a população, mas também equacionar desafios teóricos, metodológicos e tecnológicos que a reforçam enquanto disciplina científica (29).

Relativamente à promoção da saúde, verifica-se que tem sido objeto de muitas discussões, especialmente relacionadas ao redirecionamento das práticas de saúde. Czeresnia (31) faz referência aos eixos básicos do discurso da promoção da saúde, através do fortalecimento da autonomia dos sujeitos e dos grupos sociais, porém destaca que em algumas análises realizadas, estaria havendo uma construção científica e cultural voltada para uma autonomia regulada e de acordo com a economia de mercado.

Segundo Leavell \& Clarck (32) a promoção da saúde é definida de uma forma mais ampla que a prevenção, pois trata de estratégias que servem para aumentar a saúde e o bem estar gerais e não apenas de uma determinada doença ou desordem. Czeresnia(31) alerta para o fato de a singularidade e autonomia dos sujeitos "não poder ter responsabilidade atribuída a uma área de conhecimento e práticas".

\title{
Czeresnia(31) ressalta que:
}

\begin{abstract}
"Não há como trabalhar devidamente e de modo prático a construção da ideia de promoção da saúde sem enfrentar duas questões fundamentais e interligadas: a necessidade da reflexão filosófica e a consequente reconfiguração da educação (comunicação) nas práticas de saúde."
\end{abstract}

Nesse contexto, Ayres (33) refere ser necessária a contribuição de "novas vozes no campo da saúde...como a filosofia, a arte, o direito, as sabedorias tradicionais, os saberes populares, os saberes práticos". Ressalta também que "as palavras altamente significativas de nossa linguagem cotidiana...segundo a hermenêutica, faz a razão humana manifestar-se mais plenamente na sua condição emancipadora". 0 mesmo autor destaca a importância da recuperação do projeto existencial dos indivíduos, que permite o estabelecimento de vínculo terapêutico efetivo e propicia um melhor manejo das ações de saúde (34). Significa dizer também que " a busca ativa de projetos de felicidade daqueles de quem se cuida, traz para o espaço do encontro terapêutico, potencializando-o, um processo de (re)construção identitária que implica mutuamente profissionais e usuários (34)".

Zoboli (35) coloca que "no bojo da responsabilidade para com a comunidade estão ideias humanistas e valores morais, como a justiça social, os direitos humanos, o engajamento comunitário e a equidade". A autora também ressalta a importância do conhecimento das necessidades de comunidades e da interlocução entre a comunidade e as equipes de saúde. Dessa forma, conhecer as comunidades, interagir e promover oportunidades de expressão dos projetos de vida dos indivíduos configura-se como um dos sustentáculos para oportunidades de promoção da saúde e de emancipação e empoderamento, que poderão significar, por exemplo, a efetividade de ações de educação em saúde. 


\subsubsection{Bioética de Intervenção, corpo, meio ambiente e saúde}

Este projeto procurou também destacar aspectos relativos a iniciativas de cuidados e emancipação individual e coletiva nas comunidades, de maneira a propiciar espaços de reflexão e crescimento, com a valorização dos indivíduos e a (re)descoberta de potenciais sociais que fortaleçam as pessoas. Dessa maneira, não poderia deixar de ser mencionada a Bioética de Intervenção como uma das ferramentas que servem de fomento à intervenção proposta.

A bioética de intervenção é um dos campos da bioética que busca a igualdade, através da equidade para aqueles que estão inseridos no contexto dos países periféricos, ou os excluídos sociais. Os países centrais buscam legitimar sua ideologia e moral como padrão único, com ênfase no materialismo e no desenvolvimento tecnológico como objetivos essenciais para a humanidade, sem considerar as diferenças morais e com priorização nos mercados e no lucro. Em contrapartida, a luta dos países periféricos está calcada na conquista de acesso à saúde e de outros itens indispensáveis para uma vida humana digna.

Relativamente à compreensão em relação ao corpo e sua percepção sensorial, buscou-se conhecer o pensamento de Mário Testa (36) na contextualização do corpo e fazer uma reflexão de suas relações com o ambiente, a saúde e a bioética de intervenção.

A origem do corpo humano está inserida dentro de um processo de evolução de construção permanente, de início impreciso, onde o corpo é percebido como uma máquina que adapta seu funcionamento às condições existenciais do ser humano. Dessa maneira, Testa (36) refere que:

\footnotetext{
"todas as expressões do signo que é o corpo foram sendo criadas ou modificadas através da história. O corpo como signo histórico em sua expressão feliz é a saúde; o contrário é a doença. Por sua vez a história pode ser entendida como o processo social através do qual são construídos (produzidos e reproduzidos) os corpos dos seres humanos"..."as transformações filogenéticas do corpo da espécie são simultâneas a outras mudanças que não ocorrem no corpo, mas no modo pelo qual este se relaciona com a natureza ... o processo que realiza a intermediação entre essa relação e a modificação do corpo é o trabalho".
}

A partir da revolução industrial, o comportamento dos indivíduos da sociedade capitalista foi alicerçado na idéia de que a felicidade e o bem-estar advêm da satisfação irrestrita do consumismo desenfreado e do crescimento ilimitado. Passou-se a viver em uma sociedade onde o ter é muito mais importante que o ser. Nesse sentido, "o relacionamento de um indivíduo ou grupo com o mundo passa a ser a posse, em que tudo e todos são sua propriedade" (37). O consumo é a forma de posse mais importante da sociedade industrial capitalista e neoliberal. Dessa maneira, é possível projetar a idéia de consumo e dominação dos países centrais, que se utilizam de diversas formas de dominação e persuasão, na intenção de permanecerem em uma posição privilegiada. 
Segundo Testa (36), não existe uma ciência definitiva e o primeiro momento de uma reflexão científica deve ser aquele que corresponde a colocar objetos e métodos de estudo em um contexto histórico. Ademais, o autor coloca que a tarefa científica começa no momento em que se realiza a recontextualização, e exemplifica que, na história da Grécia, pode ser observado que, em cada momento, pode haver mais de uma ciência em relação a um mesmo problema, ou seja, havia uma medicina para os escravos (que eram tratados apenas para continuarem a ser máquinas funcionantes) e outra para os cidadãos, onde seus corpos haviam passado para a condição de signo, devendo ser cuidados para a manutenção da beleza e perfeição físicas.

A importância da percepção do corpo culturalmente construído no processo social torna-se um ponto de destaque. A formação da identidade do corpo em uma determinada comunidade ou cultura é permeada pela percepção dos indivíduos nas relações de corporalidade, onde se evidencia a importância dos conceitos de Mário Testa para a compreensão do papel do corpo como instrumento para conscientização social. Entender como as pessoas dos países periféricos percebem seus corpos, utilizam seus corpos, têm seus corpos dominados pelo prazer, dor e exploração pela ideologia dos países centrais também é essencial na compreensão das necessidades contextualizadas.

Os corpos e os indivíduos estão a serviço dos interesses econômicos e científicos dos países centrais. A ciência e os métodos científicos aplicados nos países em desenvolvimento atendem às necessidades do primeiro mundo. $O$ povo do mundo subdesenvolvido é objeto de exploração e experimentação.

Segundo Junges (38), o filósofo francês Michel Foucault entendeu que o capitalismo socializou o corpo como força de produção, onde o controle social se opera de forma ideológica, porém, inicialmente através dos corpos. Assim, a medicina seria uma estratégia biopolítica. Junges (38) ainda coloca que Foucault analisou três considerações sobre a medicina social: a primeira, desenvolvida na Alemanha no início do século XVIII, onde o Estado instituiu a polícia médica para controlar a saúde do povo, para que os indivíduos fossem fortes e saudáveis e, dessa maneira, contribuíssem para a formação de uma nação forte; a segunda, desenvolvida na França no final do século XVIII que, com a urbanização, motivou a burguesia a se preocupar com a higiene urbana, através do fechamento e reestruturação de hospitais e cemitérios e; a terceira, desenvolvida na Inglaterra como consequência da industrialização e da necessidade da reprodução e conservação da força de trabalho, que era composta especialmente por indivíduos pobres que precisavam ser atendidos, para evitar convulsões sociais. Junges (38) completa a colocação dizendo que "essas disciplinas sobre o corpo e regulações sobre a população são duas estratégias de biopolítica, desenvolvidas pelo poder sobre a vida".

Porto e Martinez-Alier (39), referem que a relação entre saúde e ambiente não é de nossos dias, mas descrita de forma tradicional na saúde pública brasileira a partir de dois paradigmas básicos: o biomédico, com modelo ecológico nas doenças infectocontagiosas, e o do saneamento, cuja abordagem se alicerça a partir da engenharia ambiental com ênfase na preocupação no desenvolvimento de infraestrutura de água potável, esgoto e lixo para prevenção de doenças. Estes mesmos autores colocam ainda que existe um terceiro paradigma, que influenciou no surgimento da saúde cole- 
tiva no Brasil, cujas principais características são a ampliação do olhar sobre a relação saúde-ambiente a partir de processos sociais e econômicos de desenvolvimento.

A introdução de abordagens na saúde pública que integrem o cenário social com os ecossistemas para a compreensão dos problemas de saúde da população é de vital importância e, aliadas à percepção corporal das comunidades, pode ser um campo de estudo importante que ajude a desenvolver novas formas de promoção da saúde, contextualizadas para a realidade de cada lugar. Seria uma forma de "descoberta", ou "redescoberta" de valores, com a participação efetiva das comunidades e, como Mário Testa citou, uma "recontextualização" de maneira a propiciar avanços importantes na qualidade de vida dos indivíduos dos países em desenvolvimento.

Segundo Porto e Martinez-Alier (39), a economia ecológica, através da produção de indicadores e índices de sustentabilidade advindos do desenvolvimento e operacionalização em relação ao "metabolismo social" tem contribuído sobremaneira, de forma a ligar as ciências naturais e as ciências sociais, onde a economia é descrita como uma relação entre os fluxos dos sistemas de produção (energia e materiais) e os fluxos comerciais (produtos e serviços). Dessa forma, em uma economia sustentável esses fluxos estariam contabilizados e seriam incluídos, por exemplo, instrumentos de política ambiental baseados no princípio da precaução.

Na visão de uma ecologia política, Porto e Martinez-Alier (39) colocam que esta tem sido a base teórica para um movimento de justiça ambiental, através da análise dos conflitos advindos das desigualdades nos processos econômicos e sociais, que interferem profundamente com a sobrecarga negativa do desenvolvimento sobre as populações mais pobres, discriminadas e socialmente excluídas. Esse problema tem se refletido no atual modelo de desenvolvimento do Brasil, com a geração de muitos conflitos entre a economia e a preservação ambiental.

Dessa maneira, através de uma economia ecológica, política e do princípio da precaução, contextualizados e discutidos nas comunidades, seria possível o desenvolvimento de sistemas de produção que não afetassem a saúde das pessoas e que preservassem os ecossistemas. A bioética de intervenção seria uma das ferramentas que auxiliariam nesse processo, já que esta propicia um olhar pelos indivíduos vulneráveis e pelas necessidades daqueles social e economicamente excluídos. Os países em desenvolvimento, que são os grandes fornecedores de matérias primas para o primeiro mundo precisam ficar atentos, pois existe uma contradição muito grande, onde o primeiro mundo, vive da exploração das terras, da natureza, dos corpos e indivíduos das nações em desenvolvimento, e estas, que podem viver de seus recursos, parece que não possuem efetivamente sua soberania.

Os países em desenvolvimento são desprovidos de autonomia, ou seja, os corpos e as pessoas desses países estão vulneráveis. A busca de alternativas para reverter este quadro tem conformidade com a bioética de intervenção, no resgate da autonomia, no poder de voz, na busca da eqüidade para superar as desigualdades. Conhecer e perceber o corpo pode ser um dos caminhos na construção da bioética de intervenção, bem como na retomada da construção da história dos países dominados, com a busca de uma identidade própria, a serviço da proteção dos vulneráveis, do atendimento das necessidades essenciais contextualizadas, na preservação dos recursos naturais, que são finitos, bem como da vida global. 


\subsubsection{Qualidade de vida: instrumento de medida WHOQOL e WHOQOL-Bref}

Existem vários instrumentos que foram desenvolvidos para medir a qualidade de vida. Destes, destaca-se o WHOQOL, que através da Organização Mundial de Saúde (OMS), foi idealizado pelo WHOQOL Group. Com a colaboração internacional de quinze países de todo o mundo, foi elaborado um instrumento de avaliação multidimensional, passível de tradução e adaptação para diversas línguas, contendo vinte e quatro facetas ou dimensões da Qualidade de Vida, organizadas hierarquicamente em seis domínios: físico, psicológico, nível de independência, relações sociais, ambiente e espiritualidade, religião e crenças pessoais. Esse instrumento foi denominado WHOQOL-100 (40, 41).

A demanda por instrumentos curtos, que utilizassem pouco tempo para seu preenchimento, porém com características psicométricas satisfatórias, fez com que esse mesmo grupo de especialistas desenvolvesse uma versão abreviada do WHOQOL-100, chamado de WHOQOL-Bref ou WHOQOL Abreviado. O WHOQOL-Bref possui 26 questões, sendo duas questões gerais e vinte e quatro restantes que representam cada uma das vinte e quatro facetas que compõe o instrumento original. Enquanto no WHOQOL-100 cada uma das vinte e quatro facetas é avaliada a partir de quatro questões, no WHOQOL-Bref é avaliada por apenas uma questão. Ademais, o WHOQOL-Bref abrange quatro domínios: físico, psicológico, relações sociais e ambiente $(40,41)$.

Continua

\begin{tabular}{|l|l|}
\hline \multicolumn{1}{|l|}{ DOMÍNIOS E FACETAS DO WHOQOL -Bref(40,41) } \\
\hline \multirow{2}{*}{ Domínio I } & Dor e desconforto \\
Energia e fadiga & Sono e repouso \\
& Atividades da vida cotidiana \\
& Dependência de medicação ou de tratamentos \\
& Mobilidade \\
& Capacidade de trabalho \\
\hline \multirow{3}{*}{ Domínio II } & Sentimentos positivos \\
Psicológico & Pensamento, aprendizagem, memória e concentração \\
& Auto-estima \\
& Imagem corporal e aparência \\
& Sentimentos negativos \\
& Espiritualidade/religião/ crenças pessoais \\
\hline Domínio III & Relações pessoais \\
Relações Sociais & Suporte (Apoio) social \\
& Atividade sexual \\
\hline
\end{tabular}




\section{Conclusão}

\begin{tabular}{|l|l|}
\hline \multicolumn{1}{|l|}{ DOMÍNIOS E FACETAS DO WHOQOL -Bref(40,41) } \\
\hline \multirow{3}{*}{ Domínio IV } & $\begin{array}{l}\text { Segurança física e proteção } \\
\text { Ambionte no lar }\end{array}$ \\
& $\begin{array}{l}\text { Recursos financeiros } \\
\text { Cuidados de saúde e sociais: disponibilidade e qualidade } \\
\text { Oportunidades de adquirir novas informações e habilidades } \\
\text { Participação em e oportunidades de recreação / lazer } \\
\text { Ambiente físico: (poluição/ruído/trânsito/clima) } \\
\text { Transporte }\end{array}$ \\
\hline
\end{tabular}

Na pesquisa desenvolvida durante a Dissertação de Mestrado da aluna, este instrumento foi o eleito para medir a qualidade de vida nos usuários das bibliotecas públicas do Distrito Federal (DF) e Região do Entorno. Não foram encontradas dificuldades na sua aplicação, nem na compreensão do questionário por parte dos entrevistados.

\subsubsection{Caracterização da Região Integrada de Desenvolvimento do Entorno RIDE1.1.7 Caracterização da Região Integrada de Desenvolvimento do Entorno RIDE-DF}

A aceleração da ocupação da região, promovida por políticas governamentais de incentivo à migração para construção e ocupação da Capital Federal no final da década de 1950, foi um fator que favoreceu o surgimento de novas cidades, além das já existentes, dentro e ao redor do Distrito Federal. Diversos graus de acesso à infraestrutura criada nesses anos, aos serviços e ao emprego, produziram sérios desequilíbrios econômicos e sociais entre o DF e os municípios vizinhos, alguns deles mais antigos do que o próprio Distrito Federal (42).

Dessa forma, a Região Integrada de Desenvolvimento do Distrito Federal e Entorno -RIDE-DF - foi criada em 1998, com o objetivo de promover a articulação inter-setorial como meio de aprimoramento e ampliação dos serviços públicos essenciais e a promoção de atividades econômicas na região, buscando a criação de emprego e geração de renda. Alguns dos municípios do Entorno de Brasília absorveram grande parte do contingente populacional que se deslocou para a região (42).

A RIDE-DF abrange um conjunto de 22 municípios e o Distrito Federal, sendo dividida em quatro regiões - Entorno Sul, Entorno Norte, Região de Unaí e Região dos Pireneus - com uma área total de $57.169 \mathrm{Km} 2$. Três dos municípios pertencem ao estado de Minas Gerais e os 19 restantes ao estado de Goiás. O DF tinha uma população aproximada de 2,6 milhões de habitantes em 2008 e, em 2015, já estava com quase três milhões de habitantes. O conjunto de municípios do Entorno somavam, aproximadamente, mais de um milhão de pessoas em 2008 e, em 2015, os dados indicaram que o Entorno do DF estava com cerca de 1.200.000 habitantes, sendo que a população total do DF e Entorno (RIDE/DF) é, atualmente, cerca de 4.202.00 habitantes. (42). 


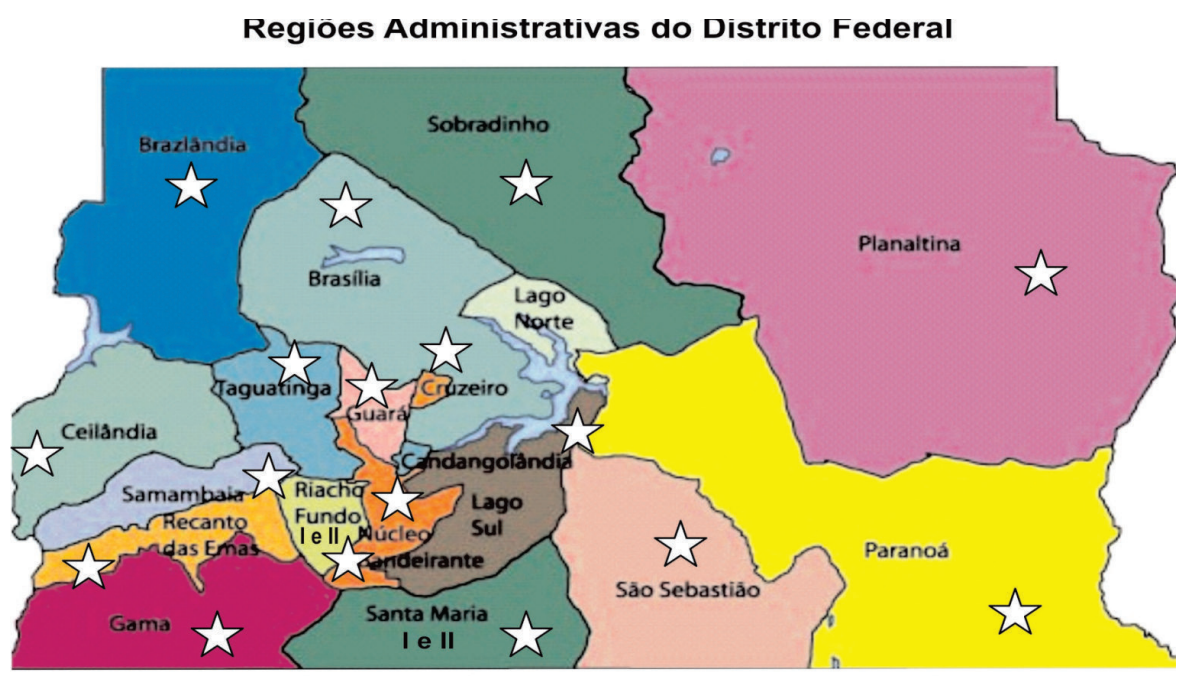

Figura 1. DISTRIBUIÇÃO GEOGRÁFICA DOS LOCAIS DE REALIZAÇÃO DA PESQUISA

NO DISTRITO FEDERAL. (Mapa: www.setur.df.gov.br) ${ }^{(43)}$

Municípios pertencentes à Região Integrada de Desenvolvimento do DF e Entorno (RIDE - DF)

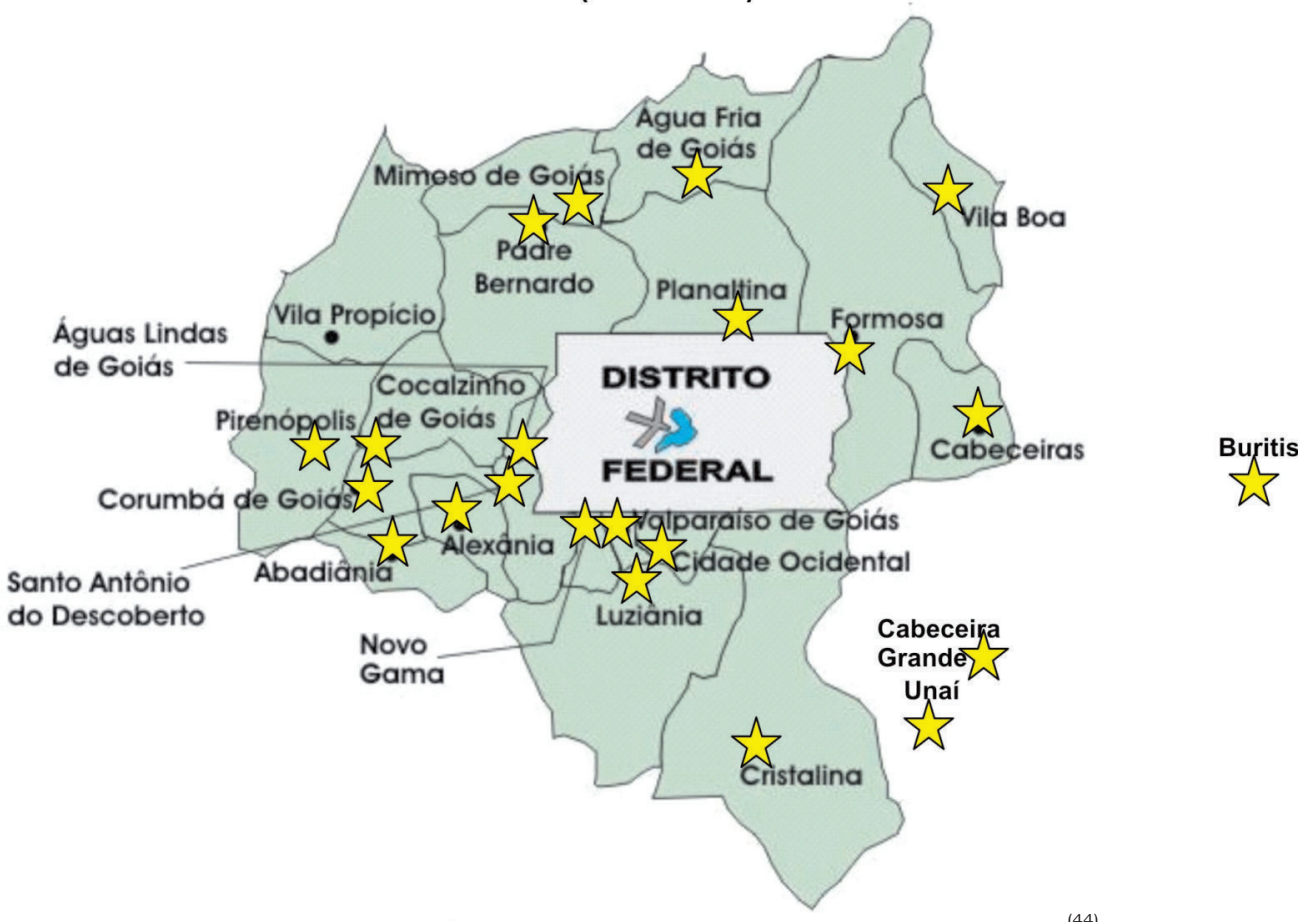

Figura 2. DISTRIBUIÇÃO GEOGRÁFICA DOS LOCAIS DE REALIZAÇÃO DA PESQUISA NOS 


\subsubsection{Resultados do Mestrado}

Este projeto de pesquisa em nível de Doutorado tem como linha de base o estudo de avaliação de situação pré-intervenção desenvolvido pela candidata durante o Mestrado, no período de 2006 a 2008. Para melhor elucidação da abrangência da proposta para Doutoramento, é importante que sejam expostos os principais resultados obtidos nessa Dissertação (45), conforme segue (vide Anexo 1).

Foi realizado um estudo epidemiológico analítico do tipo transversal com uma amostra de indivíduos usuários das bibliotecas públicas do Distrito Federal (Brasília e cidades satélites) e Região do Entorno (22 municípios). Foram selecionados indivíduos acima de doze anos, caracterizando-se a amostra por conveniência. O número de bibliotecas públicas em que foi realizada a pesquisa correspondeu a 39 de um universo de 43, pois quatro bibliotecas estavam em reforma na ocasião do período de coleta de dados.

O instrumento de coleta de dados incluiu as seguintes variáveis preditoras: sócio-econômicas e demográficas (sexo, faixa etária, renda pessoal, renda familiar, escolaridade, adequação do nível de escolaridade com a faixa etária, local de moradia, participação social). As outras variáveis incluíram questões sobre de auto-cuidado, antropometria para cálculo do Índice de Massa Corporal e de conhecimento sobre recursos de assistência à saúde existentes na comunidade, saneamento básico e infraestrutura urbana.

Foram utilizados dois instrumentos de coleta de dados: Escala de Medida de Qualidade de Vida - WHOQOL-Bref (40) e uma entrevista semi-estruturada com questionamentos relativos à saúde, alimentação, morbidades, saneamento básico e recursos de assistência à saúde, com um total de 592 entrevistas. Os resultados obtidos foram os seguintes (45):

$\checkmark$ A faixa etária no Distrito Federal variou entre 18 e 64 anos e no Entorno entre 12 e 68 anos;

$\checkmark$ A idade acima de 24 anos foi em maior proporção nas duas regiões estudadas;

$\checkmark$ As mulheres foram em maior proporção no Entorno versus os homens no DF;

$\checkmark$ A renda pessoal foi acima de 1,5 salários mínimos nas duas regiões e a familiar acima de 3,5 salários mínimos foi maior no DF;

$\checkmark$ Teve maior frequência de pessoas com emprego no Entorno;

$\checkmark$ Os estudantes eram em maior proporção no DF e a maioria tinha ensino médio completo no DF e fundamental incompleto no Entorno;

$\checkmark$ A igreja foi o local mais frequentado no Entorno e no DF, dois terços dos indivíduos não participavam de organizações ou associações;

$\checkmark$ A maioria dos entrevistados relatou bons hábitos de higiene;

$\checkmark$ Foi alta a frequência de exposição solar entre 10 e 16 horas nas duas regiões, sendo que as pessoas relataram usar pouca proteção;

$\checkmark$ No DF metade dos entrevistados consideraram sua saúde boa e no Entorno quase metade;

$\checkmark$ Sobrepeso e obesidade tiveram frequência alta nas duas regiões.

$\checkmark$ Os hábitos alimentares eram razoáveis nas duas regiões para a frequência de consumo de frutas, verduras e legumes, sendo que pessoas com maior renda familiar relataram consumir mais esses produtos;

$\checkmark$ O consumo de leite era alto entre os que possuíam renda familiar menor; 
$\checkmark$ Metade dos indivíduos disseram consumir álcool no DF e um pouco mais da metade no Entorno;

$\checkmark$ Cerca de $11 \%$ dos entrevistados eram tabagistas;

$\checkmark$ Os recursos de assistência à saúde estavam presentes nas duas regiões e o Programa Saúde da Família era mais atuante no Entorno;

$\checkmark$ O saneamento básico estava presente em alta proporção nas duas regiões;

$\checkmark$ As bibliotecas eram usadas mais por motivos de estudo no DF versus por motivos sociais no Entorno;

$\checkmark$ Quanto à qualidade de vida avaliada pelo WHOQOL-Bref, foi verificado que as mulheres, com idade acima de 25 anos, com menor renda pessoal e menor escolaridade apresentaram insatisfações com maior frequência.

Como conclusões do estudo, todos os objetivos foram alcançados, sendo permitido se obter amplo conhecimento/diagnóstico acerca da percepção dos usuários das bibliotecas públicas do Distrito Federal e Entorno relativos ao auto-cuidado com o corpo, saúde física e mental e qualidade de vida. Foi sugerido um planejamento e intervenção na área de educação em saúde nas bibliotecas públicas, por estas serem nichos sociais importantíssimos, que devem ser preenchidos e ocupados com ações que auxiliem na promoção da saúde e prevenção de doenças nas comunidades (45). 


\section{JUSTIFICATIVA}

No Distrito Federal e Região do Entorno não existem ações voltadas à promoção da saúde nas bibliotecas públicas. Por isto, ressalta-se a importância de ser realizado um trabalho de intervenção visando à promoção da saúde nas comunidades, porém, com a busca de indivíduos em espaços diferenciados das unidades de saúde, onde, em geral, a demanda é caracterizada pela procura por atendimento às doenças. Ademais, o fato de existirem bibliotecas públicas em todas as localidades do Distrito Federal facilita na disponibilidade de locais para esse trabalho de intervenção, bem como para a realização da pesquisa.

Dessa forma, existe a disponibilidade de espaços sociais, no caso as bibliotecas públicas, que se configuram em locais de reunião de indivíduos, onde pode ser realizada esta pesquisa, através da promoção de ações de educação em saúde com os usuários. Outro aspecto importante a ser referido é que os indivíduos que frequentam as bibliotecas públicas são pessoas diferenciadas, no sentido de estarem em busca de conhecimentos e de melhoria de situação social, cultural e econômica. Isso faz com que sejam formadores de opinião, portanto importantes multiplicadores de informações para as comunidades e potenciais colaboradores de ações educativas.

Assim sendo, a pergunta/problema de pesquisa deste estudo é: "Qual a efetividade de uma intervenção de Educação em Saúde na Qualidade de Vida de indivíduos frequentadores de bibliotecas públicas?"

Quanto às hipóteses, temos que:

Hipótese Nula (Ho): Uma intervenção de educação em saúde não tem efetividade na qualidade de vida de indivíduos frequentadores de bibliotecas públicas.

Hipótese Alternativa (H1): Uma intervenção de educação em saúde tem efetividade na qualidade de vida de indivíduos frequentadores de bibliotecas públicas. 


\section{OBJETIVOS}

\subsection{Objetivo Geral}

Realizar uma intervenção de educação em saúde no âmbito de bibliotecas públicas do Distrito Federal, para promover a saúde, melhoria da qualidade de vida e prevenir doenças, bem como verificar os efeitos dessa intervenção.

\subsection{Objetivos Específicos}

\subsubsection{Criação do Ambiente de Suporte}

- Criar as Sociedades de Amigos da Biblioteca com ênfase na estruturação de grupos de Amigos da Saúde no contexto das mesmas, com o envolvimento dos funcionários das bibliotecas, dos usuários, agentes comunitários de saúde e comunidades;

- Criar a "Estante da Saúde" nas bibliotecas públicas com um acervo que contemple materiais educativos como livros, DVDs e outras mídias, bem como materiais do Ministério da Saúde;

- Promover o uso de tecnologias da informação para permitir o acesso a redes e sistemas de informação na área da saúde;

- Credenciar as bibliotecas públicas no BiblioSUS/Biblioteca Virtual de Saúde.

\subsubsection{Intervenção}

- Disseminar conteúdos relacionados à promoção da saúde e qualidade de vida através da proposição e desenvolvimento de ações nas bibliotecas públicas das comunidades, com o apoio e participação das Sociedades de Amigos da Biblioteca/Grupos de Amigos da Saúde;

- Promover no âmbito das famílias dos usuários a leitura de material relacionado aos cuidados de higiene corporal, higiene bucal e estratégias de organização do cotidiano;

- Descrever o processo de intervenção de forma contextualizada nos diversos cenários.

\subsubsection{Avaliação da Intervenção}

- Verificar o acesso e a utilização de informações disponibilizados na "Estante da Saúde";

- Conhecer e comparar dados quanto à qualidade de vida e promoção da saúde obtidos na pesquisa de Mestrado com os dados obtidos dos Tutores na pesquisa de Doutorado, para analisar mudanças ocorridas no intervalo de tempo entre ambas as coletas;

- Avaliar o efeito da intervenção nos participantes relativo às possíveis mudanças quanto à qualidade de vida e com relação à percepção de mudanças nos âmbitos psicológico, do corpo físico, do ambiente familiar, do ambiente do trabalho ou estudo e quanto ao lazer. 


\section{MÉTODOS}

O campo de estudo abrangeu quatro (quatro) bibliotecas públicas do Distrito Federal (Brasília e suas cidades satélites). As bibliotecas públicas onde o estudo foi desenvolvido foram as seguintes: Taguatinga, Ceilândia, Águas Claras, e Gama, com a participação de alguns indivíduos da Biblioteca de Vicente Pires, que participaram da formação de Tutores na Biblioteca da Ceilândia.

O tipo de estudo foi analítico, observacional, longitudinal prospectivo, através da estratégia do tipo Estudo de Painel (46) para avaliação de intervenção antes-depois. A população foi constituída de indivíduos usuários de bibliotecas públicas do DF. Quanto aos sujeitos, a amostra foi constituída por indivíduos acima de doze anos, de qualquer escolaridade e rendas pessoal e familiar, de ambos os gêneros, usuários das bibliotecas públicas do Distrito Federal, caracterizando-se a amostra por conveniência.

O tamanho da amostra foi calculado para detectar diferenças de dez pontos percentuais na presença de uma variável, cuja frequência no grupo menos exposto (vulnerável) é quinze por cento (15\%) e no grupo mais exposto é vinte e cinco por cento $(25 \%)$. Foi definida a probabilidade de Erro Tipo I $(\alpha)<0,05$, e a probabilidade de Erro Tipo II $(\beta)<0,20$ [poder $(1-\beta)>0,80$ ]. Nessas condições, o tamanho estimado foi duzentos (200) indivíduos, em dois grupos de cem (100) indivíduos, porém, sendo o mesmo grupo comparado consigo mesmo, na estratégia antes-depois. No entanto, devido às dificuldades de recrutamento, somente foi possível obter-se um grupo de 85 (oitenta e cinco) indivíduos para aplicar a intervenção, fazendo-se a comparação dos 85 indivíduos no momento pré-intervenção, com os mesmos 85 indivíduos no momento pós-intervenção. No momento pré e pós-intervenção foram aplicados os questionários WHOQOL-Bref, para verificação da qualidade de vida antes e depois da intervenção.

Um segundo grupo de 76 (setenta e seis) indivíduos, os quais tiveram a formação de tutoria para a intervenção e que eram usuários e alguns, também funcionários das bibliotecas públicas, foi emparelhado artificialmente com o grupo trabalhado no Mestrado da aluna (44). Neste grupo foram aplicados os questionários WHOQOL-Bref e a entrevista semi-estruturada acima citadas. Esse grupo não sofreu intervenção e foi comparado com um grupo do Mestrado com a mesma quantidade de indivíduos e características semelhantes, com o objetivo de verificar-se, no espaço temporal, quais mudanças ocorreram, relativamente à aspectos de saúde e, em especial, com relação à qualidade de vida. 
Com relação ao desenho do estudo, o mesmo teve a seguinte configuração:

\section{DESENHO DO ESTUDO}

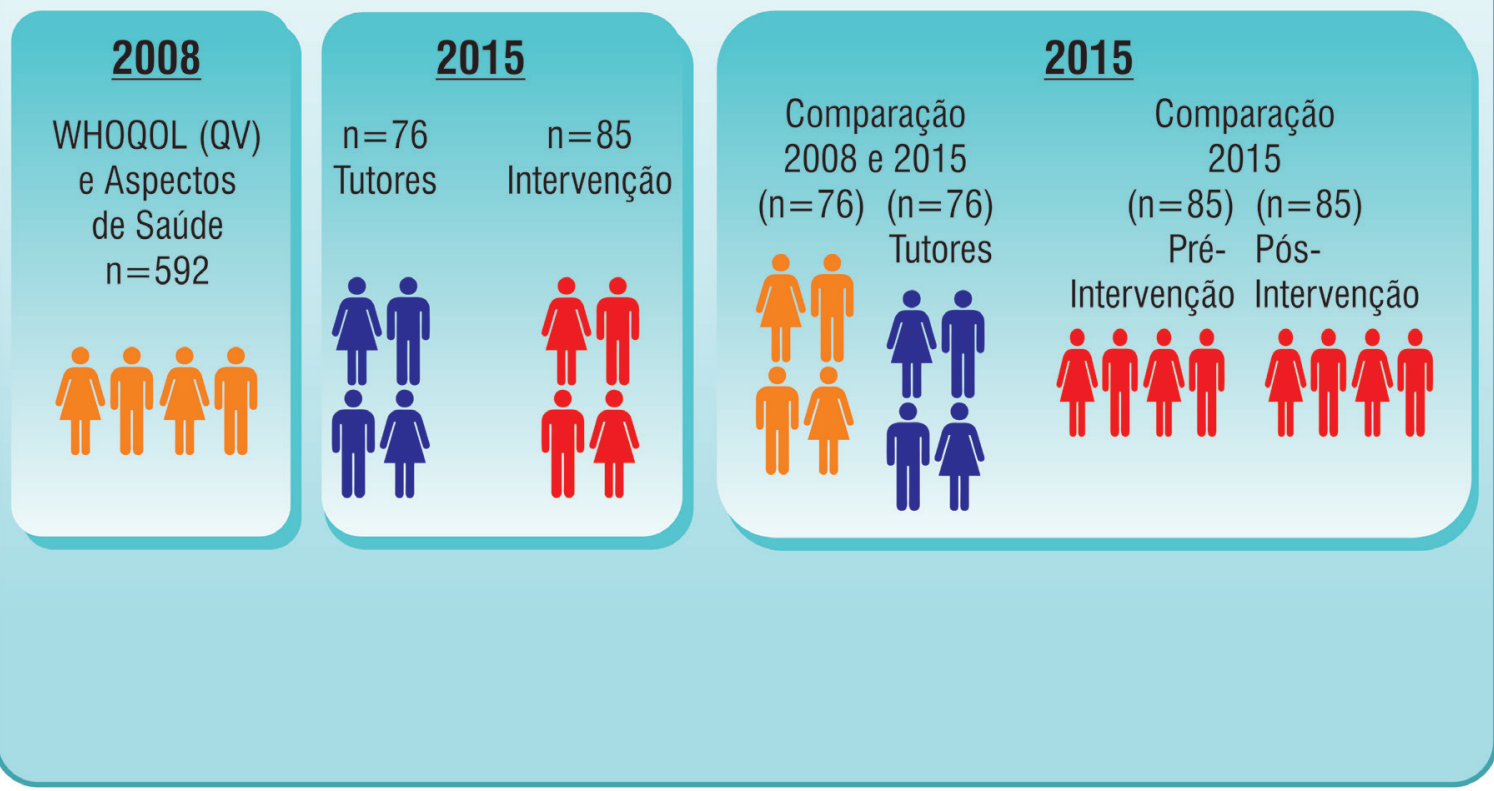

Figura 3. Desenho do Estudo.

Vale salientar que no presente estudo foram seguidas as diretrizes estabelecidas pelo STROBE 2007 (Strengthening the Reporting of Observational Studies in Epidemiology), conforme aponta Malta et al (47) e detalhado abaixo no Quadro 01: 
Quadro 01: Itens essenciais que devem ser descritos em estudos observacionais, segundo a declaração Strengthening the Reporting of Observational Studies in Epidemiology (STROBE). 2007.

\begin{tabular}{lrl}
\hline Item & $\mathrm{N}^{\circ}$ & \multicolumn{1}{c}{ Recomendação } \\
\hline Título e Resumo & 1 & $\begin{array}{l}\text { Indique o desenho do estudo no título ou no resumo, com } \\
\text { termo comumente utilizado } \\
\text { Disponibilize no resumo um sumário informativo e equilibrado do } \\
\text { que foi feito e do que foi encontrado }\end{array}$ \\
$\begin{array}{l}\text { Introdução } \\
\text { Contexto/Justificativa } \\
\text { Objetivos }\end{array}$ & 2 & Detalhe o referencial teórico e as razões para executar a pesquisa. \\
& 3 & Descreva os objetivos especif́cos, incluindo quaisquer hipóteses pré-existentes.
\end{tabular}

Métodos

Desenho do estudo

Contexto (setting)

Participantes

Variáveis

Fontes de dados/ Mensuração $8^{\mathrm{a}}$

Viés

Tamanho do estudo

Variáveis quantitativas

Métodos estatísticos

Resultados

Participantes

Dados descritivos
4 Apresente, no início do artigo, os elementos-chave relativos ao desenho do estudo.

5 Descreva o contexto, locais e datas relevantes, incluindo os períodos de recrutamento, exposição, acompanhamento (follow-up) e coleta de dados.

6 Estudos de Coorte: Apresente os critérios de elegibilidade, fontes e métodos de seleção dos participantes. Descreva os métodos de acompanhamento. Estudos de Caso-Controle: Apresente os critérios de elegibilidade, as fontes e o critério-diagnóstico para identifi cação dos casos e os métodos de seleção dos controles. Descreva a justificativa para a eleição dos casos e controles Estudo Seccional: Apresente os critérios de elegibilidade, as fontes e os métodos de seleção dos participantes.

Estudos de Coorte: Para os estudos pareados, apresente os critérios de pareamento e o número de expostos e não expostos.

Estudos de Caso-Controle: Para os estudos pareados, apresente os critérios de pareamento e o número de controles para cada caso.

7 Defina claramente todos os desfechos, exposições, preditores, confundidores em potencial e modifi cadores de efeito. Quando necessário, apresente os critérios diagnósticos.

$8^{a}$ Para cada variável de interesse, forneça a fonte dos dados e os detalhes dos métodos utilizados na avaliação (mensuração). Quando existir mais de um grupo, descreva a comparabilidade dos métodos de avaliação.

9 Especifique todas as medidas adotadas para evitar potenciais fontes de vies.

10 Explique como se determinou o tamanho amostral.

11 Explique como foram tratadas as variáveis quantitativas na análise. Se aplicável, descreva as categorizações que foram adotadas e porque.

12 Descreva todos os métodos estatísticos, incluindo aqueles usados para controle de confundimento.

Descreva todos os métodos utilizados para examinar subgrupos e interações.

Explique como foram tratados os dados faltantes ("missing data")

Estudos de Coorte: Se aplicável, explique como as perdas de acompanhamento foram tratadas.

Estudos de Caso-Controle: Se aplicável, explique como o pareamento dos casos e controles foi tratado.

Estudos Seccionais: Se aplicável, descreva os métodos utilizados para considerar a estratégia de amostragem.

Descreva qualquer análise de sensibilidade.

$13^{a}$ Descreva o número de participantes em cada etapa do estudo (ex: número de participantes potencialmente elegíveis, examinados de acordo com critérios de elegibilidade, elegíveis de fato, incluídos no estudo, que terminaram o acompanhamento e efetivamente analisados)

Descreva as razões para as perdas em cada etapa.

Avalie a pertinência de apresentar um diagrama de fluxo

$14^{\mathrm{a}}$ Descreva as características dos participantes (ex: demográficas, clínicas e sociais) e as informações sobre exposições e confundidores em potencial. Indique o número de participantes com dados faltantes para cada variável de interesse.

Estudos de Coorte: Apresente o período de acompanhamento (ex: média e tempo total) 


\begin{tabular}{|c|c|c|}
\hline \multicolumn{3}{|l|}{ Continuação do Quadro 01: } \\
\hline Item & $\mathrm{N}^{\circ}$ & Recomendação \\
\hline Desfecho & $15^{\mathrm{a}}$ & $\begin{array}{l}\text { Estudos de Coorte: Descreva o número de eventos-desfecho ou as } \\
\text { medidas-resumo ao longo do tempo } \\
\text { Estudos de Caso-Controle: Descreva o número de indivíduos em cada categoria } \\
\text { de exposição ou apresente medidas-resumo de exposição. } \\
\text { Estudos Seccionais: Descreva o número de eventos-desfecho ou } \\
\text { apresente as medidas-resumo. }\end{array}$ \\
\hline Resultados principais & 16 & $\begin{array}{l}\text { Descreva as estimativas não ajustadas e, se aplicável, as estimativas ajustadas } \\
\text { por variáveis confundidoras, assim como sua precisão (ex: intervalos de } \\
\text { confi ança). Deixe claro quais foram os confundidores utilizados } \\
\text { no ajuste e porque foram incluídos. } \\
\text { Quando variáveis contínuas forem categorizadas, informe os } \\
\text { pontos de corte utilizados. } \\
\text { Se pertinente, considere transformar as estimativas de risco relativo em termos } \\
\text { de risco absoluto, para um período de tempo relevante. }\end{array}$ \\
\hline Outras análises & 17 & $\begin{array}{l}\text { Descreva outras análises que tenham sido realizadas. Ex: análises } \\
\text { de subgrupos, interação, sensibilidade. }\end{array}$ \\
\hline \multicolumn{3}{|l|}{ Discussão } \\
\hline Resultados principais & 18 & Resuma os principais achados relacionando-os aos objetivos do estudo. \\
\hline Limitações & 19 & $\begin{array}{l}\text { Apresente as limitações do estudo, levando em consideração fontes potenciais } \\
\text { de viés ou imprecisão. Discuta a magnitude e direção de viéses em potencial. }\end{array}$ \\
\hline Interpretação & 20 & $\begin{array}{l}\text { Apresente uma interpretação cautelosa dos resultados, considerando os } \\
\text { objetivos, as limitações, a multiplicidade das análises, os resultados de estudos } \\
\text { semelhantes e outras evidências relevantes. }\end{array}$ \\
\hline Generalização & 21 & Discuta a generalização (validade externa) dos resultados. \\
\hline \multicolumn{3}{|l|}{ Outras Informações } \\
\hline Financiamento & 22 & $\begin{array}{l}\text { Especifi que a fonte de financiamento do estudo e o papel dos financiadores. Se } \\
\text { aplicável, apresente tais informações para o estudo original } \\
\text { no qual o artigo é baseado. }\end{array}$ \\
\hline
\end{tabular}

a Descreva essas informações separadamente para casos e controles em Estudos de Caso-Controle e para grupos de expostos e não expostos, em Estudos de Coorte ou Estudos Seccionais. Nota: Documentos mais detalhados discutem de forma mais aprofundada cada item do checklist, além de apresentarem o referencial teórico no qual essa lista se baseia e exemplos de descrições adequadas de cada item (Vandenbroucke et al.24,25 A checklist do STROBE é mais adequadamente utilizada um conjunto com esses artigos (disponiveis gratuitamente no site das revistas PLoS Medicine [www. plosmedicine.org], Annals of Internal Medicine [] e Epidemiology []). No website da iniciativa STROBE () estão disponíveis versões separadas de checklist para Estudos de Coorte, Caso-Controle ou Seccionais. Reproduzida de von Elm E, Altman DG, Egger M, Pocock SJ, Gøtzsche PC, Vandenbroucke JP. Declaração STROBE: Diretrizes para a comunicação de estudos observacionais[material suplementar na internet]. Malta M, Cardoso LO, tradutores.In: Malta M, Cardoso LO, Bastos FI, Magnanini MMF, Silva CMFP. Iniciativa STROBE: subsídios para a comunicação de estudos observacionais. Rev Saude Publica. 2010;44(3):559-65. 


\section{Quanto às variáveis, as mesmas foram relacionadas conforme segue:}

\section{Variáveis do grupo de Tutores $(\mathrm{n}=76)$ :}

- Variáveis Preditoras: socioeconômicas e demográficas, ou seja, gênero, faixa etária, renda pessoal, renda familiar, escolaridade e participação social;

- Variáveis de Desfecho: higiene geral, exposição solar, auto-percepção de saúde e morbidade auto-referida, morbidade referida e aconselhamento de profissionais de saúde, consumo de alimentos, consumo de bebidas não alcoólicas, mudanças de hábitos alimentares, consumo de bebidas alcoólicas, tabagismo, peso, altura, índice de massa corporal, recursos de assistência à saúde, profissionais de saúde, saneamento básico, referências ao tema saúde, motivo da presença e frequência às bibliotecas;

Variáveis do grupo submetido à intervenção $(n=85)$ :

- Variáveis de Desfecho Qualitativas: estado psicológico, estado físico, ambiente de casa, ambiente do trabalho e lazer;

\section{Variáveis do grupo de Tutores e do grupo submetido à intervenção:}

- Variáveis relacionadas à Qualidade de Vida (WHOQOL-Bref):

Domínio Físico: dor, desconforto, energia, fadiga, sono, repouso, atividades da vida cotidiana, dependência de medicação ou de tratamento médico, mobilidade, capacidade para o trabalho;

Domínio Psicológico: sentimentos positivos, pensar, aprender, memória, concentração, autoestima, imagem corporal, aparência, sentimentos negativos, espiritualidade, religião, crenças pessoais;

Relações Sociais: relações pessoais, suporte/apoio social, atividade sexual;

Ambiente: segurança física, proteção, ambiente no lar, recursos financeiros, disponibilidade e qualidade de cuidados de saúde e sociais, oportunidades de adquirir novas informações e habilidades, participação/oportunidades de recreação e lazer, ambiente físico quanto à poluição, ruído, trânsito e clima; transporte.

Como critérios de inclusão, foram admitidos para participar do estudo indivíduos acima de doze anos, de qualquer escolaridade e rendas pessoal e familiar, de ambos os gêneros, que pertenciam às comunidades selecionadas e que concordaram em participar das atividades pré-intervenção e daquelas de intervenção de educação em saúde, mediante assinatura do Termo de Consentimento Livre e Esclarecido. Os critérios de exclusão abrangeram indivíduos que não se enquadraram nos critérios acima especificados e que não satisfizeram critérios mínimos de adesão às ações de educação e promoção da saúde.

Quanto às considerações éticas, o presente projeto foi encaminhado para o Comitê de Ética em Pesquisa da Faculdade de Ciências da Saúde da UnB, para fins de análise. $O$ estudo foi iniciado apenas após a aprovação expressa do referido Comitê (Projeto $n^{\circ}$ 156/2011, em 09 de novembro de 2011, em respeito à Resolução $n^{\circ}$ 196/1996 do Conselho Nacional de Saúde (48) que regulamentava a pesquisa com 
seres humanos no Brasil, em vigor na época da submissão do projeto (Anexo 2), bem como após a assinatura pelos sujeitos de pesquisa do Termo de Consentimento Livre e Esclarecido TCLE (Anexo 3).

Quanto aos procedimentos, o estudo foi desenvolvido em continuidade àquele realizado no Mestrado da aluna, sendo que o presente projeto foi aplicado em três etapas de atividades, em consonância com os objetivos propostos, através do desenvolvimento de ações que integraram a criação do ambiente de suporte, bem como a intervenção, conforme segue curriculum das seguintes atividades:

a) Realização nos locais da pesquisa de Curso de Dinamização e Uso da Biblioteca Pública, o qual incluiu um módulo de Projetos Especiais, com a proposição da criação das Sociedades de Amigos da Biblioteca com ênfase na estruturação de grupos de Amigos da Saúde no contexto das bibliotecas, para estimular a participação dos usuários e funcionários ( $n=76$ - grupo de Tutores) através de palestras e exposição de material que abordava a higiene corporal, cuidado com os dentes e tema relativo à organização pessoal. Foi aplicada a Escala de Medida de Qualidade de Vida - WHOQOL-Bref (40), (Anexo 4), e entrevista semi-estruturada (Anexo 5) no grupo de tutores. Todas essas atividades foram desenvolvidas no período de abril a agosto de 2015 , em atendimento ao item 3.2.1 dos Objetivos Específicos;

b) Foi aplicada a Escala de Medida de Qualidade de Vida - WHOQOL-Bref (40), (Anexo 4) e questionamentos orais sobre o estado psicológico, físico, do ambiente de casa, do ambiente do trabalho e lazer a ser respondido de forma aberta, antes da intervenção, no outro grupo, apenas de usuários $(n=85)$, que foi selecionado para a mesma, no período de outubro de 2015 , em atendimento ao item 3.2.3 dos Objetivos Específicos;

c) Também foram desenvolvidas exposições de material relativo ao cuidado com os dentes e dinâmicas com conteúdos acessíveis, especialmente às pessoas menos letradas, com ênfase na abordagem sobre questões de saúde em geral (Anexos 6 e 7), durante os meses de novembro e dezembro de 2015, em atendimento ao item 3.2.2 dos Objetivos Específicos;

d) Estabelecimento de diretrizes para estruturar e formar o acervo da "Estante da Saúde" de cada biblioteca pública em conjunto com os participantes e em consonância com as demandas contextualizadas, com a inclusão de material educativo do Ministério da Saúde, cujas atividades foram desenvolvidas durante o período de junho a setembro de 2015, em atendimento ao item 3.2.1 dos Objetivos Específicos;

e) Fornecimento de orientações aos Tutores e usuários das bibliotecas públicas quanto ao uso da tecnologia da informação para acessar sites do Ministério da Saúde e outros, em atendimento ao item 3.2.1 dos Objetivos Específicos;

f) Fornecimento de informações aos responsáveis pelas bibliotecas com relação ao cadastramento das mesmas no BiblioSUS, para estimular os usuários no uso da Biblioteca Virtual de Saúde/BiblioSUS como fonte de informação e es- 
clarecimento a todas as demandas, durante os meses de setembro e outubro de 2015, em atendimento ao item 3.2.1 dos Objetivos Específicos;

\section{A avaliação da intervenção foi realizada em duas etapas, conforme segue:}

Etapa 1: Foi verificada a efetividade das ações de intervenção de educação em saúde junto aos indivíduos ( $\mathrm{n}=85$ - grupo de usuários), através da aplicação pós-intervenção da Escala de Medida de Qualidade de Vida - WHOQOL-Bref (40), (Anexo 4), e de análise qualitativa das respostas dos indivíduos, relativas aos aspectos psicológico, do corpo físico, do ambiente de casa, do ambiente do trabalho e quanto ao lazer. A comparação dos resultados obtidos quanto à qualidade de vida foi feita em função dos indivíduos que constituíram o grupo de intervenção $(n=85)$. Também foi realizada análise quanto à saúde e qualidade de vida nos indivíduos do grupo de tutores $(n=76)$.

Para a avaliação da efetividade das ações no grupo que sofreu a intervenção ( $n=85)$, o Estudo de Painel (46) foi utilizado por ser um modelo de comparação interna. Pretendeu-se, com isso, examinar os padrões de mudança e as razões para essas mudanças. Esse grupo que foi submetido à intervenção foi comparado à si próprio. Todos esses itens até aqui citados foram cumpridos em atendimento ao item 3.2.3 dos Objetivos Específicos.

O Estudo de Painel $(49,59)$ é um delineamento híbrido entre os estudos seccional (transversal) e de coorte, sendo que apresenta como modelo conceitual a realização de uma série de estudos seccionais em uma mesma população ou amostras desta população, em diferentes intervalos de tempo. Outra característica do Estudo de Painel é de que não apresenta a mesma limitação encontrada em estudos seccionais no que se refere à inclusão de temporalidade na análise. A observação longitudinal em uma mesma população permite a inferência causa-efeito, ou seja, é possível concluir que as mudanças observadas nos indicadores de, no caso, qualidade de vida, possam estar associadas à exposição, ou seja, à intervenção. As principais limitações deste desenho referem-se ao tamanho da amostra necessária, principalmente quando o evento de interesse é raro, às perdas de seguimento na população investigada, às migrações que podem ocorrer na área e à presença de variáveis de confusão.

Relativamente ao grupo de Tutores $(n=76)$, foi realizado um emparelhamento artificial (51) com um grupo semelhante e pertencente à amostra do Mestrado, para garantir que algumas variáveis mais importantes pudessem ser controladas. Foi feita a formação de parelhas de pessoas com características semelhantes em determinados aspectos. No caso, foram selecionados indivíduos da mesma população, porém não necessariamente foram os mesmos indivíduos, mas, por exemplo, foi a mesma faixa etária, gênero e lugar. Com isso pretendeu-se que houvesse uma comparabilidade dos grupos.

O emparelhamento é uma estratégia que serve para controlar fatores de confusão, onde os mesmos ficam igualmente distribuídos. Além disso, contribui para aumentar a precisão e simplificar a logística. Esse procedimento foi realizado em consonância com o item 3.2.3 dos Objetivos Específicos.

Etapa 2: Consistiu da comparação e análise dos dados obtidos no grupo submetido à intervenção $(n=85)$ nos momentos pré e pós-intervenção, para avaliar a efetividade da intervenção. No grupo de tutores $(n=76)$, foi feita comparação e análise 
dos dados obtidos em face do grupo do Mestrado, emparelhado artificialmente a este. Esta etapa foi consoante ao item 3.2.3 dos Objetivos Específicos.

Quanto aos instrumentos, foram utilizados, para fins do presente estudo:

a) Aplicação da Escala de Medida de Qualidade de Vida WHOQOL-Bref (40) (Anexo 4), da Organização Mundial de Saúde, que incluiu vinte e seis questões, cobrindo quatro domínios: a) físico; b) psicológico; c) relações sociais e d) meio ambiente;

b) Aplicação de entrevista semi-estruturada (Anexo 5), a qual foi elaborada a partir de estudos prévios e literatura pertinente.

c) Aplicação de questionamentos orais sobre o estado psicológico, físico, do ambiente de casa, do ambiente do trabalho e lazer, com respostas abertas;

d) Registros fonográficos das reuniões com o grupo de Tutores e de usuários, com questionamentos sobre as consultas realizadas nos materiais expostos nas Estantes da Saúde;

e) Registros fonográficos/transcrições e fotográficos das reuniões com os grupos de Tutores e de usuários, bem como dos eventos de inauguração de algumas bibliotecas.

O tempo estimado para o preenchimento dos instrumentos de coleta de dados foi de aproximadamente doze (12) minutos. O período de coleta de dados foi de maio de 2015 a janeiro de 2016 .

Em relação à análise critica dos riscos, pelo fato de a pesquisa utilizar apenas atividades pedagógicas em grupo e a aplicação de questionários, os riscos referentes ao trabalho foram mínimos. O anonimato dos sujeitos de pesquisa será assegurado, pois o estudo teve enfoque nos dados como um todo e não individualmente. Os indivíduos foram identificados com um número e somente a pesquisadora sabe qual número pertence a cada indivíduo. Este estudo mostrou apenas os resultados obtidos como um todo, sem revelar o nome dos sujeitos ou qualquer informação que esteja relacionada com a privacidade destes.

Quanto às responsabilidades da pesquisadora, os dados obtidos serão mantidos no computador pessoal da mesma e terão acesso a eles somente a pesquisadora e o orientador envolvidos neste projeto. Após a finalização dos artigo científicos, os dados serão mantidos em arquivo privado da pesquisadora pelo período de cinco anos e, após, serão incinerados.

Esta pesquisa poderia ser suspensa ou encerrada em qualquer momento, mediante a recusa dos sujeitos em participar da pesquisa. $O$ encerramento do projeto deu-se após a realização de todas as atividades propostas. Para fins acadêmicos, o encerramento acontecerá com a apresentação da Tese de Doutorado, sendo divulgados os resultados obtidos nas Instituições envolvidas. O encerramento definitivo será após a publicação dos dados em forma de artigo científico. 
Com relação à análise dos dados, os quantitativos foram avaliados por meio de estatística descritiva, com a comparação da avaliação da Medida da Qualidade de Vida WHOQOL-Bref (40) entre segmentos dos usuários através de teste T de student ou Anova (análise de variância), quando a variável foi de distribuição normal. Quando a variável foi de distribuição não normal, foi utilizado o teste de médias (baseado nas medianas) de Kruskal-Wallis. Além da estratégia anterior, os dados foram analisados de maneira dicotômica, sendo medidas as prevalências de relato da qualidade de vida e das demais variáveis, e estimada a razão de prevalências entre as distintas variáveis.

Ainda com relação aos dados quantitativos, as associações foram testadas mediante o teste de Qui-quadrado. Foi considerado como nível de significância o de $p<0,05$. Além disso, nos dados do WHOQOL-Bref (40) foram calculados o Escore Bruto (EB) e os Escores Transformados 4-20 e 0-100, onde os valores variaram de 4 a 20 e de 0 a 100, respectivamente (Anexo 8).

Os dados do WHOQOL-Bref (40) foram analisados nos quatro domínios através de uma escala de escores da Organização Mundial de Saúde (41) também por Saupe (52), em seus estudos, representada por um número real, compreendido no intervalo de 0 a 100, onde valores entre 0 e 40 são considerados região de fracasso; de 41 a 69 correspondem a região de indefinição e acima de 70 seria a região de sucesso.

No grupo de Tutores, como pontos de corte, foram considerados, para a escolaridade, como os indivíduos tendo o ensino médio e o ensino superior. Para a renda pessoal o ponto de corte foi 1,5 salários mínimos e para a renda familiar 3,5 salários mínimos. Em ambos os grupos, de tutores e o submetido à intervenção, indivíduos até 24 anos foram considerados adolescentes e adultos jovens, sendo o ponto de corte igual ou menor que 24 anos e, acima de 25 anos.

Em ambos os grupos ( $n=76$ e $n=85$, ou seja, Tutores e usuários), com relação à qualidade de vida através da análise com o WHOQOL-Bref (40), foi considerado o Escore Transformado 0-100 e, como ponto de corte, abaixo de 70 e igual ou maior que 70 , onde níveis abaixo de 70 foram considerados como insatisfação na qualidade de vida e acima de 70 como satisfação na mesma. Para a análise estatística dos dados foram utilizados os programas Epiinfo 6.0 e SPSS 10.0.

Os dados qualitativos foram avaliados através da análise de conteúdo dos relatos das reuniões realizadas com os sujeitos de pesquisa antes da intervenção, das reuniões com os mesmos, realizadas após a intervenção, e dos questionários orais realizados com os grupos conforme citado acima (item "c" dos instrumentos) sob a ótica da análise da enunciação. A análise dos dados quantitativos e qualitativos foi consoante com o item 3.2.3 dos Objetivos Específicos. 


\section{Análise Quantitativa e Análise Qualitativa}

Foi na década de 50 que houve um debate expressivo entre procedimentos quantitativos e qualitativos. Algumas pessoas definiam a análise segundo o caráter quantitativo, enquanto outras defendiam a validade de uma análise qualitativa.

Segundo Bardin (53), pesquisa quantitativa se fundamenta na frequência de aparição de determinados elementos da mensagem. No caso da pesquisa qualitativa, esta recorre a indicadores não frequenciais que permitem inferências.

Contudo, as abordagens quantitativa e a qualitativa não se caracterizam pelo mesmo campo de ação. Enquanto a primeira obtém dados descritivos através de um método estatístico, sendo mais objetiva, fiel e exata, através de uma observação controlada e, além disso, sendo muito útil nas fases de verificação das hipóteses, a segunda corresponde a um procedimento mais intuitivo, mais maleável e mais adaptável a índices não previstos, ou à evolução das hipóteses. A análise qualitativa deve ser utilizada nas fases de lançamento das hipóteses, pois permite sugerir possíveis relações entre um índice da mensagem e uma ou várias variáveis do locutor ou da situação de comunicação.

Bardin (53) refere que a análise qualitativa possui certas características particulares, sendo válida, na elaboração de deduções especificas sobre um acontecimento ou uma variável de inferência precisa, e não em inferências gerais. A autora diz que esta pode funcionar sobre corpus reduzidos e estabelecer categorias mais descriminantes, visto não estar atrelada, enquanto análise quantitativa, a categorias que dêem lugar a frequências suficientemente elevadas, de forma que os cálculos se tornem possíveis.

Em conclusão, pode dizer-se que o que caracteriza a análise qualitativa é o fato de a inferência, sempre que é realizada, ser fundada na presença do índice - tema, palavra, personagem, etc. -, e não sobre a frequência da sua aparição, em cada comunicação individual (53).

Bardin (53) relata que a discussão sobre a abordagem quantitativa em face da qualitativa marcou a concepção da análise de conteúdo, sendo que na primeira metade do século $X X$, o que caracterizava a especificidade deste tipo de análise era o rigor e, portanto, a quantificação. Após, compreendeu-se que a essência da análise de conteúdo é a inferência - variáveis inferidas a partir de variáveis de inferência ao nível da mensagem -, quer as modalidades de inferência se baseiem ou não, em indicadores quantitativos.

Relativamente à análise de conteúdo (53), esta foi utilizada, em um contexto behaviorista das ciências humanas e também, devido ao interesse de alguns governos em conhecer e interpretar as orientações políticas e estratégicas de países estrangeiros, através de documentos acessíveis como imprensa e rádio.

A análise de conteúdo de mensagens é uma técnica aplicável a todas as formas de comunicação, sendo uma metodologia empírica, que analisa o discurso e o tipo de leitura, de acordo com um objetivo pré-definido. 
Segundo Bardin (53), a descrição analítica funciona seguindo determinados procedimentos sistemáticos e objetivos de descrição do conteúdo das mensagens, sendo um tratamento da informação. $O$ autor coloca que a análise de conteúdo é uma descrição objetiva, sistemática e quantitativa do conteúdo das comunicações, objetivando a interpretação dessas comunicações. Assim sendo, o autor esclarece que a análise de conteúdo é "um conjunto de técnicas de análise das comunicações, com procedimentos sistemáticos e objetivos de descrição do conteúdo das mensagens (53)."

Bardin (53) afirma que a intenção da análise de conteúdo é a inferência de conhecimentos relativos às condições de produção (ou, eventualmente, de recepção), inferência esta que recorre a indicadores, quantitativos ou não.

Para Bardin (53):

\begin{abstract}
"O analista é como um arqueólogo. Trabalha com vestígios: os documentos que pode descobrir ou suscitar. Mas os vestígios são a manifestação de estados, de dados e de fenómenos. Há qualquer coisa para descobrir por e graças a eles. Tal como a etnografia necessita da etnologia, para interpretar as suas descrições minuciosas, o analista tira partido do tratamento das mensagens que manipula, para inferir - deduzir de maneira lógica - conhecimentos sobre o emissor da mensagem ou sobre o seu meio."
\end{abstract}

É importante destacar que a inferência está relacionada a uma operação lógica, onde se admite uma proposição em face de sua ligação com outras proposições tidas como verdadeiras. Assim sendo, inferir seria a extração de uma consequência através da correspondência entre as estruturas semânticas ou linguísticas e as estruturas psicológicas ou sociológicas dos enunciados (53).

Também se faz necessário distinguir a linguística da análise de conteúdo, onde a primeira estuda a língua para descrever o seu funcionamento e a segunda, procura conhecer aquilo que está por trás das palavras sobre as quais se debruça. Desta forma, a análise de conteúdo tem o objetivo de conhecer as variáveis de ordem psicológica, sociológica, histórica, etc., através da dedução baseada em indicadores reconstruídos a partir de uma amostra de mensagens particulares.

Laurence Bardin (53) enumera três fases da análise de conteúdo, a saber:

1) A pré-análise ou fase de organização propriamente dita, que corresponde a um período de intuições. Tem o objetivo de sistematizar e tornar operacionais as ideias iniciais, de maneira a conduzir a um esquema preciso do desenvolvimento das operações sucessivas, num plano de análise. Nessa fase é essencial a escolha dos documentos a serem submetidos à análise, a formulação das hipóteses e dos objetivos e a elaboração de indicadores que fundamentem a interpretação final. A pré-análise deverá incluir:

a) A leitura flutuante, ou seja, o estabelecimento de contato com os documentos a serem analisados, o conhecimento do texto e das impressões e orientações;

b) A escolha dos documentos, segundo critérios pré-estabelecidos, selecionando-se variáveis e suas frequências; 
c) A formulação das hipóteses e dos objetivos, sendo que uma é definida como uma afirmação provisória a que nos propomos verificar - confirmar ou infirmar -, recorrendo aos procedimentos de análise. A formulação de uma hipótese é uma suposição cuja origem é a intuição e que permanece intacta enquanto não for submetida à prova de dados seguros;

d) Referenciação dos índices e elaboração de indicadores onde, ao se considerar os textos tal como uma manifestação contendo índices que a análise vai fazer falar. O trabalho preparatório será o da escolha destes em função das hipóteses, caso elas estejam determinadas e sua organização sistemática codificada em indicadores. Uma vez escolhidos os índices, procede-se à construção de indicadores precisos e seguros. Desde a pré-análise, devem ser determinadas operações: de recorte do texto em unidades comparáveis de categorização para análise temática e de modalidade de codificação para o registo dos dados;

e) Antes da análise propriamente dita, o material colhido deverá ser preparado. Essa preparação inclui desde o alinhamento dos enunciados intactos, proposição por proposição, até à transformação linguística dos sintagmas, para estandartização e classificação por equivalência.

2) A exploração do material, fase, longa e trabalhosa, que consiste de operações de codificação, desconto ou enumeração, em função de regras previamente formuladas.

3) O tratamento dos resultados, a inferência e a interpretação, onde os resultados brutos são tratados de maneira a serem significativos e válidos. São utilizadas operações estatísticas simples (percentagens), ou mais complexas (como a análise fatorial), as quais permitem a elaboração de quadros de resultados, diagramas, figuras etc.

Bardin (53) refere que a codificação é o processo pelo qual os dados brutos são transformados sistematicamente e agregados em unidades, as quais permitem uma descrição exata das características pertinentes do conteúdo.

A análise de conteúdo implica na crença de que a categorização - passagem de dados brutos a dados organizados -, não introduz desvios, por excesso ou por recusa, no material, mas fomenta índices invisíveis, ao nível dos dados brutos.

É importante saber as unidades que constituem o processo de comunicação, a saber (53):

a) O emissor/produtor da mensagem, que pode ser representado por um indivíduo ou um grupo de indivíduos emissores. Nesse sentido, poder-se-ia dizer que a mensagem exprime e representa o emissor;

b) O receptor, que pode ser um indivíduo ou um grupo de indivíduos. Dessa forma, o estudo da mensagem poderá fornecer informações relativas ao receptor ou receptores;

c) Qualquer que seja a análise de conteúdo, esta passa pela análise da própria mensagem, que se exerce através de um código e, cujo material, ponto de par- 
tida e indicador são o fomento da análise.

Para facilitar o processo de categorização, necessário para proceder-se à análise de conteúdo das questões Pré e Pós-Intervenção, o questionário foi semiestruturado, porém, com respostas abertas.

\section{Análise da Enunciação}

O Corpus: se a análise for intensiva, é necessário e suficiente trabalhar um material restrito, sendo que a qualidade da análise substitui a quantidade do material analisado. Em uma amostra pequena deve ser feita uma amostragem rigorosa. Se a análise for comparativa, é necessário que as condições sejam estandardizadas. Se, contudo, a análise estiver centrada na singularidade da elaboração individual do discurso, a redação respeita a liberdade e a criatividade individuais (53).

Fases da Análise da Enunciação, segundo Bardin (53):

a) Preparação do material: deve conduzir à transcrição exaustiva de cada produção. A transcrição de uma análise da enunciação deve conservar o máximo de informação tanto linguística, como o registro da totalidade dos significantes, como paralinguística, ou seja, a anotação dos silêncios, onomatopeias, perturbações de palavra e de aspectos emocionais tais como o riso, o tom irónico, etc..

b) As diferentes etapas da análise: a análise da enunciação é complementar de uma análise temática previamente efetuada. A análise da enunciação propriamente dita realiza-se em diversos níveis - nível das sequências, das proposições, dos elementos atípicos -, e a interpretação, ou seja, a compreensão do processo resulta da confrontação dos diferentes indicadores. Também na análise da enunciação, a validade é resultante de uma coerência interna entre os diversos traços significativos.

$\mathrm{Na}$ análise da enunciação cada entrevista é estudada em si mesma como uma totalidade organizada e singular, sendo um estudo dos casos. A dinâmica própria de cada produção é analisada e os diferentes indicadores adaptam-se à irredutibilidade de cada locutor (53).

Quanto ao alinhamento e a dinâmica do discurso, deve ser encontrada a lógica intrínseca que estrutura cada entrevista, sendo que:

$\checkmark$ Análise lógica: é uma análise das relações entre proposições. Um trabalho de observação do encadeamento das proposições.

$\checkmark$ Proposição é uma afirmação, uma declaração, um juizo, uma frase ou um elemento da frase que instaure, tal como a proposição lógica, uma relação entre dois ou mais termos.

$\checkmark$ A análise sequencial destaca a espansão, o ritmo e a progressão do discurso a um nível mais global que o nível precedente. É tambem uma análise das rupturas.

A análise lógica e a análise de sequência são duas etapas reveladoras da dinâ- 
mica da entrevista. Ao se confrontar os resultados obtidos com os da análise estilística, assim como com os dos elementos atípicos, é permitido compreender a conexão com os temas abordados, as tensões, as pausas, as perdas de domínio, os controles, as contradições, os conflitos, etc., que animam e estruturam o discurso.

Bardin (53) relata que, quanto à análise das relações, a teoria da associação de Freud e também a teoria da aprendizagem, em uma primeira etapa, assim como o aparecimento dos ordenadores em uma segunda etapa, no caso, o estruturalismo dentro da linguística e sociologia, contribuíram para orientar finalmente as técnicas de análise não mais para a simples frequência da aparição dos elementos do texto, mas para as relações que os elementos do texto mantêm entre si.

A duração do presente estudo foi de sessenta meses (cinco anos) e a responsável pela aplicação dos instrumentos foi a autora do trabalho, apoiada por membros constituintes da equipe do projeto.

Os equipamentos utilizados para a realização da pesquisa foram material referencial de consulta na forma impressa e em mídias, computador, impressora, lápis, borracha, caneta, combustível, grampeador, grampo, material impresso (questionários e TCLE), toner para impressora e prancheta.

Este estudo foi parcialmente financiado por Emenda Parlamentar concedida pelo Senador Cristovam Buarque, Processos de números UnBDoc: 124880/2013 e CCO 23106.016929/2013-09, e por recursos próprios da pesquisadora, obtidos através de empréstimo pessoal em banco. 


\section{RESULTADOS}

O presente estudo teve o seu financiamento parcial através de Emenda Parlamentar concedida pelo Senador da República Cristovam Buarque, conforme citado anteriormente.

No entanto, faz-se necessário relatar o imenso grau de dificuldades enfrentadas para a obtenção dessa verba, a qual era fundamental para viabilizar o início dos trabalhos de campo.

Como pode ser observado na Figura $n^{\circ} 4$ abaixo, a liberação da verba deu-se somente no mês de setembro de 2015, ou seja, já durante o segundo período de solicitação de prorrogação de prazo por parte da aluna. Inclusive, as solicitações de prorrogação de prazo para a defesa desta Tese de Doutorado são justificadas pela demora na liberação desses recursos, já que a aluna não possuía condições financeiras para assumir a pesquisa.

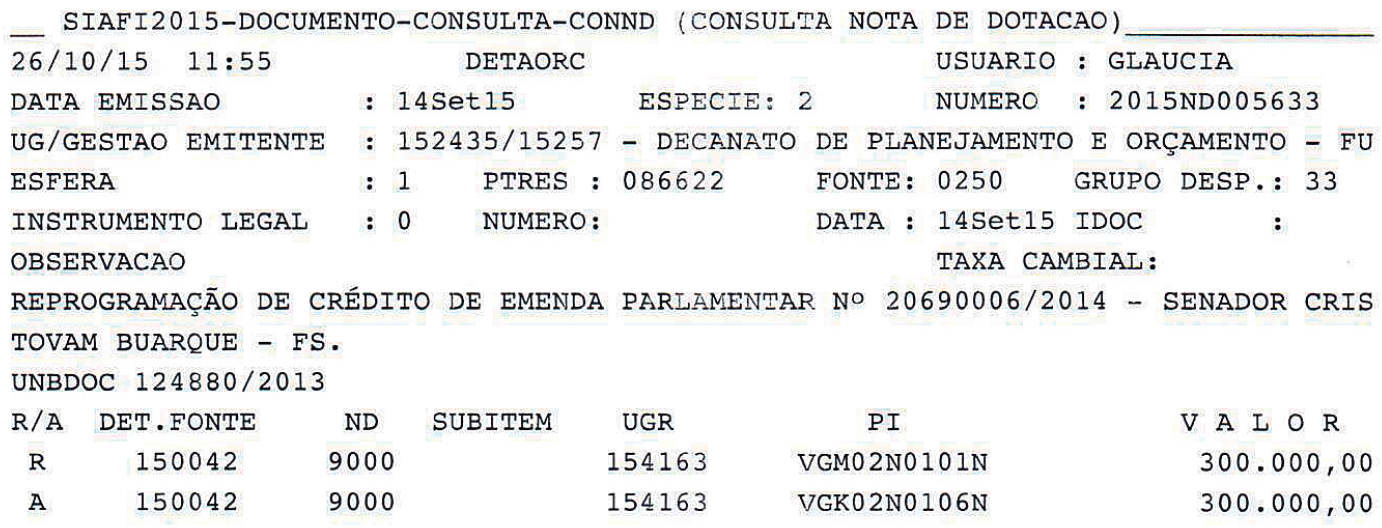
LANCADO POR : 02854204107 - DOUGLAS
UG : 154040
$14 \operatorname{Set} 15$
$17: 36$

PF1=AJUDA PF3=SAI PF4=ESPELHO PF12=RETORNA

Figura 4: Documento UnB de liberação de Emenda Parlamentar

Em nenhum momento a aluna esquivou-se das obrigações formais exigidas pela Reitoria da Universidade de Brasília - UnB, para a liberação da verba. No entanto, houve momento em que o Decanato de Administração decidiu usar todo o recurso que estava destinado para esta pesquisa em bolsas para alunos carentes, sem a anuência da aluna e de seu Orientador, sendo que os mesmos sequer foram consultados para isso. 
Isso causou sérios problemas para o desenvolvimento do trabalho, que inicialmente seria aplicado em todo o Distrito Federal, no entanto, após tantas idas e vindas, assim como manifestação do Senador Cristovam Buarque (Anexo 9), bem como cumprimento a outras inúmeras exigências da Universidade, finalmente a verba foi liberada conforme a data acima citada.

Destacamos aqui a imensa boa vontade do Decanato de Planejamento e Orçamento da Universidade de Brasília em resolver toda essa celeuma, apesar das infelizes dificuldades com o Decanato de Administração da UnB.

Como foi necessária a reprodução em gráfica dos livrinhos da Coleção Para Gente Grande, elaborada pela aluna, bem como outras providências como os trâmites burocráticos para compra de acervo, em fins de novembro de 2015 já havia as condições para iniciar o trabalho de Intervenção.

Mas nessa época haveria mais uma limitação: o ano escolar já estava findando, o que significava que diminuiria a frequência de usuários nas bibliotecas públicas.

Mesmo assim, a aluna havia feito um verdadeiro garimpo no mês de outubro de 2015, e conseguiu 85 (oitenta e cinco) sujeitos para a aplicação da Intervenção. Nesse mês de outubro, antes da Intervenção, a aluna aplicou nesses 85 participantes os questionários WHOQOL-Bref (Anexo 4) e questionamentos orais acerca do estado psicológico, físico, do ambiente de casa, do ambiente do trabalho e quanto ao lazer.

Note-se que 76 (setenta e seis) indivíduos já haviam participado do Curso de Dinamização e Uso da Biblioteca Pública, no período de abril a agosto de 2015, cuja realização também incluiu o módulo de Projetos Especiais, que continha material sobre saúde, sendo que para esta etapa, a aluna se utilizou de empréstimo pessoal em banco para financiamento da mesma.

Pois bem, em novembro e dezembro as atividades de Intervenção foram realizadas, apesar de todas as dificuldades, sendo que, no decorrer do ano de 2015 , foram obtidos os seguintes resultados conforme segue abaixo:

\section{1 - Resultados Qualitativos}

Foi realizado, no âmbito de todas as bibliotecas selecionadas, o Curso de Dinamização e Uso da Biblioteca Pública, com Certificação fornecida pela Faculdade de Ciências da Saúde da Universidade de Brasília e Sistema Distrital de Bibliotecas Públicas (Anexo 10), cuja programação incluiu 11 Módulos, sendo o último Módulo o de Projetos Especiais, que incluiu discussões sobre saúde, meio ambiente e inclusão social (Anexos 6 e 7 ).

Através da aplicação desse curso, foram selecionados indivíduos Tutores, para auxiliarem nas atividades a serem desenvolvidas antes, durante e após a Intervenção.

Com a realização do Curso de Dinamização e Uso da Biblioteca Pública, foi possível a inauguração da Biblioteca Pública de Vicente Pires e a reinauguração da 
Biblioteca Pública de Águas Claras. Além disso, na Biblioteca Pública de Taguatinga, já existiam projetos externos, cujos participantes também foram alunos do Curso de Dinamização, permitindo, dessa forma, a instalação da Estante da Saúde na Unidade de Atendimento em Meio Aberto - UAMA do Recanto das Emas e na Semiliberdade de Taguatinga. Os adolescentes da UAMA do Recanto das Emas e da Semiliberdade de Taguatinga participaram das atividades do Grupo de Amigos de Saúde.

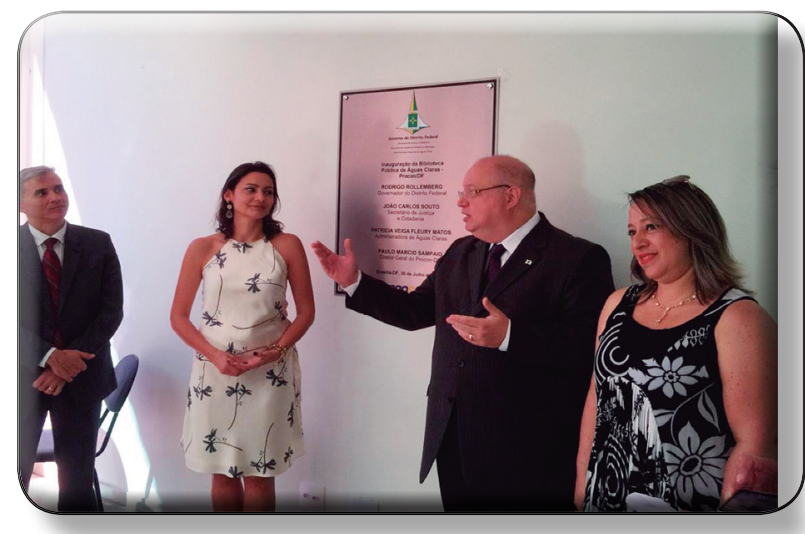

Foto $n^{\circ}$ 1: Reinauguração da Biblioteca Pública de Águas Claras

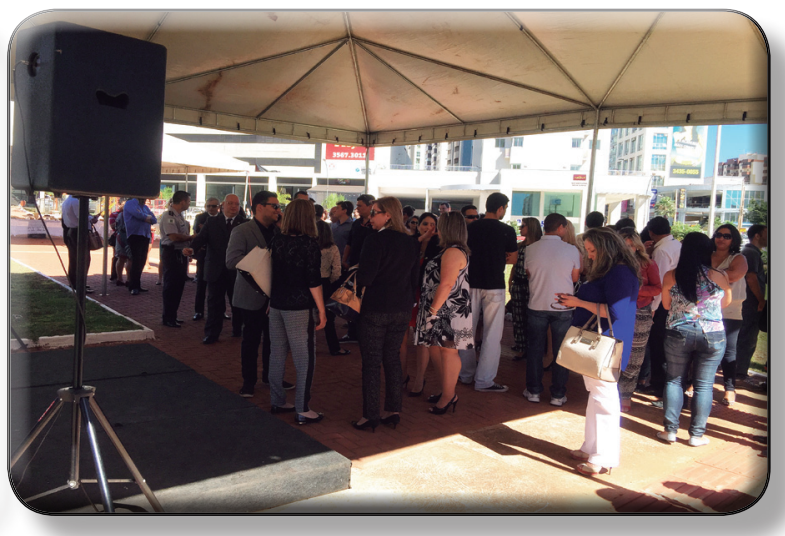

Foto $\mathrm{n}^{\circ}$ 2: Reinauguração da Biblioteca Pública de Águas Claras

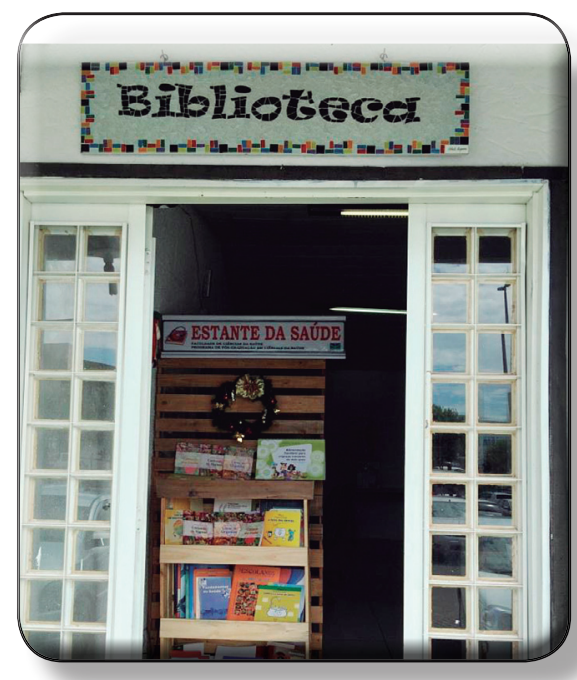

Foto $n^{\circ}$ 3: Biblioteca Pública de Vicente Pires

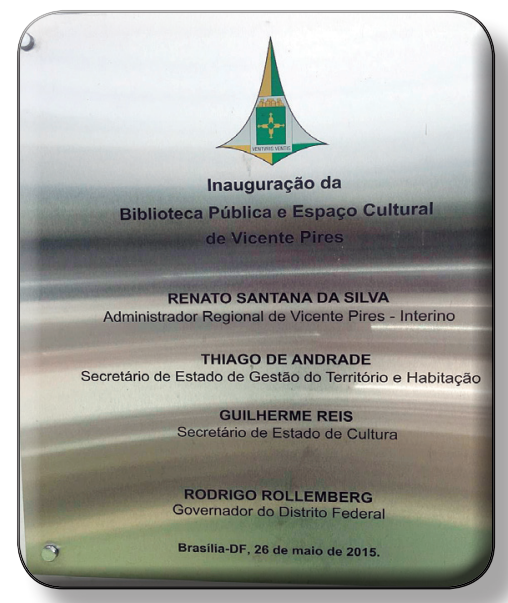

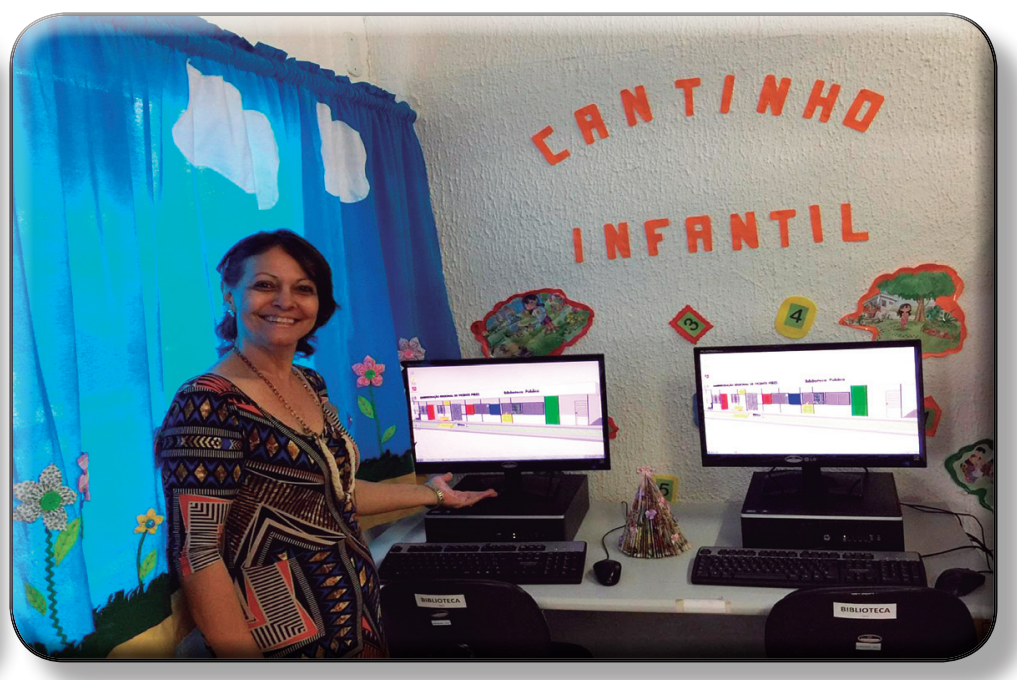

Foto $n^{\circ}$ 4: Cantinho Infantil da Biblioteca Pública de Vicente Pires
Fotos $n^{\circ}$ s 4 e 5: Placa de Inauguração e árvore de Natal confeccionada com livros da Biblioteca Pública de Vicente Pires. 


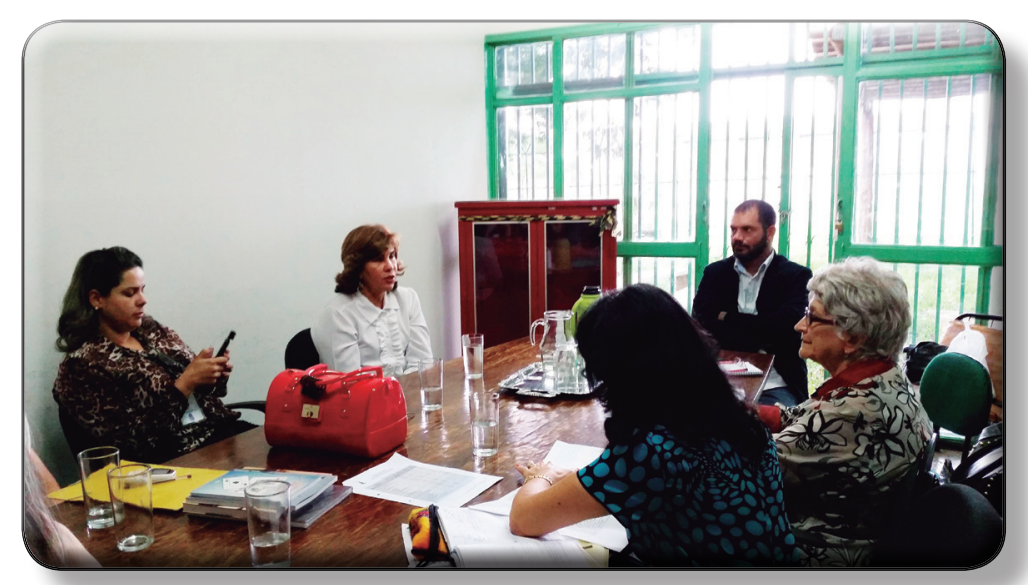

Foto $n^{\circ} 7$ : Reunião de trabalho na Biblioteca Pública do Gama

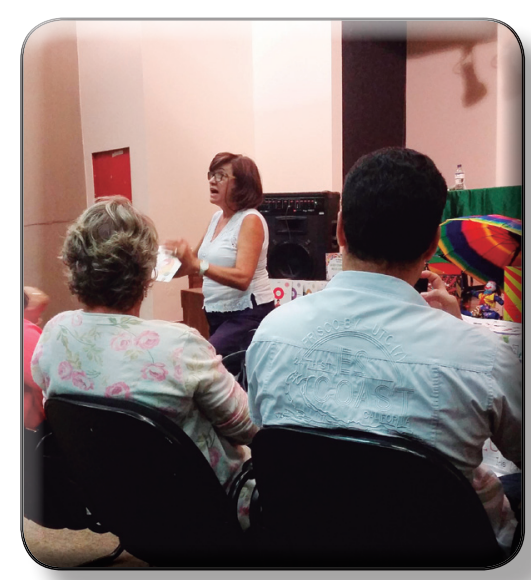

Foto $n^{\circ}$ 8: Reunião de trabalho na Biblioteca Pública do Gama

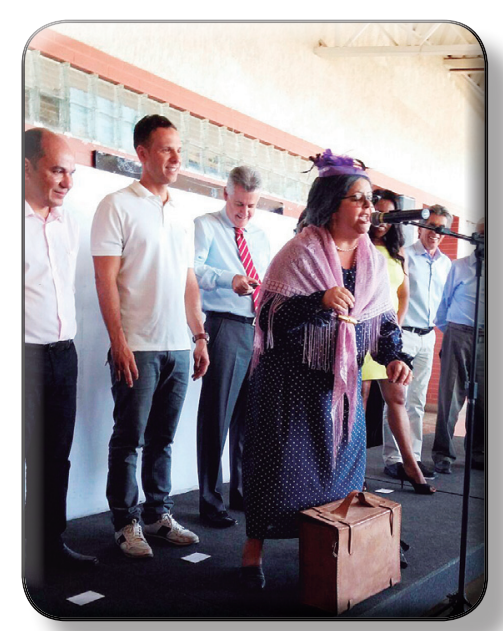

Foto $\mathrm{n}^{\circ}$ 9: Inauguração da Biblioteca da Cidade Estrutural

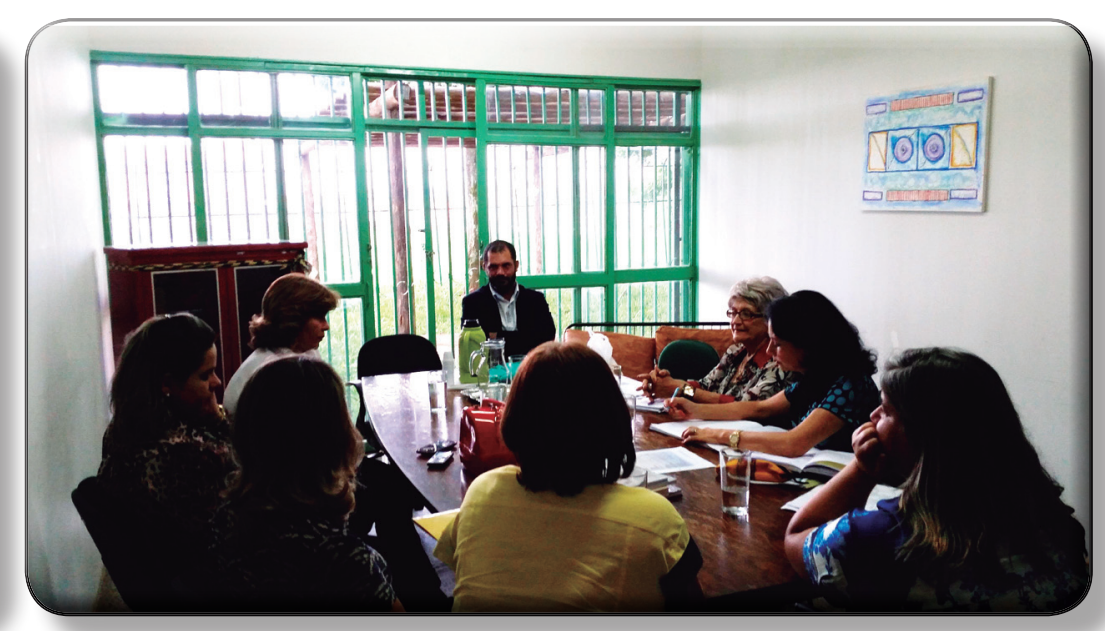

Foto $\mathrm{n}^{\circ}$ 10: Planejamento do Curso de Dinamização e Uso da Biblioteca Pública a ser ministrado aos Tutores da Biblioteca Pública do Gama

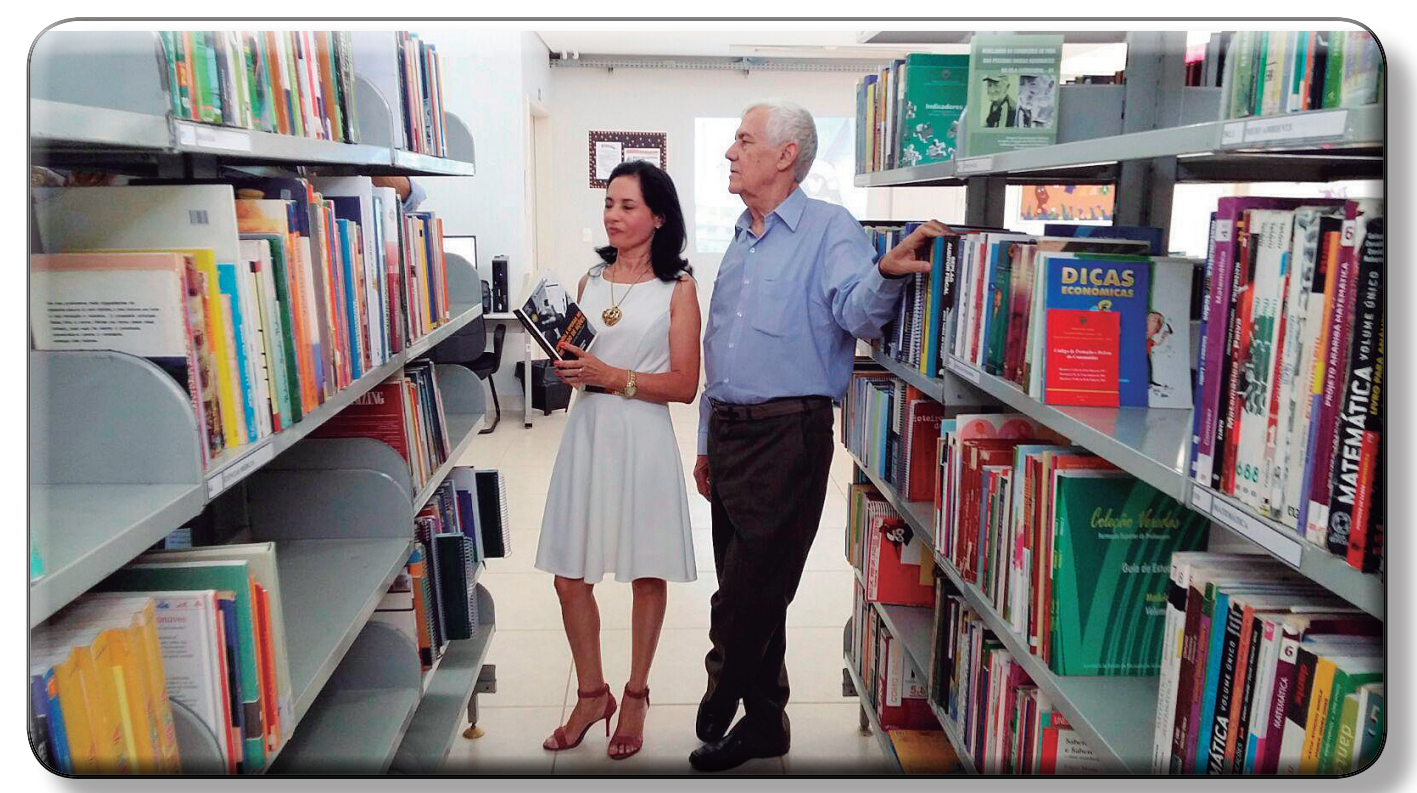

Foto $n^{\circ}$ 11: Inauguração da Biblioteca Pública da Cidade Estrutural 


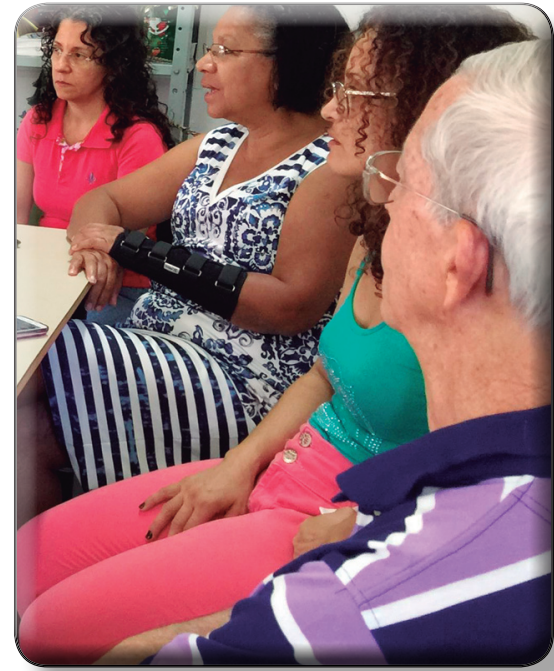

Foto $n^{\circ}$ 12: Reunião de trabalho na Biblioteca Pública de Taguatinga

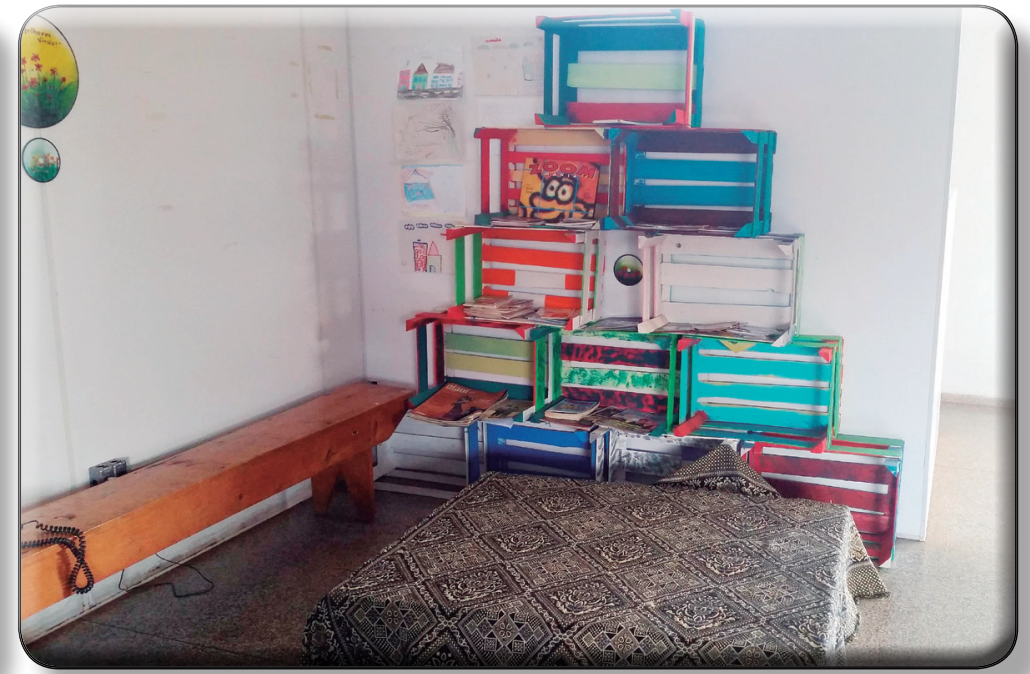

Foto $n^{\circ}$ 13: "Célula" da Biblioteca Pública de Taguatinga na Unidade de Atendimento em Meio Aberto - UAMA, no Recanto das Emas

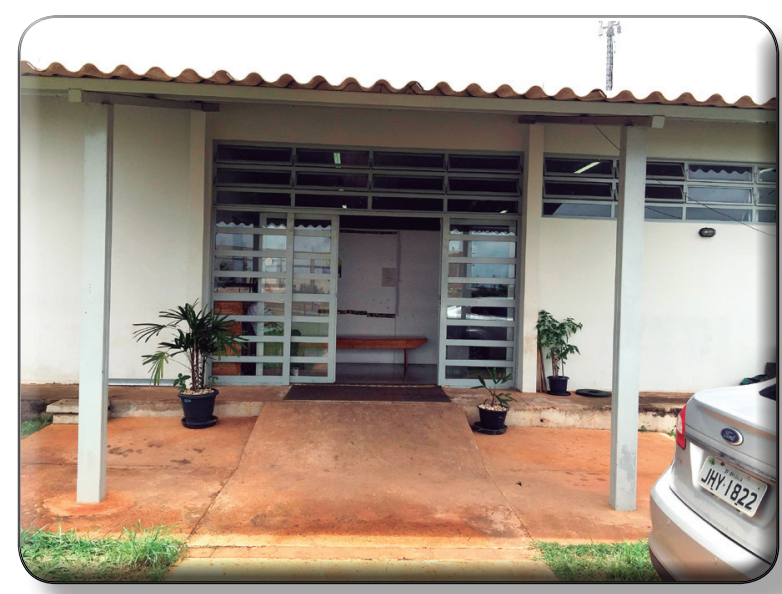

Foto $\mathrm{n}^{\circ}$ 14: Unidade de Atendimento em Meio Aberto - UAMA, no Recanto das Emas

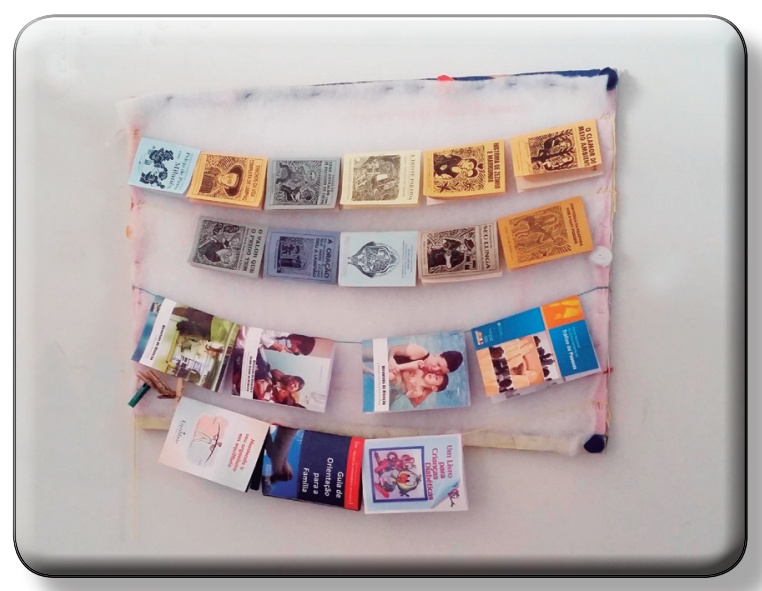

Foto $\mathrm{n}^{\circ}$ 15: Livros na Unidade de Atendimento em Meio Aberto - UAMA, no Recanto das Emas
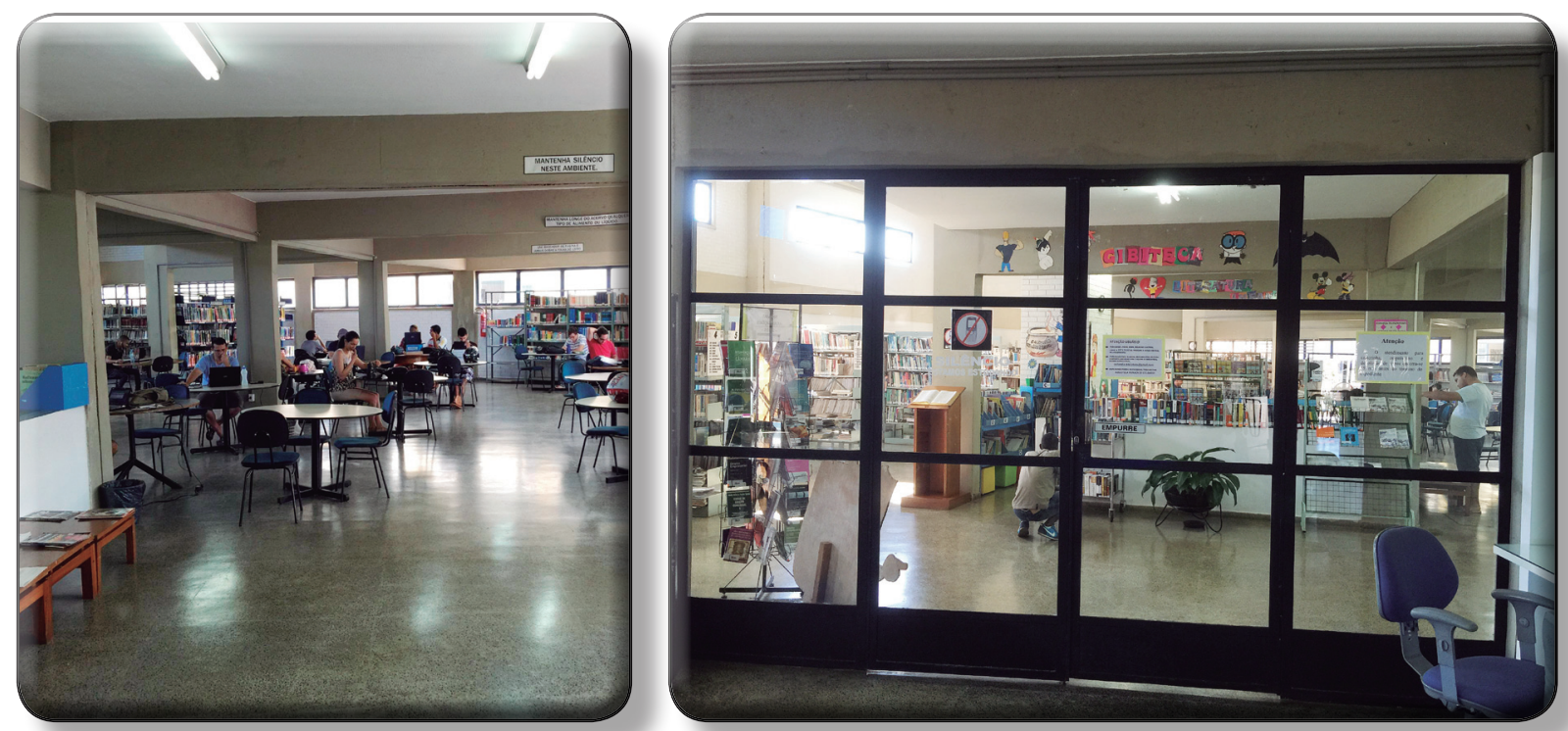

Fotos nº 16 e 17: Biblioteca Pública da Ceilândia 
A reinauguração da Biblioteca de Águas Claras teve a presença de várias autoridades e o apoio do PROCOM-DF.

$\mathrm{Na}$ Biblioteca de Vicente Pires, houve a colaboração de um marceneiro que trabalha com pallets na manufatura de alguns mobiliários. Este marceneiro é uma pessoa muito envolvida com a comunidade, inclusive havia sido Presidente da Feira Permanente de Vicente Pires. A aluna fez contato com esse Senhor e perguntou a ele se poderia fabricar as Estantes da Saúde. Imediatamente ele se disponibilizou, sendo que a aluna forneceu os insumos para a fabricação das estantes com recursos próprios, e os pallets foram fornecidos por este Senhor.

Desse contato com o marceneiro dos pallets, somado aos profissionais da UAMA Recanto das Emas e da Semiliberdade de Taguatinga, surgiu um movimento para que buscássemos um local onde pudesse ser instalada uma marcenaria, para que os meninos dessas unidades aprendessem o ofício com o marceneiro. Foi feito contato com o pessoal do Centro de Orientação Socioeducativa - COSE/Recanto das Emas e descobriu-se que nesse lugar havia uma marcenaria completa e desativada, com todos os maquinários em perfeito estado de funcionamento.

Dessa forma foi criado o Projeto Metamorfose, da união de todos das entidades acima citadas, sendo que foi realizada reunião em 11/01/2016 (Anexo 11), que contou também com a participação da Coordenadora do Sistema de Bibliotecas Públicas do Distrito Federal.

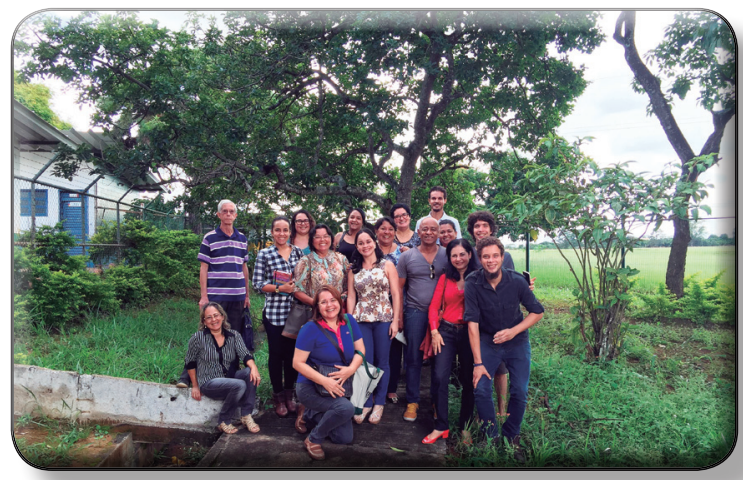

Foto $\mathrm{n}^{\circ}$ 18: Reunião do Projeto Metamorfose no COSE/Recanto das Emas

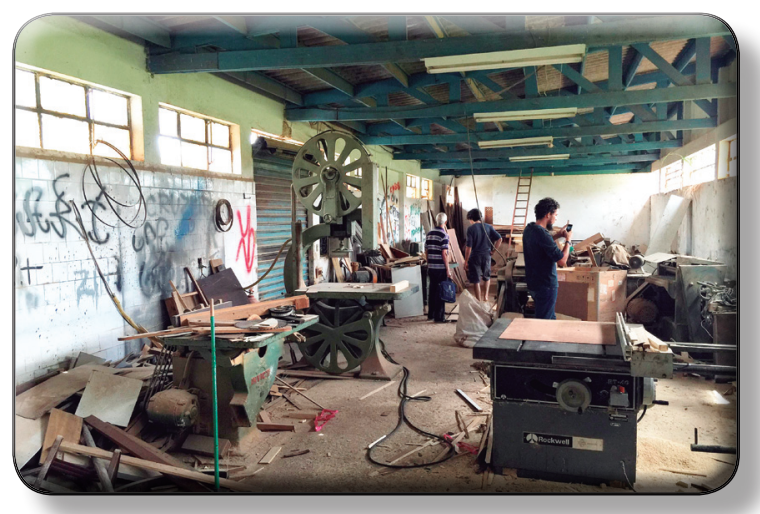

Fotos nº 19 e 20: Marcenaria do COSE/Recanto das Emas e vista externa do prédio da marcenaria

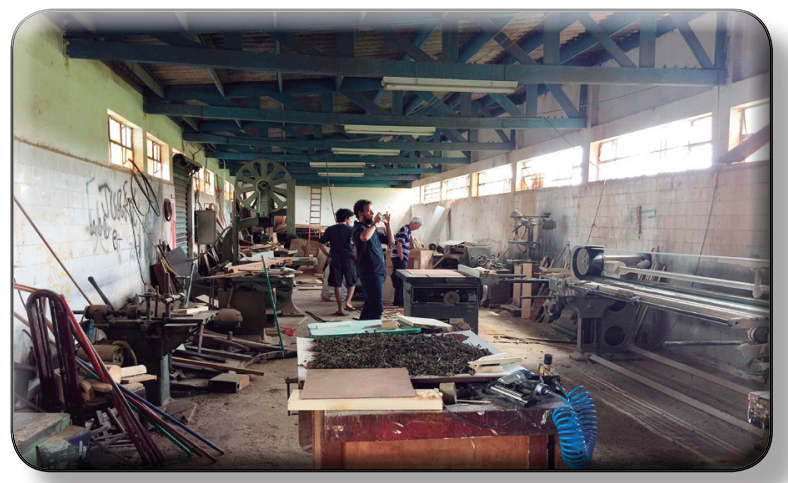

Foto $\mathrm{n}^{\circ}$ 19: Marcenaria do COSE/Recanto das Emas

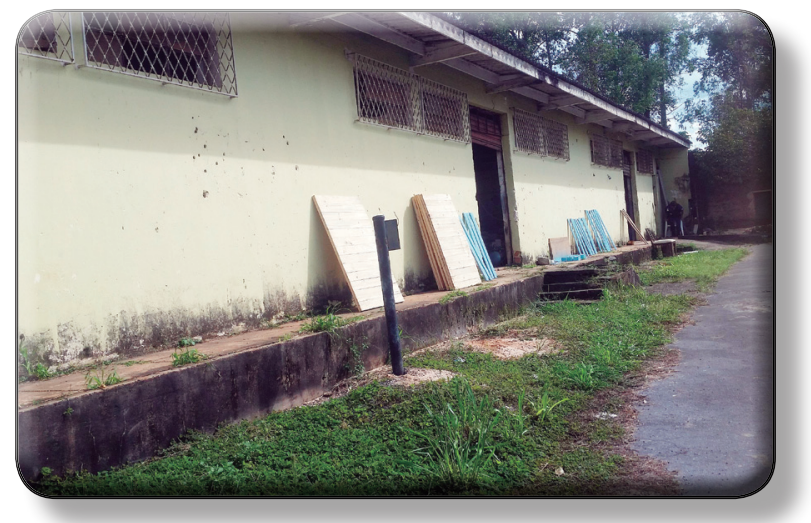



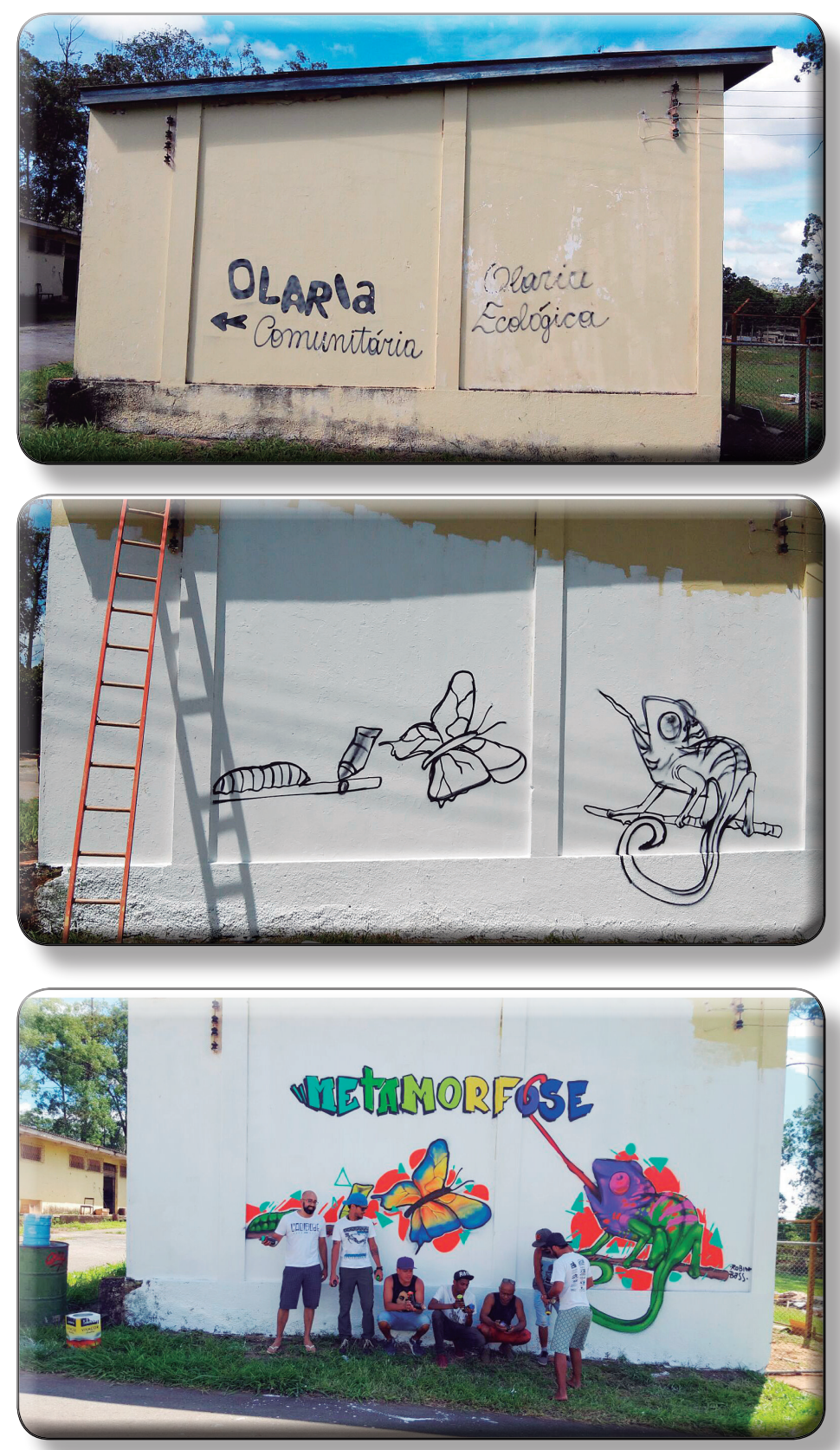

Fotos $n^{\circ}$ s 21, 22 e 23: Confecção da Logomarca do Projeto Metamorfose em janeiro de 2015

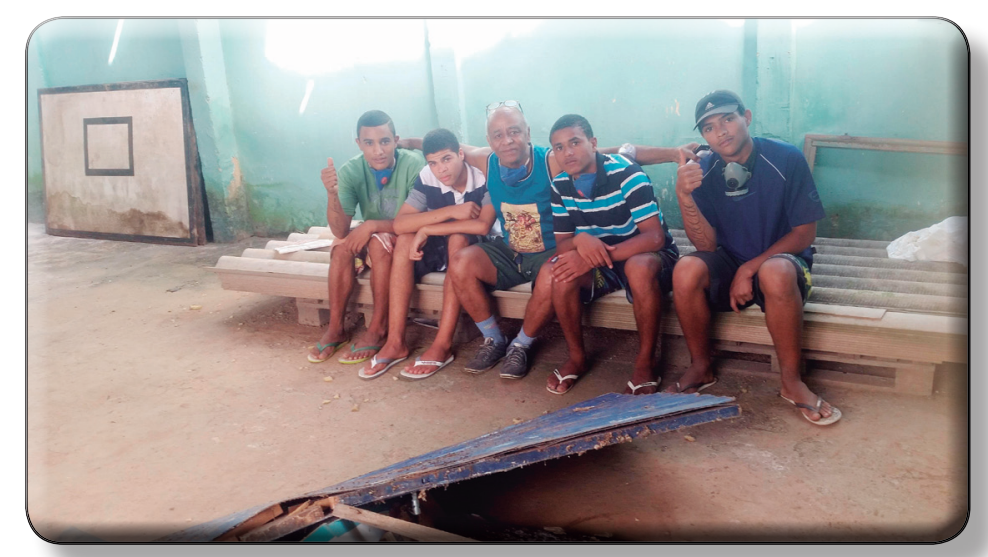

Foto $n^{\circ}$ 24: Senhor Mauro, marceneiro dos pallets, e os meninos da Semiliberdade do Recanto das Emas aprendendo o oficio 
A reinauguração da Biblioteca de Águas Claras teve a presença de várias autoridades e o apoio do PROCOM-DF.

$\mathrm{Na}$ Biblioteca de Vicente Pires, houve a colaboração de um marceneiro que trabalha com pallets na manufatura de alguns mobiliários. Este marceneiro é uma pessoa muito envolvida com a comunidade, inclusive havia sido Presidente da Feira Permanente de Vicente Pires. A aluna fez contato com esse Senhor e perguntou a ele se poderia fabricar as Estantes da Saúde. Imediatamente ele se disponibilizou, sendo que a aluna forneceu os insumos para a fabricação das estantes com recursos próprios, e os pallets foram fornecidos por este Senhor.

Desse contato com o marceneiro dos pallets, somado aos profissionais da UAMA Recanto das Emas e da Semiliberdade de Taguatinga, surgiu um movimento para que buscássemos um local onde pudesse ser instalada uma marcenaria, para que os meninos dessas unidades aprendessem o ofício com o marceneiro. Foi feito contato com o pessoal do Centro de Orientação Socioeducativa - COSE/Recanto das Emas e descobriu-se que nesse lugar havia uma marcenaria completa e desativada, com todos os maquinários em perfeito estado de funcionamento.

Dessa forma foi criado o Projeto Metamorfose, da união de todos das entidades acima citadas, sendo que foi realizada reunião em 11/01/2016 (Anexo 11), que contou também com a participação da Coordenadora do Sistema de Bibliotecas Públicas do Distrito Federal.

O Projeto Metamorfose inicialmente começou a trabalhar com o ensino do ofício de marceneiro, porém, pretende-se ampliar as atividades para outras oficinas de ensino. As atividades de limpeza e organização do espaço tiveram início em janeiro de 2016, conforme fotos abaixo:

Os meninos dessas unidades de medidas socioeducativas estão participando ativamente da oficina de marcenaria, ocasião em que estão sendo trabalhados valores importantes para esses adolescentes, especialmente através de bons exemplos.

Logo após a inauguração da Biblioteca Pública de Vicente Pires, cuja festividade contou com a presença de muitas autoridades Distritais, como o Vice-Governador do Distrito Federal, Renato Santana, um adolescente de 16 (dezesseis) anos, menino residente e domiciliado em Águas Lindas de Goiás, começou a frequentar a biblioteca. Ele procurou a responsável pela biblioteca e relatou que morava junto com uma irmã de 14 anos, e que ambos moravam com a avó, falecida há pouco, sendo que, para que pudessem continuar se sustentando, resolveram começar a cuidar das crianças da vizinhança.

O adolescente disse que realizava atividades de leitura com as crianças, além de improvisar peças de teatro, inventando fantoches ao calçar meias coloridas em suas mãos. Este pediu à responsável pela biblioteca alguns livros emprestados e, até o momento, têm visitado a biblioteca semanalmente para trocar os livrinhos.

Também foram realizados projetos na Biblioteca de Vicente Pires, como o de intercâmbio de alunos de uma escola pública de Vicente Pires e usuários da biblioteca 
com alunos de uma escola pública da Inglaterra. O intercâmbio consistiu na elaboração de cartinhas por parte dos alunos de ambos os países, as quais foram trocadas, através da visita à biblioteca de uma das professoras inglesas durante o evento.

Durante o mês de dezembro, a responsável pela biblioteca de Vicente Pires realizou, caracterizada de "Mamãe-Noel", a leitura de "Fábulas Natalinas" em viagens de um ônibus circular de Vicente Pires. Isso propiciou maior divulgação da existência da biblioteca, bem como o aumento da frequência de usuários.

O desenvolvimento desta pesquisa também propiciou a inauguração da Biblioteca Pública da Estrutural, projeto que há muito tempo estava apenas no papel (Anexo 12). A inauguração da mesma contou com a presença do Governador do Distrito Federal, Rodrigo Rolemberg.

Quanto à montagem da Estante da Saúde, algumas dificuldades foram enfrentadas, especialmente quando a aluna dirigiu-se ao Ministério da Saúde. Foram raros os setores que se dispuseram a fornecer materiais como folderes, cartazes e livros sobre saúde. O argumento utilizado pelos servidores do Órgão é que esses materiais eram prioritariamente enviados para as Secretarias Estaduais e Distrital de Saúde.

Porém, a pesquisadora perguntou aos sujeitos de pesquisa, durante as dinâmicas sobre saúde, se estes recebiam folderes informacionais sobre saúde nos Postos de Saúde ou nos Ambulatórios dos Hospitais da Rede de Saúde do Distrito Federal. De forma unânime, todos os indivíduos disseram que nunca haviam recebido folhetos do Ministério da Saúde.

Relativamente às variáveis qualitativas obtidas nos momentos Pré e Pós-Intervenção, foi realizada uma categorização das mesmas, com o auxílio do questionário semi-estruturado que foi aplicado no grupo, obtendo-se dois quadros, conforme segue abaixo:
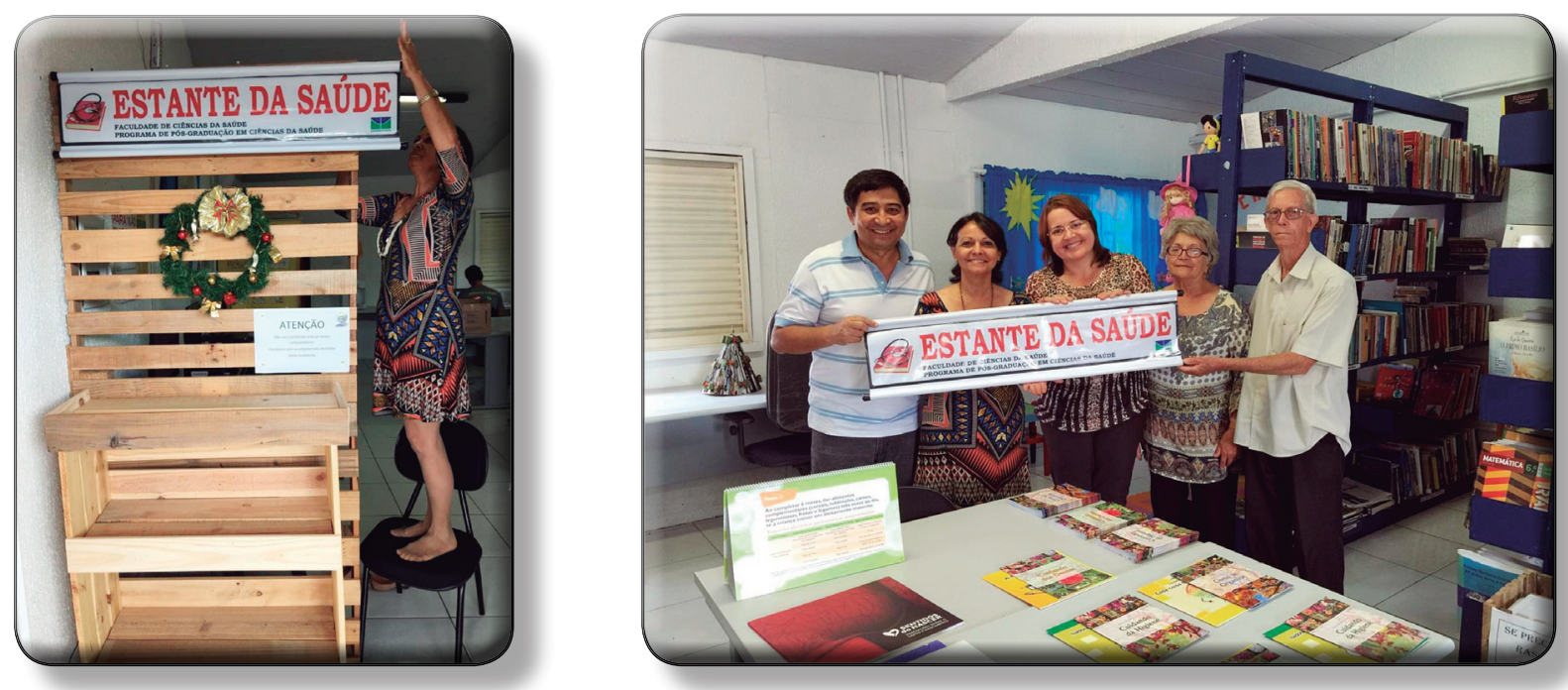

Fotos nº 25 e 26: Instalação da Estante da Saúde na Biblioteca Pública de Vicente Pires 

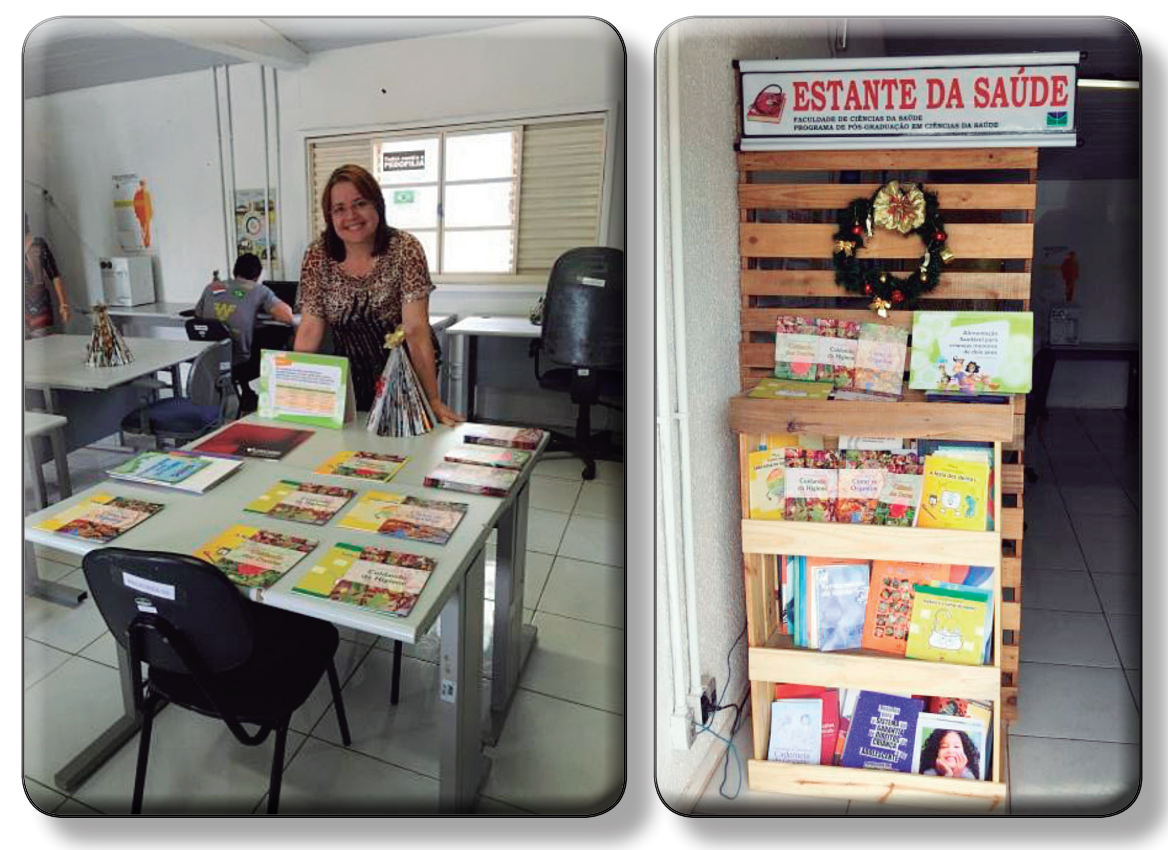

Fotos no 27 e 28: Intervenção e Estante da Saúde na Biblioteca Pública de Vicente Pires
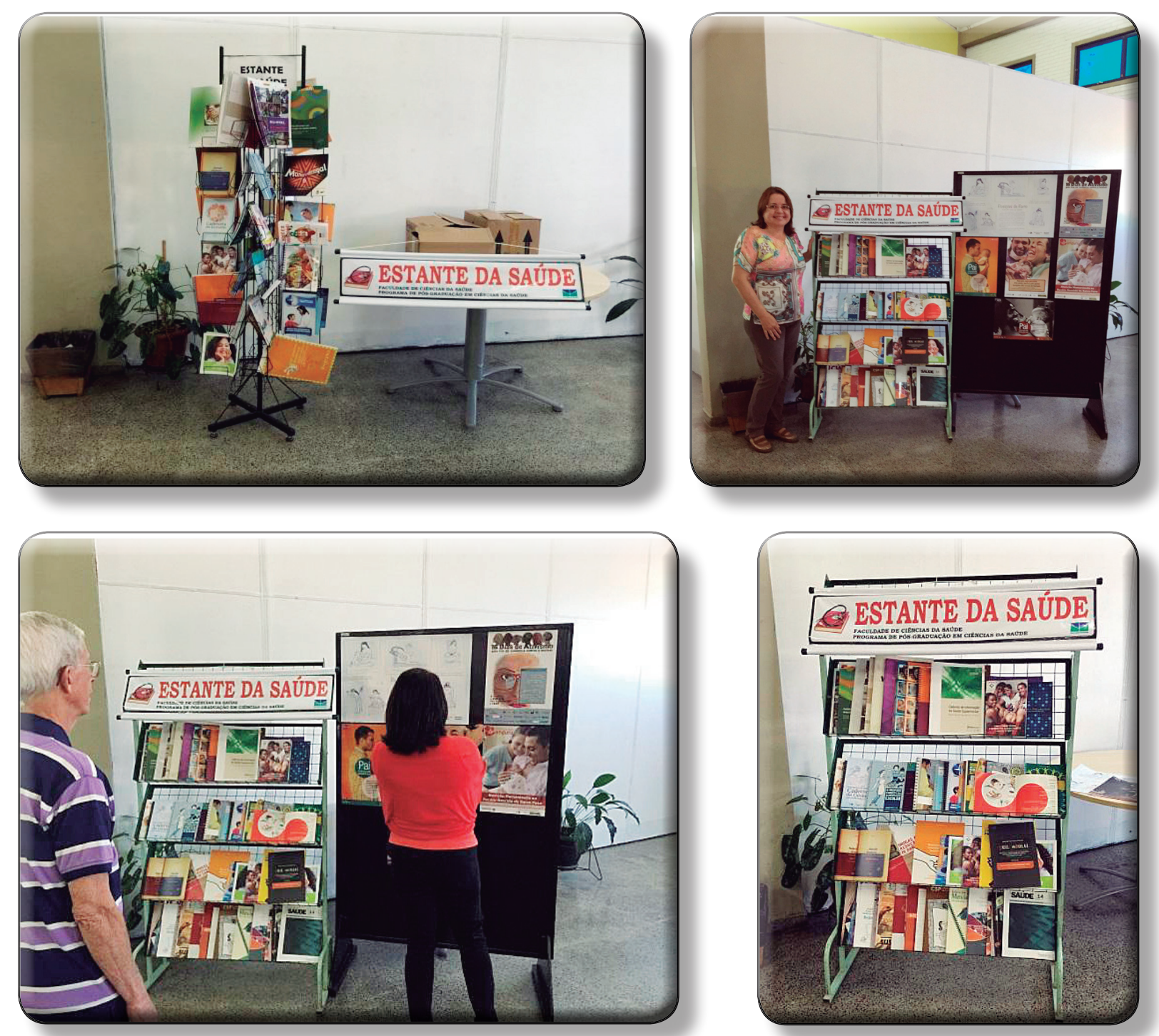

Fotos n 29, 30, 31 e 32: Montagem da Estante da Saúde na Biblioteca Pública da Ceilândia 


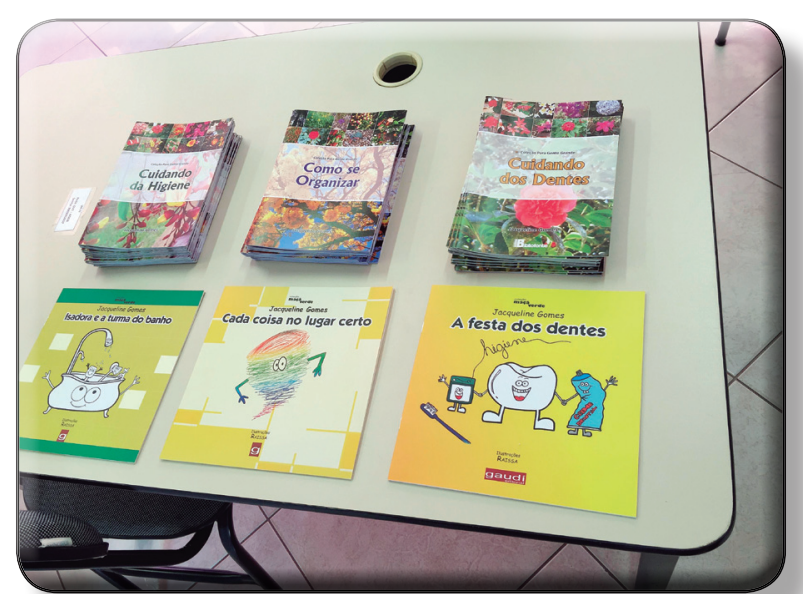

Foto $n^{\circ} 33$ : Produção literária do kit de apoio da Intervenção

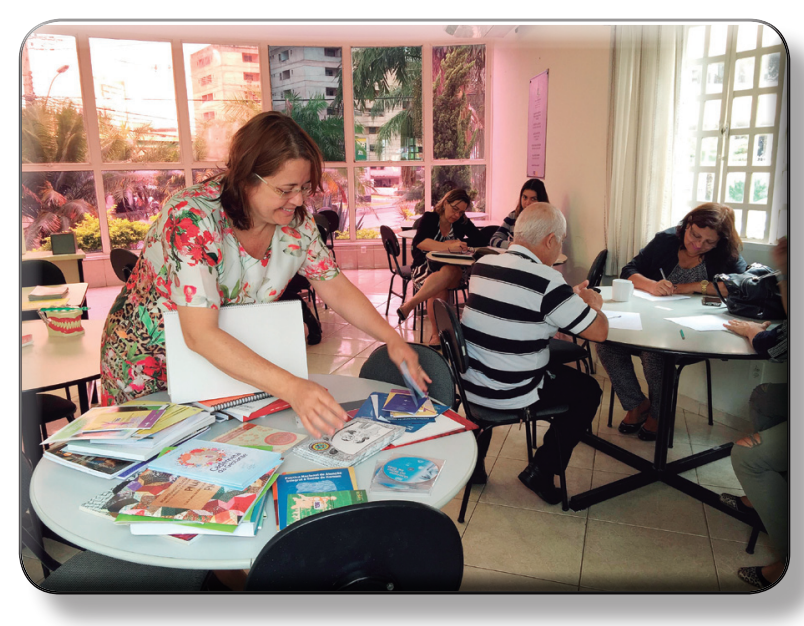

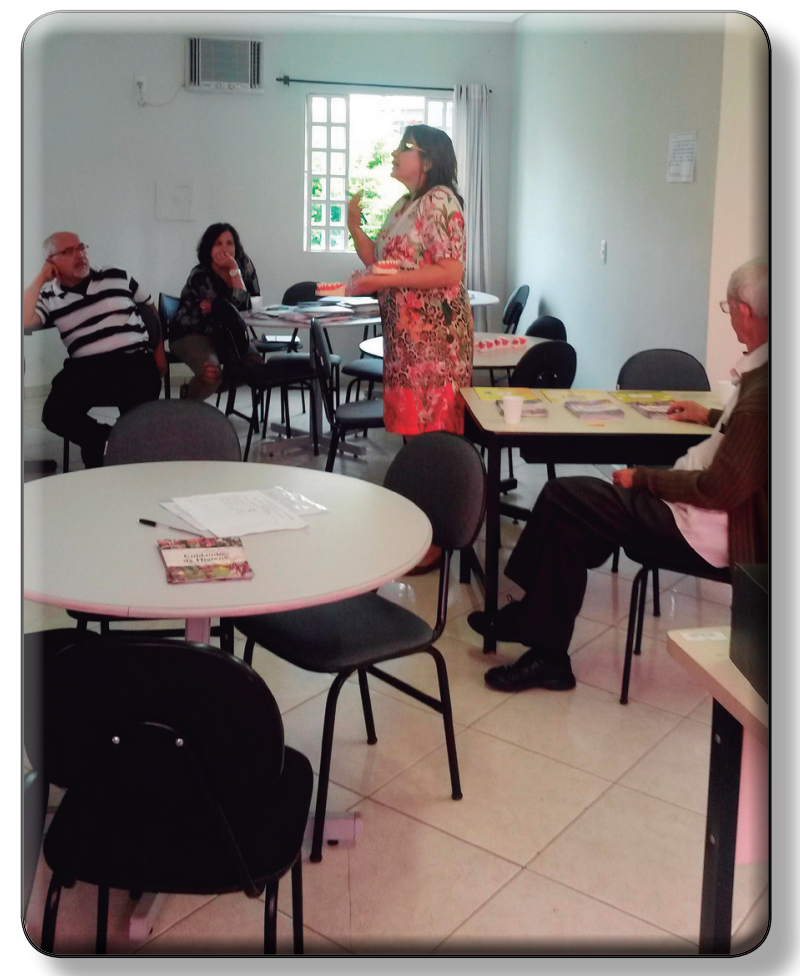

Fotos nº 35, 36 e 37: Intervenção na Biblioteca Pública de Águas Claras 


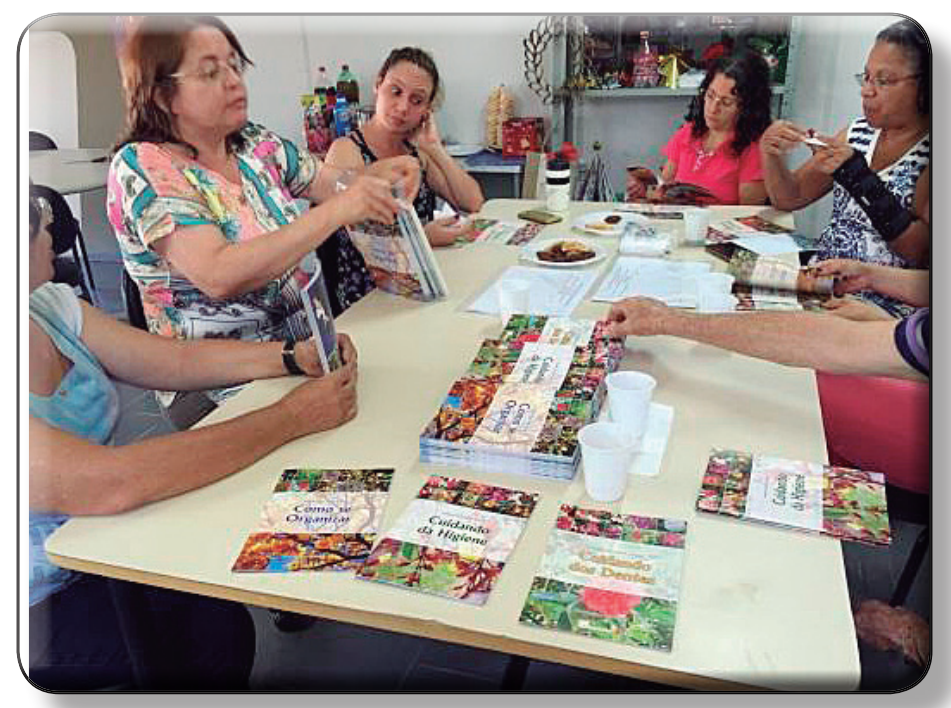

Foto $n^{\circ}$ 38: Intervenção na Biblioteca Pública de Taguatinga

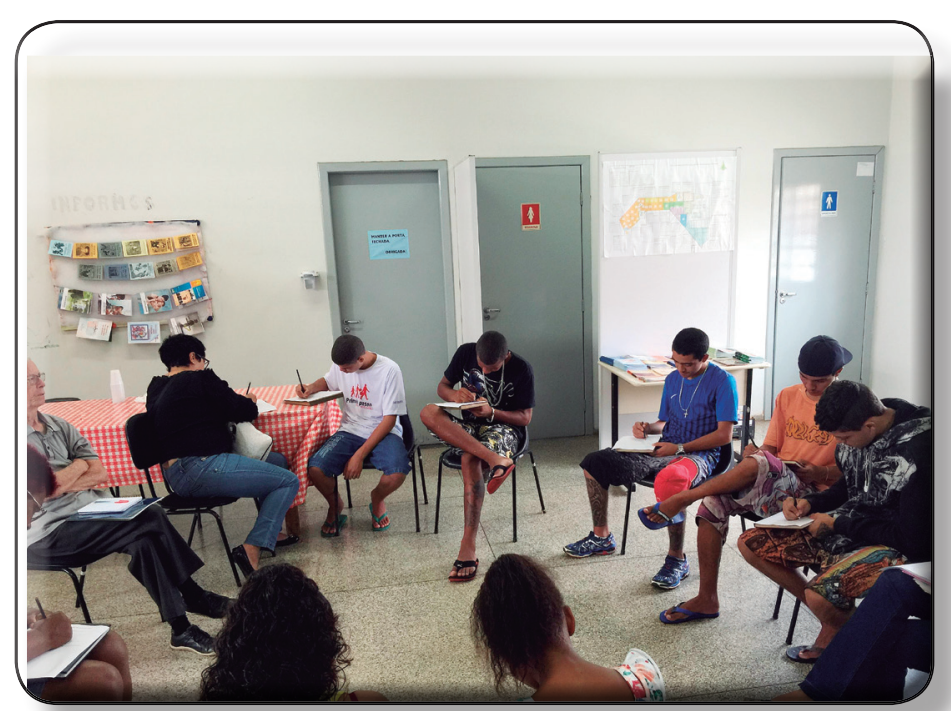

Foto $n^{\circ}$ 39: Intervenção na Unidade de Atendimento em Meio Aberto - UAMA do Recanto das Emas

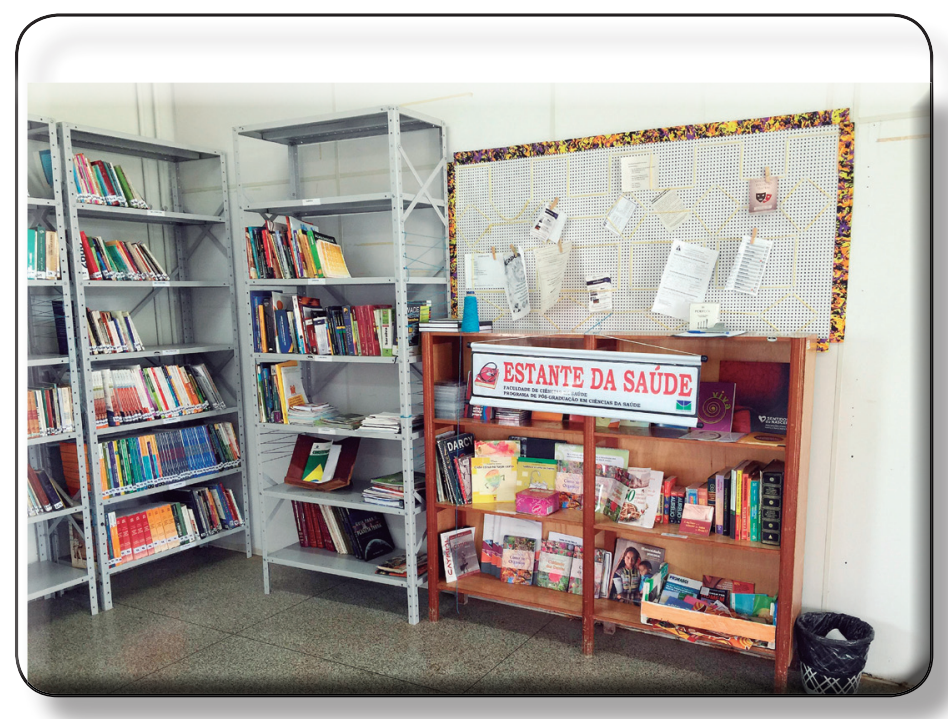

Foto n ${ }^{\circ}$ 40: "Célula" da Biblioteca Pública de Taguatinga na Unidade de Atendimento em Meio Aberto - UAMA, no Recanto das Emas 


\begin{tabular}{|c|c|}
\hline Áreas avaliadas & Relatos dos usuários de quatro Bibliotecas Públicas do Distrito Federal, 2015. \\
\hline Psicológico & 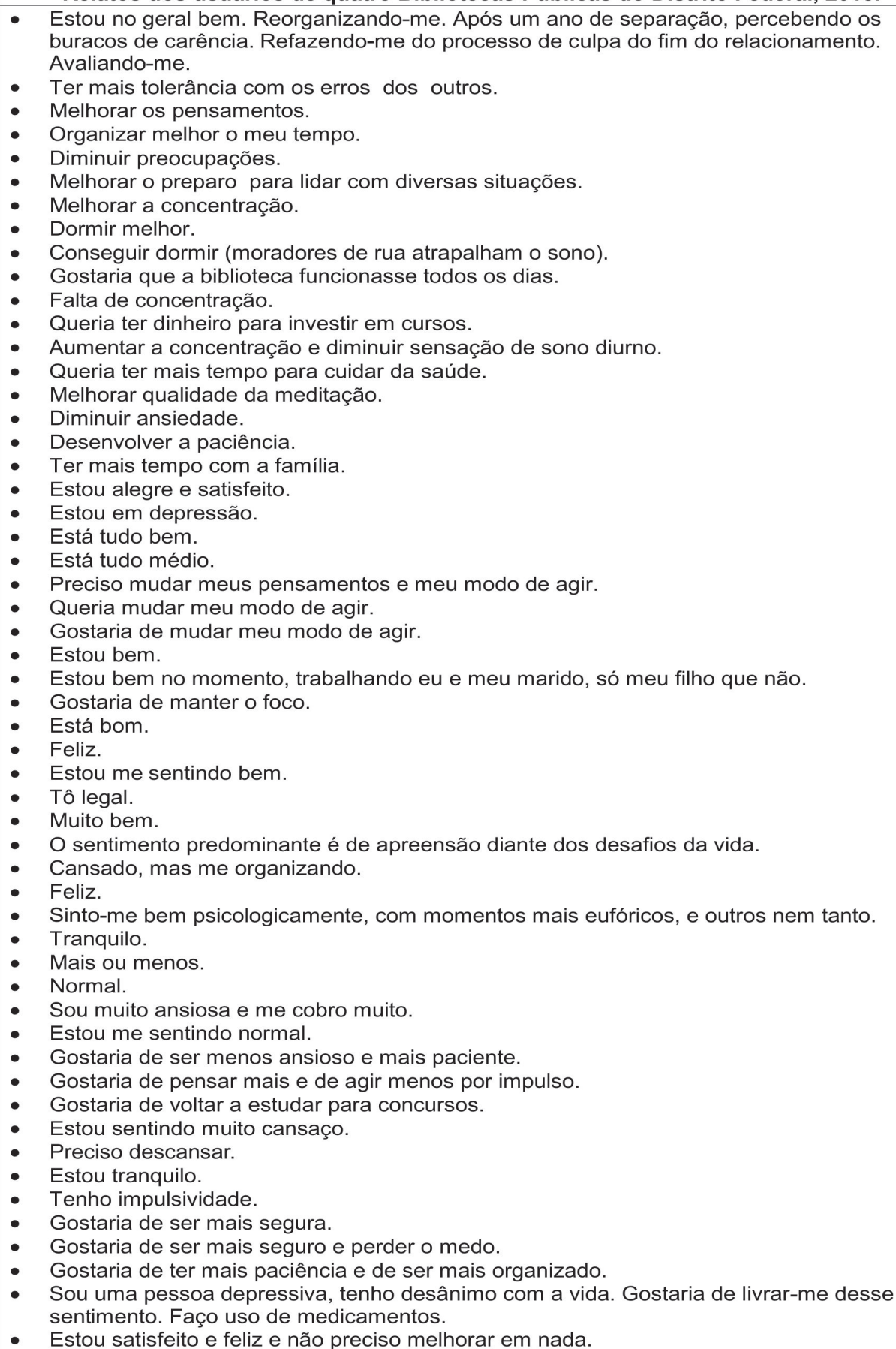 \\
\hline
\end{tabular}




\begin{tabular}{|c|c|}
\hline Corpo físico & 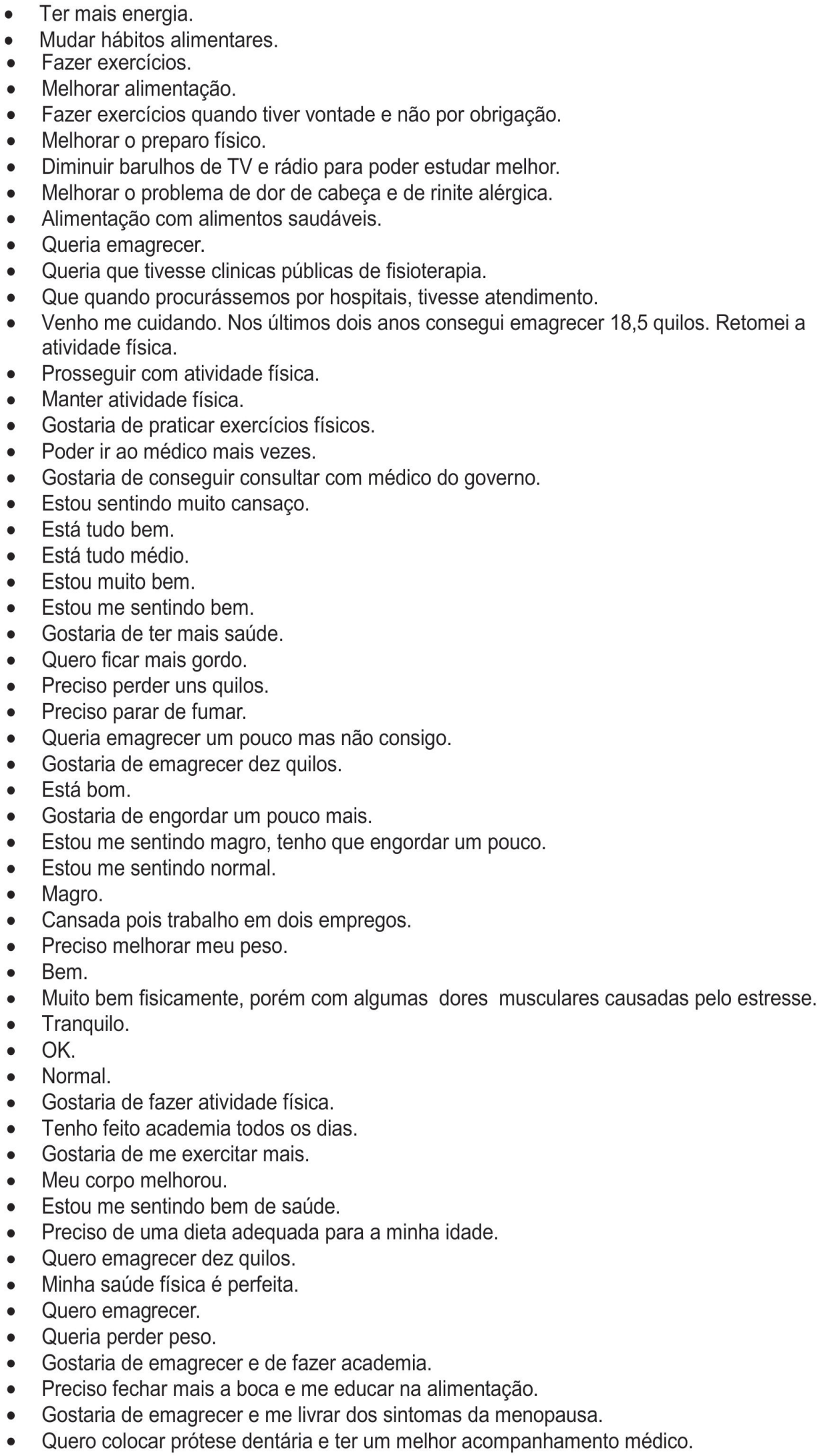 \\
\hline
\end{tabular}




\begin{tabular}{|c|c|}
\hline Ambiente de casa & 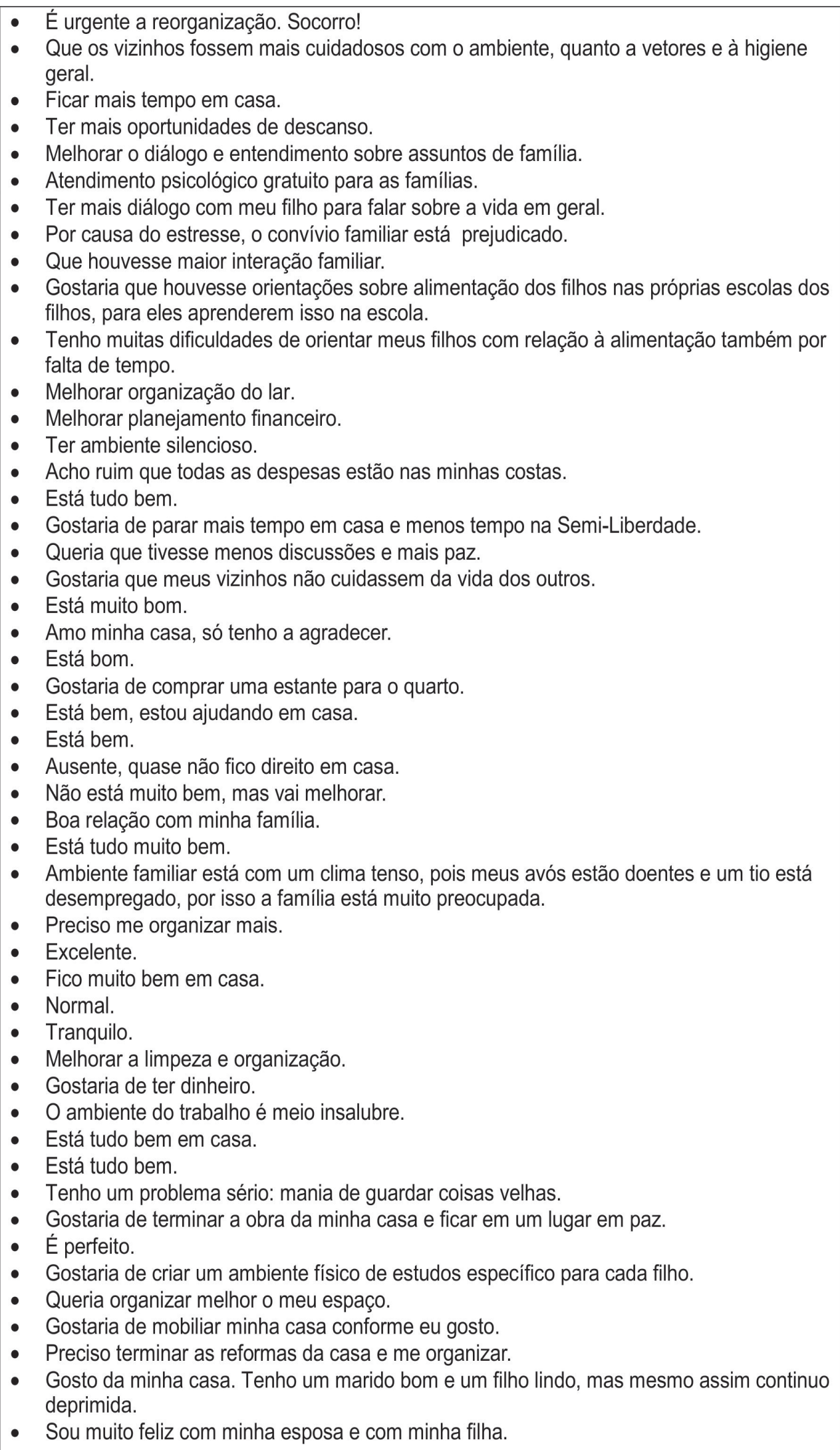 \\
\hline
\end{tabular}




\begin{tabular}{|c|c|}
\hline $\begin{array}{l}\text { Ambiente do } \\
\text { trabalho }\end{array}$ & 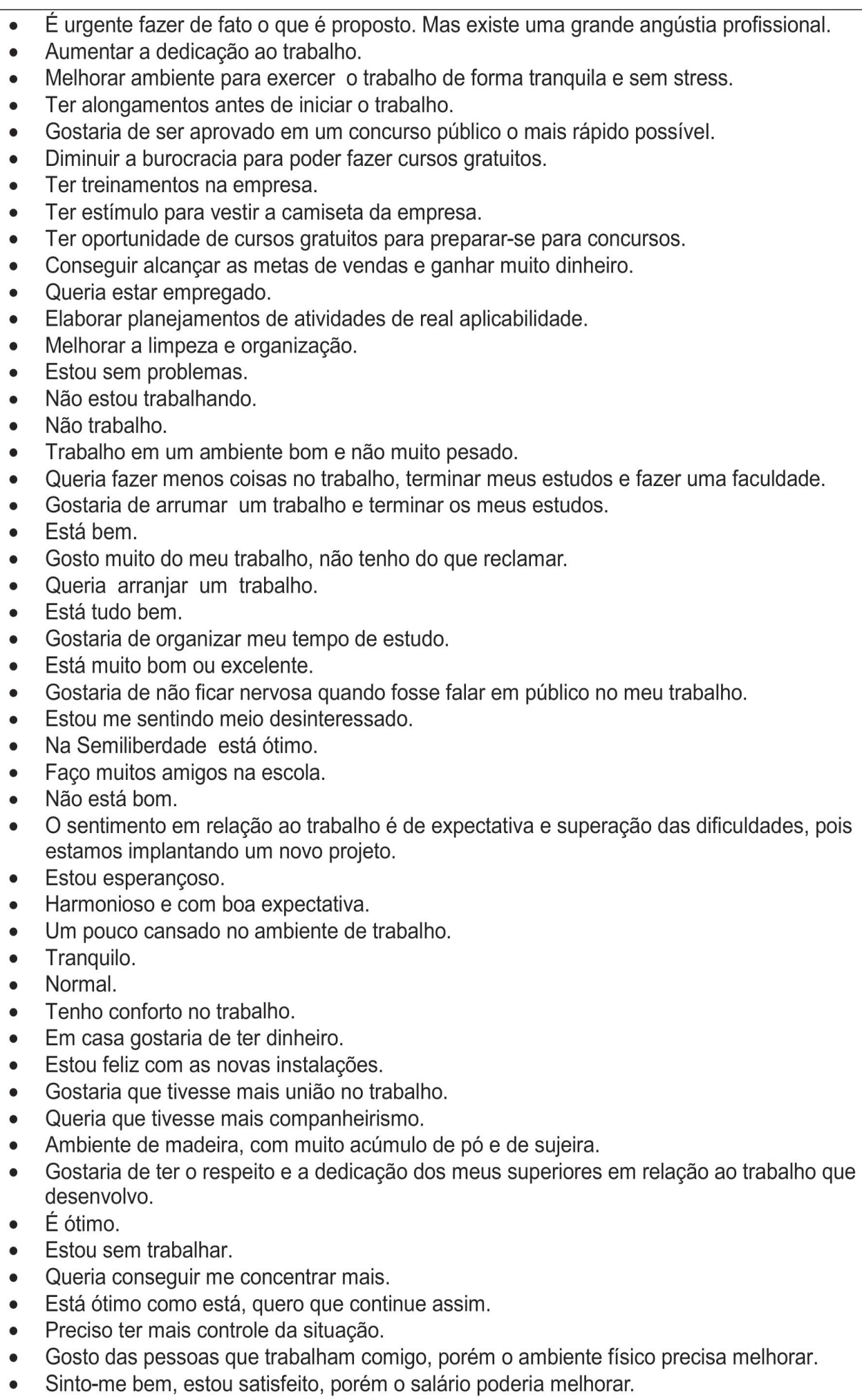 \\
\hline
\end{tabular}




\begin{tabular}{|c|c|}
\hline Lazer & 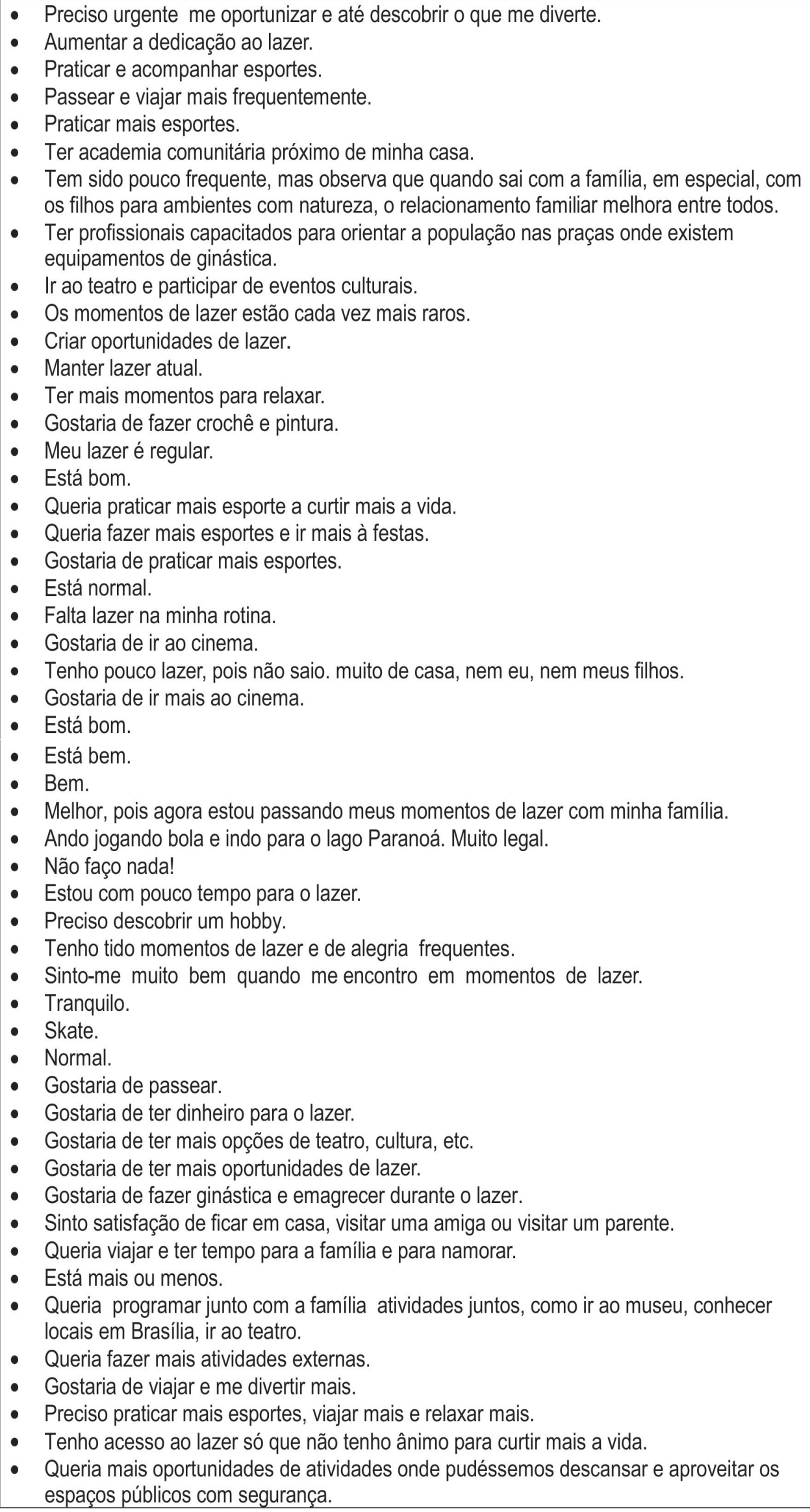 \\
\hline
\end{tabular}




\begin{tabular}{|c|c|}
\hline Áreas avaliadas & Relatos dos usuários de quatro bibliotecas Públicas do Distrito Federal, 2015. \\
\hline Psicológico & 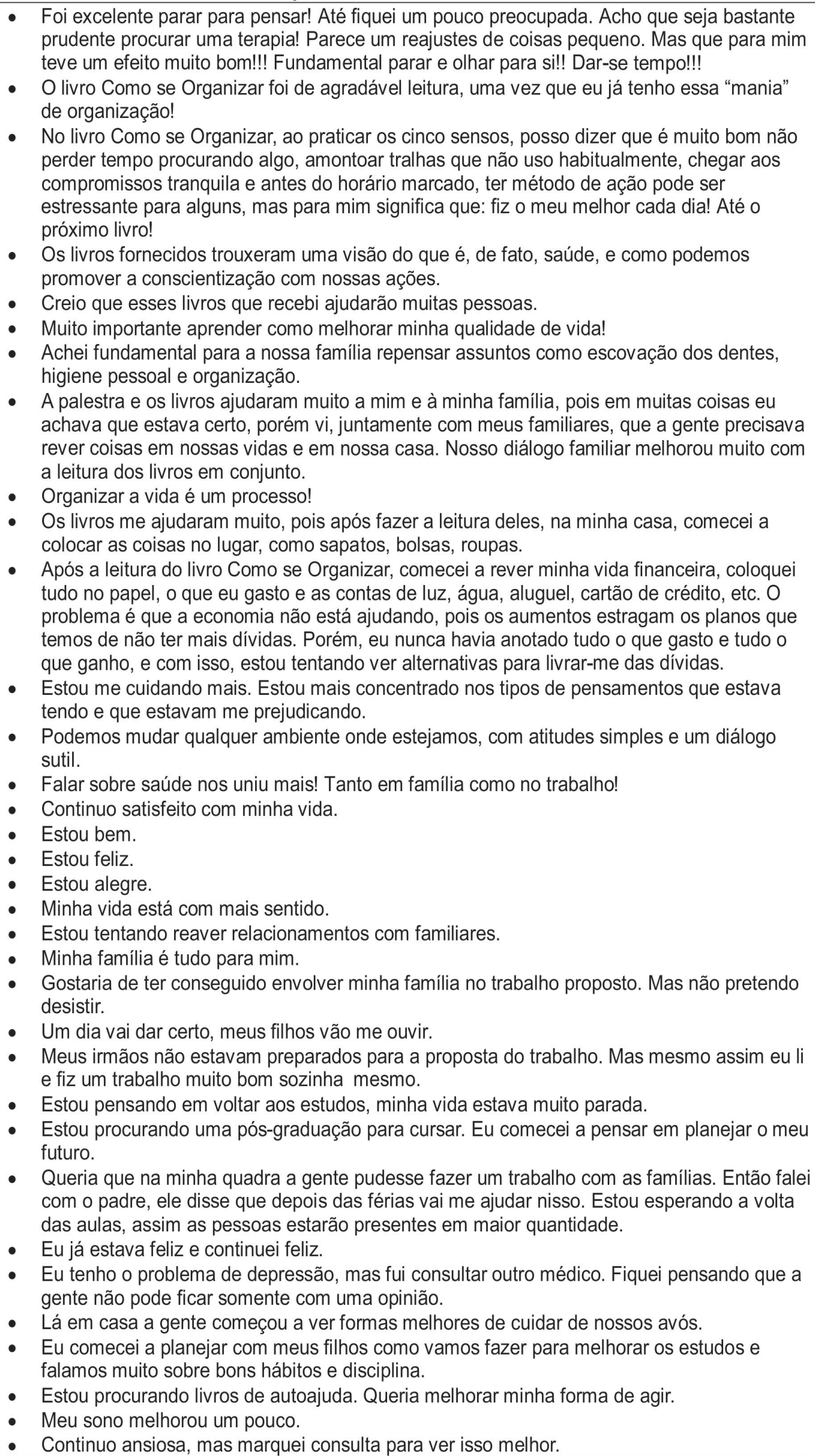 \\
\hline
\end{tabular}




\begin{tabular}{|c|c|}
\hline & 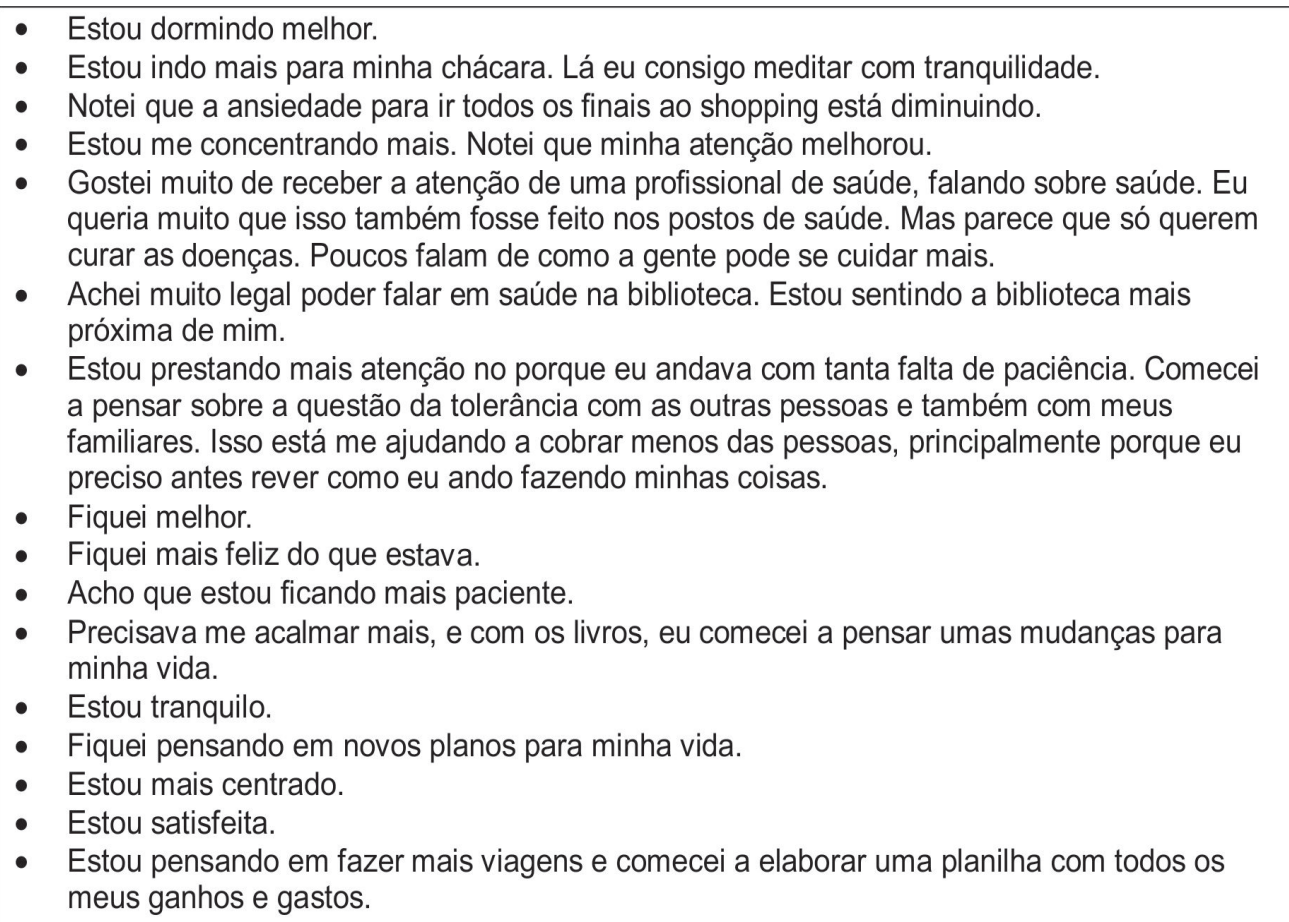 \\
\hline Corpo físico & 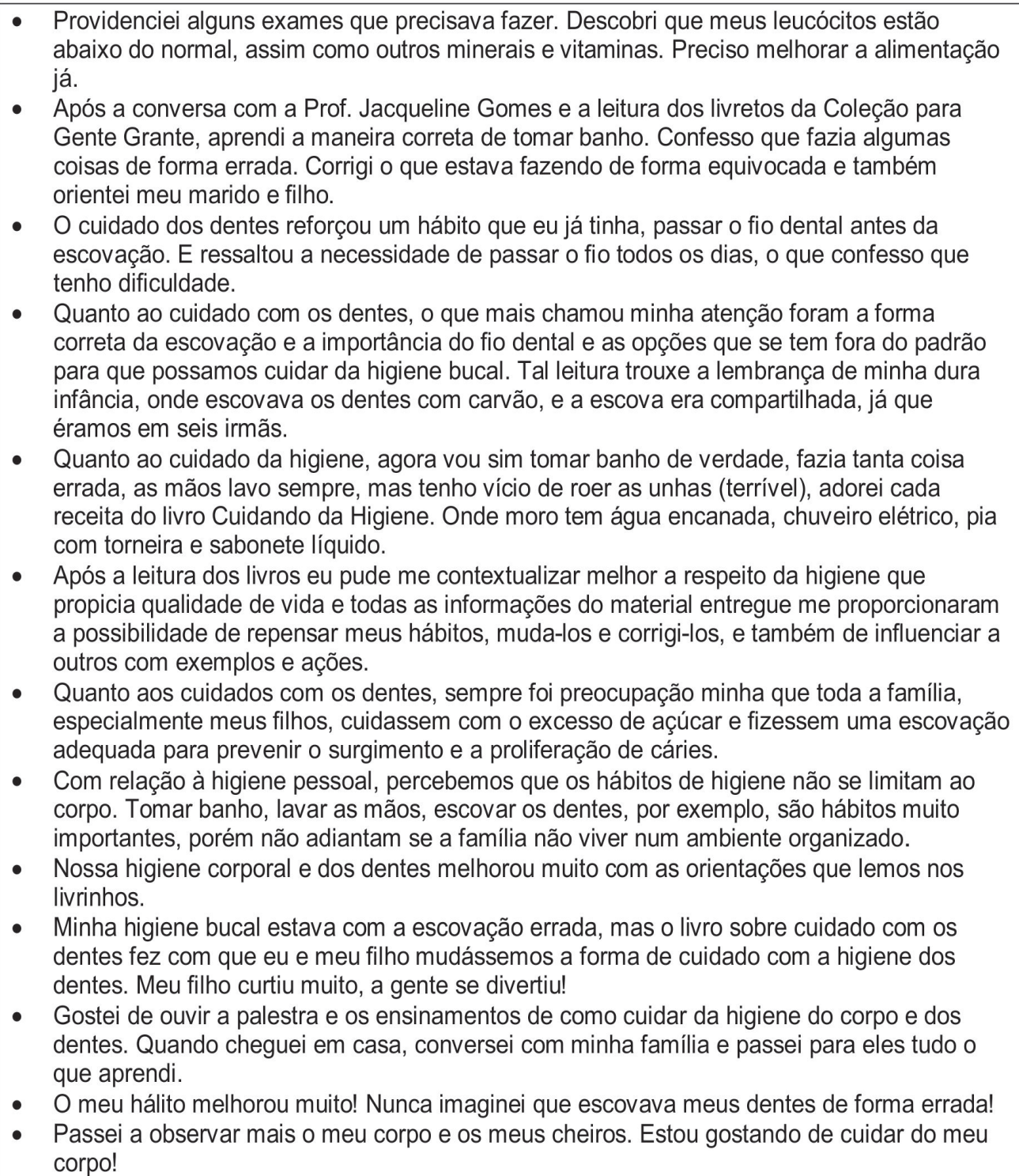 \\
\hline
\end{tabular}




\begin{tabular}{|c|c|}
\hline & 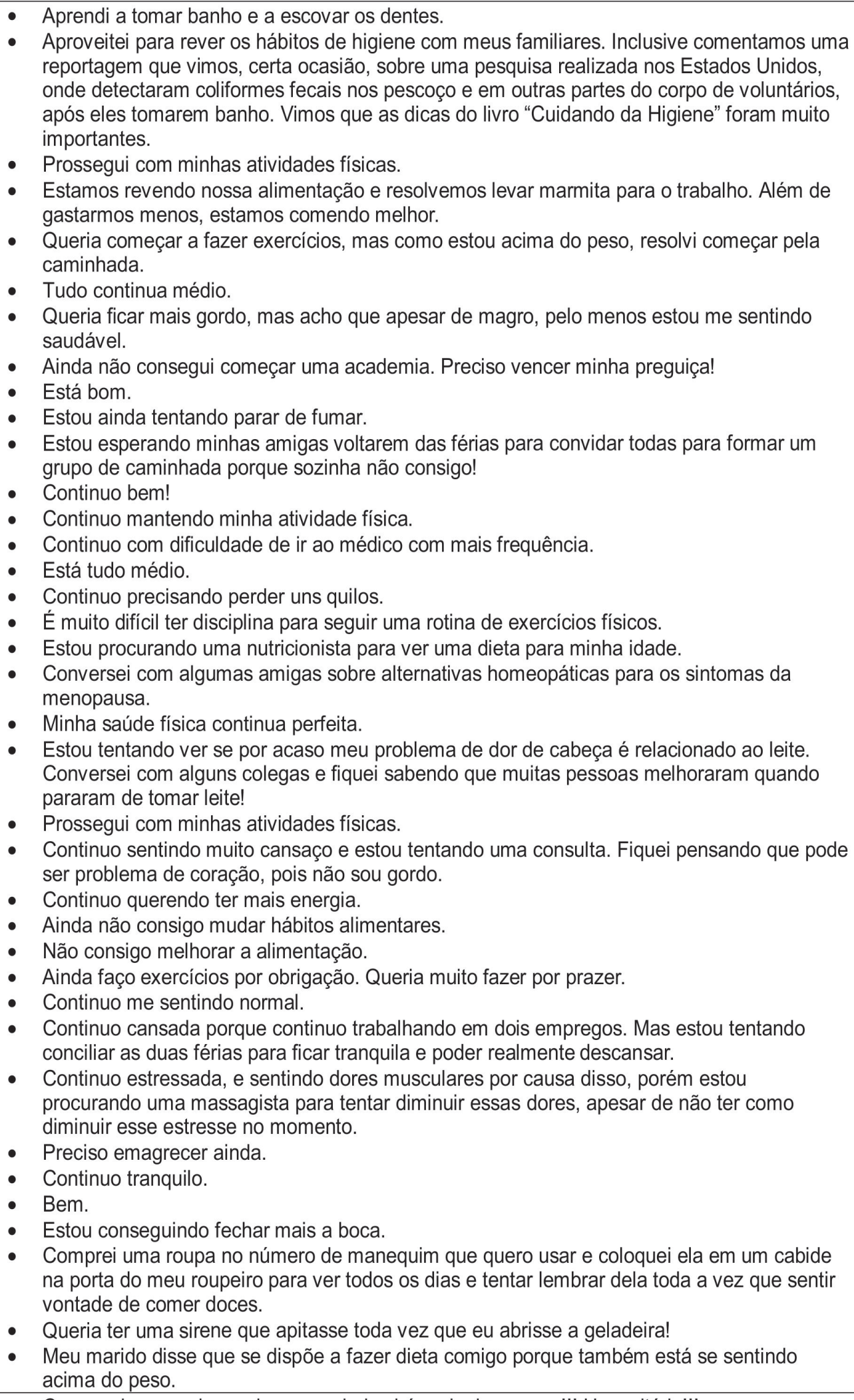 \\
\hline $\begin{array}{l}\text { Ambiente de } \\
\text { casa }\end{array}$ & $\begin{array}{l}\text { - Consegui reorganizar caixas guardadas há mais de um ano!!! Uma vitória!!! } \\
\text { - Um ambiente organizado favorece a saúde física e mental. Não consigo viver nem trabalhar } \\
\text { - } \quad \text { A organunça e na sujeira, tenho fama de neurótica, mas antes assim! } \\
\text { família organizada é uma família saudável. } \\
\text { - Eu e minha família nos reunimos e reorganizamos toda a nossa casa. Também convidamos } \\
\text { alguns parentes para lerem os livros em conjunto. Organizamos um Natal diferente: fizemos } \\
\text { uma gincana familiar, ao invés de amigo secreto. Nessa gincana, ganhava presente quem } \\
\text { tivesse feito a melhor organização do roupeiro. Foi muito divertido e útil. }\end{array}$ \\
\hline
\end{tabular}


- Com a leitura dos livros pude relembrar coisas que havia aprendido na minha infância e complementar conhecimentos. Mas o livro que mais me ajudou foi o Como se Organizar. Com a leitura dele, consegui organizar minha casa. Fiquei muito motivada, pois a desorganização que tinha em minha casa trazia muita baixa estima para mim, refletindo muito no meu lado psicológico. Também me senti capaz de fazer outras mudanças na minha vida.

- Minha casa ficou mais leve, com o ambiente mais fácil de limpar e mais agradável. Pude perceber o quanto os hábitos saudáveis proporcionam um bem estar harmônico para a família!

- Achei fundamental a conversa sobre o ambiente de casa, a importância da limpeza e da organização. Deu vontade de sair mudando tudo, revendo as coisas que não usava e remodelando a casa.

- Comecei a arrumar minha cama todos os dias! Meu quarto está mais agradável!

- Nunca imaginei como minha casa ficaria tão agradável depois que fiz uma organização enorme. Tirei tudo dos lugares, selecionei tudo que não queria mais, doei roupas, troquei objetos com alguns amigos, mudei os móveis de lugar. Estou me sentindo mais feliz e mais à vontade em minha casa!

- Fiquei feliz em fazer a leitura dos livros em família. Descobrimos juntos que ler em família é legal porque a gente discute o que leu.

- A leitura dos livros não trouxe informações novas, no entanto, eu gostei de poder discutir os pontos abordados nos livros com meus filhos, para reforçar coisas positivas nos hábitos deles com relação à saúde física.

- Como não temos muito dinheiro e queríamos organizar nossos roupeiros, pegamos caixas vazias em algumas lojas, forramos elas bem bonitinho e arrumamos nossas roupas e objetos pessoais. Ficou muito legal!

- Infelizmente as discussões continuam.

- Meus vizinhos continuam cuidando da vida dos outros.

- Amo minha casa, continuo agradecendo todos os dias por isso.

- Com as arrumações que fiz, consegui fazer uma troca com um vizinho e consegui uma estante para o meu quarto, conforme eu estava querendo.

- Está bem, continuo ajudando em casa.

- Não estava muito bem, mas melhorou um pouco.

- Continuo com boa relação com minha família.

- Está tudo muito bem.

- Ambiente familiar continua com um clima tenso, pois meus avós estão doentes e um tio está desempregado, por isso a família continua muito preocupada.

- Precisava me organizar mais, mas ainda não me animei. Vou tentar ver se junto com alguém eu consigo.

- Tudo está excelente.

- Melhorei a limpeza e organização.

- Gostaria de ter dinheiro, mas fiquei pensando que minha vida não pode ser uma escravidão por conseguir dinheiro. Não posso mais fazer isso comigo.

- Está tudo bem em casa.

- Está tudo bem.

- Continuo tendo um problema sério: mania de guardar coisas velhas, mas estou pensando que preciso me livrar disso!

- Estamos comendo em família todos os finais de semana, com a regra de todos ajudarem na cozinha e a lavar a louça.

- Como está difícil emprego, estou trabalhando com os vizinhos levando seus cachorros para passear.

- Comecei a assumir mais a lavagem das minhas roupas.

- Ainda queria melhorar minha casa decorando-a conforme meu gosto.

- Bom demais.

- Tranquilo.

- Paz e amor.

- Ainda está tudo muito bagunçado, mas estamos ficando mais tempo juntos, eu e minha esposa.

- Nada mudou.

- Os livros são ótimos. O problema sou eu!

- Achei legal essa coisa de ler em família. Inclusive percebi como meus filhos estão lendo mal. Estou programando com minha esposa para fazermos leituras em voz alta todas as noites para ver se as crianças melhoram nisso.

- Estou melhorando minha timidez com as leituras com os amigos.

- A gente inventou uma peça de teatro com o livro "Como se Organizar" 


\begin{tabular}{|c|c|}
\hline & $\begin{array}{l}\text { - Eu não consegui ler os livros, mas a moça que trabalha lá em casa leu e está tentando } \\
\text { seguir as orientações na minha casa e na dela! A faxina dela melhorou! }\end{array}$ \\
\hline $\begin{array}{l}\text { Ambiente do } \\
\text { trabalho }\end{array}$ & 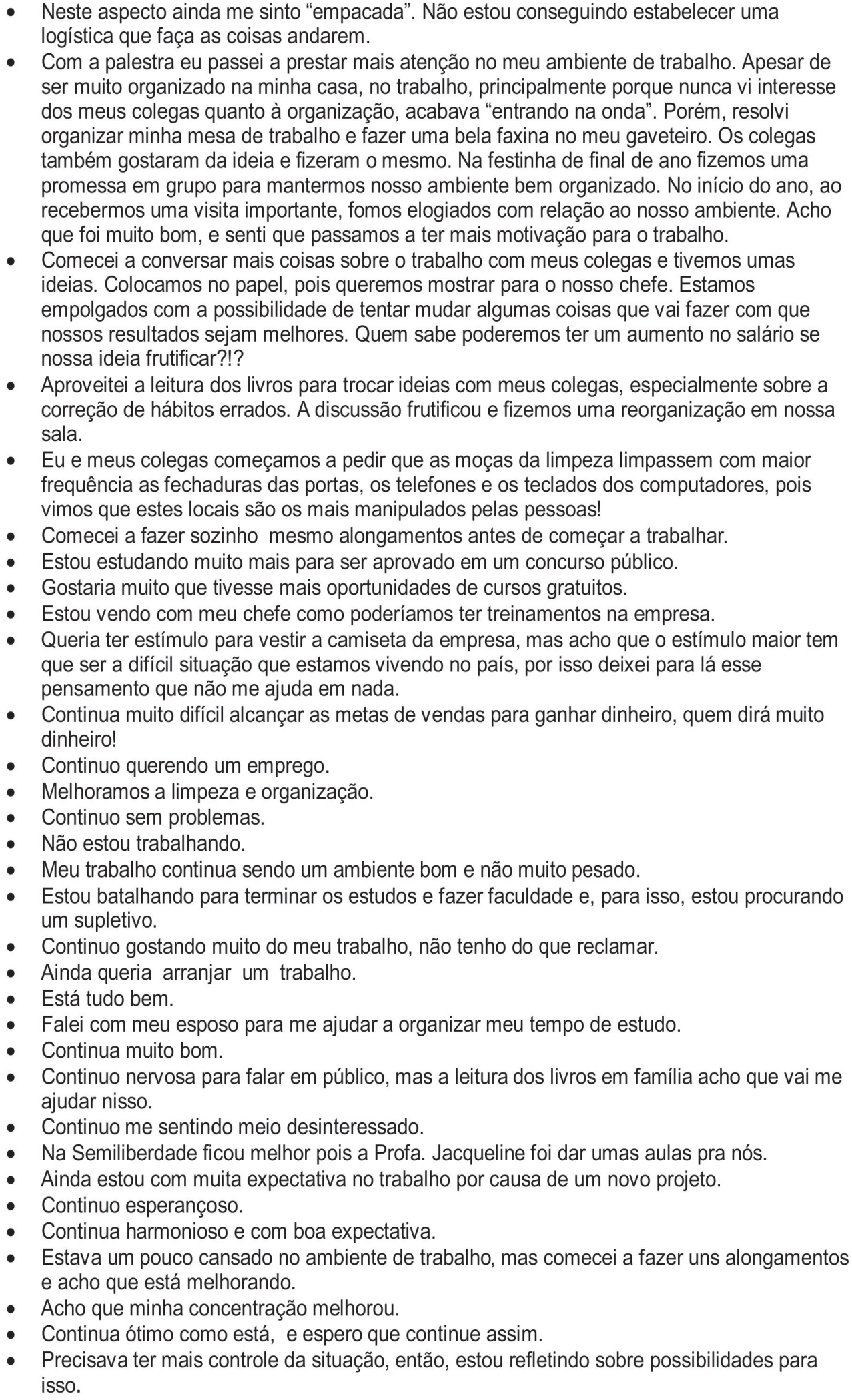 \\
\hline
\end{tabular}




\begin{tabular}{|c|c|}
\hline Lazer & 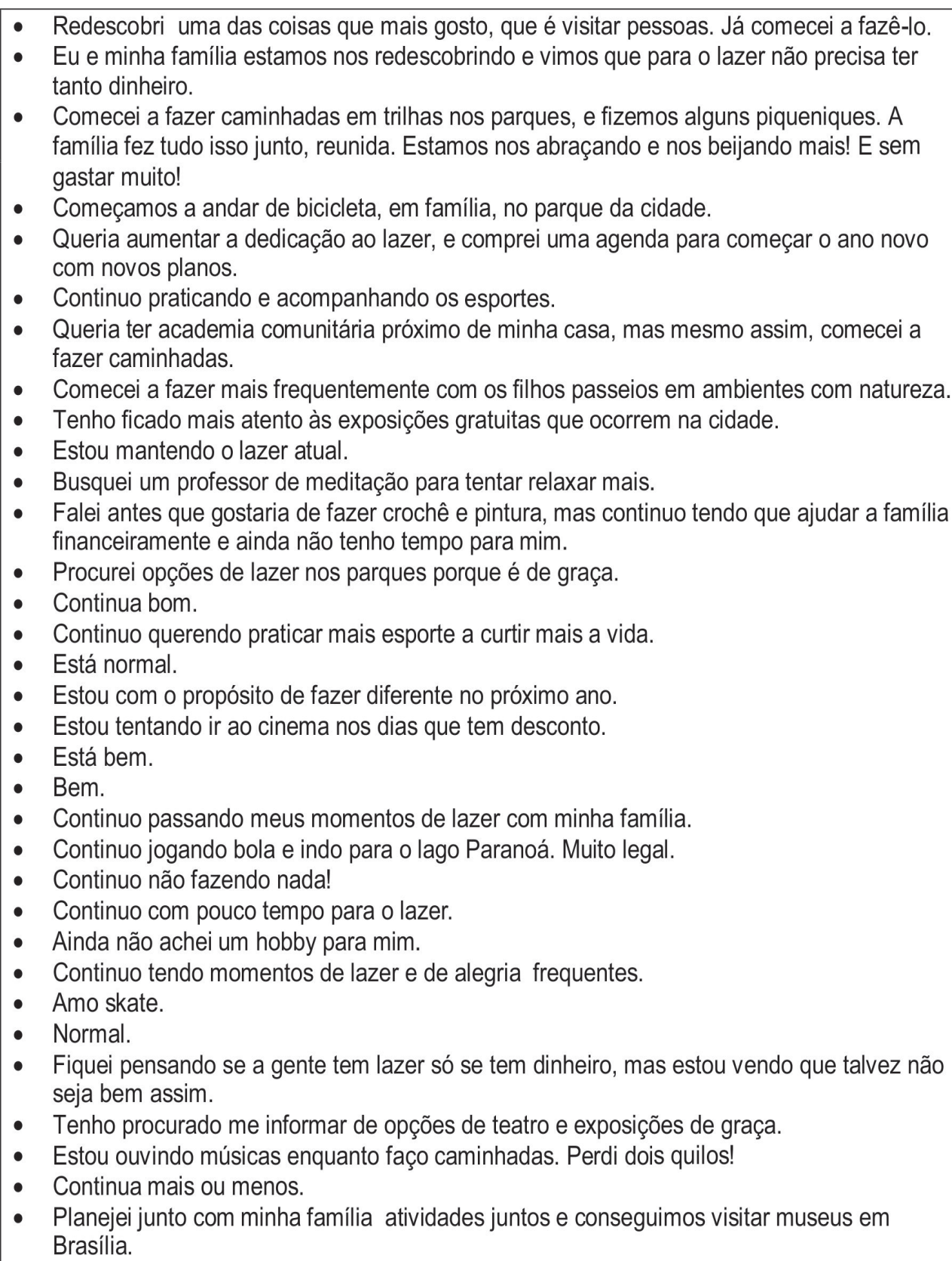 \\
\hline
\end{tabular}




\section{Quanto aos Resultados Quantitativos, estes são apresentados conforme as tabelas na sequência abaixo:}

Tabela no 01: Distribuição dos usuários de quatro bibliotecas públicas do Distrito Federal segundo a qualidade de vida, Domínio 1 - Físico do WHOQOL - Bref*, no momento Pré-Intervenção, 2015.

\begin{tabular}{|c|c|c|c|c|c|c|c|}
\hline Domínio 1- Físico & Variáveis & $\delta / n=49$ & $q / n=36$ & $\leq 24$ & $>25$ & $N$ & $\%$ \\
\hline & & & & & & TOTAL & TOTAL \\
\hline Em que medida você acha & Nada (1) & 19 & 13 & 19 & 13 & 32 & 37,6 \\
\hline que sua dor (física) impede & Muito pouco (2) & 29 & 17 & 21 & 25 & 46 & 54,1 \\
\hline \multirow{3}{*}{$\begin{array}{l}\text { você de fazer o que você } \\
\text { precisa? } \\
\text { (W3) }\end{array}$} & Mais ou menos ( 3 ) & 1 & 6 & 1 & 6 & 7,0 & 8,2 \\
\hline & Bastante (4) & 0 & 0 & 0 & 0 & 0,0 & 0,0 \\
\hline & Extremamente (5) & 0 & 0 & 0 & 0 & 0,0 & 0,0 \\
\hline \multirow{5}{*}{$\begin{array}{c}\text { O quanto você precisa de } \\
\text { algum tratamento médico } \\
\text { para levar sua vida diária? } \\
\text { (W4) }\end{array}$} & Nada (1) & 15 & 6 & 17 & 4 & 21 & 24,7 \\
\hline & Muito pouco (2) & 34 & 26 & 23 & 37 & 60 & 70,6 \\
\hline & Mais ou menos (3) & 0 & 3 & 1 & 2 & 3,0 & 3,5 \\
\hline & Bastante (4) & 0 & 1 & 0 & 1 & 1,0 & 1,2 \\
\hline & Extremamente (5) & 0 & 0 & 0 & 0 & 0,0 & 0,0 \\
\hline \multirow{5}{*}{$\begin{array}{c}\text { Você tem energia suficiente } \\
\text { para o seu dia-a-dia? } \\
\text { (W10) }\end{array}$} & Nada (1) & 0 & 0 & 0 & 0 & 0,0 & 0,0 \\
\hline & Muito pouco (2) & 3 & 1 & 1 & 3 & 4,0 & 4,7 \\
\hline & Médio (3) & 20 & 27 & 18 & 29 & 47 & 55,3 \\
\hline & Muito (4) & 26 & 8 & 22 & 12 & 34 & 40,0 \\
\hline & Completamente (5) & 0 & 0 & 0 & 0 & 0,0 & 0,0 \\
\hline \multirow{5}{*}{$\begin{array}{l}\text { Quão bem você é capaz de } \\
\text { se locomover? } \\
\text { (W5) }\end{array}$} & Muito ruim (1) & 0 & 0 & 0 & 0 & 0,0 & 0,0 \\
\hline & Ruim (2) & 0 & 0 & 0 & 0 & 0,0 & 0,0 \\
\hline & Nem ruim, nem bom (3) & 8 & 3 & 4 & 10 & 14 & 16,5 \\
\hline & Bom (4) & 34 & 27 & 33 & 28 & 61 & 71,8 \\
\hline & Muito bom (5) & 7 & 3 & 4 & 6 & 10 & 11,8 \\
\hline \multirow{5}{*}{$\begin{array}{c}\text { Quão satisfeito (a) você está } \\
\text { com seu sono? } \\
\text { (W16) }\end{array}$} & Muito insatisfeito (1) & 0 & 0 & 0 & 0 & 0,0 & 0,0 \\
\hline & Insatisfeito (2) & 0 & 0 & 0 & 0 & 0,0 & 0,0 \\
\hline & Nem satisfeito, nem insatisfeito (3) & 18 & 17 & 14 & 21 & 35 & 41,2 \\
\hline & Satisfeito (4) & 30 & 17 & 27 & 20 & 47 & 55,3 \\
\hline & Muito satisfeito (5) & 1 & 2 & 0 & 3 & 3,0 & 3,5 \\
\hline \multirow{5}{*}{$\begin{array}{c}\text { Quão satisfeito (a) você está } \\
\text { com sua capacidade de } \\
\text { desempenhar as atividades } \\
\text { do seu dia-a-dia? } \\
\text { (W17) }\end{array}$} & Muito insatisfeito (1) & 0 & 0 & 0 & 0 & 0,0 & 0,0 \\
\hline & Insatisfeito (2) & 3 & 1 & 3 & 1 & 4,0 & 4,7 \\
\hline & Nem satisfeito, nem insatisfeito ( 3 ) & 32 & 30 & 29 & 33 & 62 & 72,9 \\
\hline & Satisfeito (4) & 13 & 4 & 9 & 8 & 17 & 20,0 \\
\hline & Muito satisfeito (5) & 1 & 1 & 0 & 2 & 2,0 & 2,4 \\
\hline \multirow{5}{*}{$\begin{array}{l}\text { Quão satisfeito (a) você está } \\
\text { com sua capacidade para o } \\
\text { trabalho? } \\
\text { (W18) }\end{array}$} & Muito insatisfeito (1) & 0 & 0 & 0 & 0 & 0,0 & 0,0 \\
\hline & Insatisfeito (2) & 5 & 3 & 3 & 5 & 8,0 & 9,4 \\
\hline & Nem satisfeito, nem insatisfeito (3) & 31 & 28 & 30 & 29 & 59 & 69,4 \\
\hline & Satisfeito (4) & 12 & 4 & 8 & 8 & 16 & 18,8 \\
\hline & Muito satisfeito (5) & 1 & 1 & 0 & 2 & 2,0 & 2,4 \\
\hline TOTAL & & & & & & 85 & 100,0 \\
\hline
\end{tabular}

*WHOQOL-Bref. Percentual de Insatisfação é igual a escore transformado 0-100 abaixo de 70. Percentual de Satisfação é igual a escore transformado 0-100 igual ou maior que 70 .

Na Tabela 01, observa-se que cerca de $55 \%$ dos indivíduos relataram que dores físicas impedem muito pouco destes realizarem atividades, assim como quase $71 \%$ disseram necessitar muito pouco de tratamentos médicos na vida diária. Além disso cerca de $73 \%$ dos indivíduos disseram estarem satisfeitos com sua capacidade de desempenhar atividades diárias. 
Tabela n 0 02: Distribuição dos usuários de quatro bibliotecas públicas do Distrito Federal segundo a qualidade de vida, Domínio 2 - Psicológico do WHOQOL - Bref*, no momento Pré-Intervenção, 2015.

\begin{tabular}{|c|c|c|c|c|c|c|c|}
\hline Domínio 2- Psicológico & Variáveis & $\delta / n=49$ & $q / n=36$ & $\leq 24$ & $>25$ & $\mathrm{~N}$ & $\%$ \\
\hline & & & & & & TOTAL & TOTAL \\
\hline \multirow{5}{*}{$\begin{array}{l}\text { O quanto você aproveita a } \\
\text { vida? } \\
\text { (W5) }\end{array}$} & Nada (1) & 0 & 0 & 0 & 0 & 0,0 & 0,0 \\
\hline & Muito pouco (2) & 11 & 4 & 12 & 3 & 15 & 17.6 \\
\hline & Mais ou menos (3) & 25 & 23 & 18 & 30 & 48 & 56,5 \\
\hline & Bastante (4) & 13 & 9 & 11 & 11 & 22 & 25,9 \\
\hline & Extremamente (5) & 0 & 0 & 0 & 0 & 0,0 & 0,0 \\
\hline \multirow{5}{*}{$\begin{array}{l}\text { Em que medida você acha } \\
\text { que sua vida tem sentido? } \\
\text { (W6) }\end{array}$} & Nada (1) & 0 & 0 & 0 & 0 & 0,0 & 0,0 \\
\hline & Muito pouco (2) & 3 & 0 & 3 & 0 & 3,0 & 3,5 \\
\hline & Mais ou menos ( 3 ) & 3 & 6 & 6 & 3 & 9,0 & 10,6 \\
\hline & Bastante (4) & 15 & 9 & 14 & 10 & 24 & 28,2 \\
\hline & Extremamente (5) & 28 & 21 & 18 & 31 & 49 & 57,6 \\
\hline \multirow{5}{*}{$\begin{array}{l}\text { O quanto você consegue se } \\
\text { concentrar? } \\
\text { (W7) }\end{array}$} & Nada (1) & 0 & 0 & 0 & 0 & 0,0 & 0,0 \\
\hline & Muito pouco (2) & 8 & 5 & 4 & 9 & 2,0 & 15,3 \\
\hline & Mais ou menos ( 3 ) & 36 & 27 & 34 & 29 & 63 & 74,1 \\
\hline & Bastante (4) & 5 & 4 & 3 & 6 & 9,0 & 10,6 \\
\hline & Extremamente (5) & 0 & 0 & 0 & 0 & 0,0 & 0,0 \\
\hline \multirow{5}{*}{$\begin{array}{l}\text { Você é capaz de aceitar sua } \\
\text { aparência física? } \\
\text { (W11) }\end{array}$} & Nada (1) & 0 & 0 & 0 & 0 & 0,0 & 0,0 \\
\hline & Muito pouco (2) & 3 & 0 & 0 & 3 & 3,0 & 3,5 \\
\hline & Mais ou menos (3) & 22 & 26 & 18 & 30 & 48 & 56,5 \\
\hline & Bastante (4) & 24 & 10 & 23 & 11 & 34 & 40,0 \\
\hline & Extremamente (5) & 0 & 0 & 0 & 0 & 0,0 & 0,0 \\
\hline \multirow{5}{*}{$\begin{array}{l}\text { Quão satisfeito (a) você está } \\
\text { consigo mesmo? } \\
\text { (W19) }\end{array}$} & Muito insatisfeito (1) & 0 & 0 & 0 & 0 & 0,0 & 0,0 \\
\hline & Insatisfeito (2) & 14 & 4 & 13 & 5 & 18 & 21,2 \\
\hline & Nem satisfeito, nem insatisfeito ( 3 ) & 25 & 27 & 23 & 29 & 52 & 61,2 \\
\hline & Satisfeito (4) & 9 & 4 & 5 & 8 & 13 & 15,3 \\
\hline & Muito satisfeito (5) & 1 & 1 & 0 & 2 & 2,0 & 2,4 \\
\hline Com que frequência você & Nunca (1) & 3 & 0 & 0 & 0 & 3,0 & 3,5 \\
\hline \multirow{4}{*}{$\begin{array}{c}\text { tem sentimentos negativos } \\
\text { tais como mau humor, } \\
\text { desespero, ansiedade, } \\
\text { depressão? } \\
\text { (W26) }\end{array}$} & Algumas vezes (2) & 16 & 19 & 18 & 3 & 35 & 41,2 \\
\hline & Frequentemente (3) & 30 & 16 & 23 & 17 & 46 & 54,1 \\
\hline & Muito frequentemente (4) & 0 & 1 & 0 & 23 & 1,0 & 1,2 \\
\hline & Sempre (5) & 0 & 0 & 0 & $\begin{array}{l}20 \\
1\end{array}$ & $\begin{array}{l}1,0 \\
0,0\end{array}$ & $\begin{array}{l}1,2 \\
0,0\end{array}$ \\
\hline TOTAL & & & & & & 85 & 100,0 \\
\hline
\end{tabular}

*WHOQOL-Bref. Percentual de Insatisfação é igual a escore transformado 0-100 abaixo de 70. Percentual de Satisfação é igual a escore transformado 0-100 igual ou maior que 70 .

Na Tabela 02 , verifica-se que $74 \%$ dos indivíduos indicaram a variável "mais ou menos", quanto à capacidade de concentração. Com relação a aceitação da aparência física, cerca de $57 \%$ das pessoas indicaram a variável "médio" e, quanto à satisfação consigo mesmo, $61 \%$ dos indivíduos disseram sentirse "nem satisfeitos, nem insatisfeitos". 


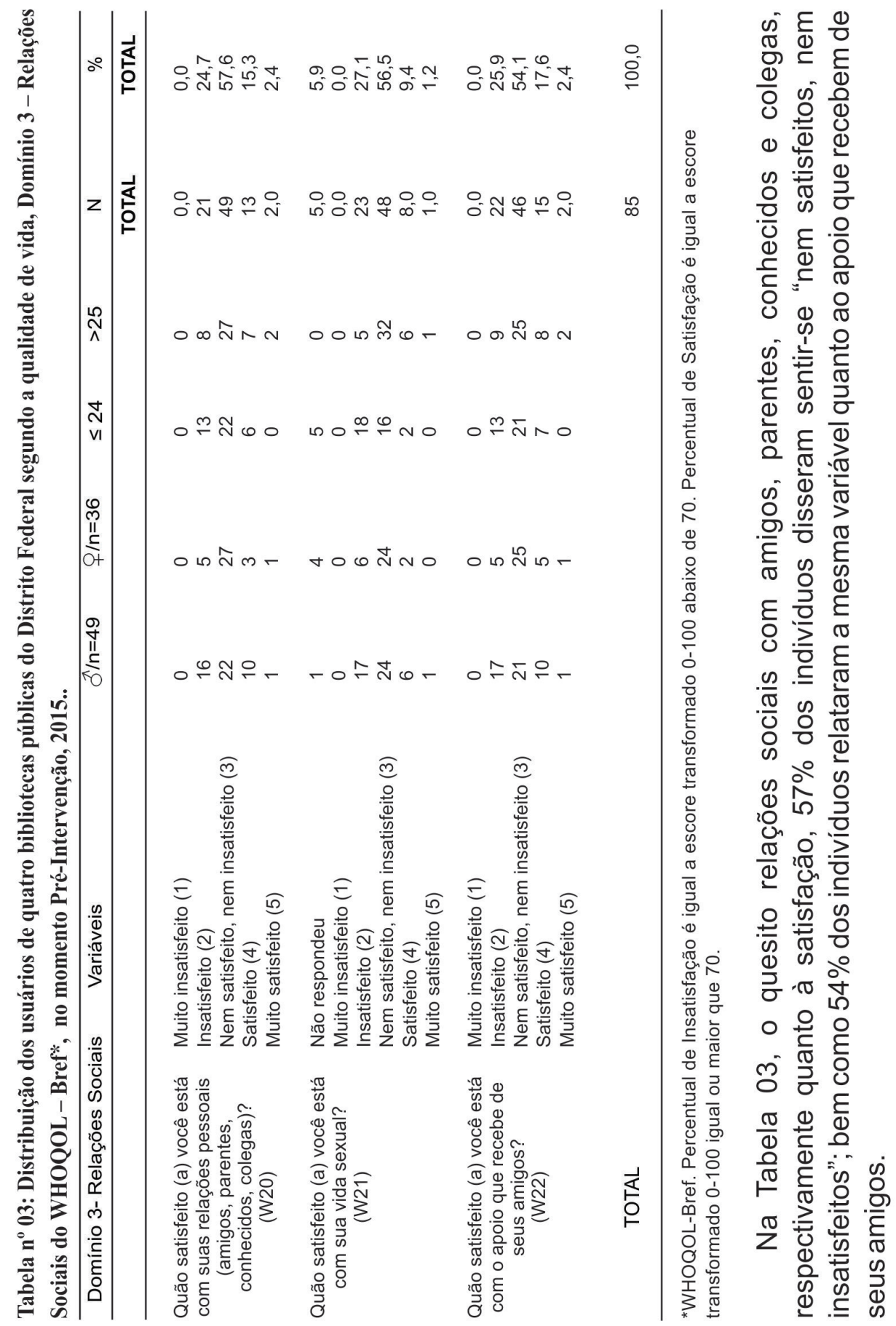


Tabela $\mathrm{n}^{0}$ 04: Distribuição dos usuários de quatro bibliotecas públicas do Distrito Federal segundo a qualidade de vida, Domínio 4 - Meio Ambiente do WHOQOL - Bref*, no momento Pré-Intervenção, 2015.

\begin{tabular}{|c|c|c|c|c|c|c|c|}
\hline \multirow[t]{2}{*}{ Domínio 4 - Meio Ambiente } & Variáveis & $\delta / n=49$ & $\phi / n=36$ & $\leq 24$ & $>25$ & $\mathrm{~N}$ & $\%$ \\
\hline & & & & & & TOTAL & TOTAL \\
\hline \multirow{5}{*}{$\begin{array}{l}\text { Quão seguro (a) você se } \\
\text { sente em sua vida diária? } \\
\text { (W8) }\end{array}$} & Nada (1) & 0 & 0 & 0 & 0 & 0,0 & 0,0 \\
\hline & Muito pouco (2) & 1 & 2 & 0 & 3 & 3,0 & 3,5 \\
\hline & Mais ou menos (3) & 40 & 29 & 34 & 35 & 69 & 81,2 \\
\hline & Bastante (4) & 8 & 4 & 7 & 5 & 12 & 14,1 \\
\hline & Extremamente (5) & 0 & 1 & 0 & 1 & 1,0 & 1,2 \\
\hline \multirow{5}{*}{$\begin{array}{l}\text { Quão saudável é o seu } \\
\text { ambiente físico (clima, } \\
\text { barulho, poluição, atrativos)? } \\
\text { (W9) }\end{array}$} & Nada (1) & 0 & 0 & 0 & 0 & 0,0 & 0,0 \\
\hline & Muito pouco (2) & 6 & 4 & 2 & 8 & 10 & 11,8 \\
\hline & Mais ou menos (3) & 37 & 30 & 36 & 31 & 67 & 78,8 \\
\hline & Bastante (4) & 6 & 1 & 3 & 4 & 7,0 & 8,2 \\
\hline & Extremamente (5) & 0 & 1 & 0 & 1 & 1,0 & 1,2 \\
\hline \multirow{5}{*}{$\begin{array}{l}\text { Você tem dinheiro suficiente } \\
\text { para satisfazer suas } \\
\text { necessidades? } \\
\text { (W12) }\end{array}$} & Nada (1) & 0 & 0 & 0 & 0 & 0,0 & 0,0 \\
\hline & Muito pouco (2) & 25 & 9 & 0 & 8 & 34 & 40,0 \\
\hline & Médio (3) & 22 & 26 & 26 & 33 & 48 & 56,5 \\
\hline & Muito (4) & 2 & 1 & 15 & 3 & 3,0 & 3,5 \\
\hline & Completamente (5) & 0 & 0 & 0 & 0 & 0,0 & 0,0 \\
\hline \multirow{5}{*}{$\begin{array}{l}\text { Quão disponíveis para você } \\
\text { estão as informações que } \\
\text { precisa no seu dia-a-dia? } \\
\text { (W13) }\end{array}$} & Nada (1) & 0 & 0 & 0 & 0 & 0,0 & 0,0 \\
\hline & Muito pouco (2) & 0 & 0 & 0 & 0 & 0,0 & 0,0 \\
\hline & Médio (3) & 37 & 32 & 33 & 36 & 69 & 81,2 \\
\hline & Muito (4) & 12 & 4 & 8 & 8 & 16 & 18,8 \\
\hline & Completamente (5) & 0 & 0 & 0 & 0 & 0,0 & 0,0 \\
\hline \multirow{5}{*}{$\begin{array}{l}\text { Em que medida você tem } \\
\text { oportunidades de atividades } \\
\text { de lazer? } \\
\text { (W14) }\end{array}$} & Nada (1) & 0 & 0 & 0 & 0 & 0,0 & 0,0 \\
\hline & Muito pouco (2) & 25 & 14 & 23 & 16 & 39 & 45,9 \\
\hline & Médio (3) & 16 & 18 & 13 & 21 & 34 & 40,0 \\
\hline & Muito (4) & 8 & 4 & 5 & 7 & 12 & 14,1 \\
\hline & Completamente (5) & 0 & 0 & 0 & 0 & 0,0 & 0,0 \\
\hline \multirow{5}{*}{$\begin{array}{l}\text { Quão satisfeito (a) você está } \\
\text { com as condições do local } \\
\text { onde mora? } \\
\text { (W23) }\end{array}$} & Muito insatisfeito (1) & 0 & 0 & 0 & 0 & 0,0 & 0,0 \\
\hline & Insatisfeito (2) & 16 & 8 & 13 & 11 & 24 & 28,2 \\
\hline & Nem satisfeito, nem insatisfeito (3) & 28 & 26 & 27 & 27 & 54 & 63,5 \\
\hline & Satisfeito (4) & 4 & 1 & 1 & 4 & 5,0 & 5,9 \\
\hline & Muito satisfeito (5) & 1 & 1 & 0 & 2 & 2,0 & 2,4 \\
\hline \multirow{5}{*}{$\begin{array}{l}\text { Quão satisfeito (a) você está } \\
\text { com seu acesso aos } \\
\text { serviços de saúde? } \\
\text { (W24) }\end{array}$} & Muito insatisfeito (1) & 9 & 17 & 9 & 17 & 26 & 30,6 \\
\hline & Insatisfeito (2) & 31 & 7 & 23 & 15 & 38 & 44,7 \\
\hline & Nem satisfeito, nem insatisfeito (3) & 7 & 12 & 9 & 10 & 19 & 22,4 \\
\hline & Satisfeito (4) & 1 & 0 & 0 & 1 & 1,0 & 1,2 \\
\hline & Muito satisfeito (5) & 1 & 0 & 0 & 1 & 1,0 & 1,2 \\
\hline \multirow{5}{*}{$\begin{array}{l}\text { Quão satisfeito (a) você está } \\
\text { com o seu meio de } \\
\text { transporte? } \\
\text { (W25) }\end{array}$} & Muito insatisfeito (1) & 9 & 17 & 9 & 17 & 26 & 30,6 \\
\hline & Insatisfeito (2) & 31 & 8 & 24 & 15 & 39 & 45,9 \\
\hline & Nem satisfeito, nem insatisfeito (3) & 7 & 11 & 8 & 10 & 18 & 21,2 \\
\hline & Satisfeito (4) & 1 & 0 & 0 & 1 & 1,0 & 1,2 \\
\hline & Muito satisfeito (5) & 1 & 0 & 0 & 1 & 1,0 & 1,2 \\
\hline TOTAL & & & & & & 85 & 100,0 \\
\hline
\end{tabular}

*WHOQOL-Bref. Percentual de Insatisfação é igual a escore transformado 0-100 abaixo de 70. Percentual de Satisfação é igual a escore transformado 0-100 igual ou maior que 70 .

Na Tabela 04, quanto ao Domínio relativo ao Meio Ambiente, $81 \%$ dos indivíduos disseram sentir-se mais ou menos seguros em suas vidas diárias. Com relação a aspectos ambientais como clima, barulho, poluição e atrativos, cerca de $79 \%$ das pessoas escolheram a variável "mais ou menos". Quanto às informações disponíveis no dia-a-dia, 81\% dos indivíduos indicaram suas respostas na variável "médio". 


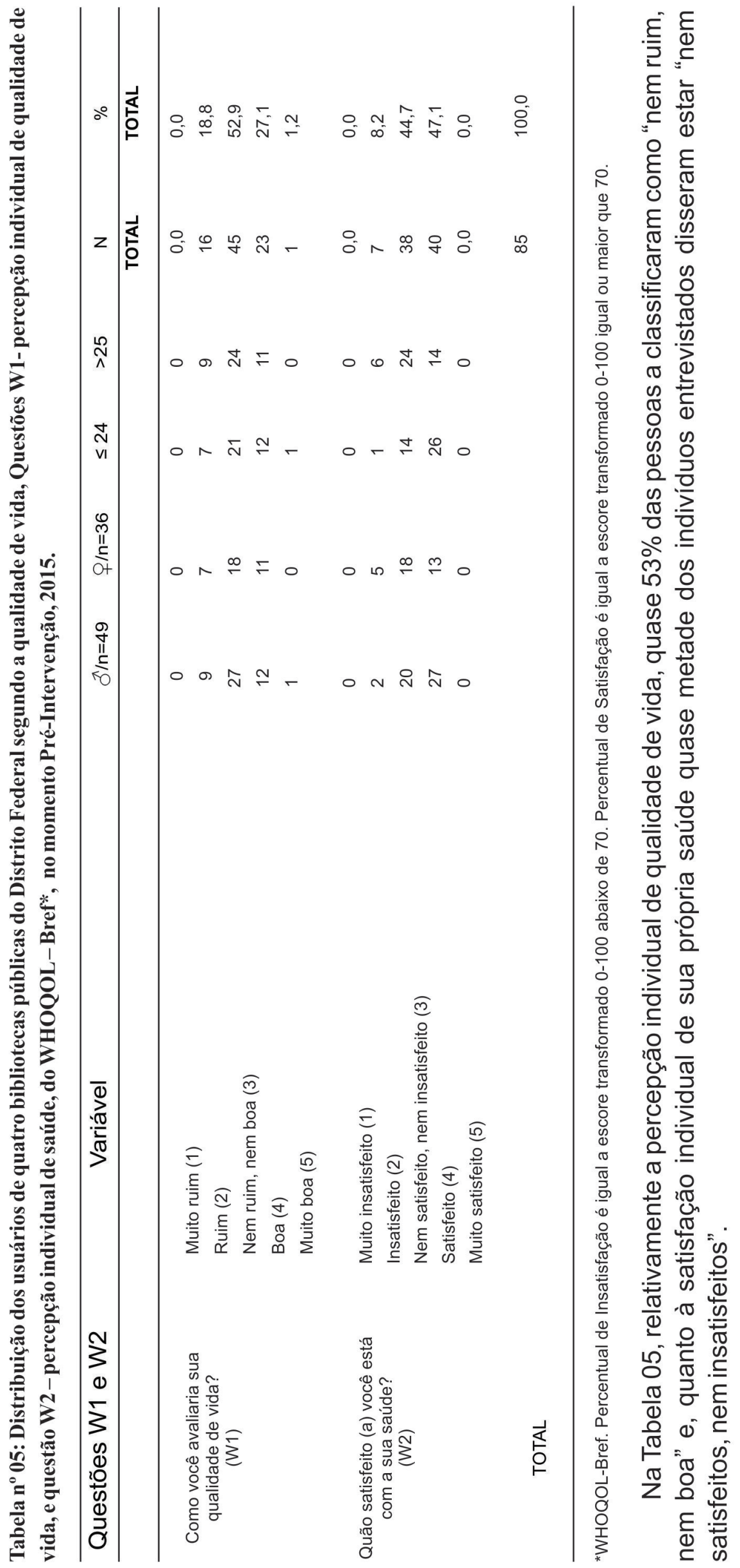


Tabela no 06: Distribuição dos usuários de quatro bibliotecas públicas do Distrito Federal segundo a qualidade de vida, Domínio 1 - Físico do WHOQOL - Bref*, no momento Pós-Intervenção, 2015.

\begin{tabular}{|c|c|c|c|c|c|c|c|}
\hline Domínio 1- Físico & Variáveis & $\delta / n=49$ & $9 / n=36$ & $\leq 24$ & $>25$ & $\mathrm{~N}$ & $\%$ \\
\hline & & & & & & TOTAL & TOTAL \\
\hline Em que medida você acha & Nada (1) & 19 & 13 & 19 & 13 & 32 & 37,6 \\
\hline que sua dor (física) impede & Muito pouco (2) & 29 & 22 & 22 & 29 & 51 & 60,0 \\
\hline \multirow{3}{*}{$\begin{array}{l}\text { você de fazer o que você } \\
\text { precisa? } \\
\text { (W3) }\end{array}$} & Mais ou menos (3) & 1 & 1 & 0 & 2 & 2,0 & 2,4 \\
\hline & Bastante (4) & 0 & 0 & 0 & 0 & 0,0 & 0,0 \\
\hline & Extremamente (5) & 0 & 0 & 0 & 0 & 0,0 & 0,0 \\
\hline O quanto você precisa de & Nada (1) & 15 & 6 & 17 & 4 & 21 & 24,7 \\
\hline algum tratamento médico & Muito pouco (2) & 34 & 29 & 24 & 39 & 63 & 74,1 \\
\hline \multirow{3}{*}{$\begin{array}{c}\text { para levar sua vida diária? } \\
\text { (W4) }\end{array}$} & Mais ou menos (3) & 0 & 0 & 0 & 0 & 0,0 & 0,0 \\
\hline & Bastante (4) & 0 & 1 & 0 & 1 & 1,0 & 1,2 \\
\hline & Extremamente (5) & 0 & 0 & 0 & 0 & 0,0 & 0,0 \\
\hline \multirow{5}{*}{$\begin{array}{c}\text { Você tem energia suficiente } \\
\text { para o seu dia-a-dia? } \\
\text { (W10) }\end{array}$} & Nada (1) & 0 & 0 & 0 & 0 & 0,0 & 0,0 \\
\hline & Muito pouco (2) & 0 & 0 & 0 & 0 & 0,0 & 0,0 \\
\hline & Médio (3) & 8 & 3 & 6 & 5 & 11 & 12,9 \\
\hline & Muito (4) & 41 & 33 & 35 & 39 & 74 & 87,1 \\
\hline & Completamente (5) & 0 & 0 & 0 & 0 & 0,0 & 0,0 \\
\hline \multirow{5}{*}{$\begin{array}{l}\text { Quão bem você é capaz de } \\
\text { se locomover? } \\
\text { (W5) }\end{array}$} & Muito ruim (1) & 0 & 0 & 0 & 0 & 0,0 & 0,0 \\
\hline & Ruim (2) & 0 & 0 & 0 & 0 & 0,0 & 0,0 \\
\hline & Nem ruim, nem bom (3) & 7 & 3 & 3 & 7 & 10 & 11,8 \\
\hline & Bom (4) & 35 & 29 & 34 & 30 & 64 & 75,3 \\
\hline & Muito bom (5) & 7 & 4 & 4 & 7 & 11 & 12,9 \\
\hline \multirow{5}{*}{$\begin{array}{c}\text { Quão satisfeito (a) você está } \\
\text { com seu sono? } \\
\text { (W16) }\end{array}$} & Muito insatisfeito (1) & 0 & 0 & 0 & 0 & 0,0 & 0,0 \\
\hline & Insatisfeito (2) & 0 & 0 & 0 & 0 & 0,0 & 0,0 \\
\hline & Nem satisfeito, nem insatisfeito ( 3 ) & 11 & 5 & 12 & 4 & 16 & 18,8 \\
\hline & Satisfeito (4) & 37 & 29 & 29 & 37 & 66 & 77,6 \\
\hline & Muito satisfeito (5) & 1 & 2 & 0 & 3 & 3,0 & 3,5 \\
\hline \multirow{5}{*}{$\begin{array}{l}\text { Quão satisfeito (a) você está } \\
\text { com sua capacidade de } \\
\text { desempenhar as atividades } \\
\text { do seu dia-a-dia? } \\
\text { (W17) }\end{array}$} & Muito insatisfeito (1) & 0 & 0 & 0 & 0 & 0,0 & 0,0 \\
\hline & Insatisfeito (2) & 0 & 0 & 0 & 0 & 0,0 & 0,0 \\
\hline & Nem satisfeito, nem insatisfeito (3) & 8 & 1 & 8 & 1 & 9,0 & 10,6 \\
\hline & Satisfeito (4) & 38 & 33 & 32 & 39 & 71 & 83,5 \\
\hline & Muito satisfeito (5) & 3 & 2 & 1 & 4 & 5,0 & 5,9 \\
\hline Quão satisfeito (a) você está & Muito insatisfeito (1) & 0 & 0 & 0 & 0 & 0,0 & 0,0 \\
\hline \multirow{4}{*}{$\begin{array}{c}\text { com sua capacidade para o } \\
\text { trabalho? } \\
\text { (W18) }\end{array}$} & Insatisfeito (2) & 0 & 0 & 0 & 0 & 0,0 & 0,0 \\
\hline & Nem satisfeito, nem insatisfeito ( 3 ) & 9 & 2 & 9 & 2 & 11 & 13,0 \\
\hline & Satisfeito (4) & 35 & 31 & 31 & 35 & 66 & 77,6 \\
\hline & Muito satisfeito (5) & 5 & 3 & 1 & 7 & 8,0 & 9,4 \\
\hline TOTAL & & & & & & 85 & 100,0 \\
\hline
\end{tabular}

*WHOQOL-Bref. Percentual de Insatisfação é igual a escore transformado 0-100 abaixo de 70. Percentual de Satisfação é igual a escore transformado 0-100 igual ou maior que 70 .

$\mathrm{Na}$ Tabela 06, verifica-se quanto a energia para o dia-a-dia, que $87 \%$ das pessoas indicaram a variável "muito"; $77,6 \%$ das pessoas relataram estarem satisfeitas com o seu sono; $83,5 \%$ das pessoas disseram estarem satisfeitas com sua capacidade de desempenhar atividades diárias, e, cerca de $78 \%$ das pessoas indicaram estarem satisfeitas com sua capacidade para o trabalho. 
Tabela nº 07: Distribuição dos usuários de quatro bibliotecas públicas do Distrito Federal segundo a qualidade de vida, Domínio 2 - Psicológico do WHOQOL - Bref*, no momento Pós-Intervenção, 2015.

\begin{tabular}{|c|c|c|c|c|c|c|c|}
\hline Domínio 2- Psicológico & Variáveis & $\delta^{1} / n=49$ & ㅇ/n=36 & $\leq 24$ & $>25$ & $\mathrm{~N}$ & $\%$ \\
\hline & & & & & & TOTAL & TOTAL \\
\hline \multirow{5}{*}{$\begin{array}{l}\text { O quanto você aproveita a } \\
\text { vida? } \\
\text { (W5) }\end{array}$} & Nada (1) & 0 & 0 & 0 & 0 & 0,0 & 0,0 \\
\hline & Muito pouco (2) & 9 & 0 & 9 & 13 & 9,0 & 10,6 \\
\hline & Mais ou menos (3) & 18 & 9 & 14 & 28 & 27 & 31,8 \\
\hline & Bastante (4) & 19 & 27 & 18 & 3 & 46 & 54,1 \\
\hline & Extremamente (5) & 3 & 0 & 0 & 0 & 3,0 & 3,5 \\
\hline \multirow{5}{*}{$\begin{array}{l}\text { Em que medida você acha } \\
\text { que sua vida tem sentido? } \\
\text { (W6) }\end{array}$} & Nada (1) & 0 & 0 & 0 & 0 & 0,0 & 0,0 \\
\hline & Muito pouco (2) & 0 & 0 & 0 & 0 & 0,0 & 0,0 \\
\hline & Mais ou menos (3) & 4 & 2 & 5 & 1 & 6,0 & 7,1 \\
\hline & Bastante (4) & 15 & 7 & 16 & 6 & 22 & 25,9 \\
\hline & Extremamente (5) & 30 & 27 & 20 & 37 & 57 & 67,1 \\
\hline \multirow{5}{*}{$\begin{array}{l}\text { O quanto você consegue se } \\
\text { concentrar? } \\
\text { (W7) }\end{array}$} & Nada (1) & 0 & 0 & 0 & 0 & 0,0 & 0,0 \\
\hline & Muito pouco (2) & 0 & 0 & 0 & 0 & 0,0 & 0,0 \\
\hline & Mais ou menos (3) & 5 & 1 & 4 & 2 & 6,0 & 7,1 \\
\hline & Bastante (4) & 42 & 35 & 37 & 40 & 77 & 90,5 \\
\hline & Extremamente (5) & 2 & 0 & 0 & 2 & 2,0 & 2,4 \\
\hline \multirow{5}{*}{$\begin{array}{l}\text { Você é capaz de aceitar sua } \\
\text { aparência física? } \\
\text { (W11) }\end{array}$} & Nada (1) & 0 & 0 & 0 & 0 & 0,0 & 0,0 \\
\hline & Muito pouco (2) & 0 & 0 & 0 & 0 & 0,0 & 0,0 \\
\hline & Mais ou menos ( 3 ) & 15 & 5 & 9 & 11 & 20 & 23,5 \\
\hline & Bastante (4) & 34 & 31 & 32 & 33 & 65 & 76,5 \\
\hline & Extremamente (5) & 0 & 0 & 0 & 0 & 0,0 & 0,0 \\
\hline \multirow{5}{*}{$\begin{array}{l}\text { Quão satisfeito (a) você está } \\
\text { consigo mesmo? } \\
\text { (W19) }\end{array}$} & Muito insatisfeito (1) & 0 & 0 & 0 & 0 & 0,0 & 0,0 \\
\hline & Insatisfeito (2) & 2 & 0 & 2 & 0 & 2,0 & 2,4 \\
\hline & Nem satisfeito, nem insatisfeito (3) & 15 & 3 & 16 & 2 & 18 & 21,2 \\
\hline & Satisfeito (4) & 28 & 30 & 22 & 36 & 58 & 68,2 \\
\hline & Muito satisfeito (5) & 4 & 3 & 1 & 6 & 7,0 & 8,2 \\
\hline \multirow{5}{*}{$\begin{array}{c}\text { Com que frequência você } \\
\text { tem sentimentos negativos } \\
\text { tais como mau humor, } \\
\text { desespero, ansiedade, } \\
\text { depressão? } \\
\text { (W26) }\end{array}$} & Nunca (1) & 3 & 0 & 9 & 3 & 3,0 & 3,5 \\
\hline & Algumas vezes (2) & 35 & 33 & 20 & 39 & 68 & 80,0 \\
\hline & Frequentemente ( 3 ) & 11 & 3 & 12 & 2 & 14 & 16,5 \\
\hline & Muito frequentemente (4) & 0 & 0 & 0 & 0 & 0,0 & 0,0 \\
\hline & Sempre (5) & 0 & 0 & 0 & 0 & 0,0 & 0,0 \\
\hline TOTAL & & & & & & 85 & 100,0 \\
\hline
\end{tabular}

*WHOQOL-Bref. Percentual de Insatisfação é igual a escore transformado 0-100 abaixo de 70. Percentual de Satisfação é igual a escore transformado 0-100 igual ou maior que 70 .

$\mathrm{Na}$ Tabela 07, observa-se, que cerca de $90 \%$ das pessoas disseram que conseguem se concentrar bastante, e, $68 \%$ dos indivíduos informaram que estão satisfeitos consigo mesmos. 


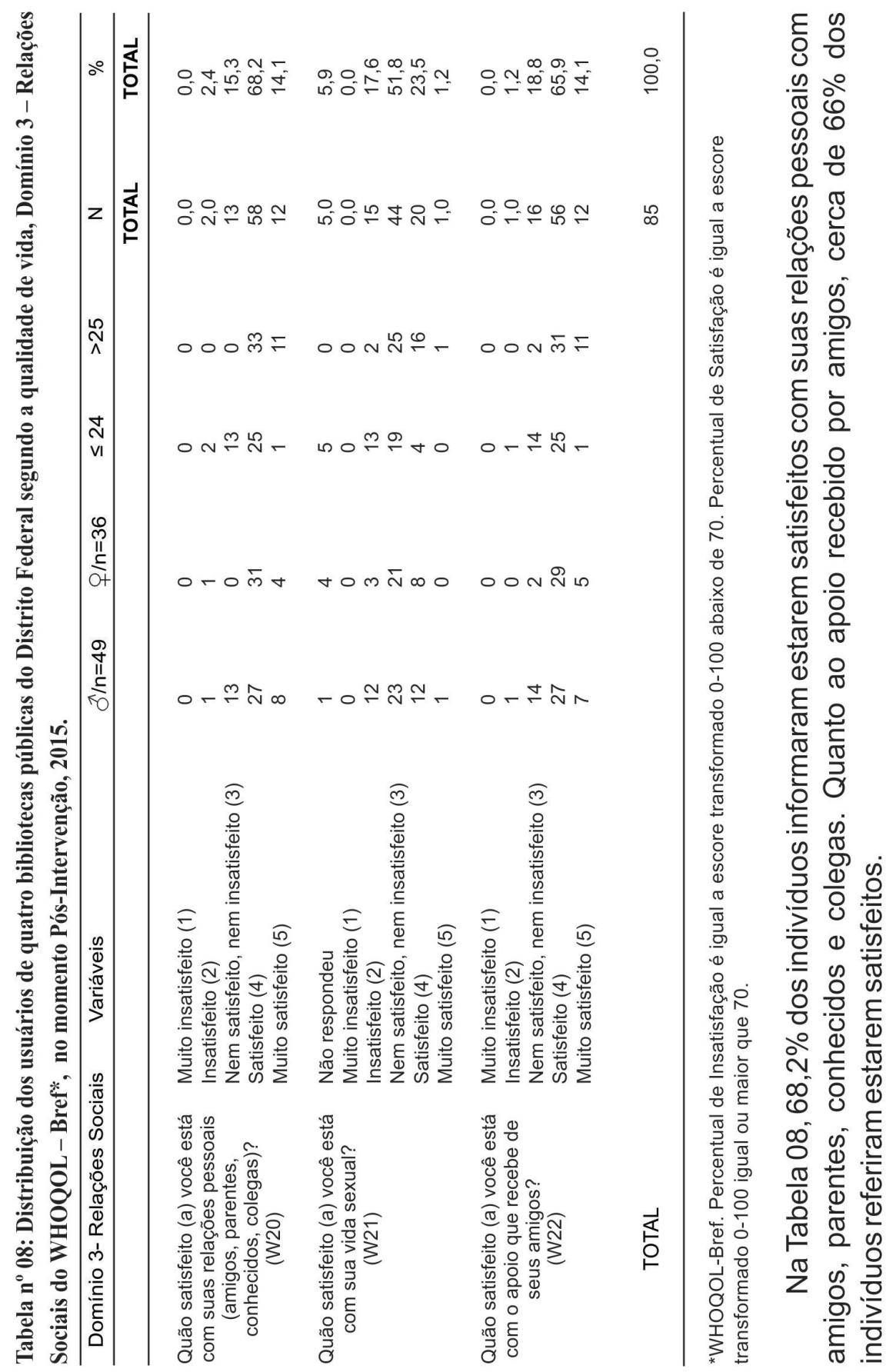


Tabela no 09: Distribuição dos usuários de quatro bibliotecas públicas do Distrito Federal segundo a qualidade de vida, Domínio 4 - Meio Ambiente do WHOQOL - Bref*, no momento Pós-Intervenção, 2015.

\begin{tabular}{|c|c|c|c|c|c|c|c|}
\hline \multirow[t]{2}{*}{ Domínio 4 - Meio Ambiente } & Variáveis & $\sigma^{\lambda} / n=49$ & $q / n=36$ & $\leq 24$ & $>25$ & $\mathrm{~N}$ & $\%$ \\
\hline & & & & & & TOTAL & TOTAL \\
\hline \multirow{5}{*}{$\begin{array}{c}\text { Quão seguro (a) você se } \\
\text { sente em sua vida diária? } \\
\text { (W8) }\end{array}$} & Nada (1) & 0 & 0 & 0 & 0 & 0,0 & 0,0 \\
\hline & Muito pouco (2) & 1 & 0 & 0 & 1 & 1,0 & 1,2 \\
\hline & Mais ou menos (3) & 26 & 19 & 21 & 24 & 45 & 52,9 \\
\hline & Bastante (4) & 22 & 16 & 20 & 18 & 38 & 44,7 \\
\hline & Extremamente (5) & 0 & 1 & 0 & 1 & 1,0 & 1,2 \\
\hline \multirow{5}{*}{$\begin{array}{c}\text { Quão saudável é o seu } \\
\text { ambiente físico (clima, } \\
\text { barulho, poluição, atrativos)? } \\
\text { (W9) }\end{array}$} & Nada (1) & 0 & 0 & 0 & 0 & 0,0 & 0,0 \\
\hline & Muito pouco (2) & 0 & 0 & 0 & 0 & 0,0 & 0,0 \\
\hline & Mais ou menos (3) & 5 & 2 & 5 & 2 & 7,0 & 8,2 \\
\hline & Bastante (4) & 43 & 32 & 35 & 40 & 75 & 88,3 \\
\hline & Extremamente (5) & 1 & 2 & 1 & 2 & 3,0 & 3,5 \\
\hline \multirow{5}{*}{$\begin{array}{l}\text { Você tem dinheiro suficiente } \\
\text { para satisfazer suas } \\
\text { necessidades? } \\
\text { (W12) }\end{array}$} & Nada (1) & 0 & 0 & 0 & 0 & 0,0 & 0,0 \\
\hline & Muito pouco (2) & 25 & 9 & 26 & 8 & 34 & 40,0 \\
\hline & Médio (3) & 20 & 24 & 13 & 31 & 44 & 51,8 \\
\hline & Muito (4) & 4 & 3 & 2 & 5 & 7,0 & 8,2 \\
\hline & Completamente (5) & 0 & 0 & 0 & 0 & 0,0 & 0,0 \\
\hline \multirow{5}{*}{$\begin{array}{l}\text { Quão disponíveis para você } \\
\text { estão as informações que } \\
\text { precisa no seu dia-a-dia? } \\
\text { (W13) }\end{array}$} & Nada (1) & 0 & 0 & 0 & 0 & 0,0 & 0,0 \\
\hline & Muito pouco (2) & 0 & 0 & 0 & 0 & 0,0 & 0,0 \\
\hline & Médio (3) & 13 & 4 & 9 & 8 & 17 & 20,0 \\
\hline & Muito (4) & 36 & 32 & 32 & 36 & 68 & 80,0 \\
\hline & Completamente (5) & 0 & 0 & 0 & 0 & 0,0 & 0,0 \\
\hline \multirow{5}{*}{$\begin{array}{l}\text { Em que medida você tem } \\
\text { oportunidades de atividades } \\
\text { de lazer? } \\
\text { (W14) }\end{array}$} & Nada (1) & 0 & 0 & 0 & 0 & 0,0 & 0,0 \\
\hline & Muito pouco (2) & 13 & 1 & 14 & 11 & 14 & 16,5 \\
\hline & Médio (3) & 16 & 9 & 14 & 32 & 25 & 29,4 \\
\hline & Muito (4) & 19 & 25 & 12 & 1 & 44 & 51,8 \\
\hline & Completamente (5) & 1 & 1 & 1 & 0 & 2,0 & 2,4 \\
\hline \multirow{5}{*}{$\begin{array}{l}\text { Quão satisfeito (a) você está } \\
\text { com as condições do local } \\
\text { onde mora? } \\
\text { (W23) }\end{array}$} & Muito insatisfeito (1) & 0 & 0 & 0 & 0 & 0,0 & 0,0 \\
\hline & Insatisfeito (2) & 0 & 0 & 0 & 0 & 0,0 & 0,0 \\
\hline & Nem satisfeito, nem insatisfeito (3) & 15 & 2 & 15 & 2 & 17 & 20,0 \\
\hline & Satisfeito (4) & 28 & 29 & 25 & 32 & 57 & 67,1 \\
\hline & Muito satisfeito (5) & 6 & 5 & 1 & 10 & 11 & 12,9 \\
\hline \multirow{5}{*}{$\begin{array}{c}\text { Quão satisfeito (a) você está } \\
\text { com seu acesso aos } \\
\text { serviços de saúde? } \\
\text { (W24) }\end{array}$} & Muito insatisfeito (1) & 9 & 17 & 9 & 17 & 26 & 30,6 \\
\hline & Insatisfeito (2) & 27 & 7 & 19 & 15 & 34 & 40,0 \\
\hline & Nem satisfeito, nem insatisfeito (3) & 11 & 11 & 13 & 9 & 22 & 25,8 \\
\hline & Satisfeito (4) & 1 & 1 & 0 & 2 & 2,0 & 2,4 \\
\hline & Muito satisfeito (5) & 1 & 0 & 0 & 1 & 1,0 & 1,2 \\
\hline \multirow{5}{*}{$\begin{array}{c}\text { Quão satisfeito (a) você está } \\
\text { com o seu meio de } \\
\text { transporte? } \\
\text { (W25) }\end{array}$} & Muito insatisfeito (1) & 9 & 17 & 9 & 17 & 26 & 30,6 \\
\hline & Insatisfeito (2) & 27 & 7 & 20 & 14 & 34 & 40,0 \\
\hline & Nem satisfeito, nem insatisfeito (3) & 11 & 11 & 12 & 10 & 22 & 25,8 \\
\hline & Satisfeito (4) & 1 & 1 & 0 & 2 & 2,0 & 2,4 \\
\hline & Muito satisfeito (5) & 1 & 0 & 0 & 1 & 1,0 & 1,2 \\
\hline TOTAL & & & & & & 85 & 100,0 \\
\hline
\end{tabular}

*WHOQOL-Bref. Percentual de Insatisfação é igual a escore transformado 0-100 abaixo de 70. Percentual de Satisfação é igual a escore transformado 0-100 igual ou maior que 70 .

Na Tabela 09, quanto à saúde do ambiente físico em que vivem, $88,3 \%$ dos indivíduos indicaram a variável "bastante", $80 \%$ dos indivíduos disseram terem muitas informações de que precisam disponíveis no dia-a-dia e, $67 \%$ das pessoas relataram estarem satisfeitas com as condições do local de moradia. 


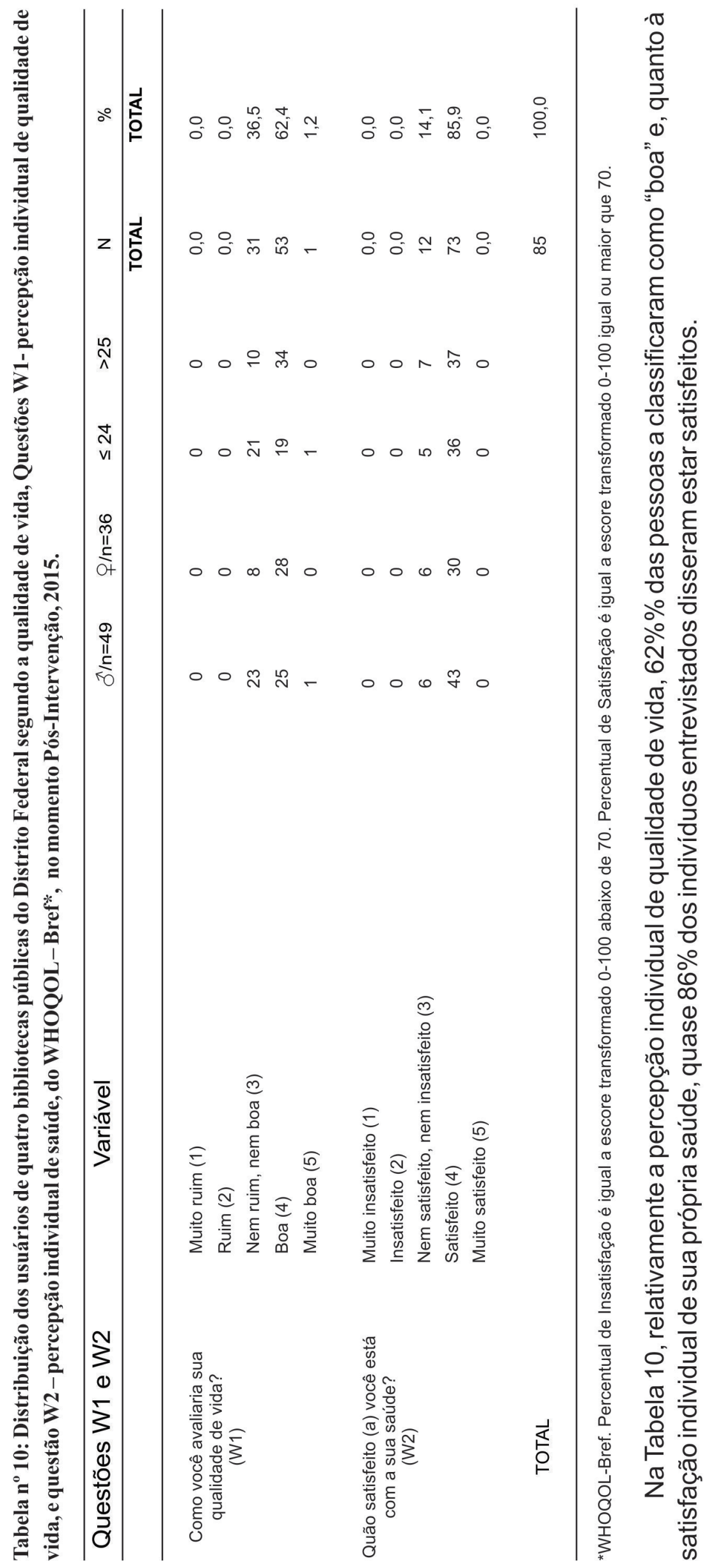




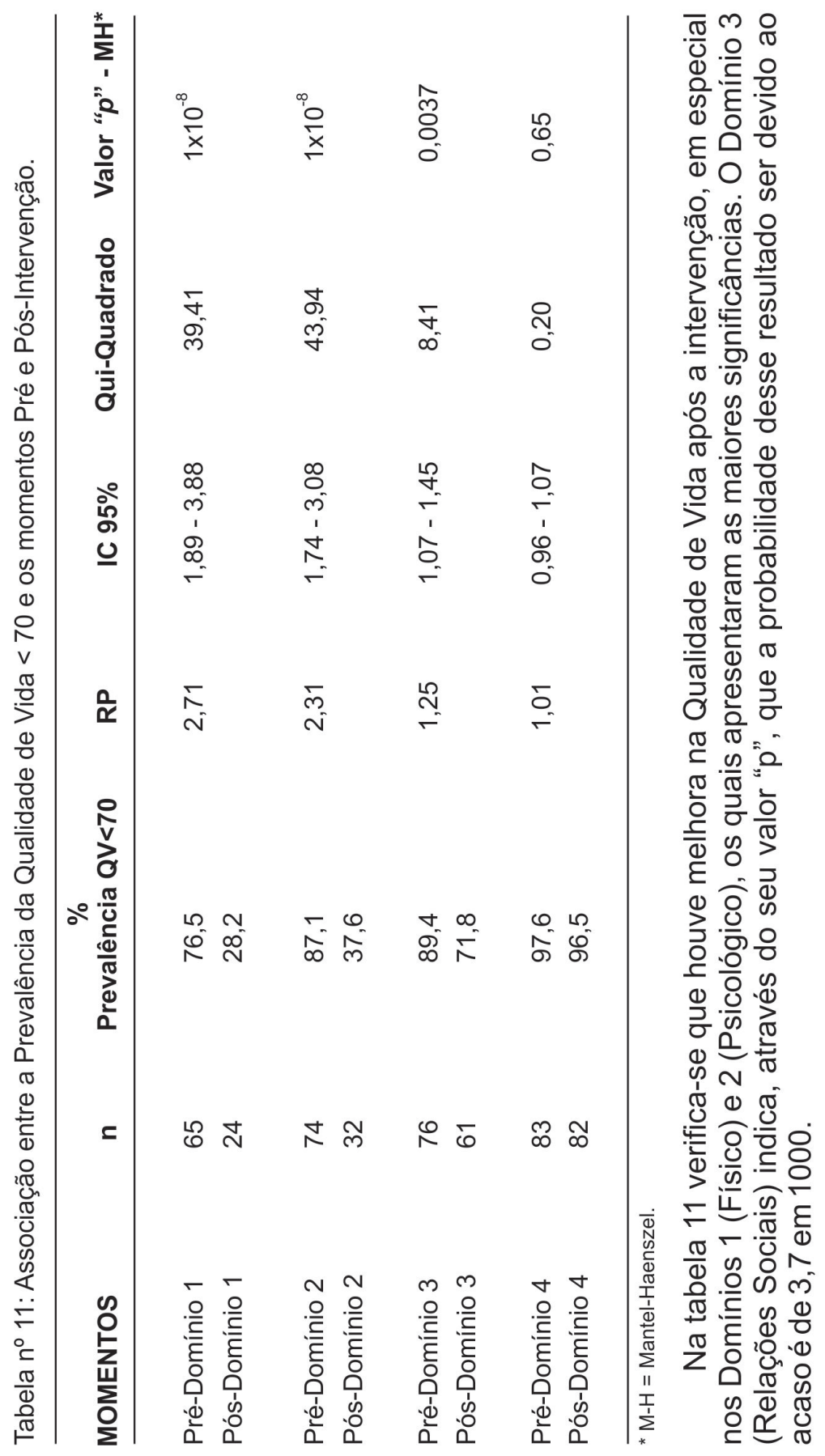




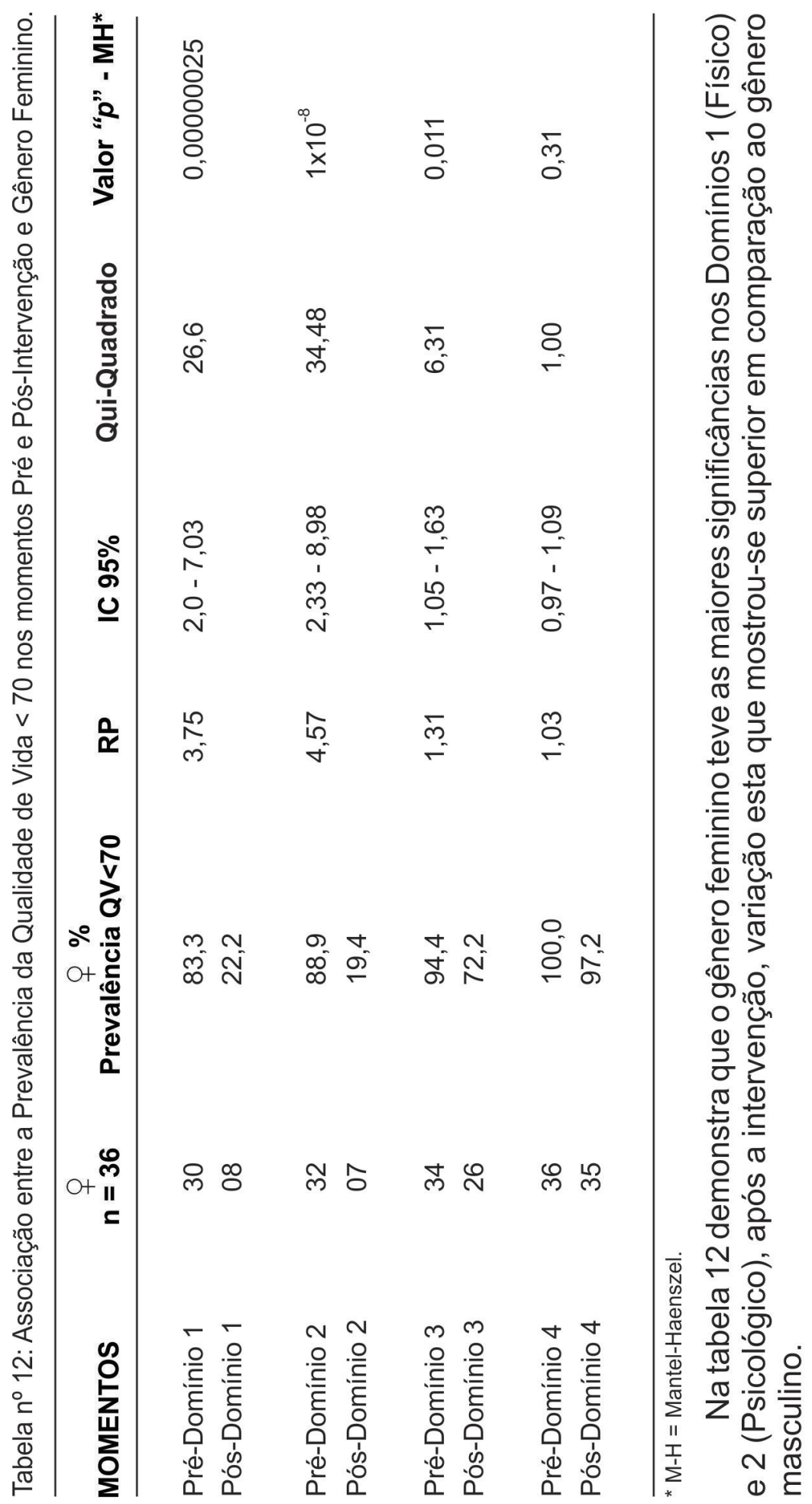




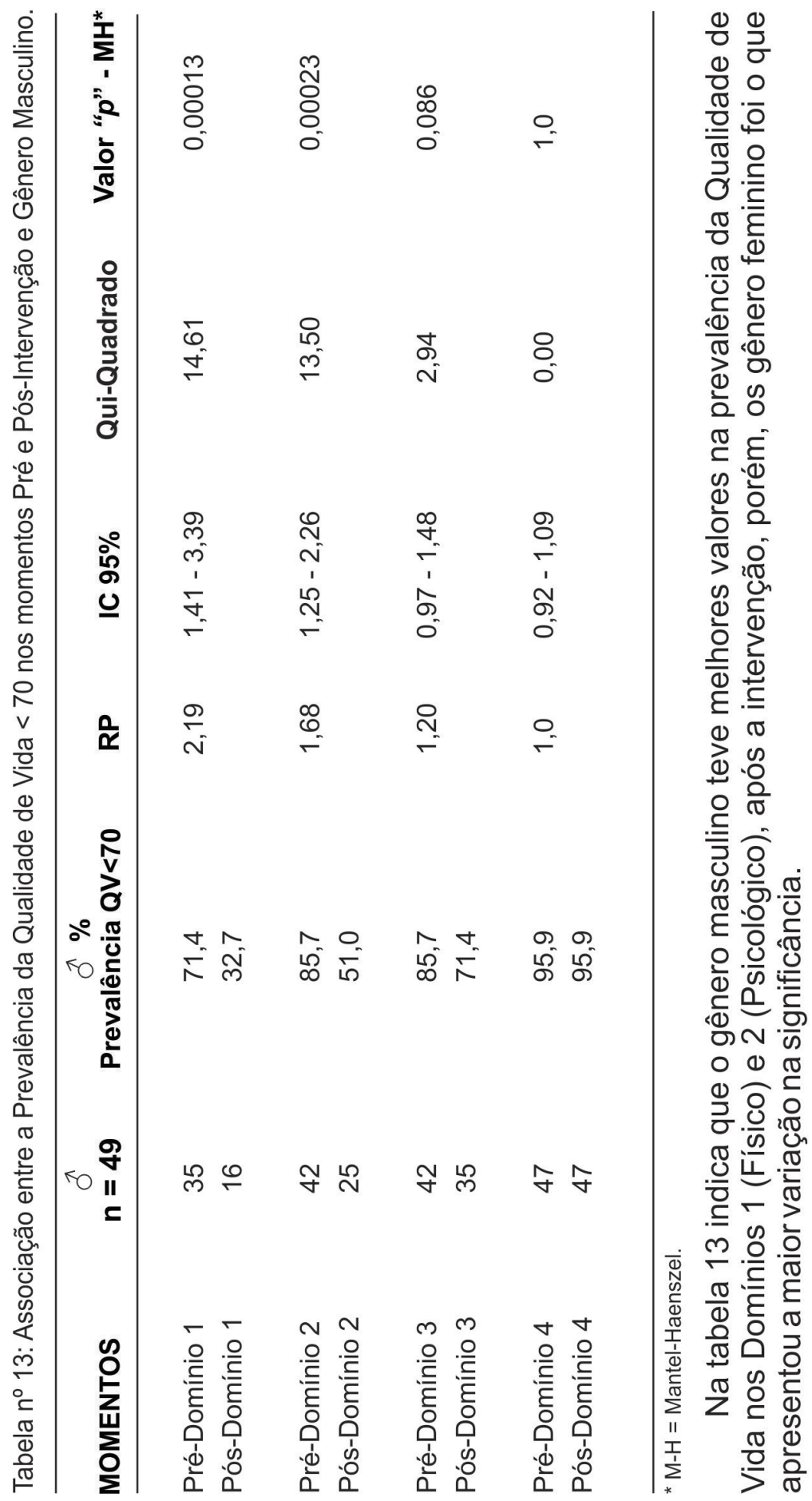




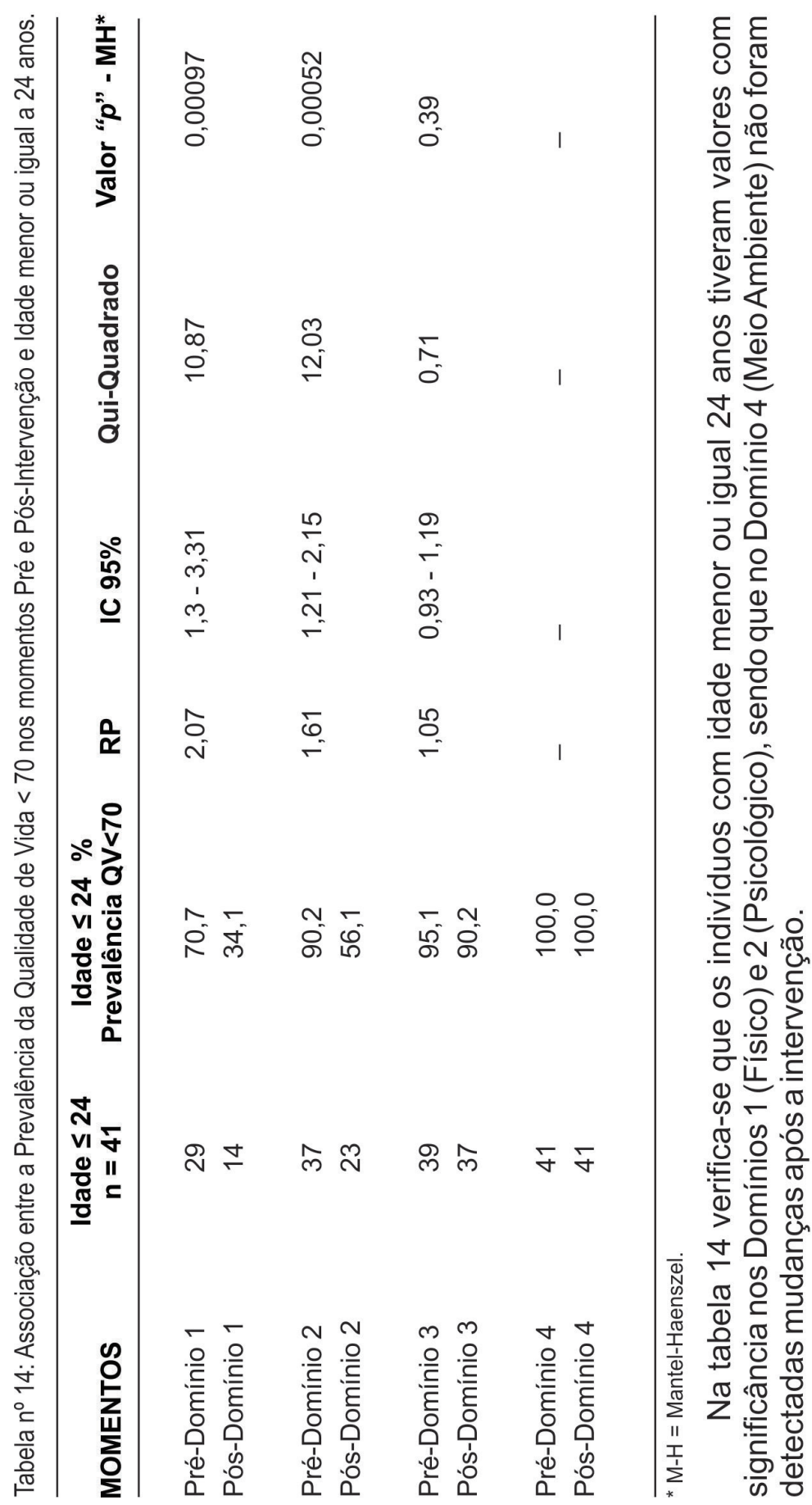




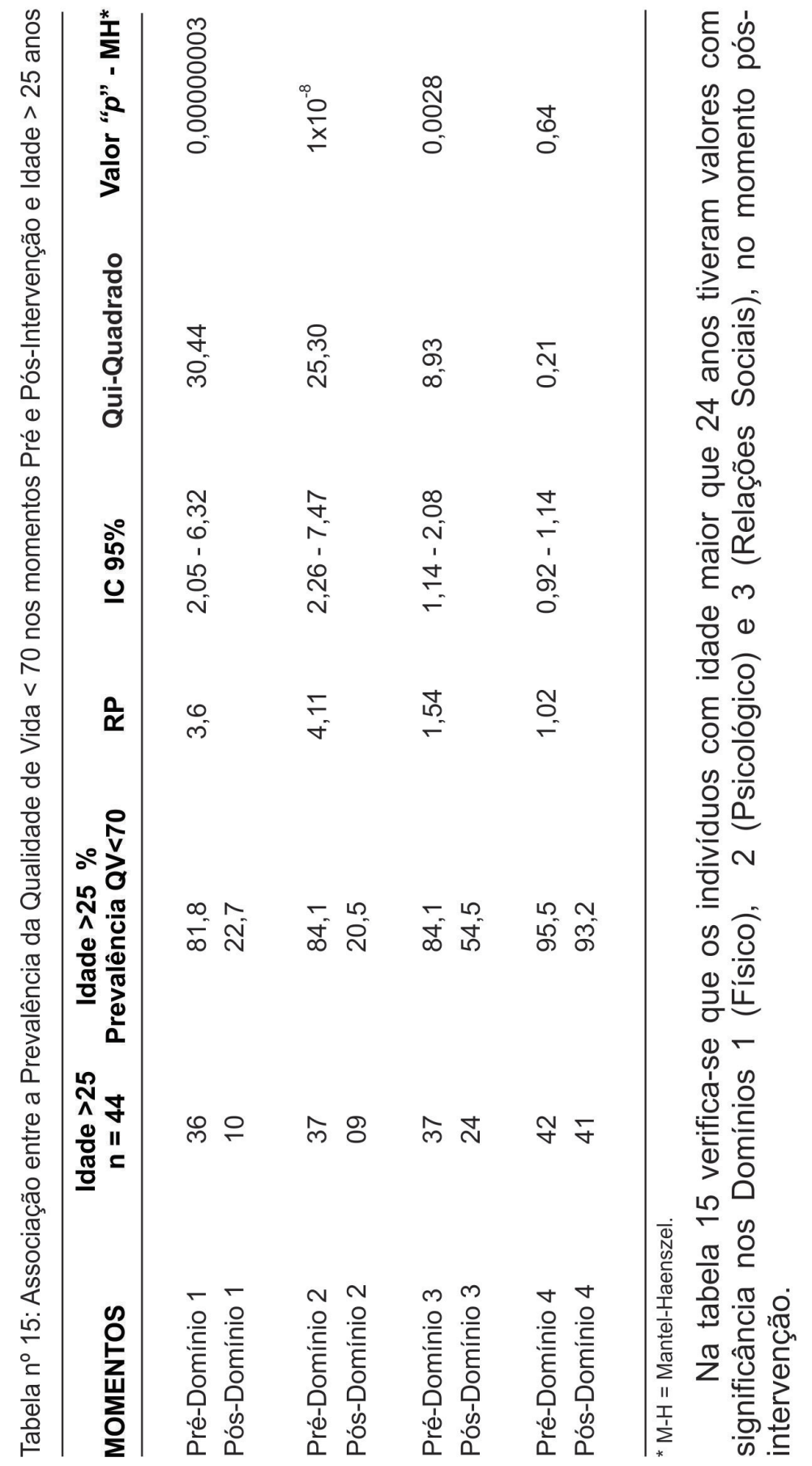




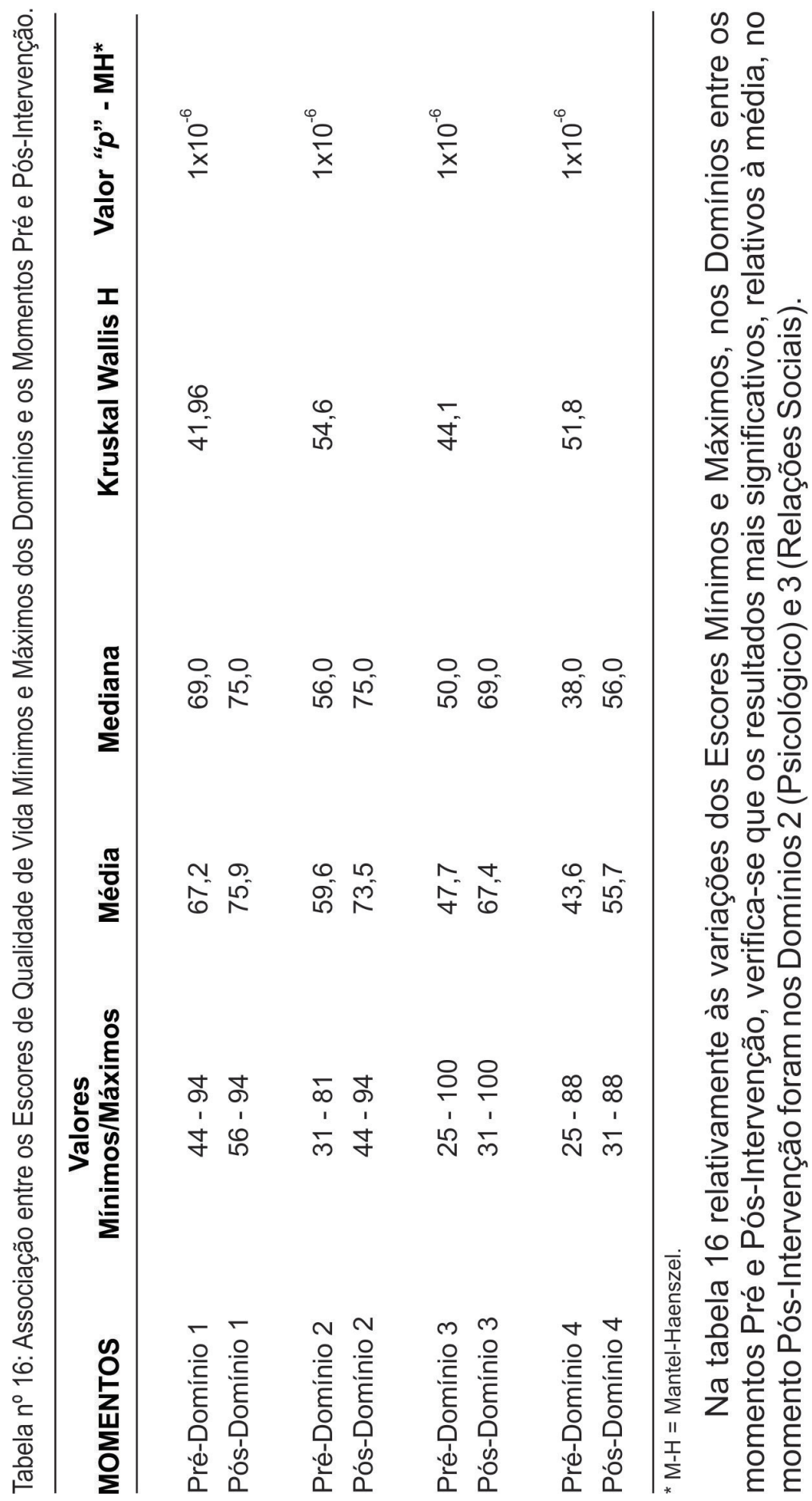


Tabela ${ }^{\circ}$ 17: Distribuição dos Tutores de quatro bibliotecas públicas do Distrito Federal segundo a qualidade de vida, Domínio 1 - Físico do WHOQOL - Bref*, 2015.

\begin{tabular}{|c|c|c|c|c|c|c|c|}
\hline Domínio 1- Físico & Variáveis & $\sigma / n=24$ & $9 / n=52$ & $\leq 24$ & $>25$ & $\mathrm{~N}$ & $\%$ \\
\hline & & & & & & TOTAL & TOTAL \\
\hline \multirow{5}{*}{$\begin{array}{l}\text { Em que medida você acha } \\
\text { que sua dor (física) impede } \\
\text { você de fazer o que você } \\
\text { precisa? } \\
\text { (W3) }\end{array}$} & Nada (1) & 6 & 12 & 4 & 14 & 18 & 23,6 \\
\hline & Muito pouco (2) & 9 & 20 & 5 & 24 & 29 & 38,2 \\
\hline & Mais ou menos (3) & 8 & 11 & 3 & 16 & 19 & 25,0 \\
\hline & Bastante (4) & 1 & 9 & 1 & 9 & 10 & 13,2 \\
\hline & Extremamente (5) & 0 & 0 & 0 & 0 & 0 & 0,0 \\
\hline \multirow{5}{*}{$\begin{array}{c}\text { O quanto você precisa de } \\
\text { algum tratamento médico } \\
\text { para levar sua vida diária? } \\
\text { (W4) }\end{array}$} & Nada (1) & 5 & 8 & 1 & 12 & 13 & 17,1 \\
\hline & Muito pouco (2) & 12 & 19 & 7 & 24 & 31 & 40,8 \\
\hline & Mais ou menos (3) & 4 & 15 & 5 & 14 & 19 & 25,0 \\
\hline & Bastante (4) & 3 & 10 & 0 & 13 & 13 & 17,1 \\
\hline & Extremamente (5) & 0 & 0 & 0 & 0 & 0 & 0,0 \\
\hline \multirow{5}{*}{$\begin{array}{l}\text { Você tem energia suficiente } \\
\text { para o seu dia-a-dia? } \\
\text { (W10) }\end{array}$} & Nada (1) & 0 & 0 & 0 & 0 & 0 & 0,0 \\
\hline & Muito pouco (2) & 2 & 5 & 1 & 6 & 7 & 9,2 \\
\hline & Médio (3) & 8 & 23 & 4 & 27 & 31 & 40,8 \\
\hline & Muito (4) & 11 & 19 & 5 & 25 & 30 & 39,5 \\
\hline & Completamente (5) & 3 & 5 & 3 & 5 & 8 & 10,5 \\
\hline \multirow{5}{*}{$\begin{array}{l}\text { Quão bem você é capaz de } \\
\text { se locomover? } \\
\text { (W5) }\end{array}$} & Muito ruim (1) & 0 & 0 & 0 & 0 & 0 & 0,0 \\
\hline & Ruim (2) & 1 & 4 & 0 & 5 & 5 & 6,6 \\
\hline & Nem ruim, nem bom (3) & 2 & 8 & 1 & 9 & 10 & 13,2 \\
\hline & Bom (4) & 9 & 19 & 5 & 23 & 28 & 36,8 \\
\hline & Muito bom (5) & 12 & 21 & 7 & 26 & 33 & 43,4 \\
\hline \multirow{5}{*}{$\begin{array}{c}\text { Quão satisfeito (a) você está } \\
\text { com seu sono? } \\
\text { (W16) }\end{array}$} & Muito insatisfeito (1) & 1 & 2 & 1 & 2 & 3 & 3,9 \\
\hline & Insatisfeito (2) & 7 & 10 & 2 & 15 & 17 & 22,4 \\
\hline & Nem satisfeito, nem insatisfeito (3) & 4 & 17 & 4 & 17 & 21 & 27,6 \\
\hline & Satisfeito (4) & 8 & 17 & 3 & 22 & 25 & 32,9 \\
\hline & Muito satisfeito (5) & 4 & 6 & 3 & 7 & 10 & 13,2 \\
\hline \multirow{5}{*}{$\begin{array}{l}\text { Quão satisfeito (a) você está } \\
\text { com sua capacidade de } \\
\text { desempenhar as atividades } \\
\text { do seu dia-a-dia? } \\
\text { (W17) }\end{array}$} & Muito insatisfeito (1) & 2 & 2 & 0 & 4 & 4 & 5,3 \\
\hline & Insatisfeito (2) & 3 & 4 & 1 & 6 & 7 & 9,2 \\
\hline & Nem satisfeito, nem insatisfeito ( 3 ) & 3 & 15 & 2 & 16 & 18 & 23,7 \\
\hline & Satisfeito (4) & 14 & 25 & 7 & 32 & 39 & 51,3 \\
\hline & Muito satisfeito (5) & 2 & 6 & 3 & 5 & 8 & 10,5 \\
\hline Quão satisfeito (a) você está & Muito insatisfeito (1) & 1 & 1 & 1 & 1 & 2 & 2,6 \\
\hline \multirow{4}{*}{$\begin{array}{c}\text { com sua capacidade para o } \\
\text { trabalho? } \\
\text { (W18) }\end{array}$} & Insatisfeito (2) & 2 & 6 & 1 & 7 & 8,0 & 10,5 \\
\hline & Nem satisfeito, nem insatisfeito ( 3 ) & 6 & 12 & 3 & 15 & 18 & 23,7 \\
\hline & Satisfeito (4) & 11 & 26 & 6 & 31 & 37 & 48,7 \\
\hline & Muito satisfeito (5) & 4 & 7 & 2 & 9 & 11 & 14,5 \\
\hline TOTAL & & & & & & 76 & 100,0 \\
\hline
\end{tabular}

*WHOQOL-Bref. Percentual de Insatisfação é igual a escore transformado 0-100 abaixo de 70. Percentual de Satisfação é igual a escore transformado 0-100 igual ou maior que 70 .

Na tabela 17 , quanto à necessidade de algum tratamento médico para a vida diária cerca de $41 \%$ dos entrevistados disseram necessitar muito pouco. Com relação à energia para o dia-a-dia, $41 \%$ dos indivíduos indicaram a variável "médio", $51,3 \%$ das pessoas disseram estarem satisfeitas com sua capacidade de desempenhar as atividades diárias e, quase $49 \%$ dos indivíduos relataram estarem satisfeitos com sua capacidade para o trabalho. 
Tabela $\mathrm{n}^{0}$ 18: Distribuição dos Tutores de quatro bibliotecas públicas do Distrito Federal segundo a qualidade de vida, Domínio 2 - Psicológico do WHOQOL - Bref*, 2015.

\begin{tabular}{|c|c|c|c|c|c|c|c|}
\hline Domínio 2- Psicológico & Variáveis & $\delta / n=24$ & 우/n=52 & $\leq 24$ & $>25$ & $\mathrm{~N}$ & $\%$ \\
\hline & & & & & & TOTAL & TOTAL \\
\hline \multirow{5}{*}{$\begin{array}{l}\text { O quanto você aproveita a } \\
\text { vida? } \\
\text { (W5) }\end{array}$} & Nada (1) & 0 & 0 & 0 & 0 & 0 & 0,0 \\
\hline & Muito pouco (2) & 4 & 8 & 2 & 10 & 12 & 15,8 \\
\hline & Mais ou menos (3) & 10 & 15 & 4 & 21 & 25 & 32,9 \\
\hline & Bastante (4) & 8 & 25 & 6 & 27 & 33 & 43,4 \\
\hline & Extremamente (5) & 2 & 4 & 1 & 5 & 6 & 7,9 \\
\hline \multirow{5}{*}{$\begin{array}{l}\text { Em que medida você acha } \\
\text { que sua vida tem sentido? } \\
\text { (W6) }\end{array}$} & Nada (1) & 0 & 0 & 0 & 0 & 0 & 0,0 \\
\hline & Muito pouco (2) & 0 & 2 & 1 & 1 & 2 & 2,6 \\
\hline & Mais ou menos (3) & 3 & 7 & 1 & 9 & 10 & 13,2 \\
\hline & Bastante (4) & 15 & 19 & 6 & 28 & 34 & 44,7 \\
\hline & Extremamente (5) & 6 & 24 & 5 & 25 & 30 & 39,5 \\
\hline \multirow{5}{*}{$\begin{array}{l}\text { O quanto você consegue se } \\
\text { concentrar? } \\
\text { (W7) }\end{array}$} & Nada (1) & 0 & 0 & 0 & 0 & 0 & 0,0 \\
\hline & Muito pouco (2) & 1 & 7 & 2 & 6 & 8 & 10,5 \\
\hline & Mais ou menos (3) & 12 & 16 & 3 & 25 & 28 & 36,8 \\
\hline & Bastante (4) & 11 & 25 & 6 & 30 & 36 & 47,4 \\
\hline & Extremamente (5) & 0 & 4 & 2 & 2 & 4 & 5,3 \\
\hline \multirow{5}{*}{$\begin{array}{l}\text { Você é capaz de aceitar sua } \\
\text { aparência física? } \\
\text { (W11) }\end{array}$} & Nada (1) & 0 & 1 & 0 & 1 & 1 & 1,3 \\
\hline & Muito pouco (2) & 3 & 3 & 2 & 4 & 6 & 7,9 \\
\hline & Mais ou menos (3) & 7 & 17 & 3 & 21 & 24 & 31,6 \\
\hline & Bastante (4) & 8 & 17 & 5 & 20 & 25 & 32,9 \\
\hline & Extremamente (5) & 6 & 14 & 3 & 17 & 20 & 26,3 \\
\hline \multirow{5}{*}{$\begin{array}{l}\text { Quão satisfeito (a) você está } \\
\text { consigo mesmo? } \\
\text { (W19) }\end{array}$} & Muito insatisfeito (1) & 1 & 3 & 1 & 3 & 4 & 5,3 \\
\hline & Insatisfeito (2) & 2 & 5 & 2 & 5 & 7 & 9,2 \\
\hline & Nem satisfeito, nem insatisfeito (3) & 3 & 7 & 2 & 8 & 10 & 13,2 \\
\hline & Satisfeito (4) & 13 & 29 & 4 & 38 & 42 & 55,2 \\
\hline & Muito satisfeito (5) & 5 & 8 & 4 & 9 & 13 & 17,1 \\
\hline \multirow{5}{*}{$\begin{array}{c}\text { Com que frequência você } \\
\text { tem sentimentos negativos } \\
\text { tais como mau humor, } \\
\text { desespero, ansiedade, } \\
\text { depressão? } \\
\text { (W26) }\end{array}$} & Nunca (1) & 5 & 8 & 4 & 9 & 13 & 17,1 \\
\hline & Algumas vezes (2) & 13 & 33 & 6 & 40 & 46 & 60,5 \\
\hline & Frequentemente (3) & 3 & 7 & 1 & 9 & 10 & 13,2 \\
\hline & Muito frequentemente (4) & 2 & 2 & 0 & 4 & 4 & 5,3 \\
\hline & Sempre (5) & 1 & 2 & 2 & 1 & 3 & 3,9 \\
\hline TOTAL & & & & & & 76 & 100,0 \\
\hline
\end{tabular}

*WHOQOL-Bref. Percentual de Insatisfação é igual a escore transformado 0-100 abaixo de 70. Percentual de Satisfação é igual a escore transformado 0-100 igual ou maior que 70 .

Na tabela 18 , cerca de $45 \%$ dos indivíduos indicaram a variável "bastante", quanto à opinião do sentido de suas vidas, $47,4 \%$ das pessoas disseram conseguir se concentrar bastante e, cerca de $55 \%$ das pessoas referiram estarem satisfeitas consigo mesmas. 


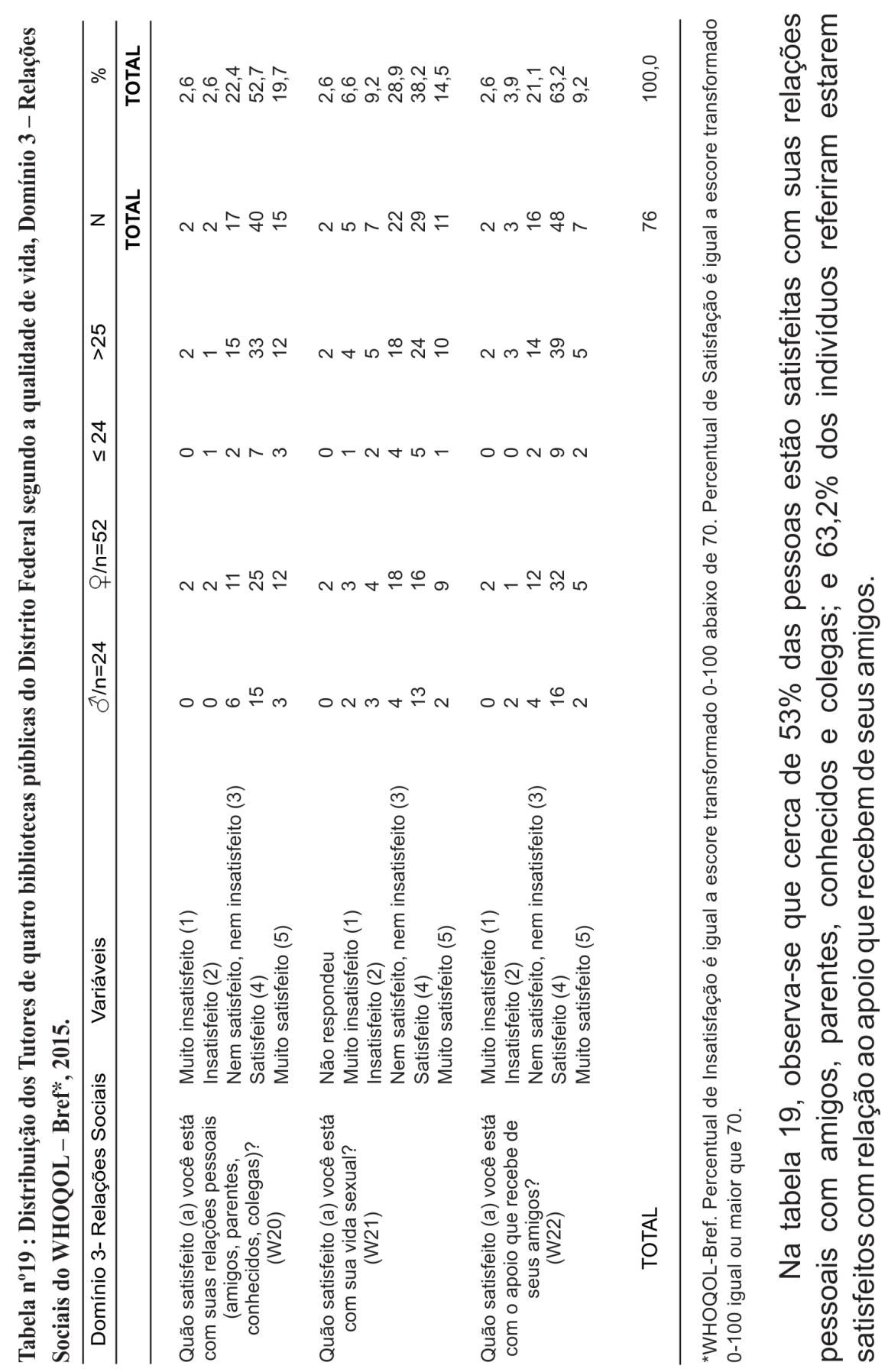


Tabela $\mathrm{n}^{0}$ 20: Distribuição dos Tutores de quatro bibliotecas públicas do Distrito Federal segundo a qualidade de vida, Domínio 4 - Meio Ambiente do WHOQOL - Bref*, 2015.

\begin{tabular}{|c|c|c|c|c|c|c|c|}
\hline \multirow[t]{2}{*}{ Domínio 4 - Meio Ambiente } & Variáveis & $\sigma^{\lambda} / n=24$ & ㅇ/n=52 & $\leq 24$ & $>25$ & $\mathrm{~N}$ & $\%$ \\
\hline & & & & & & TOTAL & TOTAL \\
\hline \multirow{5}{*}{$\begin{array}{l}\text { Quão seguro (a) você se } \\
\text { sente em sua vida diária? } \\
\text { (W8) }\end{array}$} & Nada (1) & 0 & 0 & 0 & 0 & 0 & 0,0 \\
\hline & Muito pouco (2) & 3 & 10 & 2 & 11 & 13 & 17,1 \\
\hline & Mais ou menos (3) & 12 & 15 & 5 & 22 & 27 & 35,5 \\
\hline & Bastante (4) & 9 & 22 & 5 & 26 & 31 & 40,8 \\
\hline & Extremamente (5) & 0 & 5 & 1 & 4 & 5 & 6,6 \\
\hline \multirow{5}{*}{$\begin{array}{c}\text { Quão saudável é o seu } \\
\text { ambiente físico (clima, } \\
\text { barulho, poluição, atrativos)? } \\
\text { (W9) }\end{array}$} & Nada (1) & 0 & 0 & 0 & 0 & 0 & 0,0 \\
\hline & Muito pouco (2) & 5 & 8 & 3 & 10 & 13 & 17,1 \\
\hline & Mais ou menos (3) & 11 & 25 & 5 & 31 & 36 & 47,4 \\
\hline & Bastante (4) & 7 & 18 & 5 & 20 & 25 & 32,9 \\
\hline & Extremamente (5) & 1 & 1 & 0 & 2 & 2 & 2,6 \\
\hline \multirow{5}{*}{$\begin{array}{c}\text { Você tem dinheiro suficiente } \\
\text { para satisfazer suas } \\
\text { necessidades? } \\
\text { (W12) }\end{array}$} & Nada (1) & 0 & 3 & 0 & 3 & 3 & 3,9 \\
\hline & Muito pouco (2) & 11 & 15 & 6 & 20 & 26 & 34,2 \\
\hline & Médio (3) & 7 & 24 & 6 & 25 & 31 & 40,8 \\
\hline & Muito (4) & 2 & 10 & 1 & 11 & 12 & 15,8 \\
\hline & Completamente (5) & 4 & 0 & 0 & 4 & 4 & 5,3 \\
\hline \multirow{5}{*}{$\begin{array}{l}\text { Quão disponiveis para você } \\
\text { estão as informações que } \\
\text { precisa no seu dia-a-dia? } \\
\text { (W13) }\end{array}$} & Nada (1) & 0 & 0 & 0 & 0 & 0 & 0,0 \\
\hline & Muito pouco (2) & 2 & 5 & 2 & 5 & 7 & 9,2 \\
\hline & Médio (3) & 10 & 22 & 4 & 28 & 32 & 42,1 \\
\hline & Muito (4) & 12 & 22 & 6 & 28 & 34 & 44,8 \\
\hline & Completamente (5) & 0 & 3 & 1 & 2 & 3 & 3,9 \\
\hline \multirow{5}{*}{$\begin{array}{c}\text { Em que medida você tem } \\
\text { oportunidades de atividades } \\
\text { de lazer? } \\
\text { (W14) }\end{array}$} & Nada (1) & 0 & 1 & 0 & 1 & 1 & 1,3 \\
\hline & Muito pouco (2) & 7 & 17 & 3 & 21 & 24 & 31,6 \\
\hline & Médio (3) & 11 & 20 & 6 & 25 & 31 & 40,8 \\
\hline & Muito (4) & 5 & 13 & 3 & 15 & 18 & 23,7 \\
\hline & Completamente (5) & 1 & 1 & 1 & 1 & 1 & 2,6 \\
\hline \multirow{5}{*}{$\begin{array}{c}\text { Quão satisfeito (a) você está } \\
\text { com as condições do local } \\
\text { onde mora? } \\
\text { (W23) }\end{array}$} & Muito insatisfeito (1) & 0 & 1 & 0 & 1 & 1 & 1,3 \\
\hline & Insatisfeito (2) & 3 & 5 & 0 & 8 & 8 & 10,5 \\
\hline & Nem satisfeito, nem insatisfeito (3) & 5 & 9 & 4 & 10 & 14 & 18,4 \\
\hline & Satisfeito (4) & 11 & 28 & 6 & 33 & 39 & 51,4 \\
\hline & Muito satisfeito (5) & 5 & 9 & 3 & 11 & 14 & 18,4 \\
\hline \multirow{5}{*}{$\begin{array}{c}\text { Quão satisfeito (a) você está } \\
\text { com seu acesso aos } \\
\text { serviços de saúde? } \\
\text { (W24) }\end{array}$} & Muito insatisfeito (1) & 6 & 8 & 5 & 9 & 14 & 18,4 \\
\hline & Insatisfeito (2) & 8 & 22 & 5 & 25 & 30 & 39,6 \\
\hline & Nem satisfeito, nem insatisfeito (3) & 8 & 7 & 1 & 14 & 15 & 19,7 \\
\hline & Satisfeito (4) & 2 & 13 & 2 & 13 & 15 & 19,7 \\
\hline & Muito satisfeito (5) & 0 & 2 & 0 & 2 & 2 & 2,6 \\
\hline \multirow{5}{*}{$\begin{array}{c}\text { Quão satisfeito (a) você está } \\
\text { com o seu meio de } \\
\text { transporte? } \\
\text { (W25) }\end{array}$} & Muito insatisfeito (1) & 2 & 8 & 2 & 8 & 10 & 13,2 \\
\hline & Insatisfeito (2) & 9 & 20 & 6 & 23 & 29 & 38,1 \\
\hline & Nem satisfeito, nem insatisfeito ( 3 ) & 4 & 4 & 1 & 7 & 8 & 10,5 \\
\hline & Satisfeito (4) & 6 & 13 & 2 & 17 & 19 & 25,0 \\
\hline & Muito satisfeito (5) & 3 & 7 & 2 & 8 & 10 & 13,2 \\
\hline TOTAL & & & & & & 76 & 100,0 \\
\hline
\end{tabular}

*WHOQOL-Bref. Percentual de Insatisfação é igual a escore transformado 0-100 abaixo de 70. Percentual de Satisfação é igual a escore transformado 0-100 igual ou maior que 70 .

Na tabela 20 , observa-se que cerca de $41 \%$ das pessoas indicaram a variável "médio" com relação a ter dinheiro suficiente para satisfação de suas necessidades; $41 \%$ dos indivíduos referiram a variável "médio" quanto às oportunidades de lazer. Quanto à satisfação das condições do local de moradia, 51,4\% das pessoas disseram estarem satisfeitas e, cerca de $40 \%$ dos indivíduos referiram insatisfação quanto ao acesso aos serviços de saúde. 


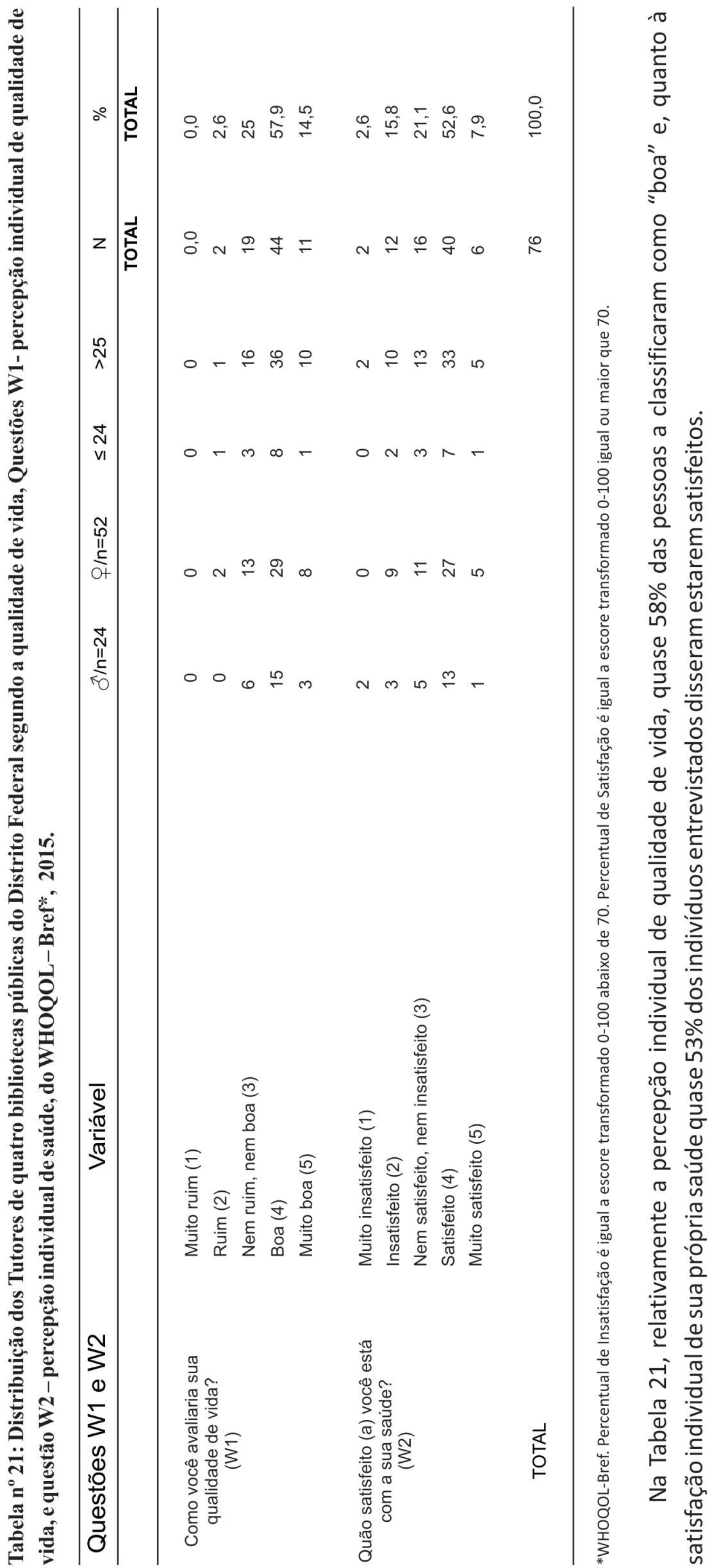




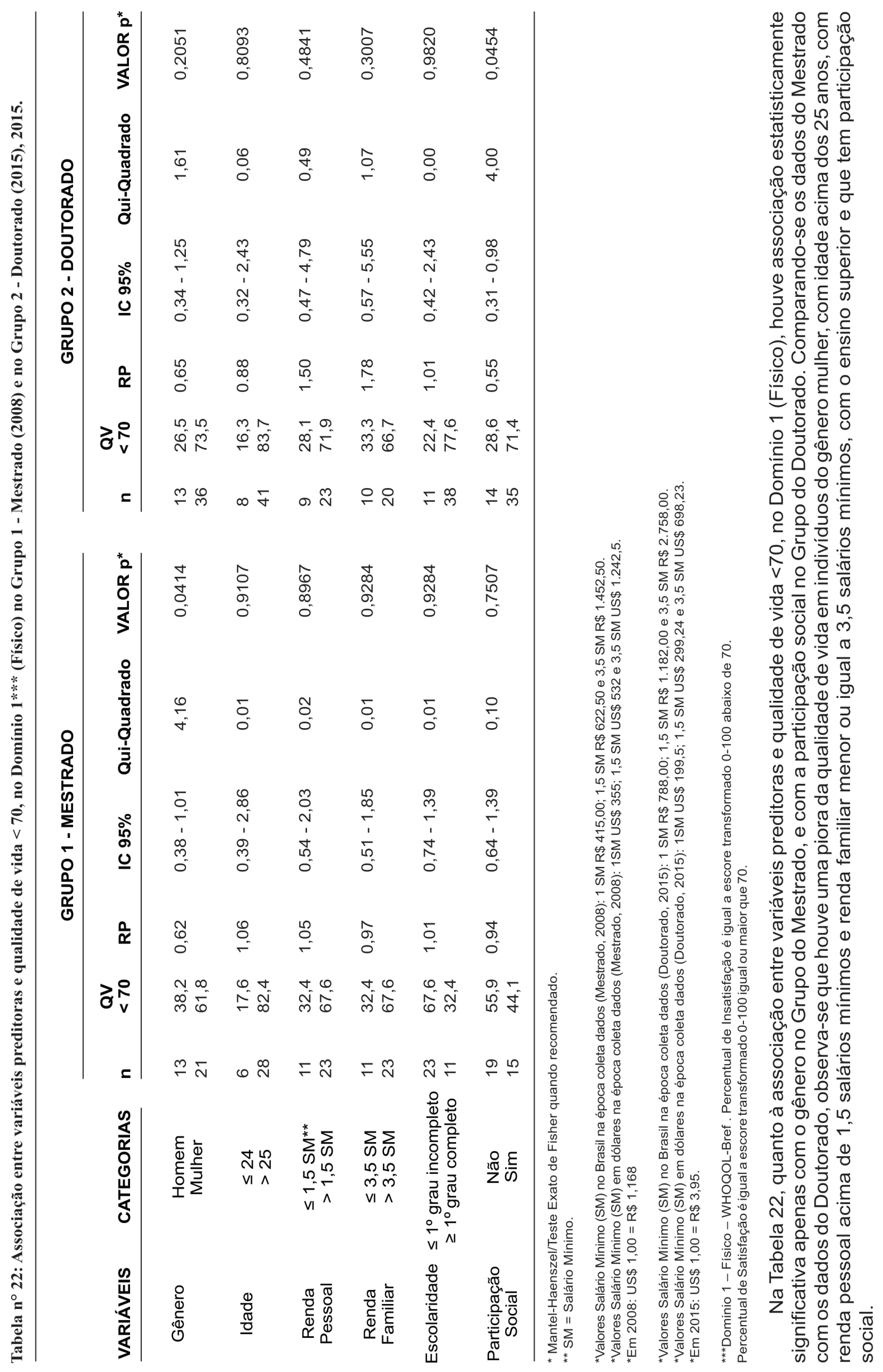




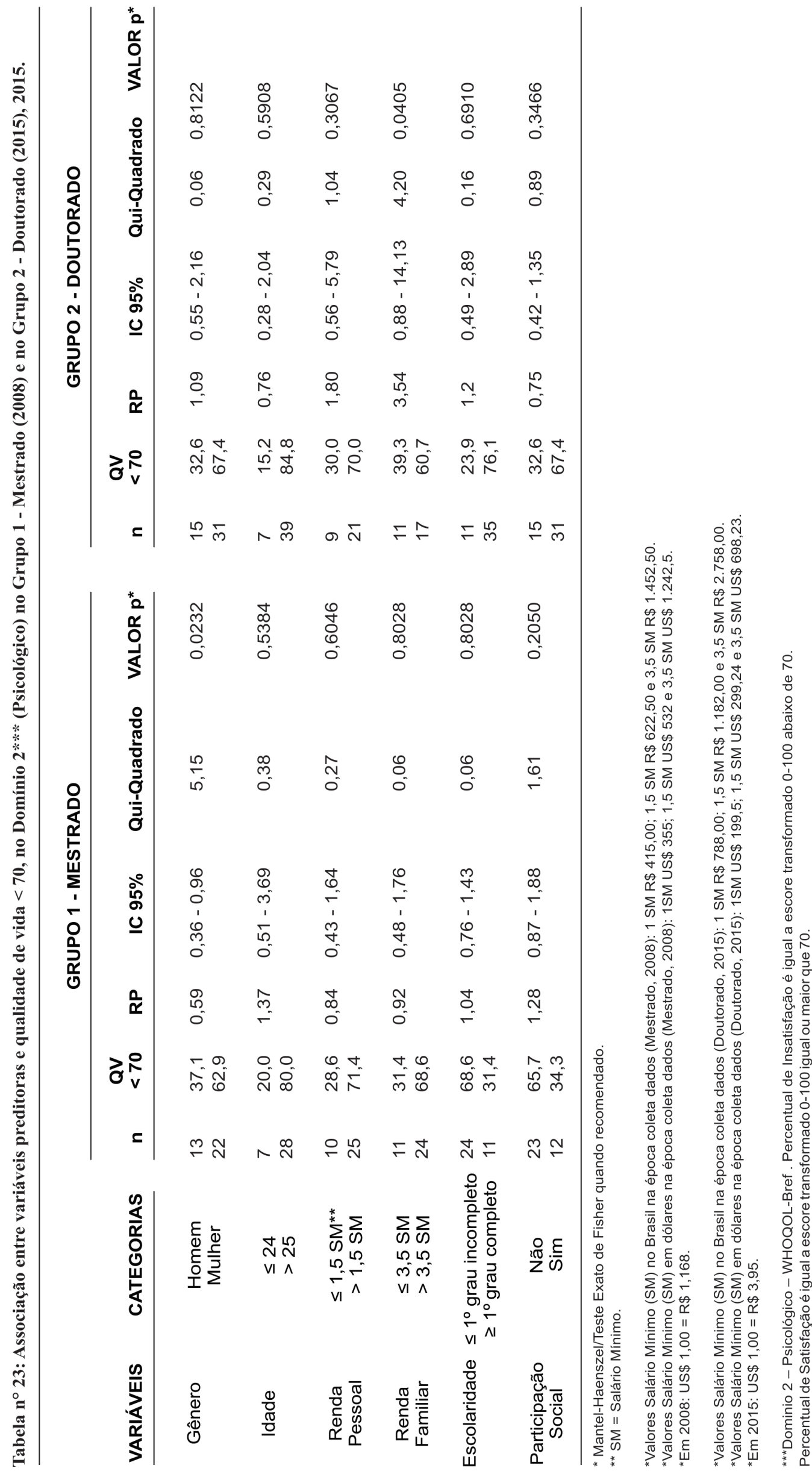

융응 워

.ते है कै

元

की

(1) 0 \%

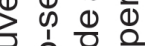

융 중 क

ลิ $\frac{\pi}{0} \frac{0}{0}$

등 ब

OU

क्र $\frac{0}{0}$ ह

\% 융

○

뭉

응응 응

○응은

은 군 $\frac{0}{2} \frac{\pi}{\pi}$

$\circ$ 을

$\checkmark$ 흔 $\frac{\varepsilon}{0}$

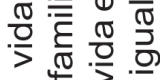

융 중 융

응 인 응

它

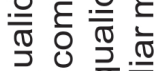

б० 0

(1) $0 \frac{\pi}{0} \pi$

윤

궁

ฮ $\sum_{0}^{0}$

흐응 잉

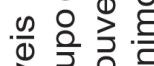

雨

类

$>$ 중.은

인

단

ब

원요

․ㅠ है ह

¿

की $\frac{\pi}{0} \frac{\pi}{0}$

- $\pi \frac{2}{\pi}$

욜ำ बै

듀 융 응

은 क

ஸ

N $\frac{0}{\infty} \frac{\pi}{0} \square$

뜽 용 웅

๙

$\vdash \frac{\pi}{0} 0$

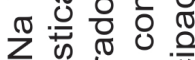
要 बू山 


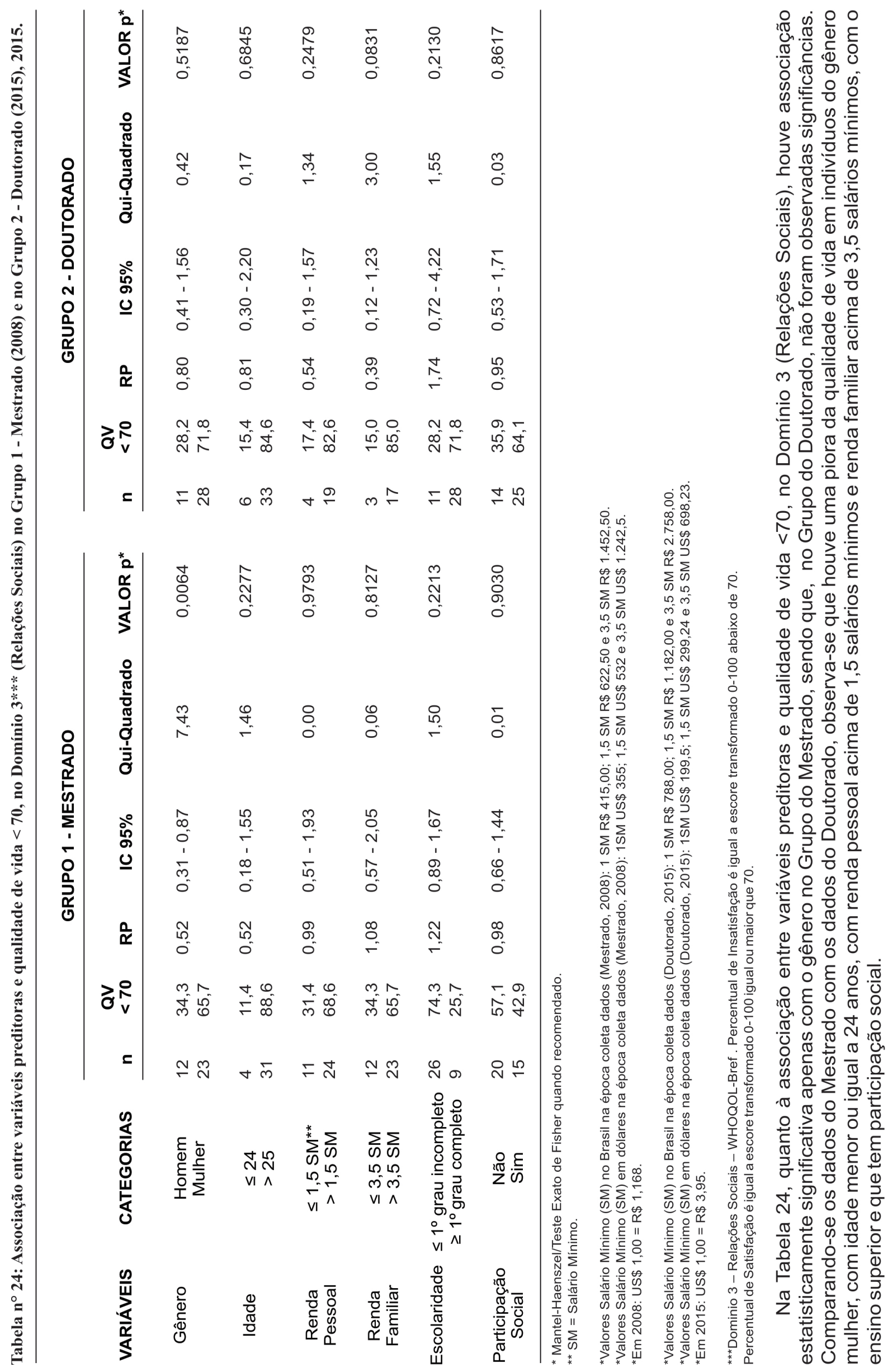




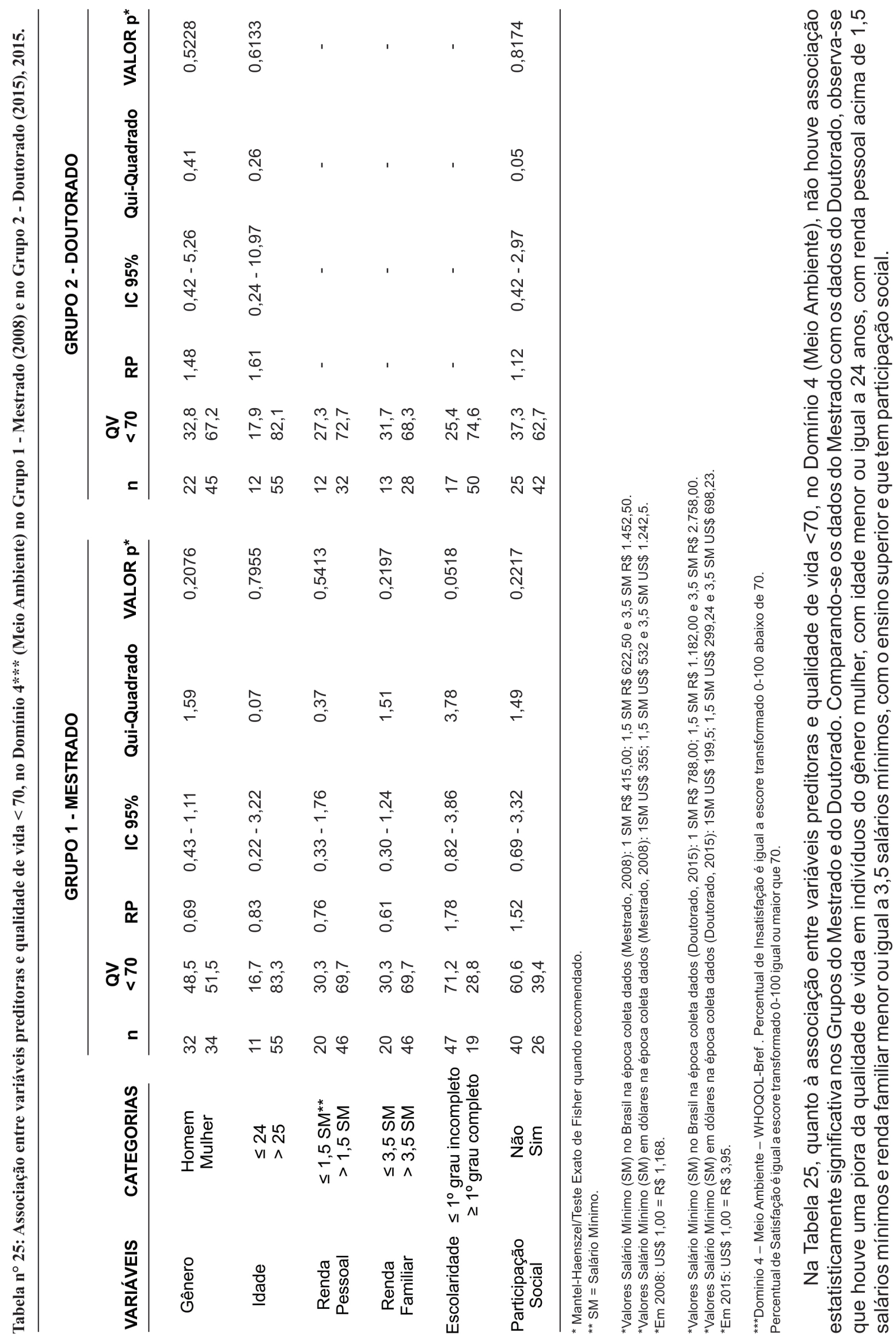




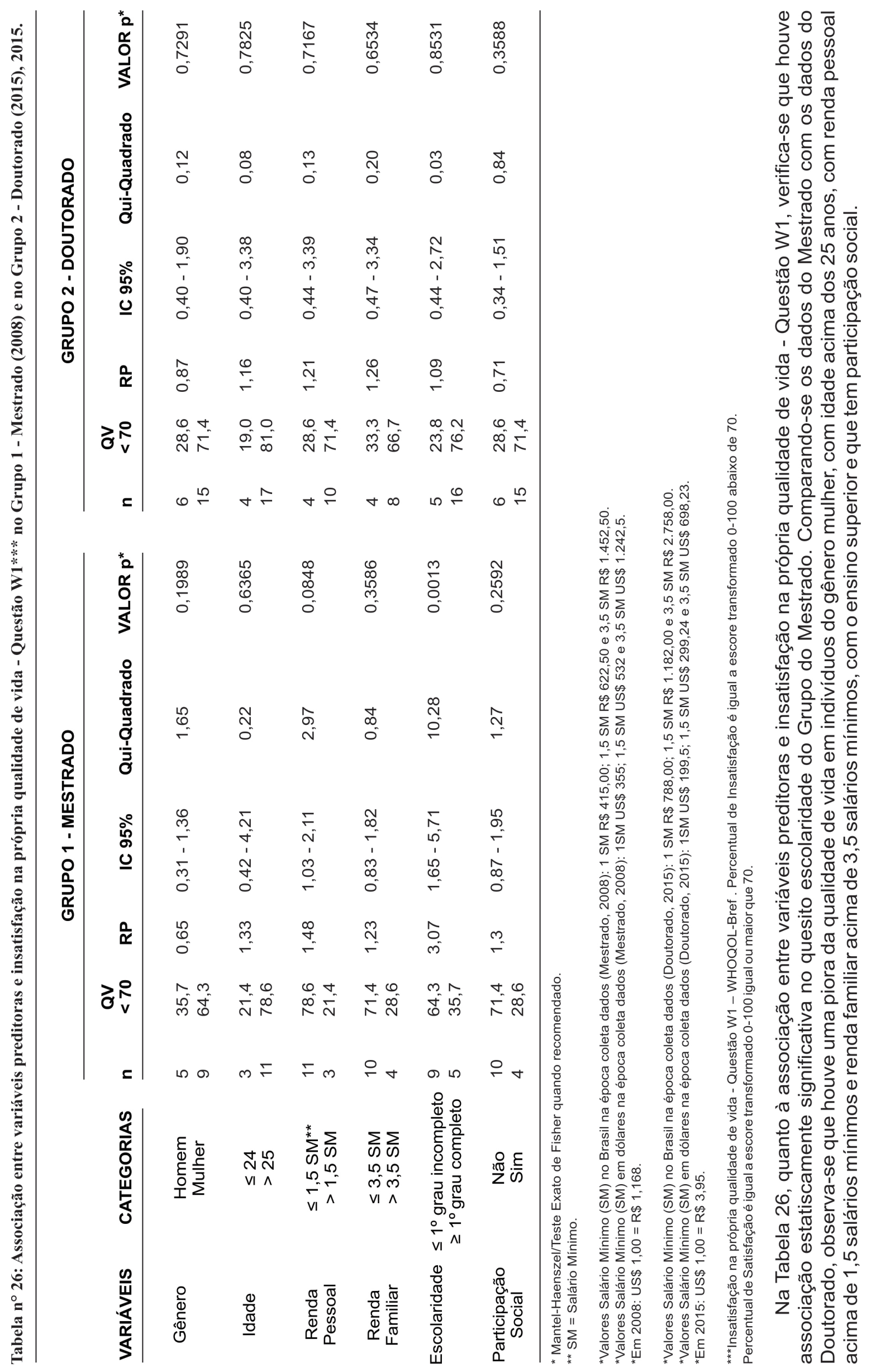




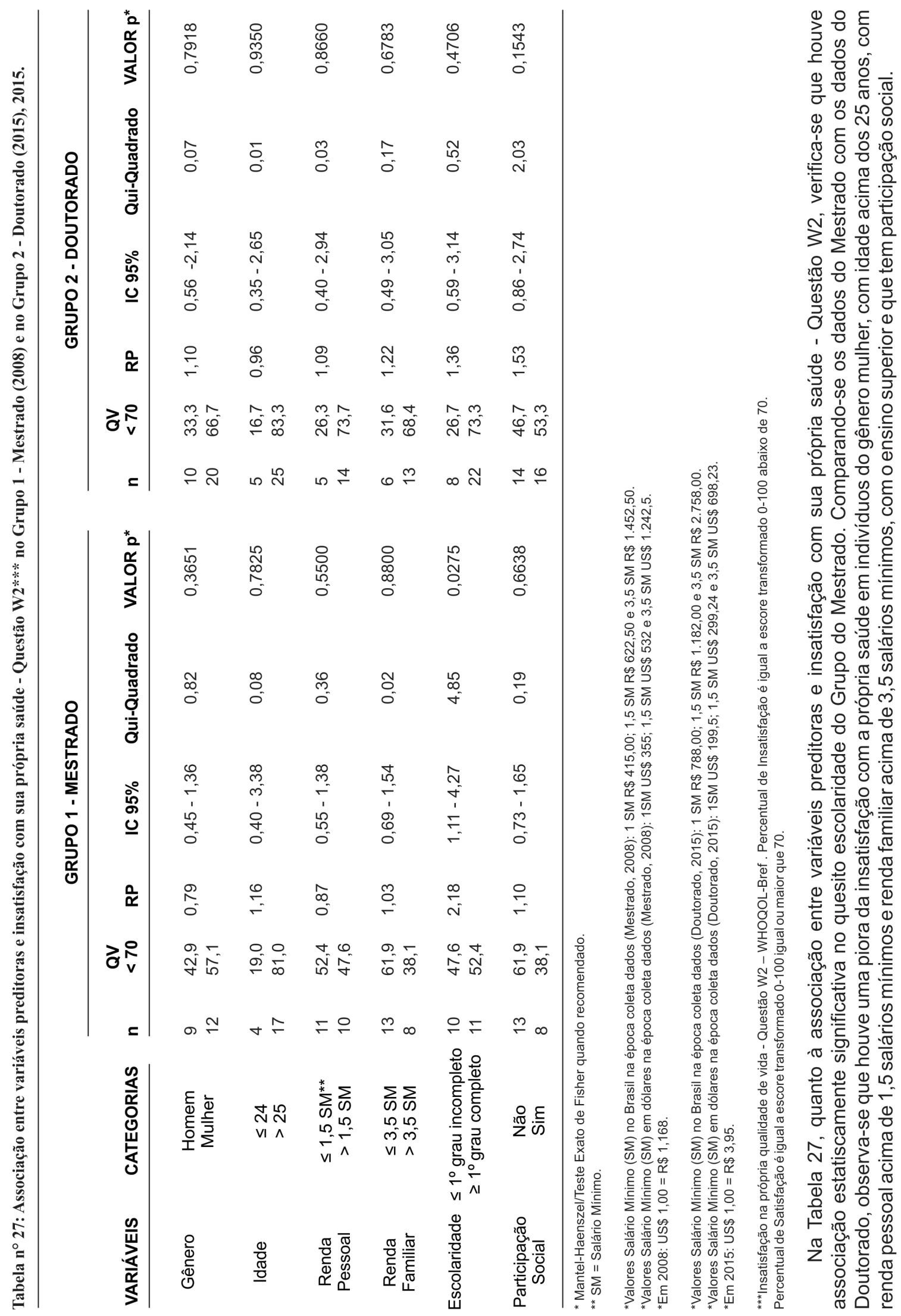


Tabela n 28: Caracterização do acervo, atendimento e serviços de quatro Bibliotecas do Distrito Federal pelos Tutores, 2015.

\begin{tabular}{|c|c|c|c|c|}
\hline QUESTÕES & $\operatorname{Sim}_{n}$ & $\%$ & Não & $\%$ \\
\hline
\end{tabular}

1. Obtenção de informações, livros e outros materiais:

$\begin{array}{llll}48 & 63,2 & 28 & 36,8 \\ 30 & 39,5 & 46 & 60,5 \\ 69 & 90,8 & 7 & 9,2 \\ 61 & 80,3 & 15 & 19,7 \\ 45 & 59,2 & 31 & 40,8 \\ 46 & 60,5 & 30 & 39,5 \\ 48 & 63,2 & 28 & 36,8 \\ 52 & 68,4 & 24 & 31,6 \\ 65 & 85,5 & 11 & 14,5 \\ 44 & 57,9 & 32 & 42,1 \\ 19 & 25,0 & 57 & 75,0 \\ 11 & 14,5 & 65 & 85,5 \\ 26 & 34,2 & 50 & 65,8 \\ 12 & 15,8 & 64 & 84,2\end{array}$

14. O usuário questionado participa da Sociedade de Amigos da Biblioteca ?

Obs.: O número total de Tutores foi de 76 indivíduos.

Na tabela 28, a maioria dos indivíduos do Grupo de Tutores fez observações muito positivas com relação aos acervos e aos serviços oferecidos pelas bibliotecas públicas envolvidas no estudo, porém, um grande número de pessoas referiu muitas carências relativas ao acesso à internet, bem como serviços das bibliotecas que poderiam ser oferecidos online. 


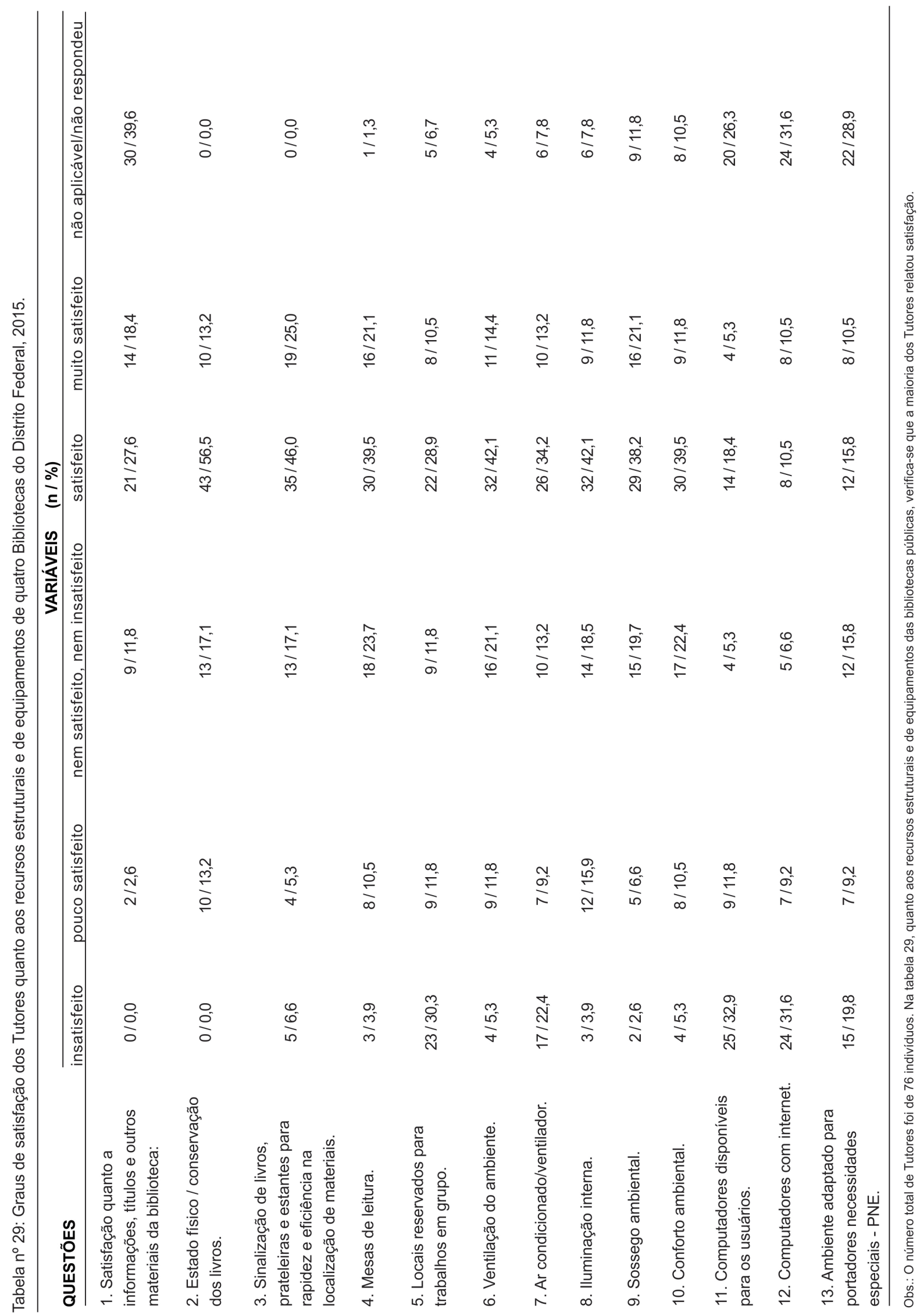




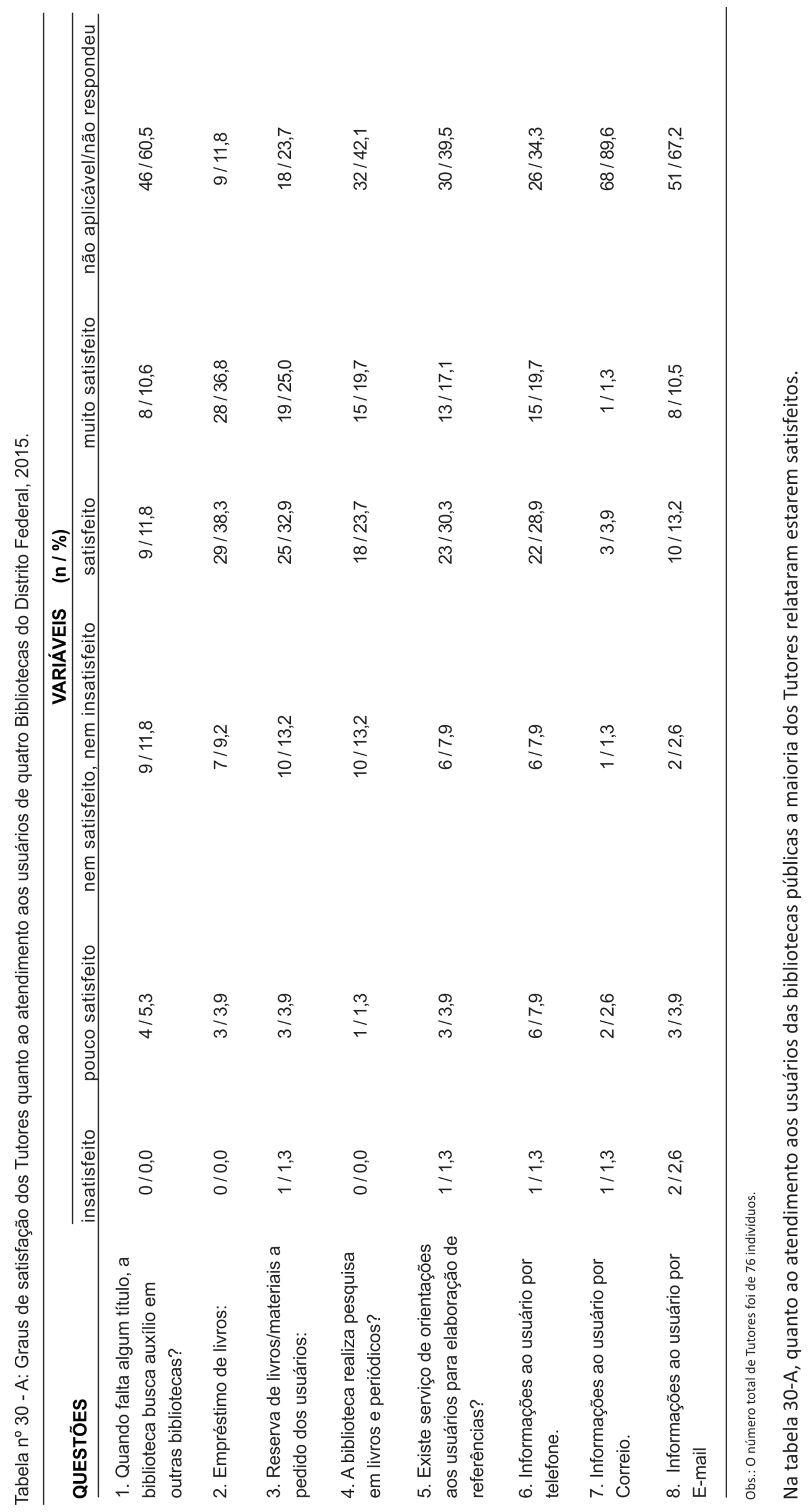




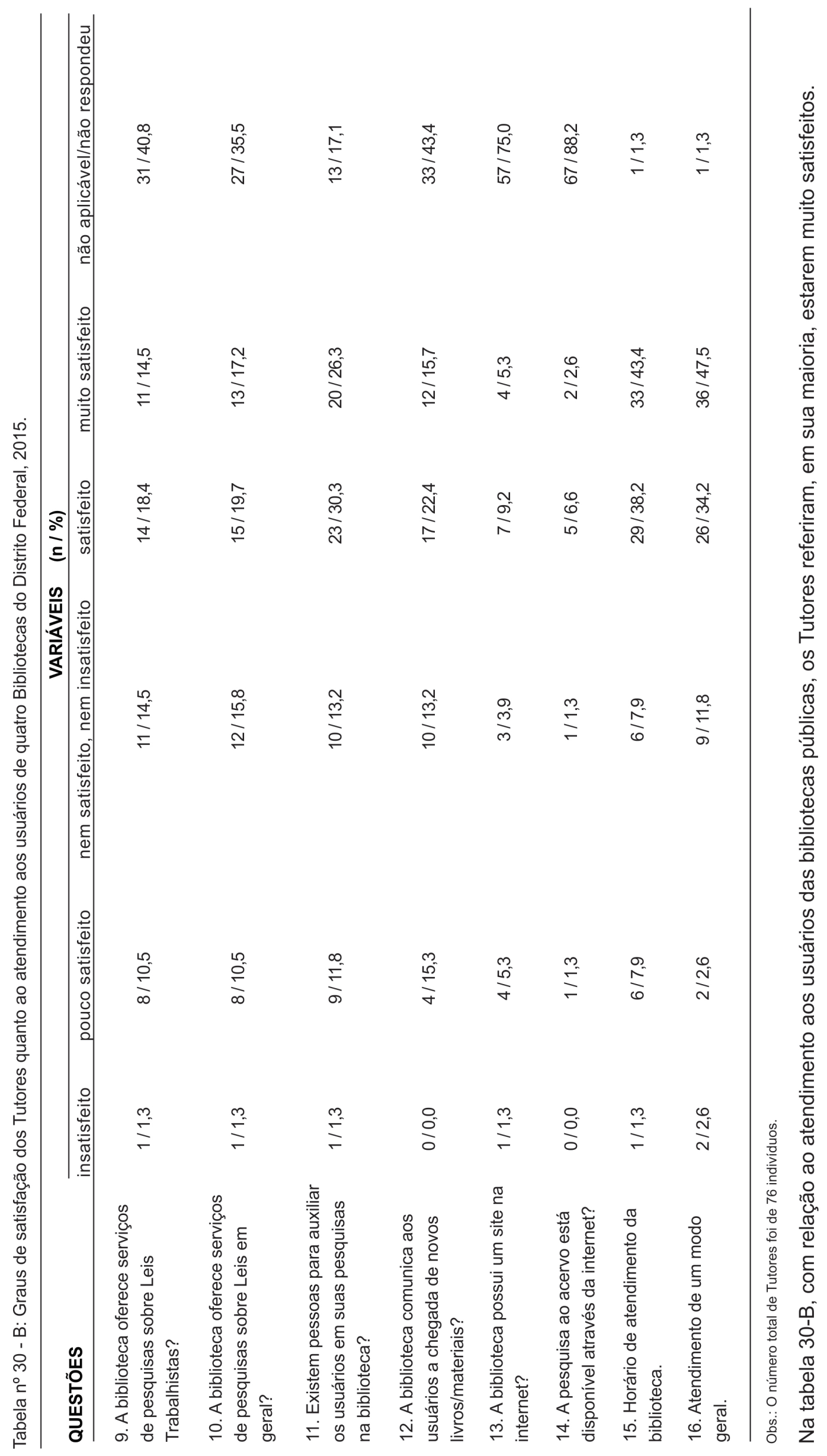




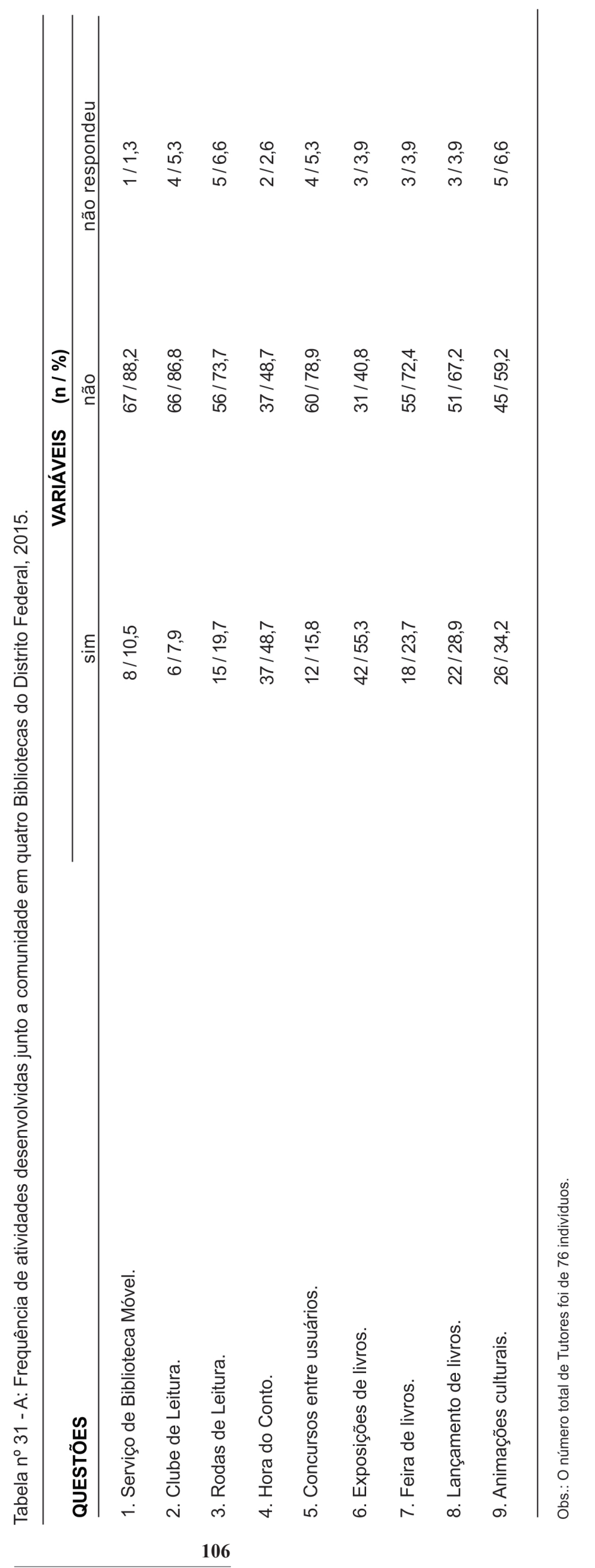




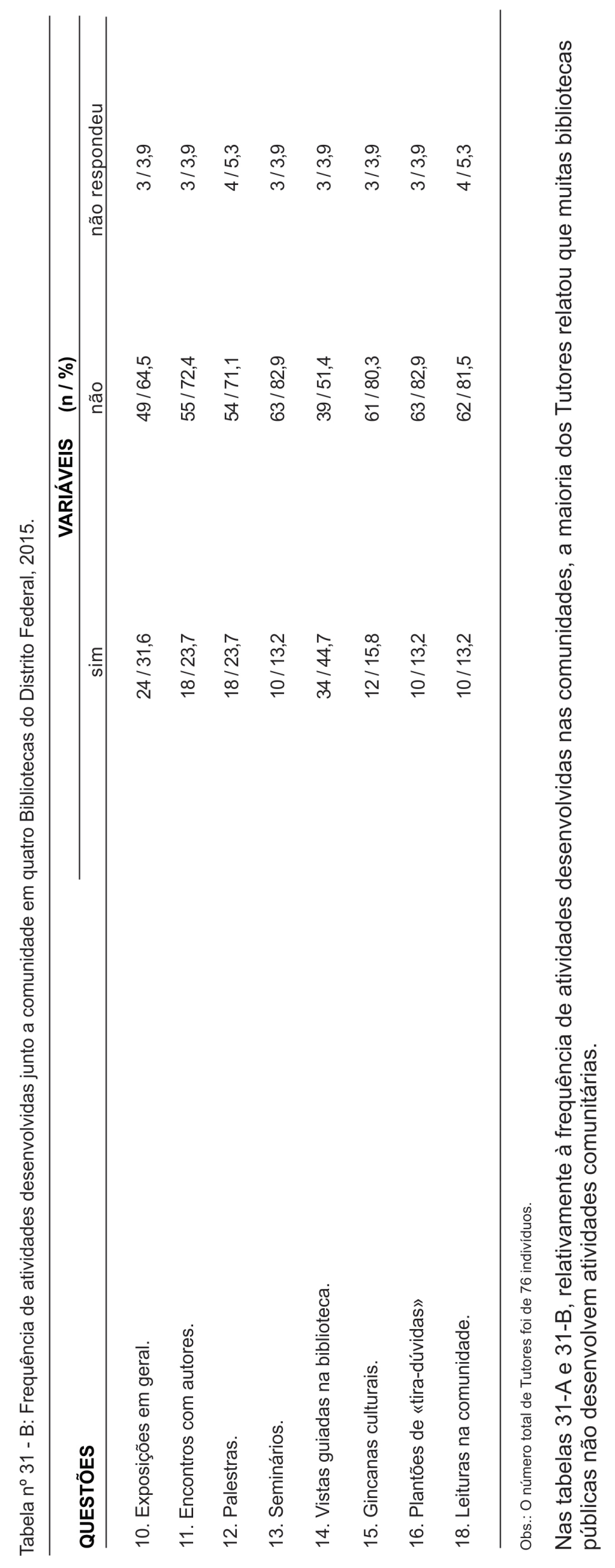




\section{DISCUSSÃO}

A saúde, a qualidade de vida e grau de satisfação dos indivíduos em vários âmbitos, são elementos essenciais em uma sociedade, tendo como foco central a promoção da saúde. A prevenção das doenças não contempla a dimensão histórica e social, de políticas públicas saudáveis e intersetoriais, nem propicia o empoderamento das comunidades e a valorização de seus potenciais, bem como a melhoria de suas condições de vida e de trabalho. A promoção da saúde está mais vinculada a uma visão holística e socioambiental, atingindo limites extramuros das instituições de saúde tradicionais.

Verifica-se que o conceito de saúde é, em verdade, dinâmico, pois necessita ser visto de forma contextualizada, onde as pessoas sejam vistas na integralidade de suas histórias de vida, de sua autonomia, de sua cultura e de seus conhecimentos empíricos.

Segundo Muñoz e Salinas (54), não existe apenas uma teoria que subsidie as necessidades das pessoas e a qualidade de vida. Os autores fazem referência aos nove tipos universais de necessidades elencados por Manfred Max-Neef, quais sejam: subsistência, proteção, afeto, entendimento, participação, ócio, criação, identidade e liberdade. Essas necessidades são consideradas universais, independentemente do tipo de cultura ou de contexto populacional. Os autores colocam ainda que essas necessidades não modificam com o tempo, mas sim, os meios utilizados para satisfazê-las.

A educação em saúde é uma ferramenta importante para se promover a saúde, no entanto, é importante interagir com o saber popular, que fomenta o processo educativo de uma comunidade. Constatou-se, com a realização deste trabalho, que a educação em saúde pode ser feita na comunidade em vários locais, dentre os quais, as bibliotecas públicas, que são espaços privilegiados, caracterizando-se estas como núcleos comunitários de aprendizado, intervenção e promoção da saúde. Aliado a isso, a epidemiologia através de suas bases teóricas e metodológicas, somada a princípios éticos e morais, direciona esforços para entender e contribuir na redução das desigualdades na saúde e melhoria da qualidade de vida dos indivíduos. A epidemiologia também é fundamental para subsidiar as políticas públicas efetivamente saudáveis, demonstrando os melhores caminhos e alternativas para a efetividade da promoção da saúde. A aferição da qualidade de vida é uma ferramenta de extrema importância, pois sinaliza pontos que necessitam ser trabalhados para se alcançar efetividade nas políticas de saúde e, consequentemente, subsidiar estratégias para se alcançar patamares mais elevados de saúde nas populações.

Com relação à aplicação do Curso de Dinamização e Uso da Bibliotecas pública, a participação dos alunos auxiliou sobremaneira na capacitação dos indivíduos que trabalham nas bibliotecas estudadas. Na biblioteca de Taguatinga, que já realizava projetos extramuros, houveram desdobramentos inesperados da presente pesquisa, no caso, o Projeto Metamorfose.

Apesar de ter havido um certo receio por parte da aluna, antes do primeiro contato com os jovens pequenos infratores, com o decorrer das atividades de saúde que foram desenvolvidas com eles, tais como oficina de cuidados com os dentes e higiene geral, as quais foram realizadas de uma forma muito tranquila, houve uma mudança na 
forma de a aluna enxergá-los. Os meninos são extremamente carentes de atenção. A grande maioria verbalizou interesse em aprender uma profissão, como mecânico, marceneiro, técnico em informática, etc. Eles também pediram para serem feitas atividades de gastronomia. As tardes com os adolescentes foram muito agradáveis.

A maior lição dessa atividade é que se nós, privilegiados sociais, não fizermos nada por esses menores, certamente uma bala de um revólver que porventura um deles esteja usando, poderá atingir à nós ou a algum ente muito querido de nossa família. Portanto, não podemos assistir ao aumento da violência de braços cruzados. Precisamos dedicar um pouco de nossas vidas a esses seres humanos, na grande maioria com histórias de vida terríveis. Assim, estaremos também protegendo o bem estar e a saúde e segurança de todos e contribuindo para diminuir a violência na sociedade.

Outros desdobramentos do curso ministrado nas bibliotecas e desta pesquisa, como a inauguração da biblioteca da Estrutural e a reinauguração da biblioteca de Águas Claras foram propulsores para muitas melhorias das comunidades adjacentes às mesmas. No caso da biblioteca de Vicente Pires, com o adolescente que trabalhava com leitura e teatro para crianças, este foi considerado uma "célula" dessa biblioteca. Também em Vicente Pires, o projeto de intercâmbio dos alunos, sendo que a biblioteca tinha tão pouco tempo de funcionamento, significou muito para a comunidade, ampliando horizontes e indo além de fronteiras. A "Mamãe Noel e suas Fábulas Natalinas" no ônibus circular de Vicente Pires significou a biblioteca indo até a população. Em todas as visitas realizadas nessas bibliotecas inauguradas há pouco tempo, verificou-se que o empenho de seus administradores foi fundamental para "fazê-las nascer com maturidade", ou seja, além dos usuários que as frequentam diariamente, seja para ler, ou para estudar, os seus projetos extramuros demonstraram que seus dirigentes têm a perfeita noção do papel da biblioteca pública nas comunidades e para a sociedade.

A instalação das Estantes da Saúde foi de extrema importância em todas as bibliotecas, porque possibilitou uma aproximação mais estreita das informações em saúde para os usuários. O fato de o Ministério da Saúde não enviar folhetos educativos para as bibliotecas públicas é uma grande lacuna para a Atenção Primária em Saúde, pois são desperdiçadas oportunidades ímpares de se atingir uma proporção extremamente significativa da população, sem considerar-se o fato de que pessoas que frequentam bibliotecas públicas são multiplicadores de informações na comunidade.

Segundo Mendes (55), a ampliação do Programa de Saúde da Família (PSF) não teve efetividade devido ao fato de permanecerem problemas estruturais, apesar de alguns bons resultados que foram obtidos. Dessa forma, o PSF foi exitoso dentro de limites pré-estabelecidos que foram elencados para que se desenvolvesse.

O autor coloca que, a principal razão para não ter havido grande êxito no PSF, pelo motivo de o Sistema Único de Saúde - SUS, estar estruturado em um modelo de gestão de oferta, ao invés de estar focado nas necessidades da população usuária, onde existe uma ampla demanda, porém uma estrutura de oferta restrita, não capaz de atender às reais necessidades, contextualizadas, dos usuários dos serviços de saúde (56). 
O modelo de oferta do SUS é construído com base em séries históricas que refletem a organização política de sua capacidade instalada, contrapondo-se às reais necessidades dos usuários (56).

Mendes (55) refere que existe uma incoerência entre a situação de saúde da população e o sistema de atenção à saúde vigente e propõe a implantação das Redes de Atenção à Saúde para a resolução desse contexto.

\title{
As Redes de Atenção à Saúde - RAS
}

\begin{abstract}
"As RAS são organizações poliárquicas de conjuntos de serviços de saúde, vinculados entre si por uma missão única, por objetivos comuns e por uma ação cooperativa e interdependente, que permitem ofertar uma atenção contínua e integral a determinada população, coordenada pela Atenção Primária em Saúde - APS -, prestada no tempo certo, no lugar certo, com o custo certo, com a qualidade certa, de forma humanizada e segura e com equidade -, com responsabilidades sanitária e econômica pela população adstrita e gerando valor para essa população (55)"
\end{abstract}

No modelo de RAS observa-se que não existe hierarquia entre os serviços de saúde, sendo suas diferenças apenas na oferta de tecnologias, ou seja, ocorre uma perfeita interlocução entre os níveis primário, secundário e terciário, onde o principal ponto é a resolutividade de uma condição de saúde através da integralidade do cuidado, pelo percurso do ciclo completo de atenção à saúde. Mendes (55) também refere que "o centro de comunicação da RAS situa-se na Atenção Primária em Saúde - APS".

Dentro da proposta de RAS, verifica-se que, para que estas existam, ser necessário considerar-se três elementos: a população, cujas características devem ser obtidas através da articulação da Atenção Primária em Saúde; a estrutura operacional da RAS, onde (55):

"A estrutura operacional da RAS compõe-se de cinco componentes: o centro de comunicação, a APS; os pontos de atenção à saúde secundários e terciários; os sistemas de apoio (sistemas de apoio diagnóstico e terapêutico, sistemas de assistência farmacêutica, sistemas de teleassistência e sistemas de informação em saúde); os sistemas logísticos (registro eletrônico em saúde, sistemas de acesso regulado à atenção e sistemas de transporte em saúde); e o sistema de governança da RAS. Os três primeiros correspondem aos nós das redes e, o quarto, às ligações que comunicam os diferentes nós, como pode ser observado na Figura 5, adiante." 
Figura 5. Estrutura Operacional da RAS

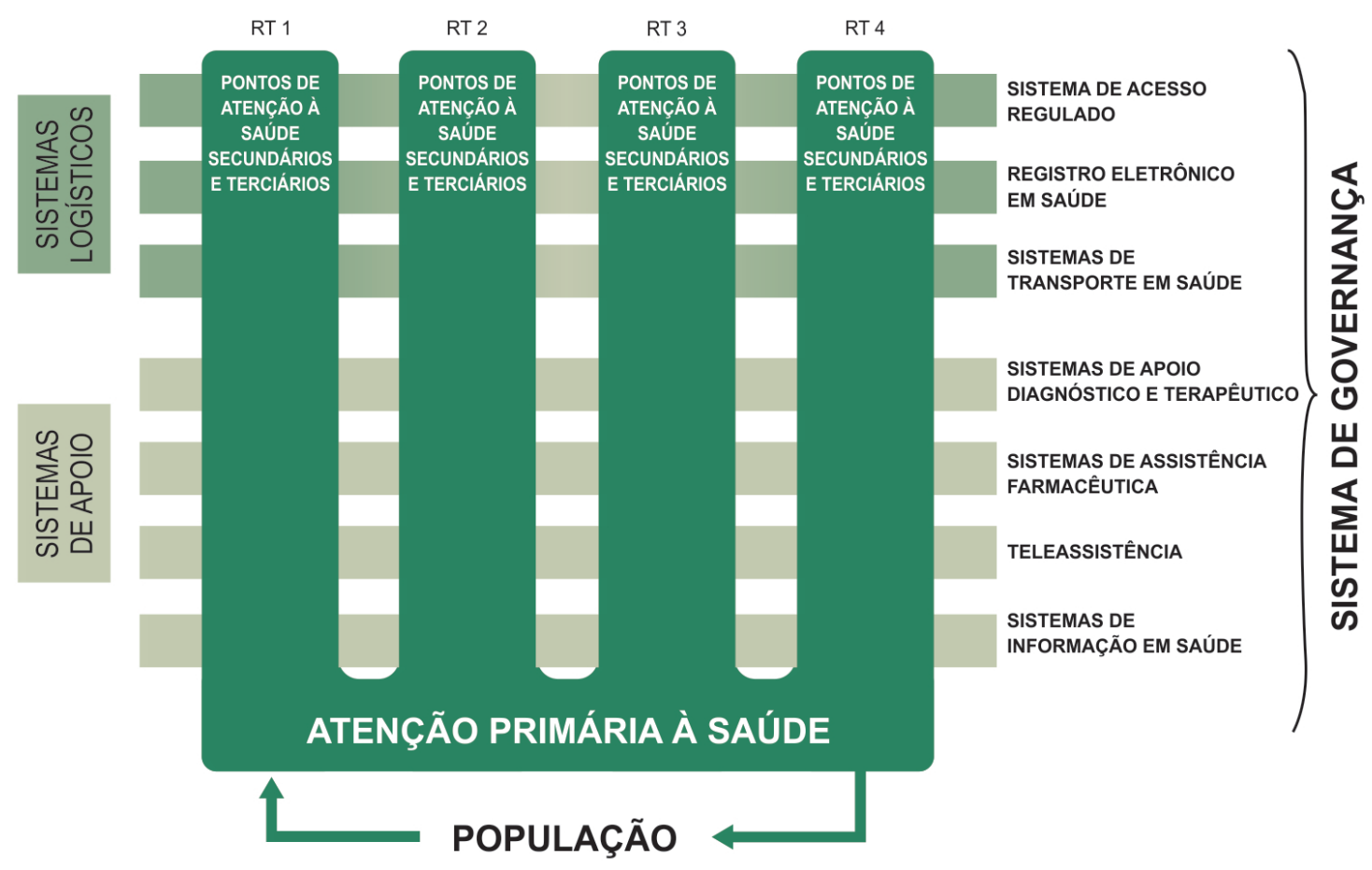

Fonte: Mendes (2011)

No caso específico desta Tese, as bibliotecas públicas inserem-se nos "Sistemas de Informações em Saúde", caracterizando-se como um novo espaço de disseminação de informações para a promoção da saúde.

Ainda considerando-se a estrutura das RAS, verifica-se que o terceiro elemento são os modelos de atenção à saúde, que organizam o funcionamento das RAS de acordo com a interlocução dos componentes da rede e as ações sanitárias, em face da prevalência, demografia, epidemiologia e características sociais da saúde, em certo tempo e estrutura social (55). Esses modelos de atenção à saúde poderão ser relativos aos eventos agudos, condições agudas e às condições crônicas.

Segundo a Organização Mundial de Saúde (56), um grande problema atual dos Sistemas de Atenção à Saúde é o fato de estes responderem à condições crônicas não agudizadas através de modelos de atendimento a eventos agudos, gerando resultados sanitários e econômicos ruins. Como consequência, esse modelo não é capaz de manter a estabilidade nas condições crônicas, nem mesmo de conter a evolução dessa condições, ocorrendo recorrentes agudizações.

Ademais, verifica-se, em larga escala, em vários serviços de saúde no país, em especial nas emergências e pronto-socorros, que existe uma demanda muito significativa de usuários que procuram esses serviços, mas que no entanto, recebem uma Classificação de Risco azul ou verde, condição que teria resolução na própria Atenção Primária, ou na Atenção Primária Especializada.

O sistema de Classificação de Risco possui muitas vertentes, porém, usualmente 
é utilizado o Protocolo de Manchester (57), caracterizado conforme segue:

Quadro 4. Classificação de Risco pelo Sistema de Manchester

\begin{tabular}{|c|c|c|c|}
\hline Número & Nome & Cor & Tempo Alvo \\
\hline 1 & Emergente & Vermelho & 0 \\
\hline 2 & Muito urgente & Laranja & 10 \\
\hline 3 & Urgente & Amarelo & 60 \\
\hline 4 & Pouco urgente & Verde & 120 \\
\hline 5 & Não urgente & Azul & 240 \\
\hline
\end{tabular}

Sendo assim, o fortalecimento das Redes de Atenção à Saúde, a partir da Atenção Primária em Saúde, seria uma das ferramentas para aumentar a resolutividade ou eficiência, eficácia e efetividade dos serviços de saúde para as necessidades das populações, sempre de maneira contextualizada.

Mendes (55) analisou vários estudos e verificou que dentre os problemas mais frequentes na APS, existe a necessidade de priorizar, nos cuidados primários, atividades de promoção da saúde e prevenção de doenças, bem como à enfermidades como hipertensão arterial sistêmica, diabetes melito, alterações metabólicas lipídicas, atenção às gestantes e às crianças, processos depressivos, infecções de vias aéreas superiores, hipotireoidismo, obesidade e afecções na região lombar, caracterizando-se a maior demanda por problemas crônicos.

O autor (55) pesquisou em outras fontes e também constatou que, tanto no Brasil como em outros países, dentre os motivos de consultas a médicos de família, destacam-se a avaliação médica e também motivos de prevenção de doenças. $O$ mesmo autor destaca que "a solução está em delegar as ações preventivas a outros profissionais não médicos”.

Verifica-se, desta forma, a grande importância de estimular a formação e permanência de Grupos de Amigos da Saúde no contexto das bibliotecas públicas, ocasião em que temas relativos à prevenção de doenças e à promoção da saúde podem ser amplamente contemplados, fazendo com que as bibliotecas se estabeleçam também como ferramentas no contexto das Redes de Atenção à Saúde, dentro de sistemas de informação em saúde.

Dentro do processo de construção social da APS, as bases operacionais estão pautadas nos modelos de Donabedian e da Gestão por Processos (55). O modelo de Donabedian propicia a mensuração de níveis de saúde e a satisfação de cuidados recebidos pelos usuários, além de resultados de avaliações econômicas. Dentro do modelo de Gestão de Processos, não existem barreiras, ou seja, é possível a visualização da organização como um todo, assim como uma interlocução entre os diferentes agentes.

\section{A estratégia educacional do processo e construção social da APS}

O processo de mudanças na PS implica adensá-la tecnologicamente para capacitá-la a responder socialmente, de forma efetiva, aos diferentes perfis de demandas por cuidados primários. nesse sentido, envolve um conjunto de ações que se dão em dois componentes do Modelo de Donabedian: a estrutura e os processos. 
As mudanças na estrutura envolvem uma nova concepção de estrutura física, a ampliação da equipe de saúde e a adequação dos recursos materiais e financeiros.

As mudanças nos processos envolvem a organização oferta por meio de: os macro e microprocessos básicos; os macroprocessos de atenção aos eventos agudos; os macroprocessos de atenção às condições crônicas não agudizadas; às pessoas hiperutilizadoras e às enfermidades; os macroprocessos da atenção preventiva; os macroprocessos das demandas administrativas; os macroprocessos da atenção domiciliar; e os macroprocessos do autocuidado apoiado.

A implantação dessas mudanças requer a utilização de estratégia educacional através de oficinas tutoriais, cursos e auditoria de produtos. As oficinas tutoriais alternam momentos presenciais e de dispersão, estes com tarefas bem definidas a serem executadas (55).

Os resultados desta Tese trouxeram importantes constatações quanto à aplicabilidade e efetividade de estratégias de educação em saúde entre usuários das bibliotecas públicas escolhidas para a aplicação da pesquisa.

Para uma melhor compreensão e visão sistematizada do trabalho executado, foi elaborado um quadro de Sistematização da Realização da Pesquisa, cujo objetivo principal foi propiciar um check-list dos objetivos propostos, as estratégias utilizadas para o cumprimento dos mesmos e, os seus respectivos resultados, conforme segue: 


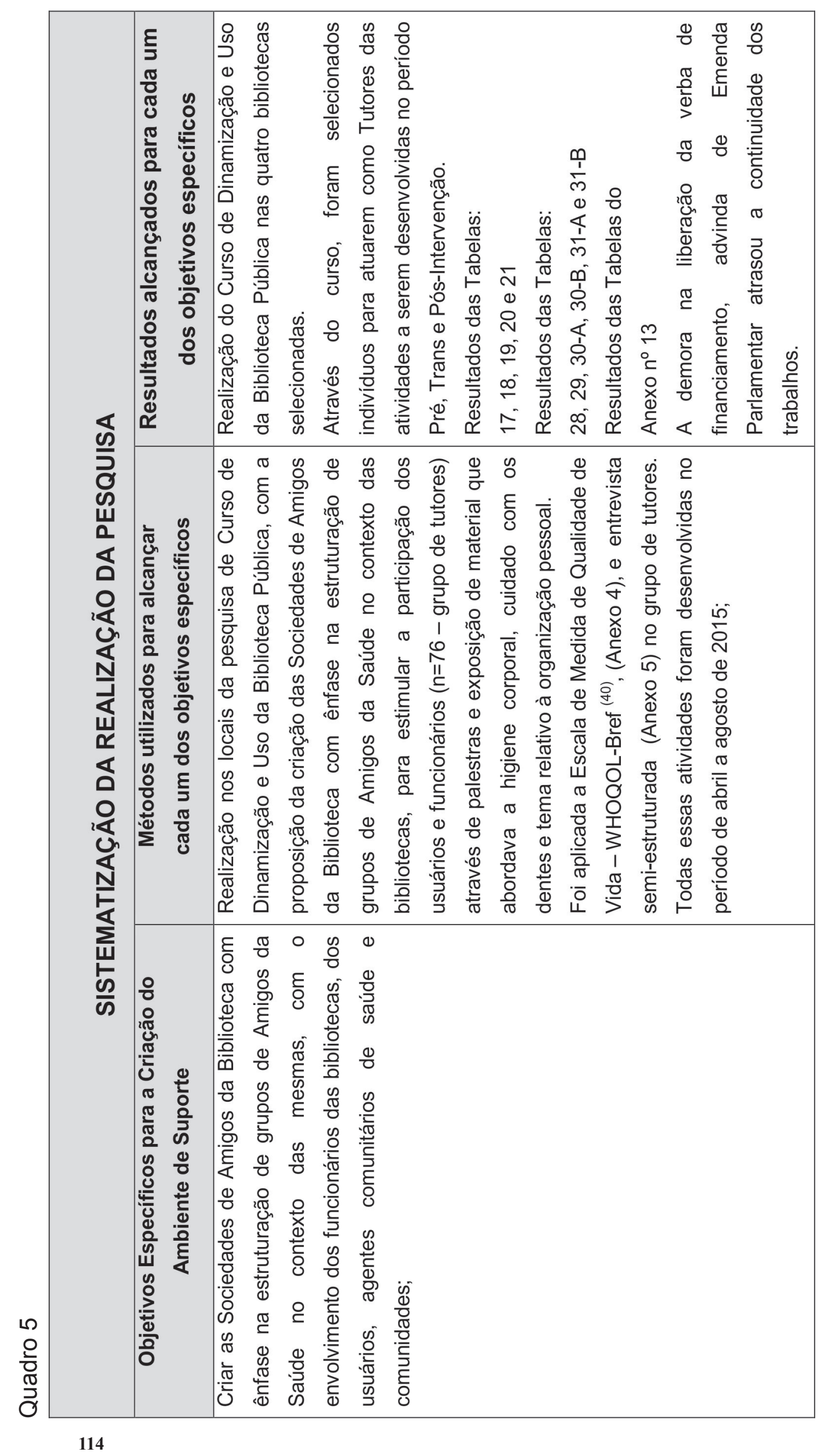




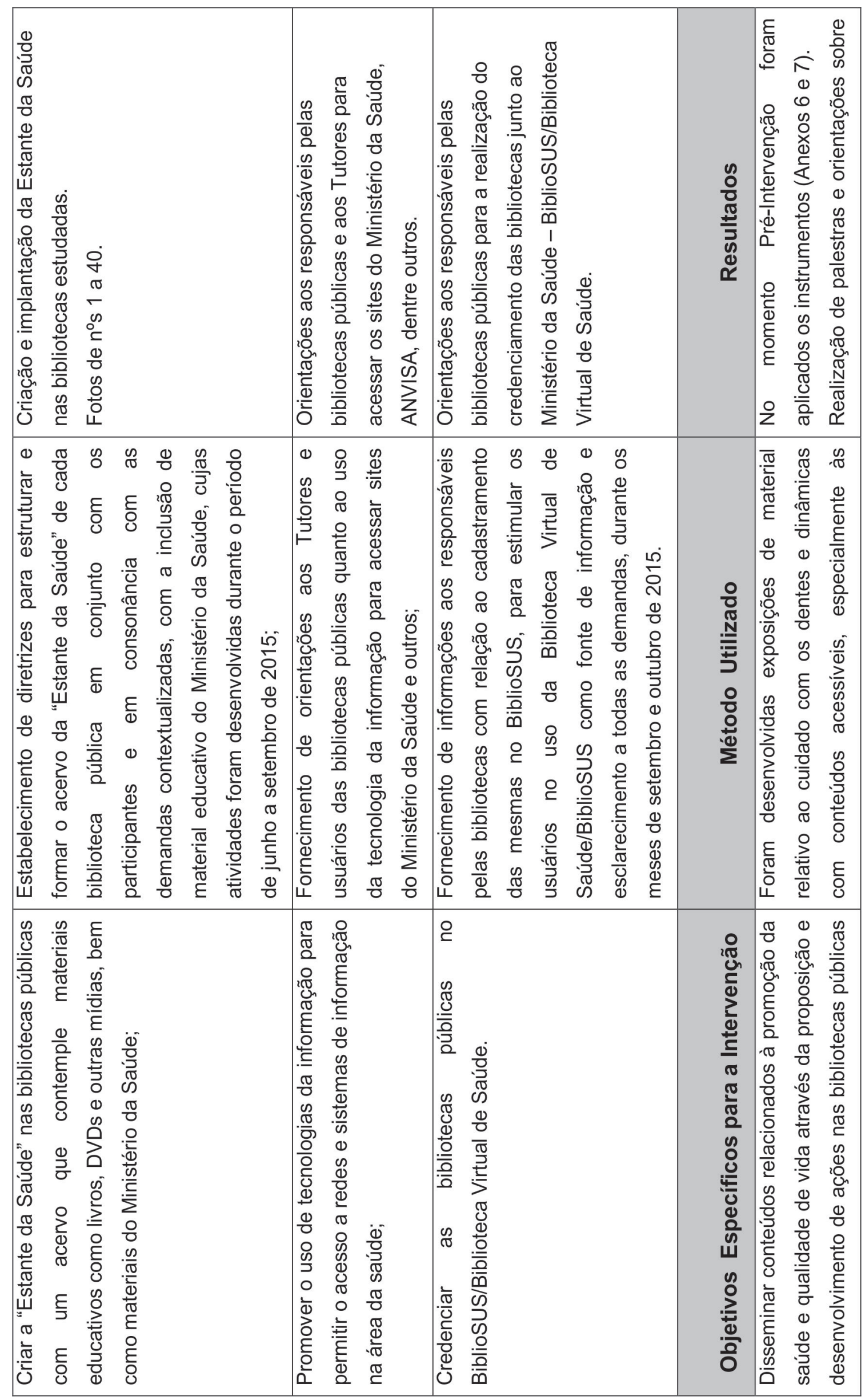




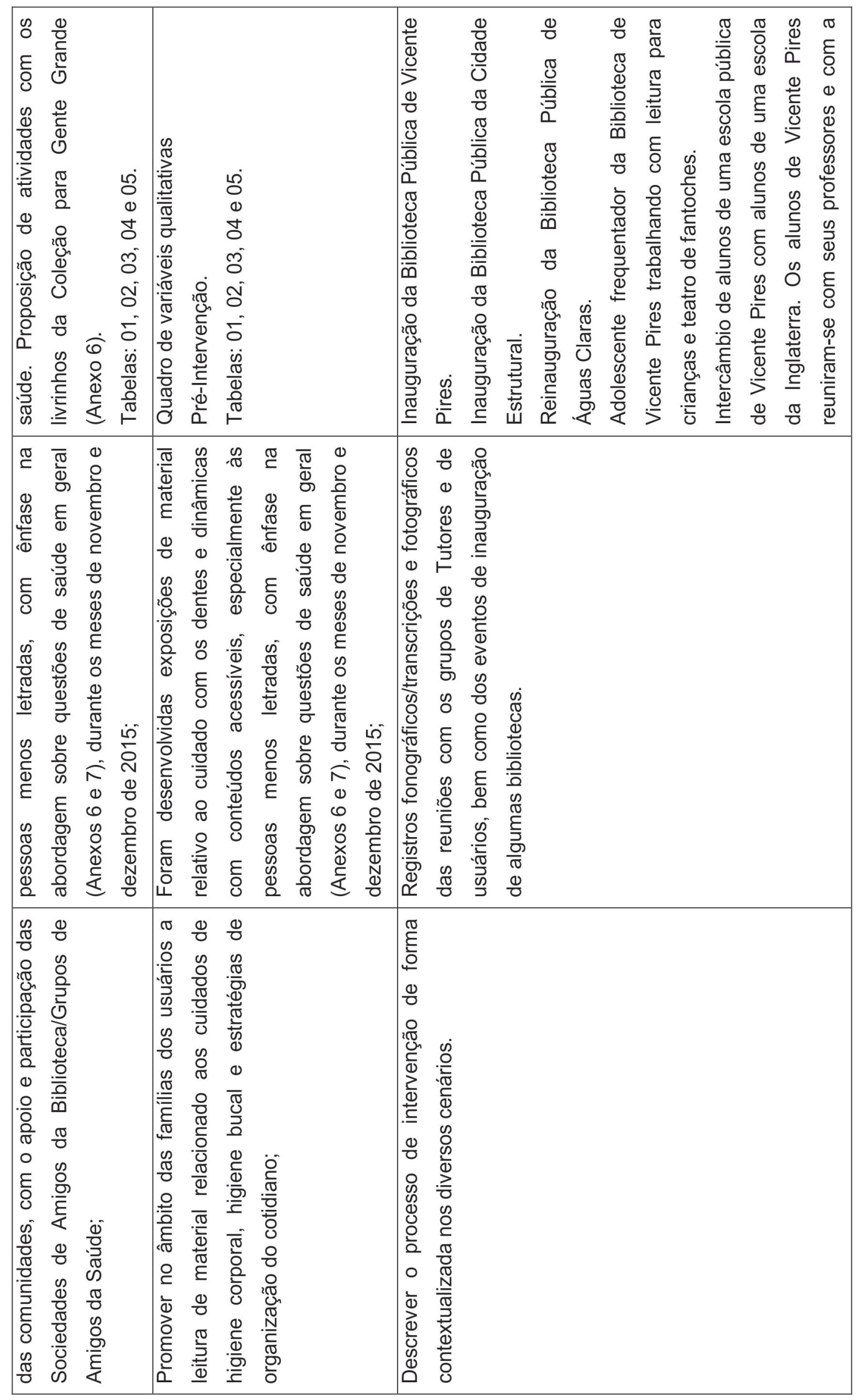




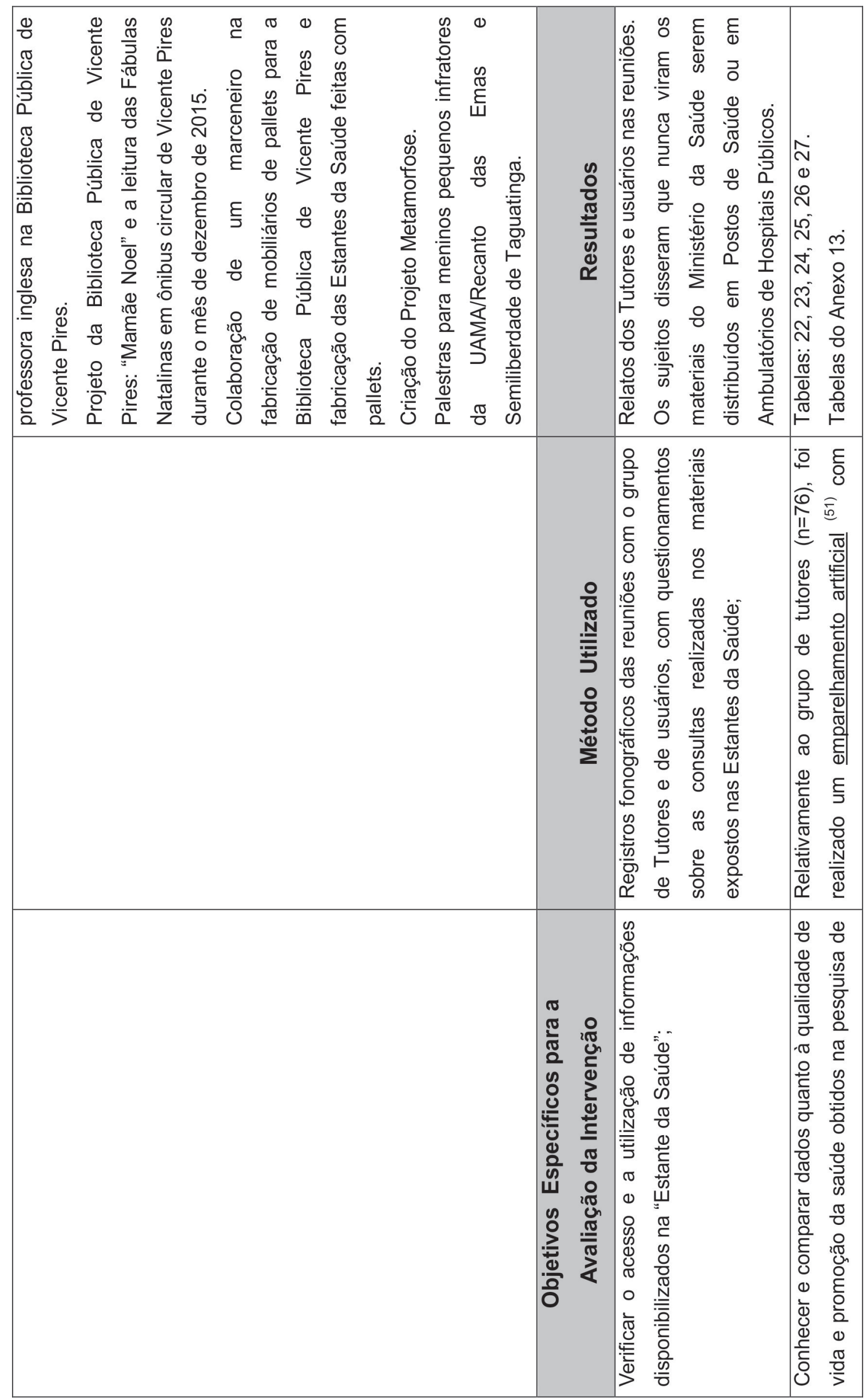




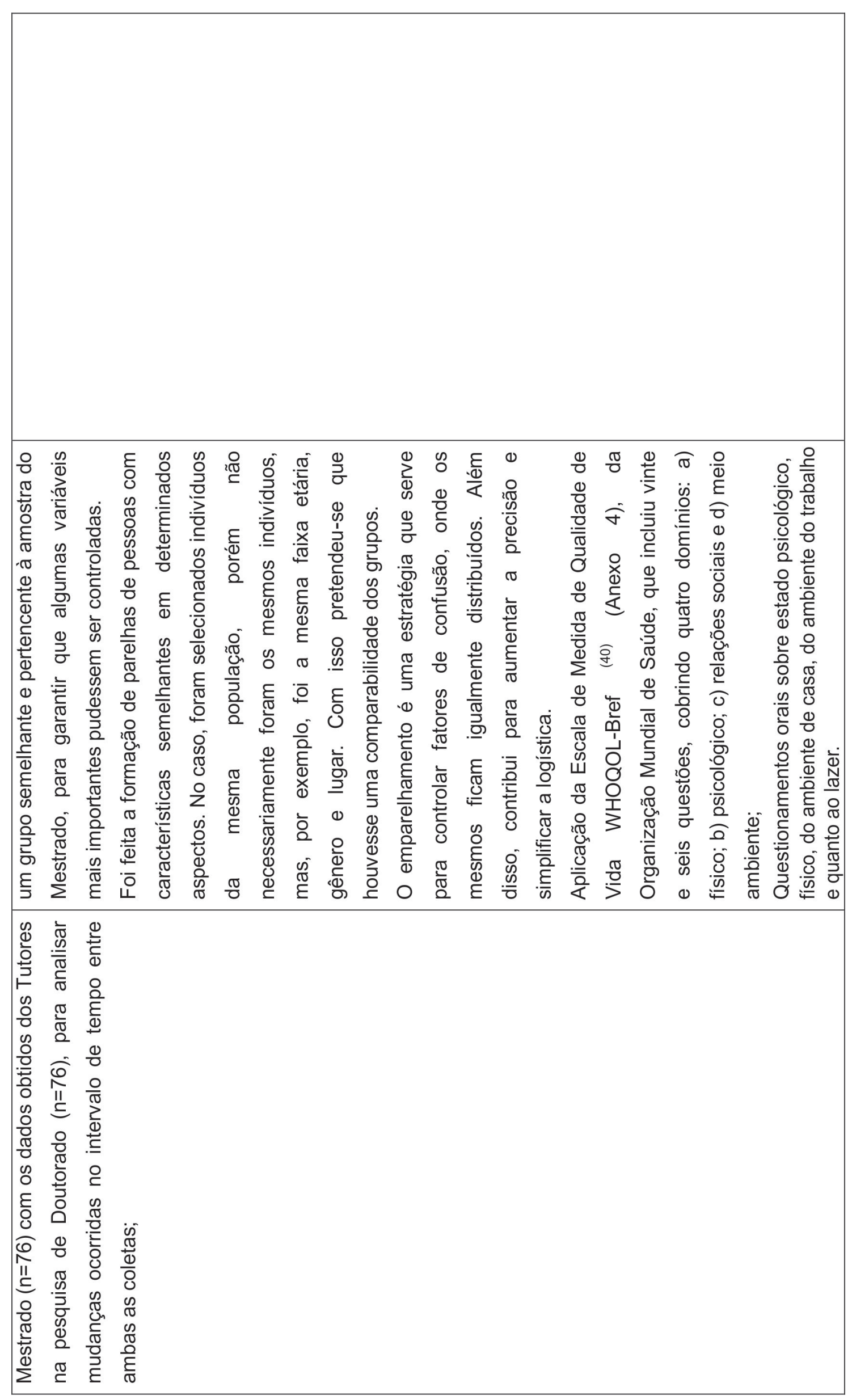




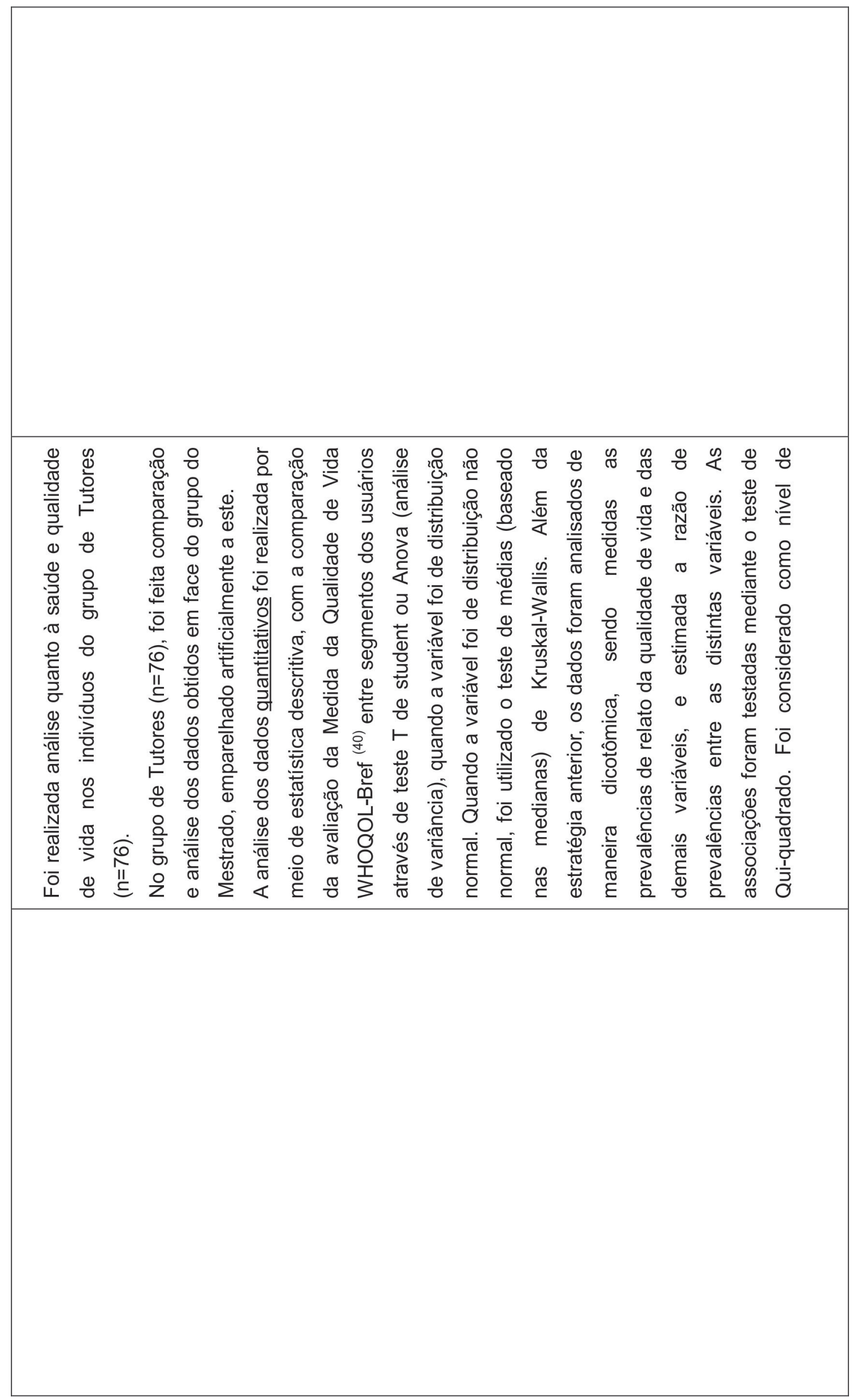




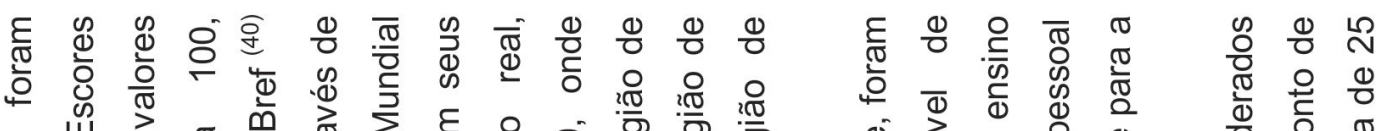
山 $>$ ब

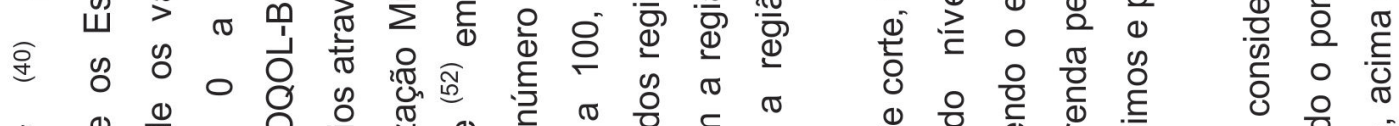
屯

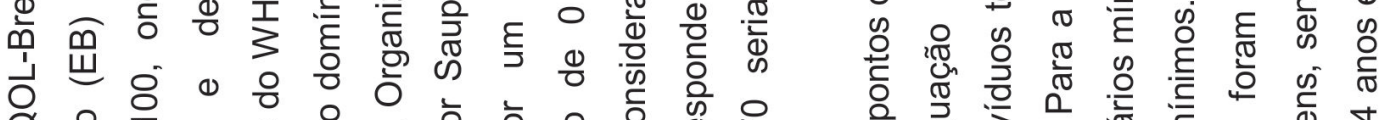
号

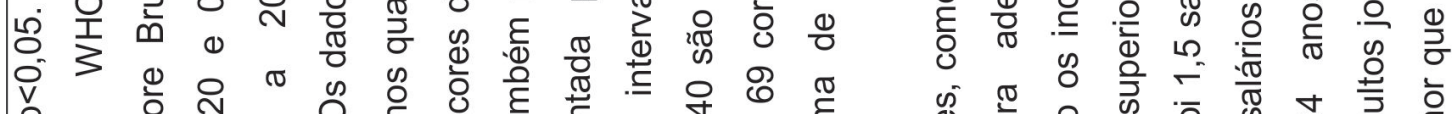

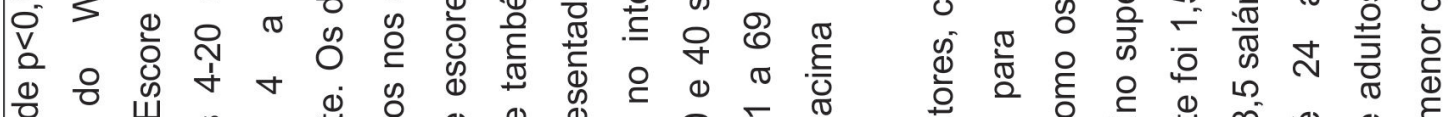

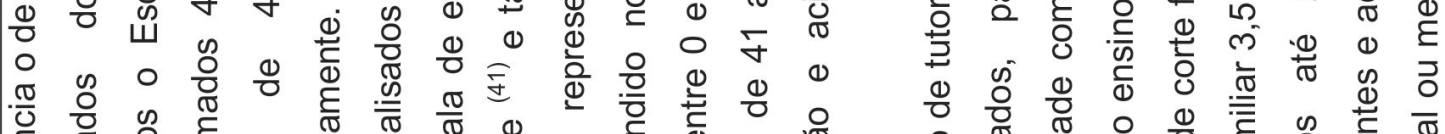

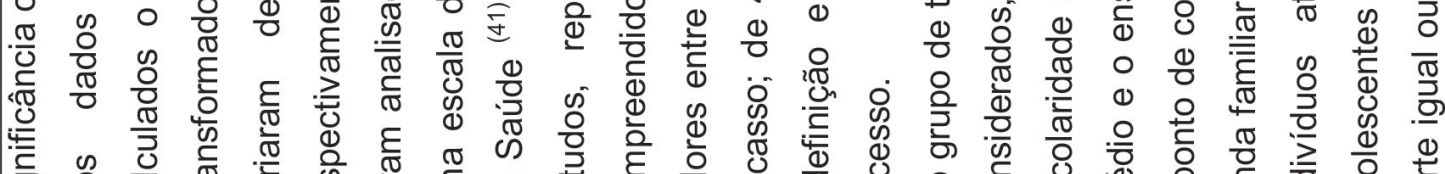

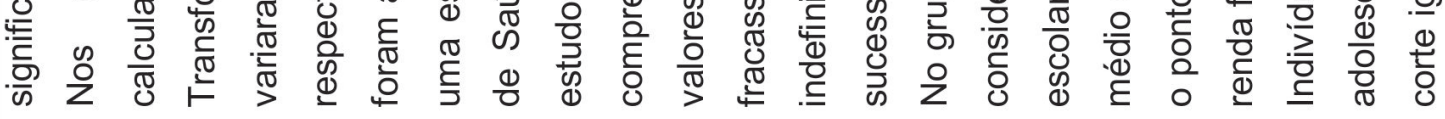




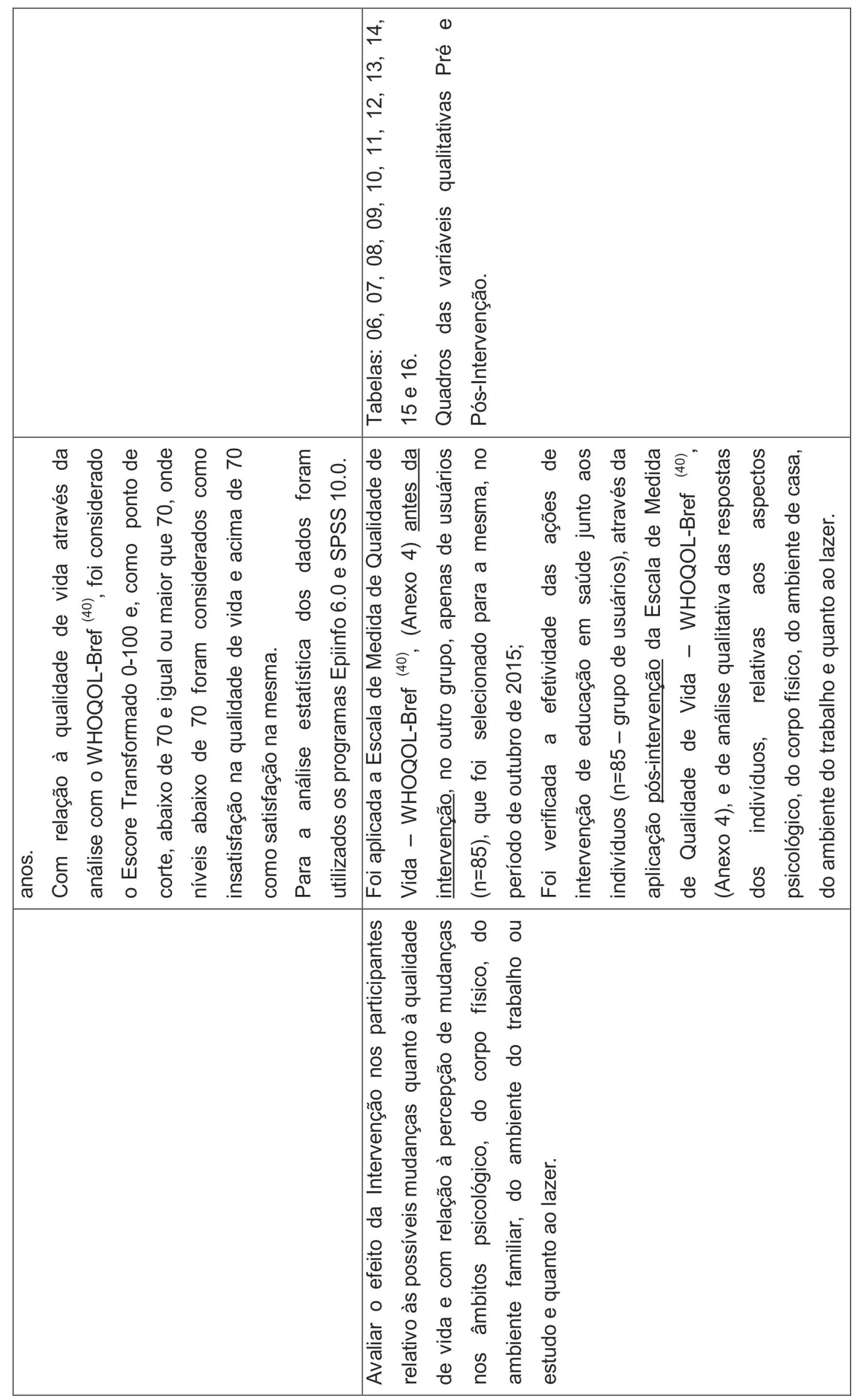




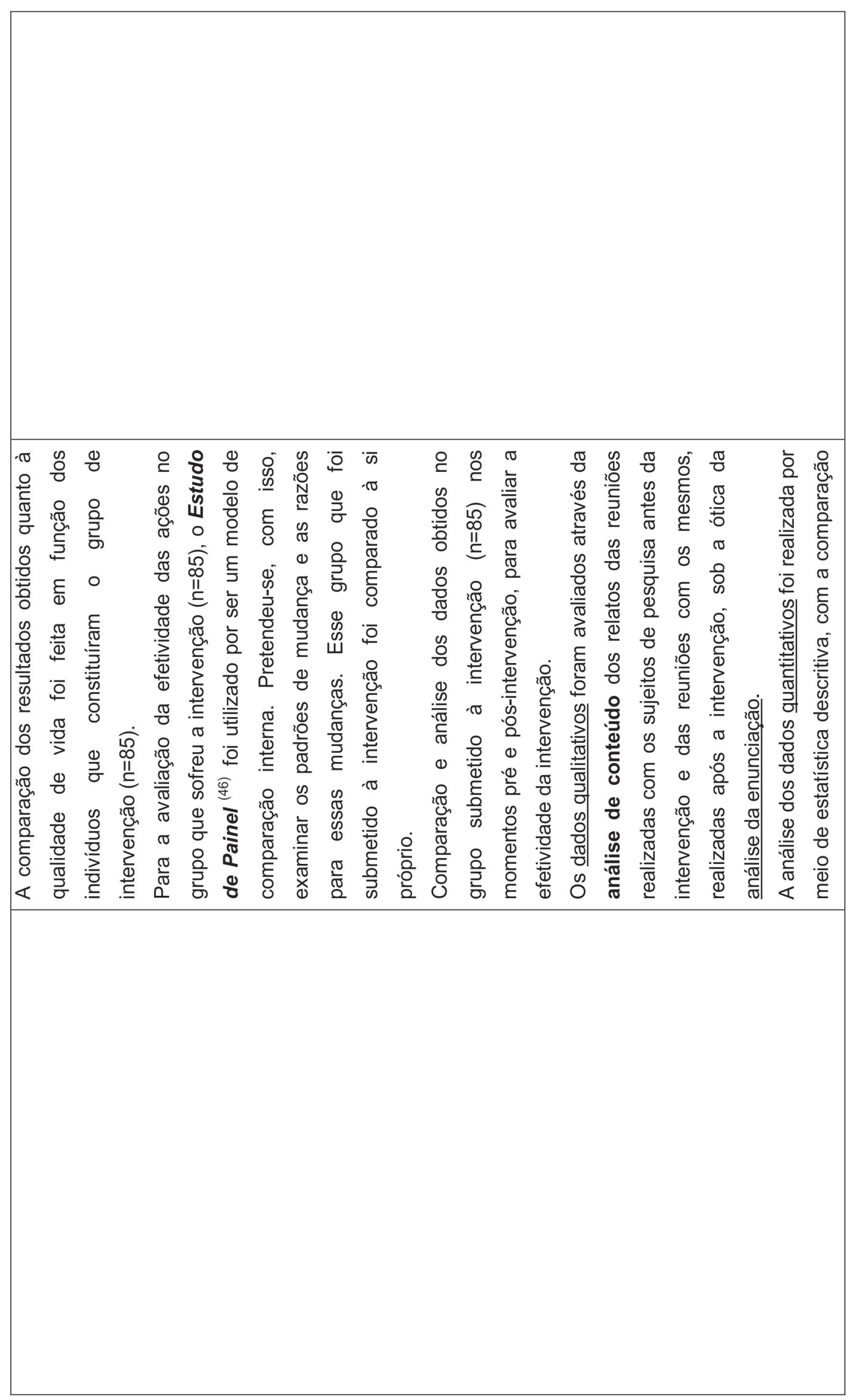




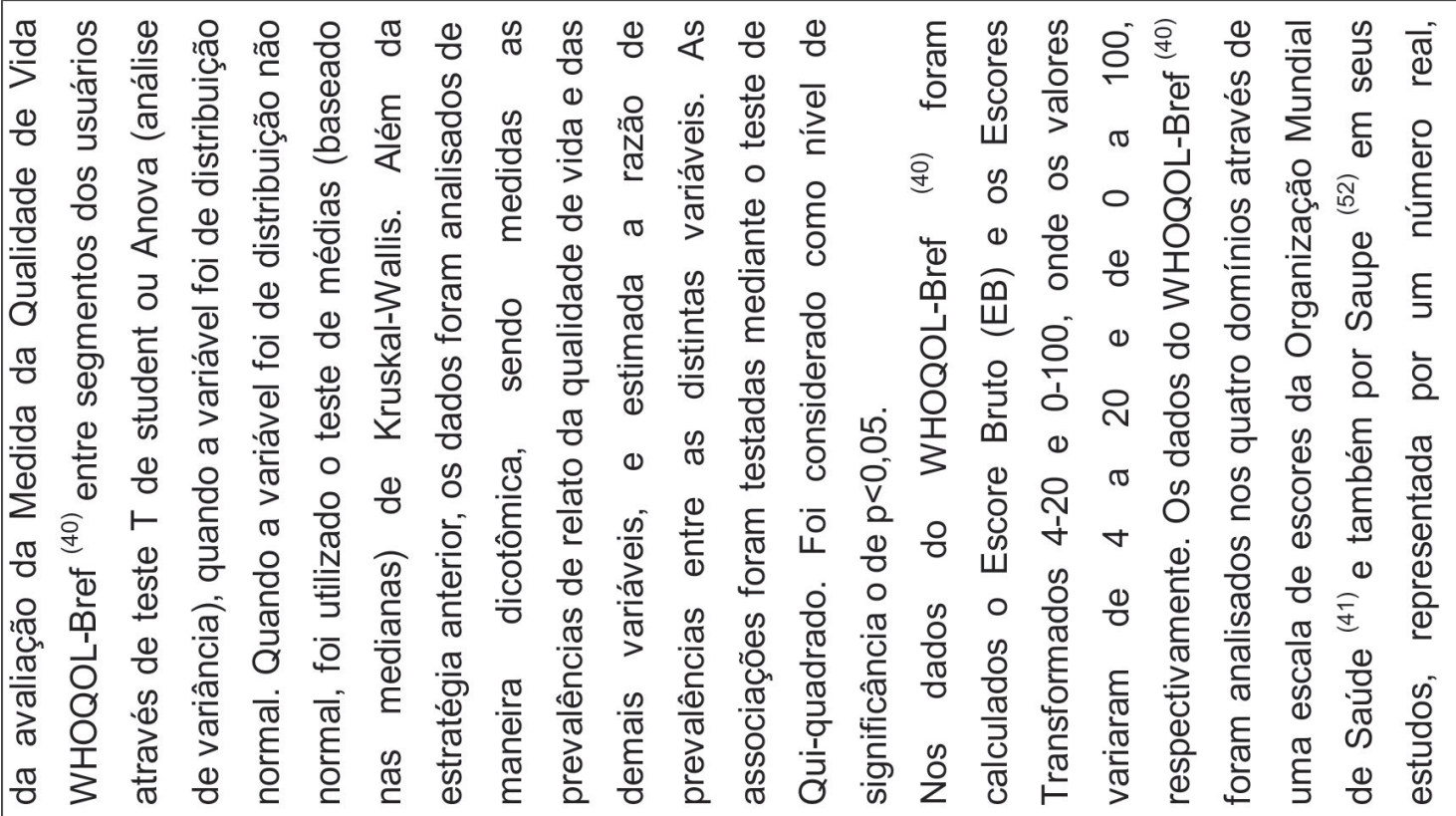




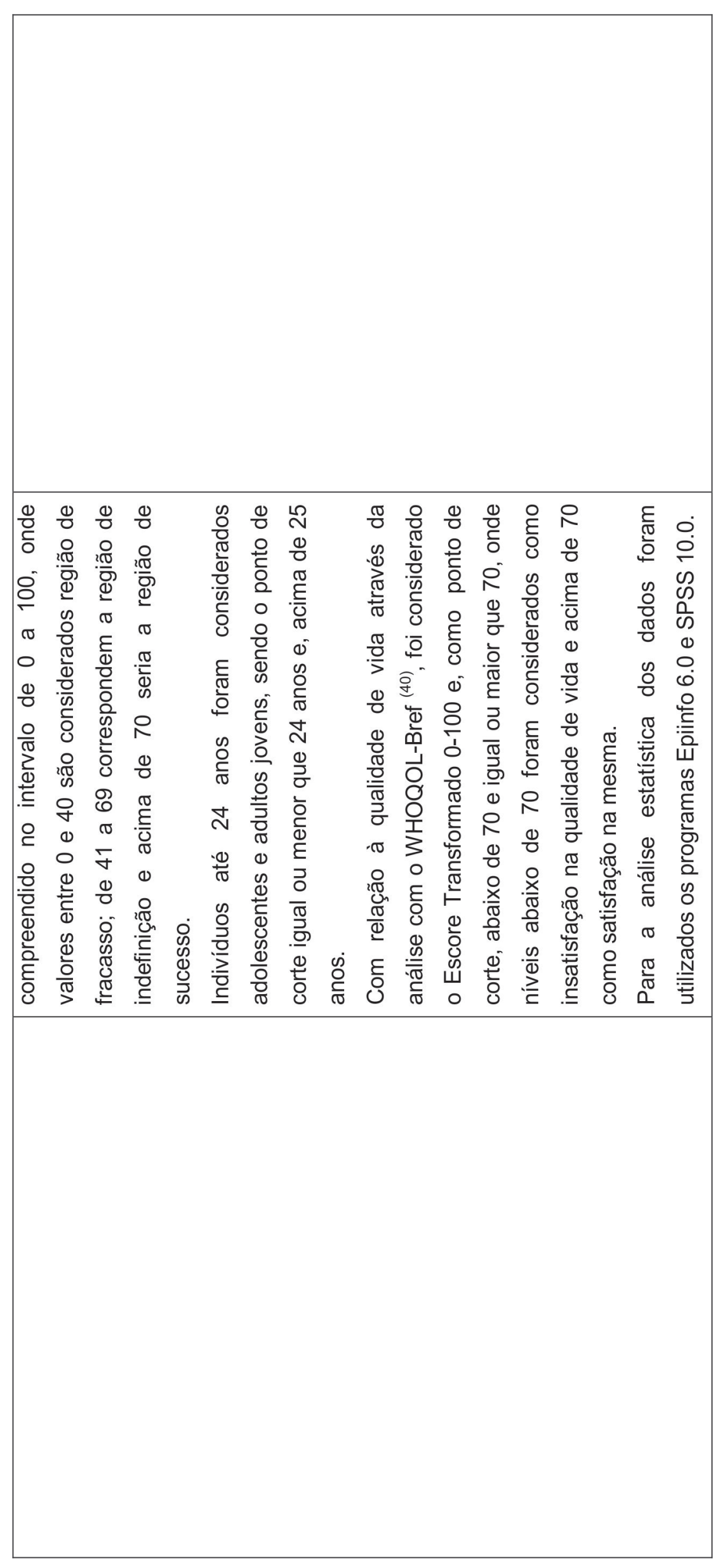


Em consonância ao proposto no quadro acima, seguiremos com as considerações em face da sequência dos resultados apresentados.

Relativamente aos resultados qualitativos do grupo submetido à intervenção, através da análise de conteúdo, foi montada uma categorização dos questionamentos orais em cinco áreas: psicológico, físico, ambiente de casa, ambiente do trabalho e lazer. Através da Análise de Conteúdo, sob a ótica da Análise da Enunciação, observou-se que os comentários queixosos do momento Pré-Intervenção tiveram uma mudança positiva no momento Pós-Intervenção.

Não se pretendeu fazer uma análise qualitativa profunda através da Análise da Enunciação, por esta ser um recurso da Análise de Conteúdo extremamente complexo, no entanto, procurou-se seguir as orientações quanto às categorizações com vistas à possibilidade de visualizar-se possíveis mudanças nos relatos dos indivíduos, em face da intervenção realizada.

Não se pretendia fazer uma análise psicológica profunda, dado o fato de a aluna ser enfermeira, no entanto, os seus trinta anos de experiência profissional lidando com seres humanos desenvolveram uma sensibilidade bastante elevada por parte da aluna, de forma que esta percebesse nos sujeitos da pesquisa, após a Intervenção, olhares mais entusiasmados, esperançosos. $O$ fato de ter sido dada atenção a pessoas que, em geral, são marginalizadas e excluídas do convívio social, como no caso dos adolescentes da UAMA Recanto das Emas e da Semiliberdade de Taguatinga, ambos grupos frequentadores da Biblioteca Pública de Taguatinga, propiciou algum benefício, sem dúvida, a esses meninos.

A possibilidade de eles poderem se expressar sobre outros assuntos que não os relativos aos delitos que cometeram pode ter feito com que se sentissem também integrados a pessoas que efetivamente se preocupam com seus interesses. Não é necessário ser psicólogo ou psiquiatra para entender que isso pode ser o divisor de águas entre a "volta para os delitos" e "uma nova chance, outras possibilidades".

A oficina de marcenaria do Projeto Metamorfose, já com seus trabalhos iniciados, significa um "estender as mãos", dizer a esses adolescentes que existe outro tipo de vida, com esperança e com futuro. E em falar-se que tudo começou com um pedido para fabricação da Estante da Saúde em pallets......

Além disso, pelo motivo de as pessoas terem sido ouvidas e terem tido oportunidade de se expressar, colocando seus problemas, tendo alguém para escutá-las, já foi algo realmente muito positivo dentre os demais participantes do estudo.

Em continuidade à análise iniciada e seguindo-se a sequência de resultados do Quadro de Sistematização da Realização da Pesquisa, temos que, com relação ao grupo de Tutores, conforme demonstrado na Tabela 17, quanto ao Domínio 1 - Físico, do WHOQOL-Bref, em comparação com o grupo de usuários - Tabela 01, pode ser observado que o primeiro teve queixas em menor proporção.

Na Tabela 18, Domínio 2 - Psicológico, do WHOQOL-Bref, em comparação com a Tabela 02, pode ser também constatado que o grupo de Tutores teve queixas 
em menor proporção. Quanto ao Domínio 3 - Relações Sociais, do WHOQOL-Bref, Tabela 19, em face da Tabela 03, verificou-se que o grupo de usuários teve percentuais de queixas mais elevados. Na Tabela 20, Domínio 4 - Meio Ambiente, do WHOQOL-Bref, em comparação à Tabela 04, novamente observa-se que o grupo mais queixoso é o de usuários.

Essas diferenças acima citadas podem ser relacionadas à melhores condições de vida, emprego, escolaridade e outros determinantes sociais do Grupo de Tutores, já que estes, em sua maioria, eram funcionários das bibliotecas, o que significa dizer que pelo menos quanto à sua subsistência, estariam razoavelmente atendidos.

Com relação às Tabelas 28, 29, 30-A, 30-B, 31-A e 31-B, observa-se que as condições estruturais, de serviços e de acervos das bibliotecas públicas estudadas estão bastante razoáveis, tendo em vista a atual condição econômica ruim em todas as esferas governamentais.

A criação e implantação da Estante da Saúde foi de extrema importância, inclusive no quesito de envolvimento do Programa de Pós-Graduação em Ciências da Saúde, da Faculdade de Ciências da Saúde da Universidade de Brasília, no sentido de devolver à comunidade os investimentos que esta faz para a sociedade através do pagamento de tributos. A participação da Universidade em todas as esferas sociais é fundamental, pois as pesquisas realizadas precisam retornar para a sociedade em benefícios. Ressalte-se o fato de ter sido constatada a lacuna quanto ao fornecimento de materiais educativos do Ministério da Saúde, e consequente benefícios que poderiam frutificar na saúde e qualidade de vida da população com esse expediente.

Outro ponto importante foi a possibilidade de fornecimento de orientações às pessoas envolvidas na pesquisa quanto às informações em meio digital que estão disponíveis no site do Ministério da Saúde e de outros órgãos como a Agência Nacional de Vigilância Sanitária - ANVISA, dentre outros. Quanto às informações para o cadastramento das bibliotecas públicas no BiblioSUS/Biblioteca Virtual de Saúde, do Ministério da Saúde, estas foram fornecidas, no entanto, muitas vezes a internet das bibliotecas não funciona muito bem, ou existem problemas com os computadores. No entanto, fazia-se necessário fornecer orientações sobre essa importante ferramenta do Ministério da Saúde.

Quanto à disseminação dos conteúdos relativos à promoção da saúde, foi fundamental a aplicação, no grupo de usuários, tanto do questionário WHOQOL-Bref, como do questionário semiestruturado qualitativo, no momento Pré-Intervenção, porque forneceram informações importantes para o conhecimento do diagnóstico inicial. Os livrinhos elaborados especialmente para esta pesquisa foram utilizados como proposta inicial para se falar em saúde e, juntamente com eles, a realização das palestras sobre higiene, cuidados com os dentes e estratégias de organização de forma complementar. De acordo com os relatos das variáveis qualitativas Pós-Intervenção, verifica-se que muitos participantes fizeram as dinâmicas com seus familiares, sendo isso um ponto muito positivo, pois a leitura em voz alta propicia muitos benefícios, não somente em relação ao acesso a novas informações, como melhora da dicção, da compreensão e oportunidade de reflexão coletiva sobre os temas estudados.

A questão da reinauguração da biblioteca de Águas Claras e inauguração das 
bibliotecas de Vicente Pires e da Cidade Estrutural (Anexo 12) é um ponto importante a ser comentado. O Curso de Dinamização e Uso da Biblioteca Pública, formação inicial, ou seja, primeira atividade deste trabalho, foi fundamental, pois ajudou na articulação dos dirigentes e representantes das comunidades, que envidaram esforços para concretizar essas ações. O resultado foi a criação de espaços públicos diferenciados, ou seja, as bibliotecas públicas e, juntamente com estas, novas oportunidades de informações para a população.

O fato de ter acontecido a realização de projetos extramuros na Biblioteca Pública de Vicente Pires, tão pouco tempo após sua inauguração, demonstra o comprometimento social da equipe e dos gestores, sendo que os maiores beneficiados são as pessoas que puderam viver essas experiências.

Relativamente à comparação realizada entre o Grupo do Mestrado e o Grupo do Doutorado (Tutores), conforme as Tabelas 22, 23, 24, 25, 26 e 27, observou-se que, na Tabela 22 - Domínio 1 (Físico) do WHOQOL-Bref, as mulheres continuam referindo níveis piores de qualidade de vida, sendo que, nesse espaço de quase oito anos entre a coleta de dados entre o Mestrado e o Doutorado, a qualidade de vida no aspecto físico piorou.

Chama à atenção as diferenças econômicas brutais, ou seja, o poder aquisitivo, nesse espaço temporal, piorou muito e, obviamente, isso influencia sobremaneira na aferição da qualidade de vida. Quanto à Tabela 23 - Domínio 2 (Psicológico) do WHOQOL-Bref, verifica-se novamente que houve piora da qualidade de vida no Grupo do Doutorado, em mulheres, acima de 25 anos e com rendas pessoal e familiar abaixo de 1,5 e 3,5 salários mínimos respectivamente.

Apesar de os governos insistirem em afirmar as melhorias na vida das pessoas, os números indicam que, em verdade isso não procede. Obviamente que nesse intervalo de tempo entre o Mestrado e o Doutorado, assistiu-se um aumento na proporção de indivíduos que possuem nível superior, inclusive demonstrada nas Tabelas 22 à 27. Isso poderá estar relacionado às inúmeras facilidades para pessoas menos favorecidas economicamente ingressarem em instituições de ensino superior, ou até mesmo por conta das cotas nas universidades públicas. No entanto, ao se verificar as diferenças do dólar em 2008, em face dos valores em 2015, é incontestável o quanto piorou a capacidade de consumo de forma geral, e como isso acaba afetando indireta e diretamente a oferta de empregos, serviços, etc.

Nas demais Tabelas, ou seja, 24 e 25, relativas aos Domínios 3 (Relações Sociais) e 4 (Meio Ambiente), observa-se também piora da qualidade de vida nesses aspectos, de 2008 para 2015, sendo que as mulheres continuam em pior situação. Nas Tabelas 26 e 27, ou seja, W1 (Insatisfação com a própria qualidade de vida) e W2 (Insatisfação com a própria saúde) do WHOQOL-Bref, os valores demonstram novamente pioras, sendo mais uma vez das mulheres a maior proporção das queixas.

A análise das Tabelas 06 a 16 demonstra que a intervenção de educação em saúde foi estatisticamente significante, onde os valores com maior significância foram no gênero mulher e faixa etária acima de 25 anos. Isso indica que as atividades de educação em saúde desenvolvidas com os indivíduos tiveram desfechos favoráveis. 
Mas tem que ser considerado que o tipo de estudo desenvolvido possui limitações, bem como, na época da intervenção, no caso, meses de novembro e dezembro de 2015, a grande maioria dos frequentadores das bibliotecas era de pessoas muito comprometidas com seus propósitos de estudos, já que nesse período existe uma grande diminuição de frequência de usuários devido aos períodos de recesso e de férias. Isso poderá ter afetado a amostra, no entanto, a dificuldade de recrutamento foi muito grande, por esses mesmos motivos, mas as pessoas demonstraram muito boa vontade e interesse em participar das atividades de Intervenção.

O Domínio que teve as menores variações foi o de número 4, relativo ao Meio Ambiente. Porém, é este o Domínio mais difícil de ser transformado, dependendo do contexto. Os demais Domínios - Físico, Psicológico e das Relações Sociais, podem ser "empoderados" de uma forma mais direta, pois são sensíveis à ações motivacionais. O Domínio do Meio Ambiente é mais dependente de outras facetas, como as políticas públicas. Não que estas não influenciem nos Domínios de 1 à 3 , mas esses três primeiros podem ser muito bem trabalhados porque dependem muito mais de cada indivíduo, de como cada um percebe o seu meio e reage à este.

Ao se consultar a cartilha do Relatório de Situação do Distrito Federal, editado pelo Ministério da Saúde em 2011 (57), verifica-se que, quanto à Promoção da Saúde e Vigilância de Fatores de Risco para Doenças Crônicas Não-Transmissíveis, no quesito lazer, a frequência de adultos ativos foi de $22,4 \%$, contra $14,4 \%$ no Brasil. Quanto à prevalência de tabagismo em adultos, o percentual do DF foi inferior ao do restante do país, e no quesito excesso de peso em adultos, a prevalência foi de $44,7 \%$ no DF para $48,1 \%$ no restante do país. Com relação aos dados de violência, as agressões no DF tiveram índices superiores à da Região Centro-Oeste. A vigilância em saúde ambiental com relação à qualidade da água para consumo humano indica que, apesar de existirem sistemas de abastecimento de água com tratamento no DF, as análises realizadas nas águas fornecidas indicou percentuais elevados de Escherichia coli.

A pergunta que se faz diante de todos esses comentários é: o que tem sido feito efetivamente para a saúde e qualidade de vida das populações? Os diversos escândalos noticiados pelas mídias em todo o Brasil demonstram que, em verdade, os recursos que deveriam ser destinados para o bem estar de todos, são captados para outros interesses.

Mas essa situação social, econômica, de saúde, do meio ambiente vem sendo a mesma há muito tempo. Porém, faz-se necessário aprofundar-se mais sobre as questões de saúde e o quanto estas influenciam na importância da promoção da saúde e consequente melhoria da qualidade de vida dos indivíduos, apesar de já ter sido feito comentário a respeito disso na Introdução desta Tese.

Segundo Muñoz e Salinas (54), as políticas públicas criam as possibilidades para que as pessoas possam desfrutar de uma boa qualidade de vida, sendo destaque a política de saúde, dentre as políticas sociais de um país. No campo da Promoção da Saúde, a partir das Conferências Mundiais de Promoção da Saúde, surgiu o conceito de Políticas Públicas Saudáveis, as quais têm forte influência sobre os determinantes de saúde. 
Essa ferramenta denominada de políticas saudáveis se constitui de mecanismos que garantem a saúde como um bem supremo de cuidado e melhorias para a sociedade como um todo. Dentre os quesitos necessários para a efetividade de políticas saudáveis, temos o trabalho, a paz, a educação, a justiça social e a equidade (54).

Assim sendo, as políticas públicas são aquelas que criam as condições necessárias para o desenvolvimento de estilos e de modos de vida saudáveis, onde indivíduos, famílias e comunidades tenham a possibilidade de mudar suas condutas, em especial quando estas as colocam em situações de risco evitáveis, sendo que isso implicaria o desafio de conquistar-se melhor distribuição de recursos, de forma equitativa. Significa dizer-se que as políticas públicas saudáveis são um instrumento privilegiado para se conquistar maior equidade na distribuição de recursos na sociedade (54).

É importante citar, sob a ótica da Promoção da Saúde, as principais contribuições das Conferências Internacionais de Saúde (58). A Carta de Otawa, Canadá, em 1986, representou o marco conceitual da Promoção da Saúde, com a proposição de capacitação das coletividades, melhoria das condições de vida e políticas públicas saudáveis, para a obtenção de alimentos, abrigo, saúde e, consequentemente, desenvolvimento social, através do auto-respeito e integração/participação social. Porém, nada disso seria viável sem a capacitação dos atores, a mobilização social e a ampliação de poder reconhecidas e fomentadas pelos governos.

Nas demais conferências que se seguiram a de Otawa, observa-se a definição de outras áreas a serem envolvidas para a efetiva implementação da Promoção da Saúde, através da parceria com os setores políticos, sociais, econômicos, culturais, ambientais, comportamentais e biológicos (58).

Foi na Conferência de Adelaide, na Austrália, em 1988, que ficou demonstrado o quanto as políticas públicas de todos os setores do governo influenciam os determinantes da saúde, como renda, habitação, educação, saneamento, serviço social, alimentação, lazer, agricultura, transporte, planejamento urbano, cuidados primários em saúde, sistema tributário, dentre outros, e se configuram como importantes ferramentas para a redução das iniquidades sociais e econômicas, com acesso equânime a bens, serviços e a recursos de saúde (58).

Na Conferência de Sundsval, na Suécia, em 1991, o meio ambiente foi o destaque, sendo o tema principal da conferência, a criação de ambientes saudáveis. Esta teve seus princípios reforçados com a realização da Conferência ECO 92 no Rio de Janeiro.

Na Conferência de Jacarta, na Indonésia, em 1998, já havia se iniciado o processo de globalização, com o fortalecimento do neoliberalismo e o boom do capitalismo, onde os princípios de igualdade, liberdade, solidariedade e paz estavam em segundo plano, especialmente nos países de primeiro mundo. Houve o acirramento das intolerâncias e das desigualdades econômicas e sociais. Com o intuito de buscar parcerias e alianças, a Carta de Jacarta caracterizou-se por prioridades para a Promoção da Saúde até o século XXI, através de novos conhecimentos e estratégias (58), a saber: 
"1. Promover a responsabilidade social pela saúde;

2. Aumentar a capacidade da comunidade e o poder dos indivíduos para controlar as ações que pudessem interferir nos determinantes da saúde;

3. Expandir e consolidar alianças para a saúde;

4. Aumentar as investigações para o desenvolvimento da saúde;

5. Assegurar a infraestrutura para a Promoção da Saúde."

Na V Conferência de Promoção da Saúde, no México, em 2000, o contexto mundial havia piorado e os compromissos não haviam sido cumpridos. Sendo assim, utilizaram a estratégia de comprometimento dos ministros, com a assinatura de uma "Declaração Presidencial", com o objetivo de incorporar Planos Nacionais de Ação.

Segundo Westphal (58), na VI Conferência Global de Promoção da Saúde, em Bancoc, na Tailândia, no ano de 2005, como não houve o cumprimento dos compromissos assumidos na conferência anterior. A globalização foi analisada em face das questões de saúde, tanto quanto a aspectos negativos como positivos "da difusão de conhecimentos pelos meios tecnológicos de informação".

No entanto, a mesma autora(58) enfoca a miopia da repercussão dos resultados da Conferência de Bancoc, em face da capacidade reduzida de reação aos desfechos dos determinantes econômicos e tecnológicos da sociedade global na saúde e qualidade de vida da população. A mesma enfatiza sobre a necessidade de reinterpretação dos resultados da conferência e das necessárias adequações aos contextos locais.

Relativamente ao contexto latino-americano, com a inclusão dos países em desenvolvimento, os demais encontros e conferências estiveram pautados mais especificamente ao tema equidade, cujos princípios estavam pautados em temas relativos às iniquidades, enfatizando a participação da sociedade nas decisões sobre saúde e qualidade de vida.

Westphal (58) coloca claramente sobre a necessidade de difusão de estratégias participativas para fomentar o empoderamento individual e coletivo dos sujeitos, transpondo os muros do setor saúde no enfrentamento das iniquidades.

A autora (58) refere que as conferências e a literatura elencaram os princípios definidores sobre a Promoção da Saúde, conforme segue:

"1. Ações de Promoção da Saúde devem pautar-se por uma concepção holística de saúde voltada para a multicausalidade do processo saúde-doença;

2. A equidade como princípio e como conceito;

3. A intersetorialidade como princípio da Promoção da Saúde;

4. A participação social;

5. A sustentabilidade." 
Quadro 6. Concepções de saúde e diferentes visões da Promoção da Saúde, Westphal (58)

\begin{tabular}{|c|c|c|c|}
\hline ABORDAGENS & BIOMÉDICA & COMPORTAMENTAL & SOCIOAMBIENTAL \\
\hline $\begin{array}{l}\text { Conceito } \\
\text { de saúde }\end{array}$ & $\begin{array}{l}\text { Ausência de } \\
\text { doenças e } \\
\text { incapacidades }\end{array}$ & $\begin{array}{l}\text { Capacidades } \\
\text { físico-funcionais; } \\
\text { bem-estar físico e } \\
\text { mental dos } \\
\text { indivíduos }\end{array}$ & $\begin{array}{l}\text { Estado positivo; } \\
\text { Bem-estar bio-psico-social } \\
\text { e espiritual; } \\
\text { Realização de aspirações } \\
\text { e atendimento de } \\
\text { necessidades }\end{array}$ \\
\hline $\begin{array}{l}\text { Determinantes de } \\
\text { saúde }\end{array}$ & $\begin{array}{l}\text { Condições } \\
\text { biológicas e } \\
\text { fisiológicas para } \\
\text { categorias especí- } \\
\text { ficas de doenças }\end{array}$ & $\begin{array}{l}\text { Biológicas } \\
\text { comportamentais; } \\
\text { Estilos de vida } \\
\text { inadequados à } \\
\text { saúde }\end{array}$ & $\begin{array}{l}\text { Condições de risco } \\
\text { biológicas, psicológicas, } \\
\text { socioeconômicas, educa- } \\
\text { cionais, culturais, políti- } \\
\text { cas e ambientais }\end{array}$ \\
\hline $\begin{array}{l}\text { Principais } \\
\text { estratégias }\end{array}$ & $\begin{array}{l}\text { Vacinas, } \\
\text { análises clínicas } \\
\text { individuais e } \\
\text { populacionis, } \\
\text { terapias com } \\
\text { drogas, cirurgias }\end{array}$ & $\begin{array}{l}\text { Mudanças de } \\
\text { comportamento } \\
\text { para adoção de } \\
\text { estilos de vida } \\
\text { saudáveis }\end{array}$ & $\begin{array}{l}\text { - Coalizões para advoca- } \\
\text { cia e ação política; } \\
\text { - Promoção de espaços } \\
\text { saudáveis; } \\
\text { - Empoderamento da } \\
\text { população; } \\
\text { - Desenvolvimento de } \\
\text { habilidades, conhecimen- } \\
\text { tos, atitudes; } \\
\text { - Reorientação dos } \\
\text { serviços de Saúde }\end{array}$ \\
\hline $\begin{array}{l}\text { Desenvolvimento } \\
\text { de programas }\end{array}$ & $\begin{array}{l}\text { Gerenciamento } \\
\text { profissional }\end{array}$ & $\begin{array}{l}\text { Gerencimento } \\
\text { pelos indivíduos, } \\
\text { comunidades de } \\
\text { profissionais }\end{array}$ & $\begin{array}{l}\text { Gerenciados pela comuni- } \\
\text { dade em diálogo crítico } \\
\text { com profissionais e } \\
\text { agências. }\end{array}$ \\
\hline
\end{tabular}

Westphal (58) também relata que a qualidade de vida dos indivíduos relaciona-se com a participação dos atores sociais, em todos os níveis, na definição de políticas e também no controle social e na avaliação dos serviços oferecidos à população.

Como campos de ação da Promoção da Saúde, dentre as várias estratégias citadas na Carta de Otawa, ressalta-se a criação de espaços saudáveis que apoiem a Promoção da Saúde. Nesse sentido, as bibliotecas públicas estão incluídas também como espaços saudáveis, pois são disseminadoras de informações e existem em praticamente todas as cidades brasileiras.

Westphal (58) contribui muito significativamente para a discussão do tema sobre Promoção da Saúde na medida em que refere sobre o fato de o SUS concentrar-se na atenção à doença. Essa sistemática promove a maior valorização de tecnologias médicas cada vez mais sofisticadas, favorecendo os mercados da área. Aliado a isso, a globalização erigiu o individualismo, na contramão do sentido mais importante da epidemiologia, que é a Saúde Coletiva. 
"Na maioria dos casos, os serviços de saúde tornaram-se meros consumidores do mercado sustentado pela perspectiva de desenvolvimento da modernidade. A prática sanitária atual, portanto, é configurada, direcionada pelo paradigma hegemônico, que valoriza a doença e o consumo dos meios diagnósticos e de tratamento [...] marcado pelo processo de globalização. (59)"

Segundo o Grupo de Trabalho de Promoção da Saúde da Associação Brasileira de Pós-Graduação em Saúde Coletiva - ABRASCO (60), o marco teórico da Promoção da Saúde é:

\begin{abstract}
"A compreensão da Promoção da Saúde e da qualidade de vida na América Latina pressupõe o reconhecimento do imperativo ético de responder às necessidades sociais no marco dos direitos universais fundamentais, poste que entendemos o direito à saúde como expressão direta do direito fundamental à vida. $\mathrm{A}$ resposta às necessidades sociais derivadas dos direitos se totaliza no enfrentamento dos determinantes sociais de saúde e qualidade de vida. A identificação destas necessidades sociais reinvindica uma ação coletiva participativa dentro de contextos específicos que evidenciam a complexidade de sua determinação e ilumina as potencialidades daquele contexto social em tela."
\end{abstract}

Segundo Rouquayrol (61), a implantação do Sistema Único de Saúde - SUS no Brasil teve como ferramenta principal de apoio a epidemiologia, através da Lei Orgânica de Saúde. Dessa forma, essa ciência vem contribuindo para o estabelecimento de prioridades como alocação de recursos, orientação de programas, bem como propiciando "as bases para avaliação de medidas que promovam a qualidade de vida. Hoje é consenso que a epidemiologia fomenta práticas garantidoras do aprimoramento das políticas públicas, tendo como fator primordial a intersetorialidade de ações no modo de construir saúde."

Rouquayrol (61) conceitua epidemiologia, de uma maneira simplificada, como:

"ciência que estuda o processo saúde-doença em coletividades humanas, ana-
lisando a distribuição e os fatores determinantes das enfermidades, danos à
saúde e eventos associados à saúde coletiva, propondo medidas específicas
de prevenção, controle ou erradicação de doenças, e construindo indicadores
que sirvam de suporte ao planejamento, administração e avaliação das ações
de rotina, em consonância com as políticas de promoção da saúde."

Quanto à promoção da saúde, um dos focos desta Tese, o Ministério da Saúde (62), a conceitua como "produção da saúde como direito social, equidade e garantia dos demais direitos humanos e de cidadania". Através do SUS, a promoção da saúde foi retomada com ações que respondessem às demandas sociais em saúde "para além dos muros das unidades de saúde, incidindo sobre as condições de vida e favorecendo a ampliação de escolhas saudáveis por parte dos sujeitos e coletividades no território onde vivem e trabalham."

Westphal (58), elaborou um quadro, sintetizando três conceitos de Promoção da Saúde e os tipos de práticas dominantes nas vertentes biomédica, comportamental e socioambiental. Dessa forma, a autora verificou que a prevenção das doenças estaria mais relacionada a um caráter biologicista e comportamentalista do processo saúde doença, como a identificação e atuação sobre riscos. 
Ligia de Salazar (63), ao se referir à efetividade em Promoção da Saúde, coloca que dentre as muitas experiências latino-americanas de intervenção em saúde, ressalta-se uma abordagem mais voltada para problemas de saúde, estilos de vida, atividades de informação e educação das comunidades no controle de fatores de ris$\mathrm{co}$, tais como dietas saudáveis, sedentarismo, problemas com tabagismo e ingestão de bebidas alcoólicas.

A mesma autora (63) coloca que os males de saúde e as grandes desigualdades sanitárias são provocadas pela distribuição desigual de poder, sendo que as injustiças que afetam as condições de vida das populações, como falta de atenção primária em saúde, problemas de escolaridade e educação, péssimas condições de trabalho foram aspectos desconsiderados na formulação de intervenções em saúde entre os governos de diversos países da América Latina.

De acordo com Ligia de Salazar (63):

\begin{abstract}
"A maioria dos estudos publicados nas revisões de literatura sobre promoção da saúde se concentram nos componentes das habilidades pessoais e reorientação dos serviços. As estratégias para a criação de espaços e entornos saudáveis e de políticas públicas e iniquidades em saúde são abordadas de forma tímida com um enfoque reducionista tanto do problema como da situação. São evidenciadas inconsistências entre a teoria e as prioridades em saúde dos países."
\end{abstract}

Dentre muitas experiências de promoção da saúde na América Latina, estudadas pela autora (63), destaca-se o fato de que a grande maioria dessas experiências são orientadas para o componente de reorganização dos serviços, com a prevalência do enfoque biológico para abordar a problemática de saúde, "apesar de que teoricamente insistam na necessidade de considerar as estratégias para intervir nos determinantes da saúde."

Ligia de Salazar (63) refere que, ao ser realizada uma revisão de literatura indexada sobre o tema Promoção da Saúde em face de outras fontes, somente cerca de $8 \%$ dos trabalhos citaram a criação de espaços e entornos saudáveis e $7 \%$ falaram sobre políticas públicas saudáveis.

Verifica-se que a questão da falta de equidade nos países latino-americanos continua existindo de forma extremamente significativa, em face de uma promoção da saúde enfocada em mudanças comportamentais individuais, deixando-se em plano inferior as questões sociopolíticas que fomentam as iniquidades em saúde.

A abordagem socioambiental seria a que melhor forneceria benefícios a todos, por ser mais holística e completa. Apesar de se falar tanto em equidade, e de haver total justiça nessa reinvindicação, em face de tantas iniquidades nas populações, não podemos ficar cegos a uma infeliz constatação: a sociedade é movida pela exaltação do "ter" e não do "ser". O tema equidade, tão abrangente, tão necessário, talvez fique esvaziado diante da miséria humana em exaltar o "ter". Não seria então o momento de se pensar em outras estratégias para minimizar tantas desigualdades? Talvez antes de lutar por melhores remunerações, concentrarem-se em resolver efetivamente os problemas de saneamento básico e empoderar as Redes de Atenção Primária. Por- 
que dificilmente veremos tão cedo uma distribuição de renda equitativa.

Antes de começar pela "divisão equânime de lucros", talvez tenhamos que pensar de forma mais concentrada na divisão de itens mínimos para se viver com dignidade, envidando esforços em favor de ambientes dignos para as pessoas viverem no mínimo com saúde ambiental. 


\section{CONCLUSÕES}

A intervenção de educação em saúde propicia a promoção da saúde nas comunidades e o empoderamento dos sujeitos no sentido de buscarem melhor qualidade de vida a partir dessas ações, bem como auxilia no desenvolvimento social e cultural dessas comunidades. As bibliotecas públicas necessitam fazer parte, efetivamente, dos aparelhos do Estado para a promoção da saúde, pois são frequentadas por pessoas formadoras de opinião e multiplicadoras de informações para a sociedade.

A Hipótese Alterativa (H1) deste estudo, ou seja, "Uma intervenção de educação em saúde tem efetividade na qualidade de vida de indivíduos frequentadores de bibliotecas públicas" confirmou-se, em face dos resultados apresentados.

Porém, a educação em saúde no âmbito das bibliotecas públicas é apenas uma das ferramentas, uma das engrenagens de um processo muito mais amplo na esfera da Promoção da Saúde, mas que quando muito bem articulado, poderá contribuir com mudanças extremamente significativas, dando dignidade, felicidade, saúde e qualidade de vida para todos os indivíduos. 


\section{REFERÊNCIAS}

1. Ferreira JR, Buss PM. Atenção primária e promoção da saúde. In: Brasil. Ministério da Saúde. Projeto Promoção da Saúde. Brasília: Ministério da Saúde; 2001.

2. Organização Mundial de Saúde. Declaração de Alma-Ata. http://www.opas.org.br/ coletiva/uploadArq/Alma-Ata.pdf. 18 out. 2006.

3. Organização Mundial de Saúde. Carta de Ottawa. http://www.opas.org.br/coletiva/ uploadArq/Ottawa.pdf. Acesso em:19 out. 2006.

4. Brasil. Ministério da Saúde. Projeto Promoção da Saúde. Brasília: Ministério da Saúde; 2001.

5. Brasil. Constituição Federal do Brasil. http://www.senado.gov.br/sf/legislação/ const/10k. Acesso em: 22 out 2006.

6. Brasil. Ministério da Saúde. Atenção básica e a saúde da família. http://www.drt 2004.saude.gov.br/dab/atençaobasica.php. Acesso em: 28 jun 2008.

7. Baylet TJ. Quality assurance. Postgrad Med J 1988; 64(752): 473-4.

8. Painter P. The importance of exercise training in rehabilitation of patients with endstage renal disease. Am J Kidney Dis 1994; 24:2-9.

9. Cohen C. On the quality of life: some philosophical reflections. Circulation 1982; 66:29-33.

10. Wood-Dauphinee S. Assessing quality of life in clinical research: from where are we going. J Clin Epidemiol 1999; 4(52): 355-63.

11. Seidl EMF, Zannon CML da C. Qualidade de vida e saúde: aspectos conceituais e metodológicos. Caderno de Saúde Pública 2004; 20(2): 580-88.

11. Diniz DP, Schor N. Qualidade de vida: guia de medicina ambulatorial e hospitalar - UNIFESP. São Paulo: Manole; 2006.

13. Gianchello AL. Health outcomes research in hispanics/latinos. Journal of Med Systems 1996; 21(5): 235-54.

14. Minayo MCS, Hartz ZMA, Buss PM. Qualidade de vida e saúde: um debate necessário. Ciência e Saúde Coletiva 2000; 5(1):7-18.

15. The WHOQOL group. The World Health Organization quality of life assessment (WHOQOL): position paper from the World Health Organization. Soc Sci Med 1995; 41: 1403-10.

16. OPAS - Organización Panamericana de La Salud. La salud en las Américas. Washington, D.C., vol. 1, 1998, 368p. (Publicación Científica, n. 569). 
17. Buss PM. Promoção da saúde e qualidade de vida. Ciência e Saúde Coletiva 2000; 5(1):163- 77.

18. Patrício ZM. Qualidade de vida do ser humano na perspectivas de novos paradigmas. In: Patrício ZM, Casagrande JL, Araújo MF (org). Qualidade de vida do trabalhador: uma abordagem qualitativa do ser humano através de novos paradigmas. Florianópolis: Edição do Autor; 1999.

19. Antunes W, Cavalcante GA, Antunes MC. Curso de capacitação para dinamização e uso da biblioteca pública. São Paulo: Global; 2000. p. 19.

20. Viva Leitura. Informação em saúde e cidadania. Biblioteca Monique Bourget. Programa Saúde da Família Santa Marcelina. http://www.vivaleitura.com.br. Acesso em: 26 out 2006.

21. Brasil. Ministério da Saúde. Plano de Implantação Projeto Estação BVS. Brasília: Ministério da Saúde; 2008.

22. Guard $\mathrm{R}$ et al. Health care, information needs, and outreach: reaching Ohio s rural citizens. Bull Med Libr Assoc 2000; 88(4):374-381.

23. Pifalo $V$ et al. The impact of consumer health information provided by libraries: the Delaware experience. Bull Med Libr Assoc 1997; 85(1):16-22.

24. Hicken M. Public libraries and socially excluded people. Health Inf and Lib Journal 2004; 21(Suppl. 2):45-53.

25. Valla W. Apoio social e saúde: buscando compreender a fala das classes populares. In: Costa MV, org. Educação popular hoje. São Paulo: Loyola;1998. p. 151-179.

26. Minkler M. Building supportive ties and sense of community among the inner-city elderly: the tenderloin outreach project. Health Educ Quartely 1985; 12(4): 303-314.

27. Arnaud AJ, Capeller W. Cidadania e direito à saúde. In: O direito achado na rua: introdução crítica ao direito à saúde. Brasília: CEAD/UnB; 2008. p. 31-47.

28. Delduque MC, Oliveira MSC. Tijolo por tijolo: a construção permanente do direito à saúde. In: $\mathrm{O}$ direito achado na rua: introdução crítica ao direito à saúde. Brasília: CEAD/UnB; 2008. p. 103-111.

29. Barreto ML. Por uma epidemiologia da saúde coletiva. Rev Bras Epidemiol 1998; 1(2): 104-130.

30. Paim JS, Almeida Filho N. Saúde coletiva: uma nova "saúde pública" ou campo aberto a novos paradigmas. Rev Saúde Pública 1998; 32: 299-316.

31. Czeresnia D, Freitas CM (org.). Promoção da saúde: conceitos, reflexões e tendências. Rio de Janeiro: Fiocruz, 2003. 
32. Leavell S \& Clarck EG. Medicina Preventiva. São Paulo: McGraw-Hill, 1976.

33. Ayres JRCM. Hermenêutica e humanização das práticas de saúde. Ciênc \& Saúd Col 2005; 10(3): 549-60.

34. Ayres JRCM. O cuidado, os modos de ser (do) humano e as práticas de saúde. Saúd Soc 2004; 13(3): 16-29.

35. Zoboli ELCP. Responsabilidade para com a comunidade. XI Seminário de ética. Ordem dos enfermeiros. Número 37 - junho 2011.

36. Testa M. Pensar em saúde. Porto Alegre: Artes Médicas, 1992.

37. Taylor CR. Mendes D. Entre o ter e o ser competitivo. Rev FAE 2000 Set Dez; 3(3): 47-59.

38. Junges JR. O nascimento da bioética e a construção do biopoder. (No prelo).

39. Porto MF. Martinez-Alier J. Ecologia política, economia ecológica e saúde coletiva: interfaces para a sustentabilidade do desenvolvimento e para a promoção da saúde. Cad Saúd Púb 200723 Sup 4:S503-S512.

40. WHOQOL Group. The World Health Organization Quality of Life Assessment (WHOQOL): position paper from the World Health Organization. Soc Sci Med 1995; 41: 1403-9.

41. World Health Organization. WHOQOL-Bref: introduction, administration, scoring and generic version of the assessment. Geneve: 1996.

42. Instituto Brasileiro de Geografia e Estatística. Dados sobre cidades. http://www. ibge.gov.br/cidades. Acesso em: 07 jul 2009.

43. Secretaria de Turismo do Governo do Distrito Federal. Mapas. http://www.setur. df.gov.br. Acesso em: 26 mar 2008.

44. Secretaria de Planejamento do Governo do Distrito Federal. http://www.seplan. df.gov.br. Acesso em: 26 mar 2008.

45. Gomes JRAA. Percepção de auto-cuidado, saúde e qualidade de vida em usuários das bibliotecas públicas do Distrito Federal e região do Entorno em 2008: estudo transversal. [dissertação] Brasília (DF): Faculdade de Ciências da Saúde da UnB; 2008.

46. Polit DF, Beck CT, Hungler BP. Fundamentos de pesquisa em enfermagem: métodos, avaliação e utilização. Porto Alegre: Artmed; 2004.

47. Malta $\mathrm{M}$ et al. Iniciativa STROBE: subsídios para a comunicação de estudos observacionais. Rev Saúde Pública 2010; 44(3): 559-65. 
48. Brasil. Ministério da Saúde. Conselho Nacional de Saúde. Resolução 466, de 12 de dezembro de 2012. Diretrizes e normas regulamentadoras de pesquisas envolvendo seres humanos.. Disponível em: < http://conselho.saude.gov.br/resolucoes/2012/ Reso466.pdf >. Acesso em: 06 de junho de 2015.

49. Kleinbaum D, Kupper LL, Morgenstern H. Epidemiological research: principles and quantitative methods. New York: VNB; 1982.

50. Kelsey JL, Whittemore AS, Evans AS, Thompsons WD. Methods in observational epidemiology, 2nd ed. New York: Oxford University Press; 1996.

51. Hulley SB, Cummings SR. Designing clinical research. Baltimore: Willians \& Wilkins; 1988.

52. Saupe R et al. Qualidade de vida dos acadêmicos de enfermagem. Rev Lat Am Enf 2004; 12(4):636-642.

53. Bardin L. Análise de conteúdo. Lisboa: Edições 70; 1995.

54. Muñoz F, Salinas J. Promoción de salud como política de estado. "In": Albala C, Olivares S, Salinas J, Vio F. Bases, prioridades y desafícios de la promoción de la salud. Santiago: Universidad de Chile; 2004. 1-7.

55. Mendes EV. A construção social da atenção primária em saúde. Brasília: Conselho Nacional dos Secretários de Saúde - CONASS; 2015.

56. Organização Mundial da Saúde. Cuidados inovadores para as condições crônicas: componentes estruturais de ação. Brasília: Organização Mundial de Saúde; 2013.

57. Brazil. Ministério da Saúde. Sistema Nacional de Vigilância em Saúde: Relatório de Situação. Brasília: Ministério da Saúde; 2011.

58. Westphal MF. Promoção da saúde e prevenção de doenças. "In": Campos GWS, Minayo MCS, Akerman M, Drumond Jr M, Carvalho YM (Orgs.). Tratado de saúde coletiva. São Paulo: Hucitec; 2012. 635 - 667.

59. Laurenti R, Mello-Jorge MH, Gotlieb SLD. Perfil epidemiológico da morbimortalidade masculina. Ciên Saúd Colet 2005; 10(1): 35 - 46.

60. Abrasco. Pró-GT de Promoção da Saúde. Delineando um marco conceitual para a promoção da saúde e qualidade de vida. Fórum Social Mundial. Porto Alegre, 23 de janeiro de 2003.

61. Rouquayrol MZ. Contribuição da epidemiologia. "In": Campos GWS, Minayo MCS, Akerman M, Drumond Jr M, Carvalho YM (Orgs.). Tratado de saúde coletiva. São Paulo: Hucitec; 2012. 319 - 373.

62. Brasil. Ministério da Saúde. Secretaria de Vigilância em Saúde. Secretaria de Atenção à Saúde. Política Nacional de Promoção da Saúde: PNPS: revisão da 
Portaria MS/GM n 687, de 30 de março de 2006. Brasília: Ministério da Saúde; 2015.

63. Salazar L. Lecciones desde la práctica: Estamos haciendo lo que debemos o lo que podemos? "In": Salazar L. Efectividad en promoción de la salud y salud pública. Santiago de Cali: Programa Editorial Universidad del Valle; 2009. 
ANEXOS 


\section{Anexo 1 \\ Quadro dos Resultados do Mestrado}




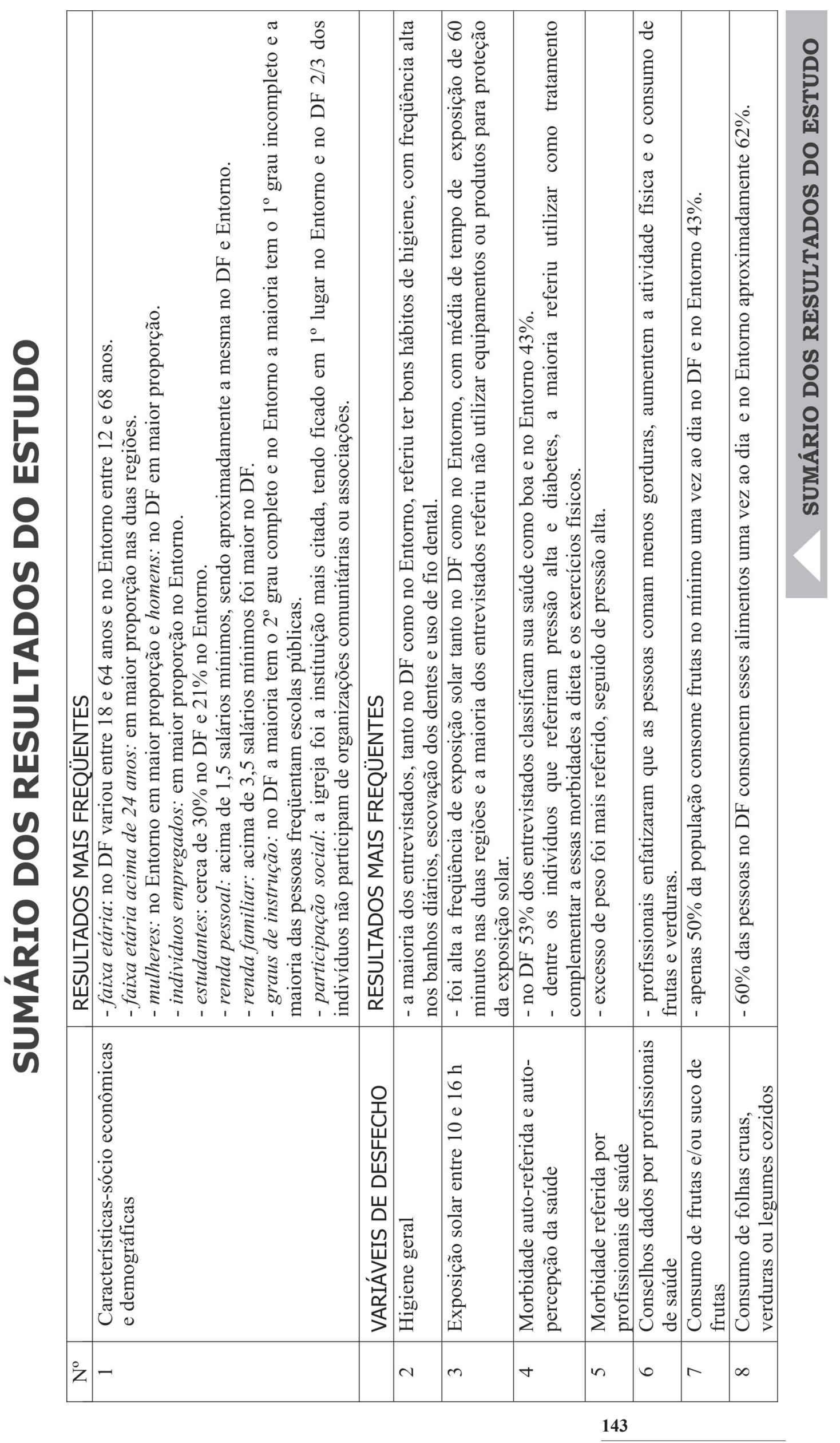




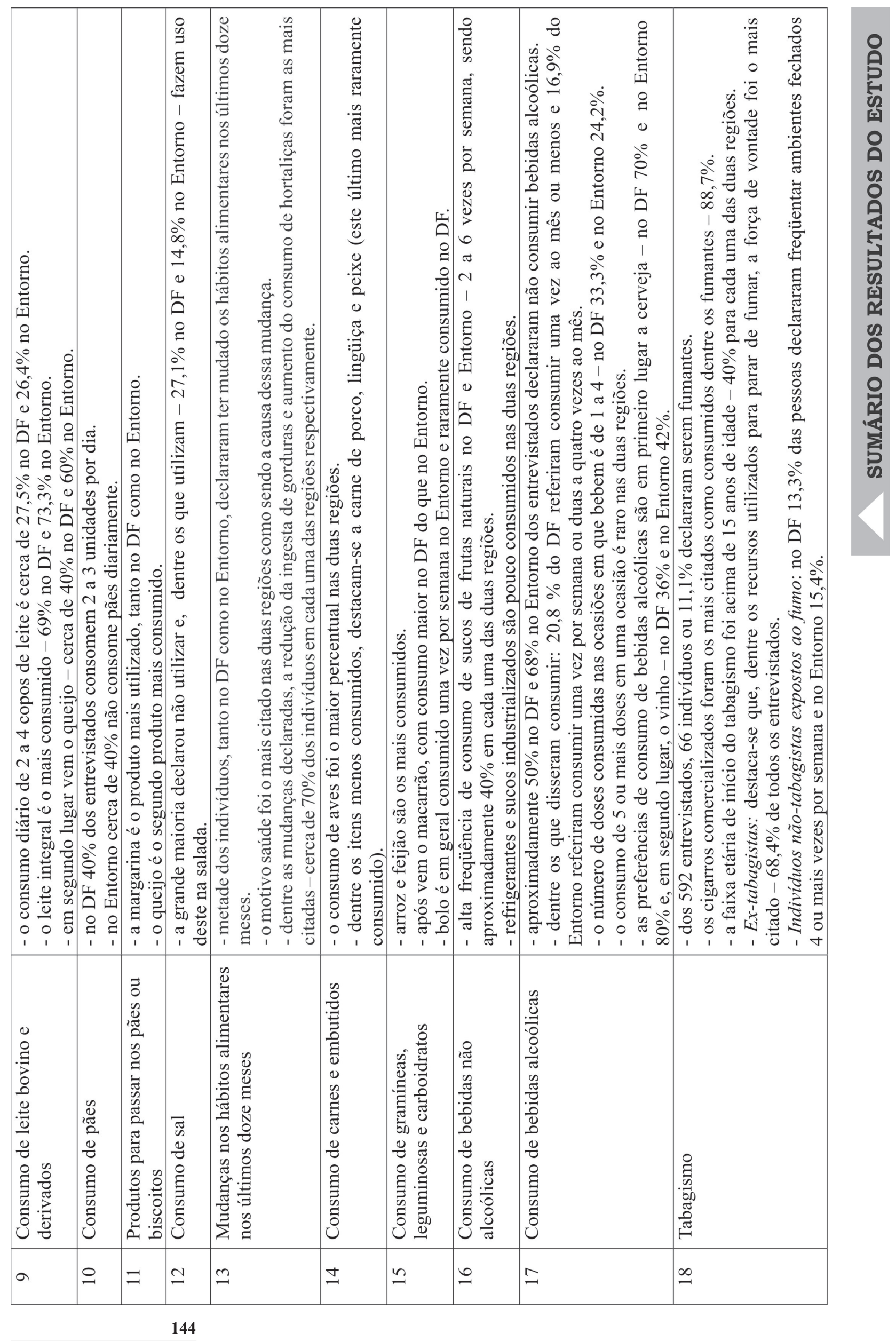




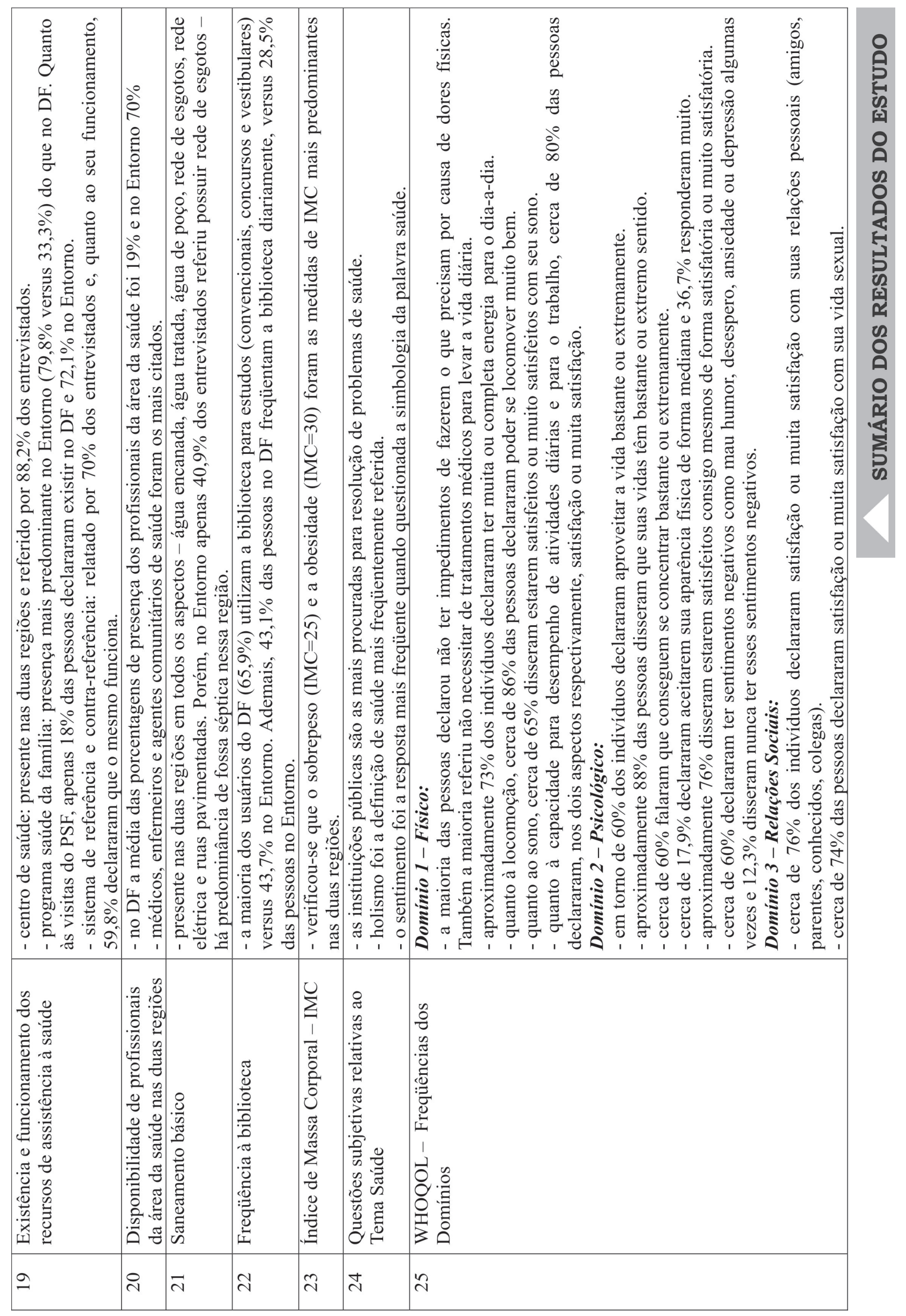




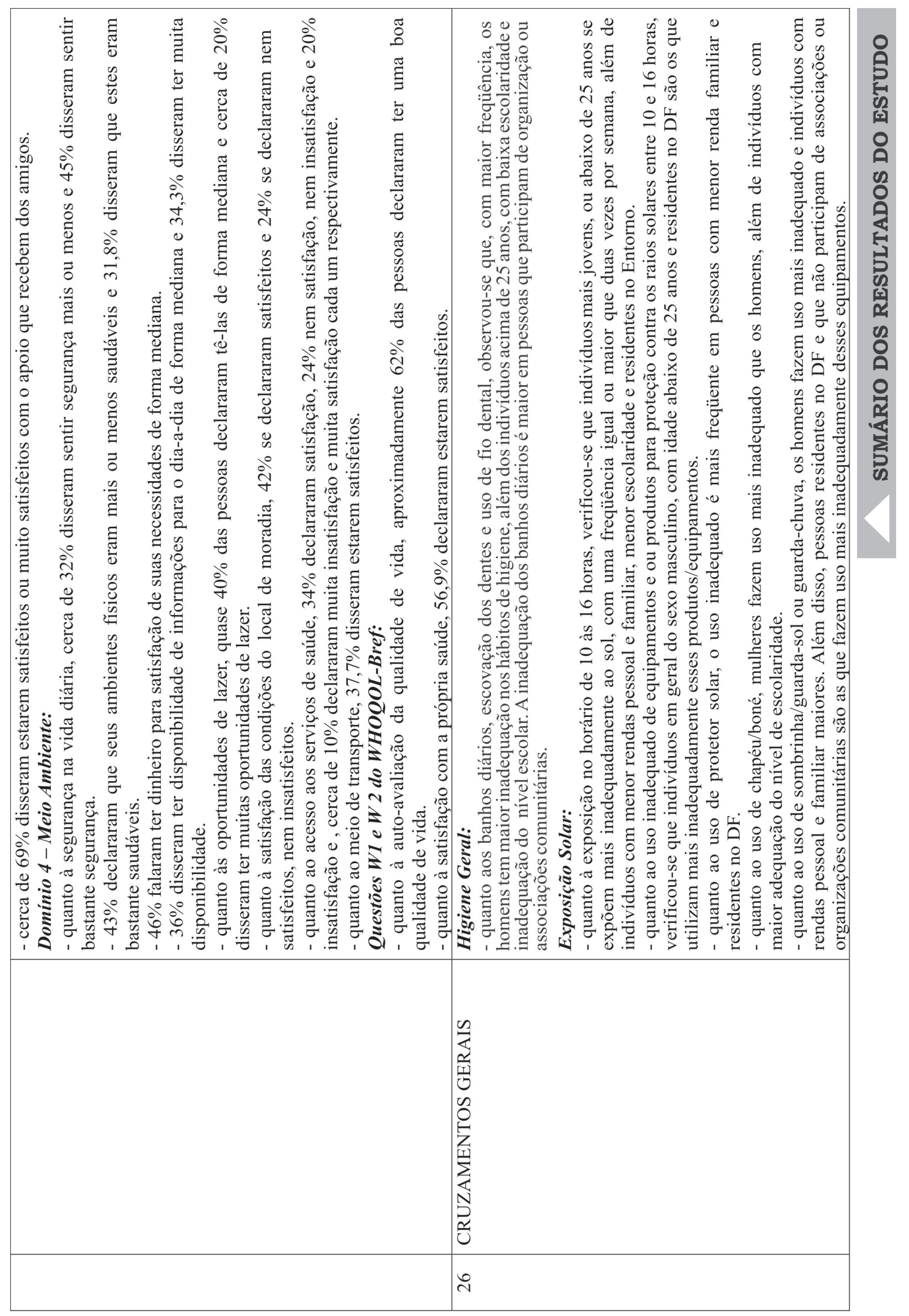




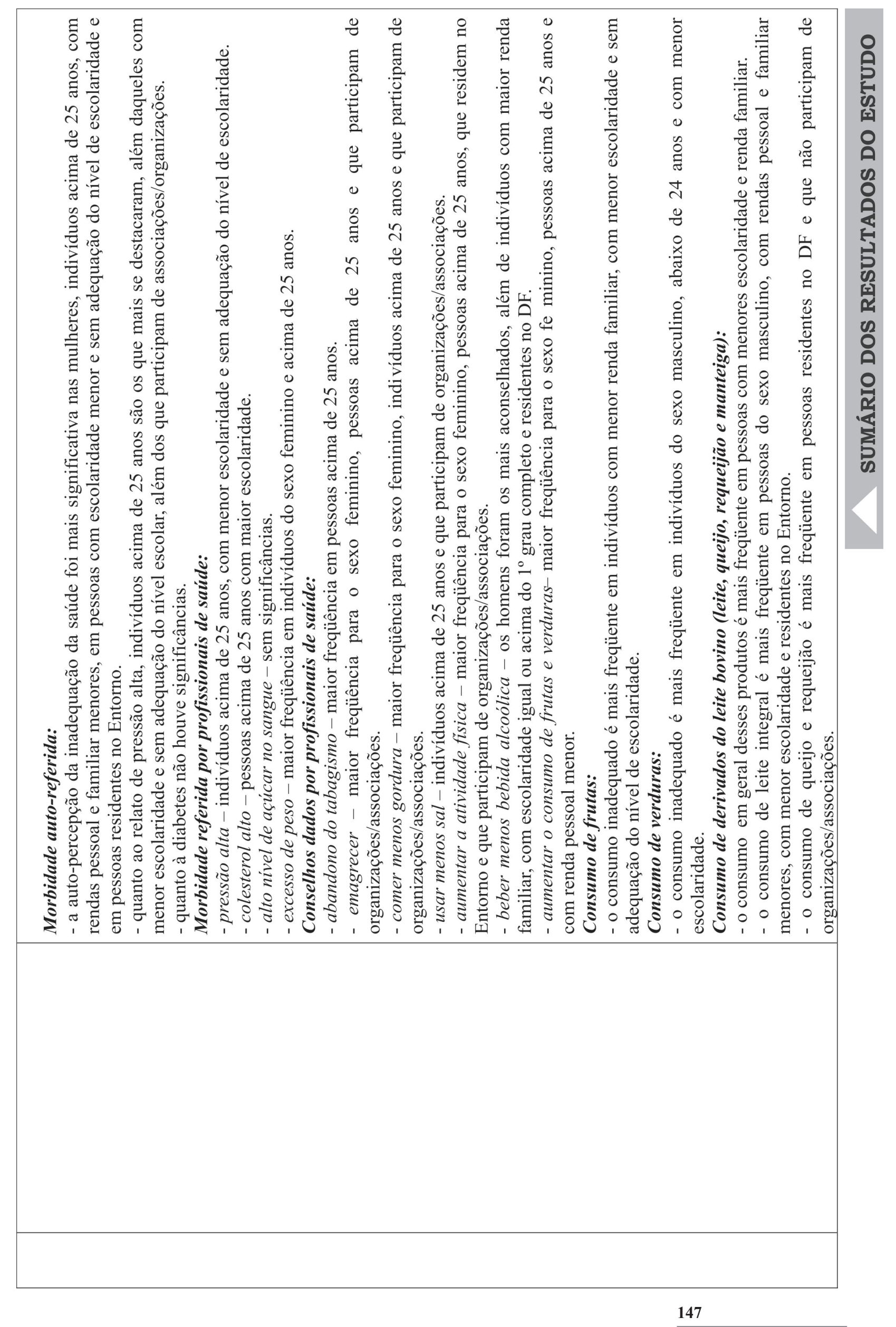




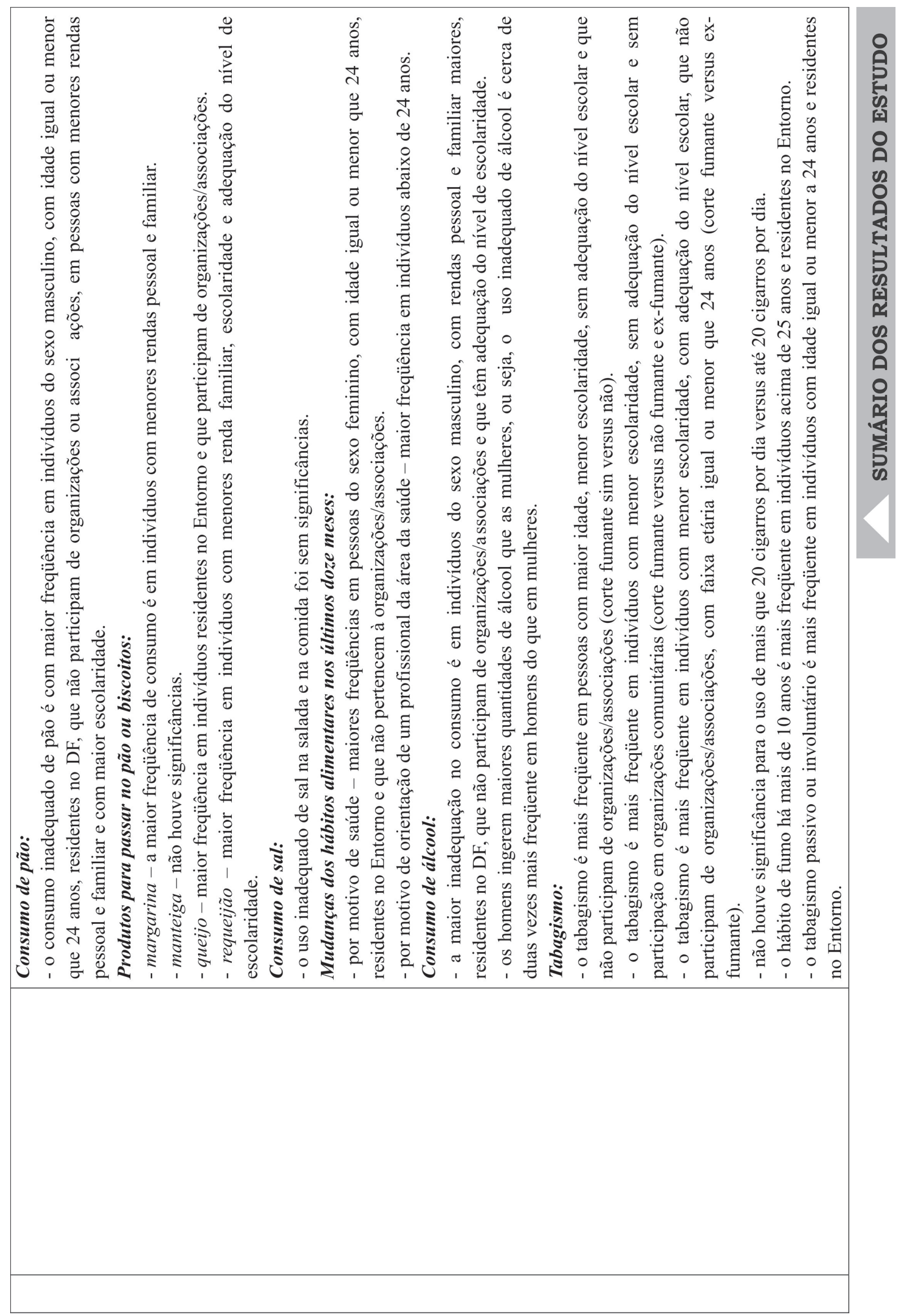




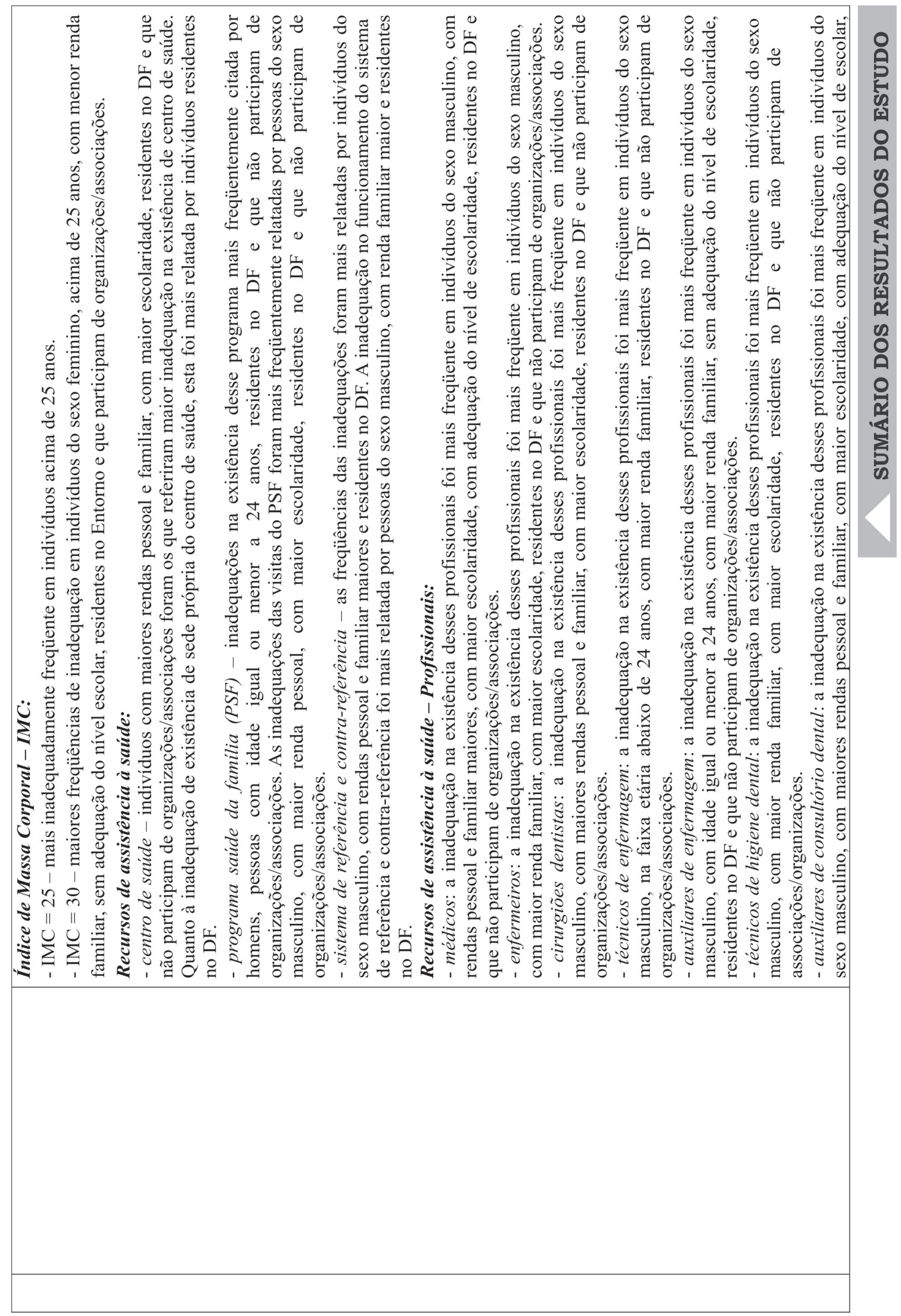




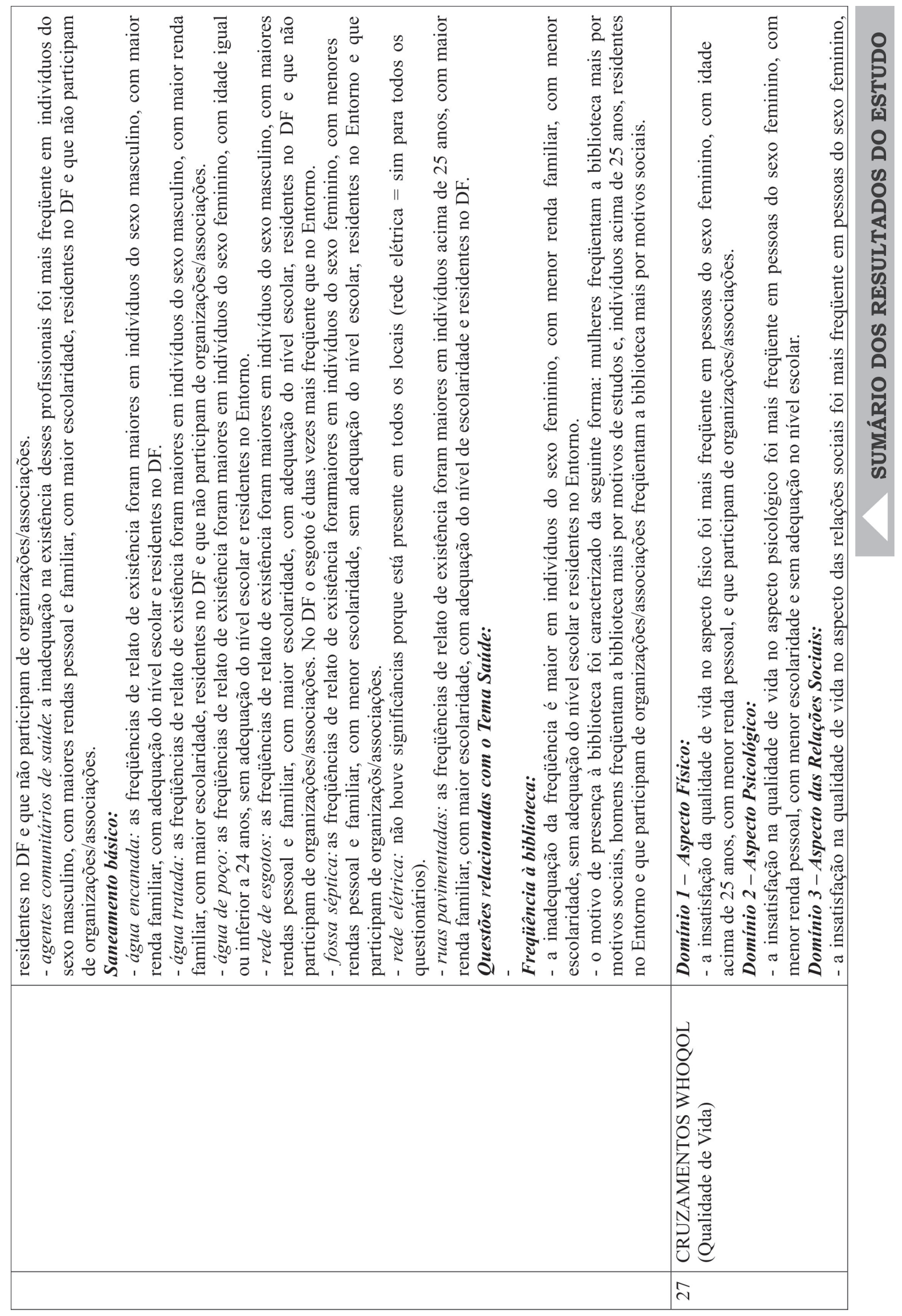




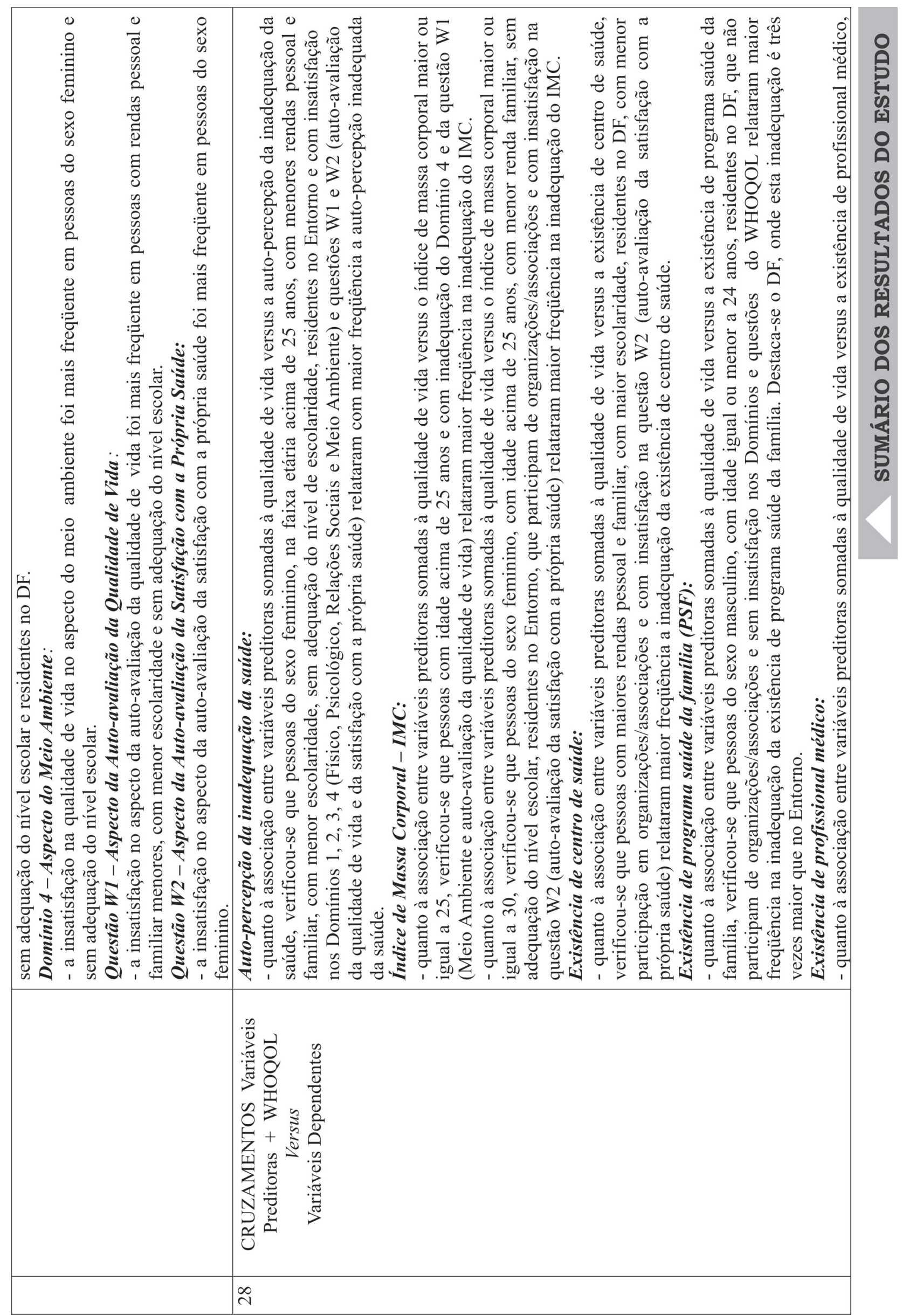









\section{Anexo 2}

CEP/FS e outros documentos 


\section{$+7$ \\ Universidade de Brasília \\ Faculdade de Ciências da Saúde \\ Comitê de Ética em Pesquisa - CEP/FS}

\section{PROCESSO DE ANÁLISE DE PROJETO DE PESQUISA}

\section{Registro do Projeto no CEP: 156/11}

Título do Projeto: "Educação em saúde nas bibliotecas públicas do Distrito Federal e Região do.Entorno: uma nova interlocução para qualidade de vida, promoção da saúde e epidemiologia."

Pesquisadora Responsável: Jacqueline Ramos de Andrade Antunes Gomes

Data de Entrada: 21/10/11

Com base na Resolução 196/96, do CNS/MS, que regulamenta a ética em pesquisa com seres humanos, o Comitê de Ética em Pesquisa com Seres Humanos da Faculdade de Ciências da Saúde da Universidade de Brasília, após análise dos aspectos éticos e do contexto técnico-científico, resolveu APROVAR o projeto 156/11 com o título: Educação em saúde nas bibliotecas públicas do Distrito Federal e Região do Entorno: uma nova interlocução para qualidade de vida, promoção da saúde e epidemiologia" analisado na $9^{\text {a }}$ reunião ordinária realizada no dia 9 de novembro de 2011.

A pesquisadora responsável fica, desde já, notificada da obrigatoriedade da apresentação de um relatório semestral e relatório final sucinto e objetivo sobre o desenvolvimento do Projeto, no prazo de 1 (um) ano a contar da presente data (item VII.13 da Resolução 196/96).

Brasília, 09 de janeiro de 2012.

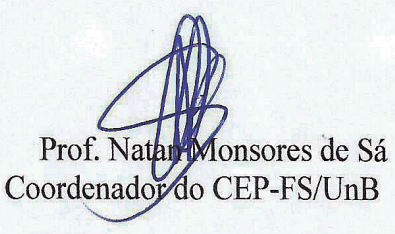




\section{Universidade de Brasilia \\ Faculdade de Ciências da Saúde}

Brasília/DF, 08 de junho de 2015

Illma. Sra.

Dra. Graça Pimentel

M.D. Coordenadora do Sistema de Bibliotecas Públicas

Secretaria da Cultura

Brasilia DF

Senhora Coordenadora,

Ao cumprimentá-la, apraz-nos apresentar a Vossa Senhoria JACQUELINE RAMOS DE ANDRADE ANTUNES GOMES, aluna do Doutorado da Faculdade de Ciências da Saúde /UnB. Ressaltamos que a referida aluna cumpriu o Programa de Mestrado também nesta Faculdade, tendo como campo de pesquisa as bibliotecas públicas de Brasília e Entorno. Na oportunidade, foram solicitados e concedidos os Termos de Consentimento correspondentes às unidades pesquisadas, tendo o projeto sido aprovado pelo Comitê de Ética desta Faculdade. O Projeto teve, da mesma forma, aprovação do Sistema de Bibliotecas Públicas/DF. Os perfis levantados ofereceram um panorama da situação das bibliotecas públicas quando foram contempladas também, questões da saúde e qualidade de vida de seus usuários.

As informações constituíram em acervo básico e específico para a continuidade dos estudos, agora em nível de doutoramento, propondo-se um processo de intervenção nas bibliotecas. Além de disseminação de informações voltadas para as demandas identificadas será criada, em cada biblioteca, a "Estante da Saúde" com documentos de apoio a leitura, a reuniões de estudos, atividades especiais como palestras, encontros, contando-se, como suporte local, com a Sociedade de Amigos da Biblioteca.

Para este trabalho junto às bibliotecas públicas, foi solicitada e concedida pelo Senador Cristovam Buarque, Emenda Parlamentar, cujo processo tramita na UnB sob os números: UnBDoc: 124880/2013 e Processo: CCO 23106.016929/2013-09.

Essa meritória ação, no contexto das bibliotecas públicas, terá por escopo a formação de uma massa crítica que embase o crescimento e desenvolvimento de pessoas capazes de utilizar a informação para o surgimento e/ou consolidação de sua cidadania, promoção da saúde e qualidade de vida. Sabemos que, dentre os equipamentos culturais hoje disponíveis, destaca-se a BIBLIOTECA PÚBLICA, presente na grande maioria 
dos municípios por este Brasil afora, verdadeira "célula-máter", da qual poderão emergir as sementes, ordens expressivas de uma nova realidade, dentre elas, miríades de leitores, exorcizando de vez os fantasmas do analfabetismo, inclusive funcional.

Nesta oportunidade, encaminhamos cópia da documentação citada ao tempo em que solicitamos seja ratificada por Vossa Senhoria o aval e apoio ao Projeto de Doutoramento citado que se desenvolve nesta Faculdade de Ciências da Saúde como trabalho acadêmico, sob a nossa orientação devendo, ao finalizar, ser-lhe encaminhados os resultados auferidos pela efetividade do mesmo.

Ao parabenizá-la por apoiar, decisivamente, este empreendimento, em prol, primacialmente, de camadas desfavorecidas da população, apresentamos a V. Excia. protestos de alta estima e distinta consideração.

Atenciosas saudações

Eniminum

Prof. Edgar Merchan Hamann

Faculdade de Ciências da Saúde/UnB 
GOVERNO DO DISTRITO FEDERAL

Secretaria de Estado de Cultura

Coordenação de Políticas do Livro e da Literatura

Diretoria do Sistema de Bibliotecas Públicas

\section{DECLARAÇÃO}

Declaro, a quem possa interessar, que a aluna do Doutorado em Ciências da Saúde, do Programa de Pós-Graduação em Ciências da Saúde da Universidade de Brasília, JACQUELINE RAMOS DE ANDRADE ANTUNES GOMES, está desenvolvendo sua Pesquisa "Leitura e uso da informação como estratégias para despertar nos usuários das Bibliotecas Públicas do Distrito Federal, especialmente no alunado do Ensino Fundamental que a frequenta, a percepção de auto-cuidado, saúde e qualidade de vida: formação e qualificação de dirigentes e usuários" nas Bibliotecas do Distrito Federal.

Informo que a aluna em epígrafe iniciou seus trabalhos no mês de maio do corrente ano em cinco Bibliotecas, a saber: Biblioteca Pública da Ceilândia, Biblioteca Pública de Taguatinga, Biblioteca Pública do Gama Biblioteca Pública de Águas Claras e Biblioteca Pública de Vicente Pires.

Declaro ainda que, o produto do trabalho inicial, que constou de curso de formação para dirigentes e responsáveis por Bibliotecas Públicas e formação de Sociedades de Amigos das Bibliotecas Públicas, contribuiu para a dinamização das Bibliotecas acima citadas, assim como para a reinauguração da Biblioteca Pública de Águas Claras e inauguração da Biblioteca Pública de Vicente Pires e da Biblioteca Pública da Estrutural.

Outrossim, informo que o Sistema de Bibliotecas Públicas do Distrito Federal, Representação Distrital do Sistema Nacional de Bibliotecas Públicas $\mathrm{BN}$, apoia integralmente a realização da Pesquisa da aluna, a qual vêm contribuindo sobremaneira para o desenvolvimento social no Distrito Federal e que, mesmo ainda não tendo sido possivel a realização da intervenção de Educação em Saúde no universo das Bibliotecas Públicas do DF, verifica-se mudanças significativas entre os usuários e servidores das Bibliotecas, no sentido destes buscarem mais frequentemente por informações e por formação, para o seu próprio crescimento pessoal e profissional.

Este Sistema de Bibliotecas Públicas do Distrito Federal espera que a Pesquisa possa efetivamente contemplar as demais Bibliotecas Públicas do Distrito Federal, de forma a contribuir para o desenvolvimento humano de nossa região.

Brasília/DF, 23 de novembro de 2015.

MARIA DAS GRAÇAS PIMLENTEL DE MENEZES

Diretora do Sistema de Bibliotecas Públicas do Distrito Federal

Subsecretaria de Politicas e Ditusão Cultural

Coordenação de Politicas do Livro e da Literatura

Diretoria do Sistema de Bibliotecas Püblicas. Diretora

"Brasília-Patrimônio Cultural da Humanidade "

SECRETARIA DE ESTADO DE CULTURA DO DISTRITO FEDERAL

Diretoria do Sistema de Bibliotecas Públicas

Setor Cultural Sul - Lote 2, Ed. da Biblioteca Nacional, Brasilia/DF CEP 70.070-150

Fone: (61) 3325-6238 email:gerenciabibliotecas@gmail.com 


\section{PROGRAMA DE PÓS-GRADUAÇÃO EM CIÊNCIAS DA SAÚDE}

\section{DEFESA DE DOUTORADO}

Título: "Educação em saúde nas bibliotecas públicas do

Distrito Federal: uma nova interlocução para qualidade de vida, promoção da saúde e epidemiologia."

Aluna: Jacqueline Ramos de Andrade Antunes Gomes Banca Examinadora:

Presidente: Edgar Merchan Hamann

Maria Margarita Urdaneta Gutierrez

Pedro Sadi Monteiro

Rafael Mota Pinheiro

Nídia Maria Lienert Lubisco

Suplente: $\quad$ Natan Monsores de Sá

Data: 03/03/2016

Horário: $14 h 30$

Local: Sala de Reuniões $n^{\circ} 1$ da FS/UnB.

Secretaria de Pós-Graduação da Faculdade de Ciências da Satute SPG/FS/UnB 
Anexo 3

TCLE 


\section{TERMO DE CONSENTIMENTO LIVRE E ESCLARECIDO}

O Senhor (a) está sendo convidado (a) participar da pesquisa: "Educação em saúde nas bibliotecas públicas do Distrito Federal e Região do Entorno: uma nova interlocução para qualidade de vida, promoção da saúde e epidemiologia". A realização deste trabalho é motivada pelo fato de terem sido levantados alguns problemas de saúde e qualidade de vida entre os usuários das bibliotecas públicas do Distrito Federal e Região do Entorno, no trabalho de Mestrado na UnB, desenvolvido pela pesquisadora responsável. Este estudo tem o objetivo de realizar uma intervenção de educação em saúde com a utilização do espaço das bibliotecas públicas, através de atividades pedagógicas interativas para adquirir e trocar conhecimentos entre os sujeitos de pesquisa. Os benefícios esperados com a realização deste trabalho estão relacionados à melhoria da qualidade de vida e dos hábitos relativos à saúde das pessoas e comunidades que utilizam as bibliotecas públicas.

O (a) senhor (a) receberá todos os esclarecimentos necessários antes e no decorrer da pesquisa e garantimos que seu nome não aparecerá, sendo mantido o mais rigoroso sigilo através da omissão total de quaisquer informações que permitam identificá - lo (a). A duração do estudo será até dezembro de 2015. A sua participação será por meio de dois (02) questionários, o WHOQOL - Bref, da OMS sobre Qualidade de Vida, e de outro elaborado pelos pesquisadores sobre dados socioeconômicos, demográficos e de saúde, que você poderá responder em aproximadamente dez (10) minutos. Não existe obrigatoriedade de um tempo pré-determinado para responder aos questionários. Será respeitado o seu tempo para respondê-lo. Informamos que a Senhor (a) pode se recusar a responder qualquer questão que o faça sentir qualquer constrangimento, podendo desistir de participar da pesquisa em qualquer momento sem nenhum prejuízo para o (a) Senhor (a).

Os resultados da pesquisa serão divulgados na Universidade de Brasília através da apresentação final do trabalho, em sessão de defesa de Doutorado, e por meio eletrônico, podendo ser publicados em revistas científicas posteriormente. Os dados e materiais utilizados na pesquisa ficarão sob a guarda da pesquisadora. Se o Senhor (a) tiver qualquer dúvida em relação à pesquisa, por favor, telefone para a pesquisadora Jacqueline nos telefones (61) 9984-9184 ou (61) 9658-9123. Este projeto foi aprovado pelo Comitê de Ética em Pesquisa da Faculdade de Ciências da Saúde da UnB. As dúvidas com relação à assinatura do TCLE ou os direitos do sujeito da pesquisa podem ser obtidos através do telefone: (61) 3107-1947. Este documento foi elaborado em duas vias, uma ficará com a pesquisadora responsável e a outra com o (a) Senhor (a). Muito obrigada pela sua valiosa colaboração!

Nome / assinatura/RG

Nome / assinatura do responsável legal/RG

Jacqueline Ramos de Andrade Antunes Gomes Pesquisadora Responsável
Prof. Dr. Edgar Merchan Hamann

Orientador 
Anexo 4

WHOQOL - Bref 


\title{
WHOQOL -ABREVIADO
}

Versão em Português

\author{
PROGRAMA DE SAÚDE MENTAL ORGANIZAÇÃO MUNDIAL \\ DA SAÚDE GENEBRA
}

Coordenação do GRUPO WHOQOL no Brasil

Dr. Marcelo Pio de Almeida Fleck Professor Adjunto

Departamento de Psiquiatria e Medicina Legal

Universidade Federal do Rio Grande do Sul

Porto Alegre - RS - Brasil 


\section{Instruções}

Este questionário é sobre como você se sente a respeito de sua qualidade de vida, saúde e outras áreas de sua vida. Por favor, responda a todas as questões. Se você não tem certeza sobre que resposta dar em uma questão, por favor, escolha entre as alternativas a que lhe parece mais apropriada. Esta, muitas vezes, poderá ser sua primeira escolha .

Por favor, tenha em mente seus valores, aspirações, prazeres e preocupações. Nós estamos perguntando o que você acha de sua vida, tomando como referência as duas últimas semanas. Por exemplo, pensando nas últimas duas semanas, uma questão poderia ser:

\begin{tabular}{||l|c|c|c|c|c||}
\hline \hline & NADA & $\begin{array}{c}\text { MUITO } \\
\text { POUCO }\end{array}$ & MÉDIO & MUITO & COMPLETAMENTE \\
\hline $\begin{array}{l}\text { Você recebe dos outros o apoio de que } \\
\text { necessita? }\end{array}$ & 1 & 2 & 3 & 4 & 5 \\
\hline \hline
\end{tabular}

Você deve circular o número que melhor corresponde ao quanto você recebe dos outros o apoio de que necessita nestas últimas duas semanas. Portanto, você deve circular o número 4 se você recebeu "muito" apoio como abaixo.

\begin{tabular}{||l|c|c|c|c|c||}
\hline \hline & NADA & $\begin{array}{c}\text { MUITO } \\
\text { POUCO }\end{array}$ & MÉDIO & MUITO & COMPLETAMENTE \\
\hline $\begin{array}{l}\text { Você recebe dos outros o apoio de que } \\
\text { necessita? }\end{array}$ & 1 & 2 & 3 & 4 & 5 \\
\hline
\end{tabular}

Você deve circular o número 1 se você não recebeu "nada" de apoio. 
Por favor, leia cada questão, veja o que você acha e circule no número e lhe parece a melhor resposta.

\begin{tabular}{||l|l|c|c|c|c|c||}
\hline \hline & $\begin{array}{c}\text { MUITO } \\
\text { RUIM }\end{array}$ & RUIM & $\begin{array}{c}\text { NEM RUIM } \\
\text { NEM BOA }\end{array}$ & BOA & $\begin{array}{c}\text { MUITO } \\
\text { BOA }\end{array}$ \\
\hline 1 & Como você avaliaria sua qualidade de vida? & 1 & 2 & 3 & 4 & 5 \\
\hline
\end{tabular}

\begin{tabular}{||c|c|c|c|c|c|c||}
\hline \hline & $\begin{array}{c}\text { MUITO } \\
\text { INSATISFEITO }\end{array}$ & INSATISFEITO & $\begin{array}{c}\text { NEM SATISFEITO } \\
\text { NEM } \\
\text { INSATISFEITO }\end{array}$ & SATISFEITO & $\begin{array}{c}\text { MUITO } \\
\text { SATISFEITO }\end{array}$ \\
\hline 2 & $\begin{array}{l}\text { Quão satisfeito (a) } \\
\text { você está com a sua } \\
\text { saúde? }\end{array}$ & 1 & 2 & 3 & 4 & 5 \\
\hline
\end{tabular}

As questões seguintes são sobre o quanto você tem sentido algumas coisas nas últimas duas semanas.

\begin{tabular}{||l|l|c|c|c|c|c||}
\hline \hline & NADA & $\begin{array}{c}\text { MUITO } \\
\text { POUCO }\end{array}$ & $\begin{array}{c}\text { MAIS } \\
\text { OU } \\
\text { MENOS }\end{array}$ & BASTANTE & EXTREMAMENTE \\
\hline 3 & $\begin{array}{l}\text { Em que medida você acha que sua } \\
\text { dor (física) impede você de fazer o } \\
\text { que você precisa? }\end{array}$ & 1 & 2 & 3 & 4 & 5 \\
\hline 4 & $\begin{array}{l}\text { O quanto você precisa de algum } \\
\text { tratamento médico para levar sua } \\
\text { vida diária? }\end{array}$ & 1 & 2 & 3 & 4 & 5 \\
\hline 5 & O quantovocê aproveita a vida? & 1 & 2 & 3 & 4 & 5 \\
\hline 6 & $\begin{array}{l}\text { Em que medida você acha que a sua } \\
\text { vida tem sentido? }\end{array}$ & 1 & 2 & 3 & 4 & 5 \\
\hline 7 & $\begin{array}{l}\text { O quanto você consegue se } \\
\text { concentrar? }\end{array}$ & 1 & 2 & 3 & 4 & 5 \\
\hline 8 & $\begin{array}{l}\text { Quão seguro (a) você se sente em sua } \\
\text { vida diária? }\end{array}$ & 1 & 2 & 3 & 4 & 5 \\
\hline 9 & $\begin{array}{l}\text { Quão saudável é o seu ambiente } \\
\text { fisico (clima, barulho, poluição, } \\
\text { atrativos)? }\end{array}$ & 1 & 2 & 3 & 4 & 5 \\
\hline \hline
\end{tabular}

As questões seguintes perguntam sobre quão completamente você tem sentido ou é capaz de fazer certas coisas nestas últimas duas semanas.

\begin{tabular}{||l|l|c|c|c|c|c||}
\hline \hline & & NADA & $\begin{array}{c}\text { MUITO } \\
\text { POUCO }\end{array}$ & MÉDIO & MUITO & COMPLETAMENTE \\
\hline 10 & $\begin{array}{l}\text { Você tem energia suficiente para seu } \\
\text { diazadia? }\end{array}$ & 1 & 2 & 3 & 4 & 5 \\
\hline 11 & $\begin{array}{l}\text { Você é capaz de aceitar sua aparência } \\
\text { física? }\end{array}$ & 1 & 2 & 3 & 4 & 5 \\
\hline 12 & $\begin{array}{l}\text { Você tem dinheiro suficiente para satisfazer } \\
\text { suas necessidades? }\end{array}$ & 1 & 2 & 3 & 4 & 5 \\
\hline 13 & $\begin{array}{l}\text { Quão disponíveis para você estão as } \\
\text { informações que precisa no seu dia-a-dia? }\end{array}$ & 1 & 2 & 3 & 4 & 5 \\
\hline 14 & $\begin{array}{l}\text { Em que medida você tem oportunidades de } \\
\text { atividade de lazer? }\end{array}$ & 1 & 2 & 3 & 4 & 5 \\
\hline
\end{tabular}


As questões seguintes perguntam sobre quão bem ou satisfeito você se sentiu a respeito de vários aspectos de sua vida nas últimas duas semanas.

\begin{tabular}{||l|c|c|c|c|c|c||}
\hline \hline & & $\begin{array}{c}\text { MUITO } \\
\text { RUIM }\end{array}$ & RUIM & $\begin{array}{c}\text { NEM RUIM } \\
\text { NEM BOM }\end{array}$ & BOM & $\begin{array}{c}\text { MUITO } \\
\text { BOM }\end{array}$ \\
\hline 15 & Quão bem você é capaz de se locomover? & 1 & 2 & 3 & 4 & 5 \\
\hline
\end{tabular}

\begin{tabular}{|c|c|c|c|c|c|c|}
\hline & & $\begin{array}{c}\text { MUITO } \\
\text { INSATISFEITO }\end{array}$ & INSATISFEITO & $\begin{array}{c}\text { NEM } \\
\text { SATISFEITO } \\
\text { NEM } \\
\text { INSATISFEITO } \\
\end{array}$ & SATISFEITO & $\begin{array}{c}\text { MUITO } \\
\text { SATISFEITO }\end{array}$ \\
\hline 16 & $\begin{array}{l}\text { Quão satisfeito (a) você } \\
\text { está com o seu sono? }\end{array}$ & 1 & 2 & 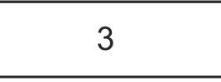 & 4 & 5 \\
\hline 17 & $\begin{array}{l}\text { Quão satisfeito (a) você } \\
\text { está com sua capacidade } \\
\text { de desempenhar as } \\
\text { atividades } \\
\text { do seu dia-a-dia? }\end{array}$ & 1 & 2 & 3 & 4 & 5 \\
\hline 18 & $\begin{array}{l}\text { Quão satisfeito (a) você } \\
\text { está com sua capacidade } \\
\text { para o trabalho? }\end{array}$ & 1 & 2 & 3 & 4 & 5 \\
\hline 19 & $\begin{array}{l}\text { Quão satisfeito(a) você } \\
\text { está consigo mesmo? }\end{array}$ & 1 & 2 & 3 & 4 & 5 \\
\hline 20 & $\begin{array}{l}\text { Quão satisfeito (a) você } \\
\text { está com suas relações } \\
\text { pessoais (amigos, } \\
\text { parentes, conhecidos, } \\
\text { colegas)? }\end{array}$ & 1 & 2 & 3 & 4 & 5 \\
\hline 21 & $\begin{array}{l}\text { Quão satisfeito (a) você } \\
\text { está com sua vida } \\
\text { sexual? }\end{array}$ & 1 & 2 & 3 & 4 & 5 \\
\hline 22 & $\begin{array}{l}\text { Quão satisfeito (a) você } \\
\text { está com o apoio que } \\
\text { você recebe de seus } \\
\text { amigos? }\end{array}$ & 1 & 2 & 3 & 4 & 5 \\
\hline 23 & $\begin{array}{l}\text { Quão satisfeito (a) você } \\
\text { está com as condições } \\
\text { do local onde mora? }\end{array}$ & 1 & 2 & 3 & 4 & 5 \\
\hline 24 & $\begin{array}{l}\text { Quão satisfeito (a) você } \\
\text { está com o seu acesso } \\
\text { aos serviços de saúde? }\end{array}$ & 1 & 2 & 3 & 4 & 5 \\
\hline 25 & $\begin{array}{l}\text { Quão satisfeito (a) você } \\
\text { está com o seu meio de } \\
\text { transporte? }\end{array}$ & 1 & 2 & 3 & 4 & 5 \\
\hline
\end{tabular}

As questões seguintes referem-se a com que freqüência você sentiu ou experimentou certas coisas nas últimas duas semanas.

\begin{tabular}{||c|c|c|c|c|c|c||}
\hline \hline & NUNCA & $\begin{array}{c}\text { ALGUMAS } \\
\text { VEZES }\end{array}$ & FREQÜENTEMENTE & $\begin{array}{c}\text { MUITO } \\
\text { FREQÜENTEMENTE }\end{array}$ & SEMPRE \\
\hline 26 & $\begin{array}{l}\text { Com que freqüência } \\
\text { você tem sentimentos } \\
\text { negativos tais como } \\
\text { mau humor, desespero, } \\
\text { ansiedade, depressão? }\end{array}$ & 1 & 2 & 3 & 4 & 5 \\
\hline
\end{tabular}

Alguém lhe ajudou a preencher este questionário?

Quanto tempo você levou para preencher este questionário?.

Você tem algum comentário sobre o questionário? 


\section{Anexo 5}

\section{Questionário Percepção}

Acerca do Auto-cuidado com o Corpo e Saúde Física e Mental na Perspectiva da Promoção da Saúde 


\begin{tabular}{|l|l|l|l|l|}
\hline Local de entrevista: Biblioteca Pública & Código & \multicolumn{2}{|l|}{} \\
\hline Local de moradia do entrevistado: & Código & & \\
\hline
\end{tabular}

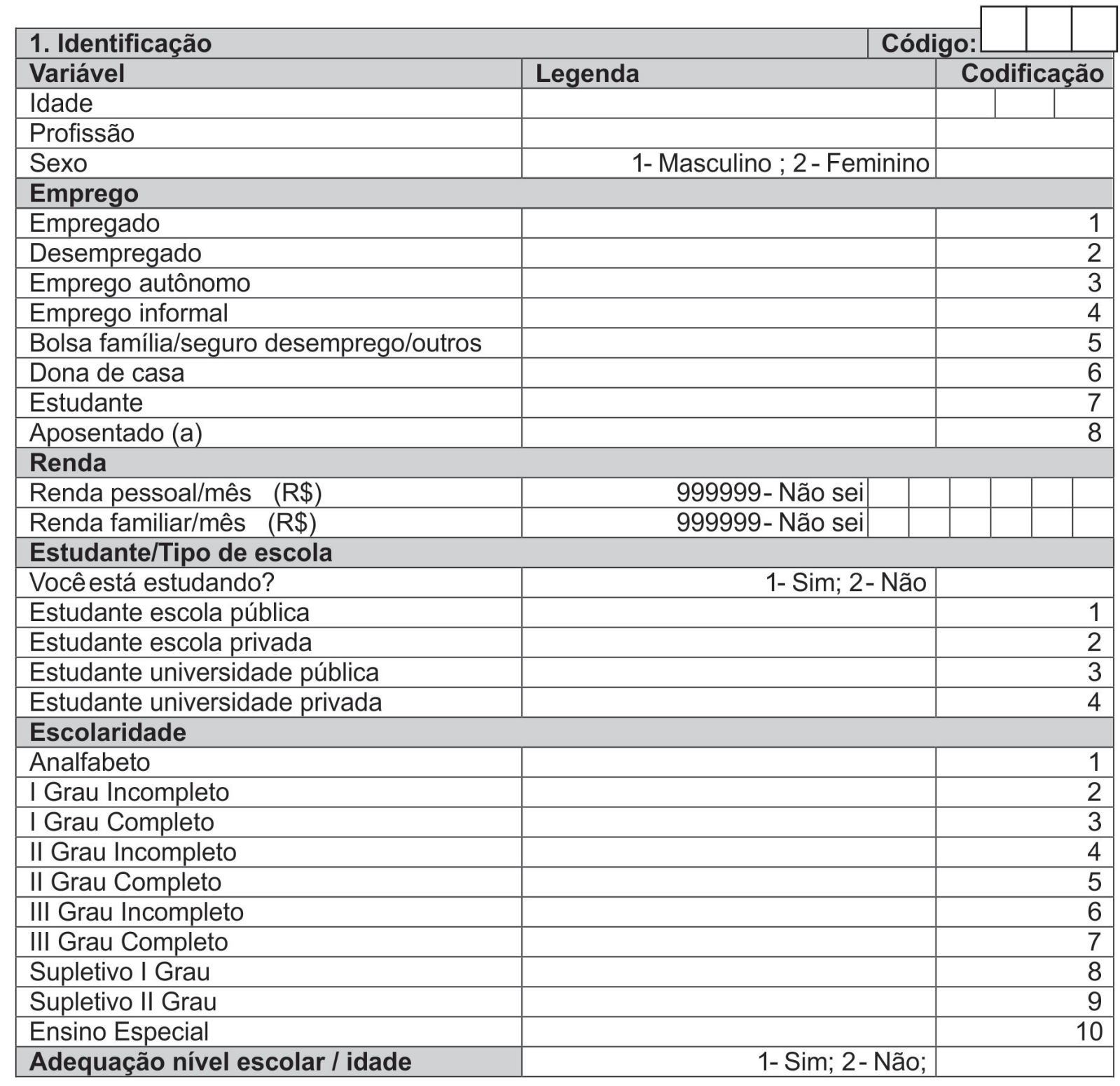

\begin{tabular}{|l|l|r|}
\hline 2. Participação Social & Legenda & Codificação \\
\hline Variável & \multicolumn{1}{|c|}{ 1- Sim; 2 - Não } \\
\hline $\begin{array}{l}\text { Pertença alguma organização comunitária ou } \\
\text { movimento social? }\end{array}$ & \\
\hline Qual(is)? Opções: & & 1 \\
\hline Associação de moradores & & 2 \\
\hline Sindicato & & 4 \\
\hline Grupo de militância & & 5 \\
\hline Conselho & & 6 \\
\hline Igreja & & 7 \\
\hline Associação & & 8 \\
\hline Agremiação & & 99 \\
\hline Outros. Qual? & & \\
\hline Não respondeu & & \\
\hline
\end{tabular}




\begin{tabular}{|c|c|c|}
\hline 3. Percepção Geral da Saúde & & \\
\hline 3.1 Avaliação da Saúde & & \\
\hline \multicolumn{3}{|l|}{ Variável } \\
\hline Percepção geral da saúde & 4-Excelente; ßBoa; 2 Regular; 7Ruim & \\
\hline \multicolumn{3}{|l|}{ Higiene } \\
\hline Higienização bucal (escovação dos dentes) & $\begin{array}{l}1-\text { Sim; 2- Não } \\
\text { Número de vezes ao dia: }\end{array}$ & \\
\hline Fio dental & Número de vezes ao dia: ${ }^{1-S i m ;}$ 2-Não & \\
\hline Banho diário & 1- Sim; 2-Não & \\
\hline Freqüência banho diário & Número de vezes ao dia: & \\
\hline \multicolumn{3}{|l|}{ Exposição Solar } \\
\hline Exposição solar entre 10 e 16 horas & 1- Sim; 2-Não & \\
\hline \multicolumn{3}{|l|}{ Freqüência exposição solar: Opções: } \\
\hline Nunca me exponho ao sol & & 1 \\
\hline 1 a 2 por semana & & 2 \\
\hline 2 a 4 por semana & & 3 \\
\hline 4 a 6 por semana & & 4 \\
\hline Todos os dias & & 5 \\
\hline Tempo exposição solar & horas ao dia & \\
\hline Usa protetor solar & 1-Sim; 2-Não; 3- Às vezes & \\
\hline Usa chapéu/boné & 1-Sim; 2-Não; 3- Às vezes & \\
\hline Usa sombrinha/guarda chuva/sol & 1-Sim: 2-Não: 3- Às vezes & \\
\hline \multicolumn{3}{|l|}{ Pressão Alta } \\
\hline Você têm pressão alta? & 1-Sim; 2-Não; 3- Não sabe & \\
\hline \multicolumn{3}{|c|}{$\begin{array}{l}\text { Você faz ou já fez tratamento para pressão alta? } \\
\text { Opções: }\end{array}$} \\
\hline Fiz Há quanto tempo parou? & 1-Sim; 2-Não & \\
\hline Nunca fiz tratamento & 1-Sim; 2-Não & \\
\hline $\begin{array}{l}\text { Faço tratamento com uso regular de } \\
\text { medicações }\end{array}$ & 1-Sim; 2-Não & \\
\hline $\begin{array}{l}\text { Faço tratamento sem uso regular de } \\
\text { medicações } \\
\text { Qual tratamento? Opções: }\end{array}$ & 1-Sim; 2-Não & \\
\hline Dieta & 1-Sim; 2-Não & \\
\hline Exercício físico & 1-Sim; 2-Não & \\
\hline Outros & 1-Sim; 2-Não & \\
\hline $\begin{array}{l}\text { Faço tratamentocom uso irregular de } \\
\text { medicações } \\
\text { Por quê? }\end{array}$ & 1-Sim; 2-Não & \\
\hline \multicolumn{3}{|l|}{ Diabetes } \\
\hline Você é diabético/têm diabetes? & 1-Sim; 2-Não; 3- Não sabe & \\
\hline \multicolumn{3}{|c|}{$\begin{array}{l}\text { Você faz ou já fez tratamento para diabetes? } \\
\text { Opções: }\end{array}$} \\
\hline Fiz Há quanto tempo parou? & 1-Sim; 2-Não & \\
\hline Nunca fiz tratamento & 1-Sim; 2-Não & \\
\hline $\begin{array}{l}\text { Faço tratamento com uso regular de } \\
\text { medicações }\end{array}$ & 1-Sim; 2-Não & \\
\hline $\begin{array}{l}\text { Faço tratamento sem uso regular de } \\
\text { medicações } \\
\text { Qual tratamento? Opções: }\end{array}$ & 1-Sim; 2-Não & \\
\hline Dieta & 1-Sim; 2-Não & \\
\hline Exercício físico & 1-Sim; 2-Não & \\
\hline Outros & 1-Sim; 2-Não & \\
\hline $\begin{array}{l}\text { Faço tratamento com uso irregular de } \\
\text { medicações } \\
\text { Por quê? }\end{array}$ & 1-Sim; 2-Não & \\
\hline
\end{tabular}


3.2 Processos de Trabalho em Saúde

\begin{tabular}{l|r|r|}
\hline Variável & Legenda & Codificação \\
\hline $\begin{array}{l}\text { Algum profissional da saúde disse que você têm: } \\
\text { Opções: }\end{array}$ & 1-Sim; 2-Não & 1-Sim; 2-Não \\
\hline Pressão alta & 1-Sim; 2-Não & 1-Sim; 2-Não \\
\hline Colesterol alto & \multicolumn{1}{|l|}{} \\
\hline Alto nível de açúcar no sangue & 1-Sim; 2-Não & \\
\hline Excesso de peso & 1-Sim; 2-Não \\
\hline $\begin{array}{l}\text { Durante os últimos 12 meses, algum profissional de saúde lhe aconselhou que: } \\
\text { Opções: }\end{array}$ & 1-Sim; 2-Não & \\
\hline Deixe de fumar & 1-Sim; 2-Não & \\
\hline Emagreça & 1-Sim; 2-Não & \\
\hline Coma menos gordura & 1-Sim; 2-Não & \\
\hline Use menos sal & 1-Sim; 2-Não & \\
\hline Aumente atividade física &
\end{tabular}

\begin{tabular}{|c|c|c|}
\hline \multicolumn{3}{|l|}{ 4. Alimentação } \\
\hline Variável & Legenda & Codificação \\
\hline $\begin{array}{l}\text { Você consome frutas/sucos de frutas todo } \\
\text { dia? }\end{array}$ & 1-Sim; 2-Não & \\
\hline \multicolumn{3}{|c|}{$\begin{array}{l}\text { Se afirmativoquantas frutas/sucos de frutas você come todo dia? } \\
\text { Opções: }\end{array}$} \\
\hline 1 por dia & & 1 \\
\hline 2 a 4 por dia & & 2 \\
\hline 4 a 6 por dia & & 3 \\
\hline \multicolumn{3}{|l|}{$\begin{array}{l}\text { Se negativo, como seria seu consumo? } \\
\text { Opções: }\end{array}$} \\
\hline 1 a 2 por semana & & 1 \\
\hline 2 a 4 por semana & & 2 \\
\hline 4 a 6 por semana & & 3 \\
\hline $\begin{array}{l}\text { Você consome folhas cruas, verduras ou } \\
\text { legumes cozidos diariamente? (exceto batata, } \\
\text { mandioca, inhame e cará) }\end{array}$ & 1-Sim; 2-Não & \\
\hline \multicolumn{3}{|c|}{$\begin{array}{l}\text { Se afirmativoquantas porções de verduras você consome por dia? } \\
\text { Opções: }\end{array}$} \\
\hline 1 porção por dia & & 1 \\
\hline 2 a 4 porções por dia & & 2 \\
\hline 4 a 6 porções por dia & & 3 \\
\hline \multicolumn{3}{|l|}{$\begin{array}{l}\text { Se negativo, como seria seu consumo? } \\
\text { Opções: }\end{array}$} \\
\hline 1 a 2 porções por semana & & 1 \\
\hline 2 a 4 porções por semana & & 2 \\
\hline 4 a 6 porções por semana & & 3 \\
\hline
\end{tabular}




\begin{tabular}{|c|c|c|}
\hline \multicolumn{3}{|l|}{ 4.1 Alimentação } \\
\hline Variável & Legenda & Codificação \\
\hline Você costuma consumir leite diariamente? & 1-Sim; 2-Não & \\
\hline \multicolumn{3}{|c|}{$\begin{array}{l}\text { Se afirmativoquantos copos/xícaras de leite você consome por dia? } \\
\text { Opções: }\end{array}$} \\
\hline $1 \mathrm{copo} /$ xícara por dia & & 1 \\
\hline 2 a 4 copos/xícaras por dia & & 2 \\
\hline 4 a 6 copos/xícaras por dia & & 3 \\
\hline \multicolumn{3}{|l|}{$\begin{array}{l}\text { Se negativo, como seria o seu consumo? } \\
\text { Opções: }\end{array}$} \\
\hline 1 a 2 copos/xícaras por semana & & 1 \\
\hline 2 a 4 copos/xícaras por semana & & 2 \\
\hline 4 a 6 copos/xícaras por semana & & 3 \\
\hline \multicolumn{3}{|c|}{$\begin{array}{l}\text { Caso faça uso, qual é o tipo de leite que normalmente utiliza? } \\
\text { Opções: }\end{array}$} \\
\hline Desnatado & 1-Sim; 2-Não & \\
\hline Semi-desnatado & 1-Sim; 2-Não & \\
\hline Integral & 1-Sim; 2-Não & \\
\hline Você costuma consumir pães diariamente? & 1-Sim; 2-Não & \\
\hline \multicolumn{3}{|c|}{$\begin{array}{l}\text { Quantos pães você normalmente consome por dia? } \\
\text { Opções: }\end{array}$} \\
\hline Não consumo pão diariamente & & 1 \\
\hline Menos de 1 unidade por dia & & 2 \\
\hline 1 unidade por dia & & 3 \\
\hline 2 a 3 unidades por dia & & 4 \\
\hline Mais de 4 unidades por dia & & 5 \\
\hline \multicolumn{3}{|c|}{$\begin{array}{l}\text { Que tipo de produto ou produtos você mais utiliza para passar no pão ou biscoitos? } \\
\text { Opções: }\end{array}$} \\
\hline Margarina $\rightarrow$ Marca: & 1-Sim; 2-Não & \\
\hline Manteiga & 1-Sim; 2-Não & \\
\hline Queijo & 1-Sim; 2-Não & \\
\hline Requeijão & 1-Sim; 2-Não & \\
\hline Nenhuma das anteriores & & 99 \\
\hline $\begin{array}{l}\text { Você costuma adicionar sal no prato nas } \\
\text { refeições? }\end{array}$ & 1-Sim; 2-Não; 3- Ás vezes & \\
\hline Em que preparação? & 1- Salada; 2- Comida & \\
\hline $\begin{array}{l}\text { Nos últimos } 12 \text { meses você mudou seus } \\
\text { hábitos alimentares? }\end{array}$ & 1-Sim; 2-Não & \\
\hline \multicolumn{3}{|l|}{$\begin{array}{l}\text { Caso afirmativo, por quê? } \\
\text { Opções: }\end{array}$} \\
\hline Saúde & 1-Sim; 2-Não & \\
\hline Estética & 1-Sim; 2-Não & \\
\hline Orientação de um profissional de saúde & 1-Sim; 2-Não & \\
\hline \multicolumn{2}{|l|}{ Outro. Especificar: } & 3 \\
\hline
\end{tabular}

\begin{tabular}{|c|c|c|}
\hline Variável & Legenda & Codificação \\
\hline \multicolumn{3}{|c|}{$\begin{array}{l}\text { Qual mudança você fez nos hábitos alimentares? } \\
\text { Opções: }\end{array}$} \\
\hline Reduzi a quantidade de comida. & 1-Sim; 2-Não & \\
\hline Reduzi a quantidade de gordura. & 1-Sim; 2-Não & \\
\hline Mudei o tipo de gorduras. & 1-Sim;2-Não & \\
\hline $\begin{array}{l}\text { Aumentei o consumo de hortaliças (exceto } \\
\text { batata, mandioca). }\end{array}$ & 1-Sim; 2-Não & \\
\hline Aumentei o consumo de frutas. & 1-Sim; 2-Não & \\
\hline Reduzi a quantidade de açúcar. & 1-Sim; 2-Não & \\
\hline Reduzi a quantidade de sal. & 1-Sim; 2-Não & \\
\hline Reduzi o consumo de carnes vermelhas. & 1-Sim; 2-Não & \\
\hline \multicolumn{2}{|l|}{ Outros. Especifique: } & 3 \\
\hline
\end{tabular}




\begin{tabular}{|l|l|l|}
\hline 4.3 Alimentaçãe Freqüência de consumo de alimentos específicos \\
\hline Variável & Legenda (mostrar tabela opções) & Codificação \\
\hline $\begin{array}{l}\text { Qual a freqüência que você consome os } \\
\text { seguintes alimentos: }\end{array}$ & $\begin{array}{l}\text { 1- Raras vezes ou nunca } \\
\text { 2- Uma ou poucas vezes ao mês } \\
\text { Opções: }\end{array}$ & \\
& $\begin{array}{l}\text { 3-1 vez na semana } \\
\text { 4-2 a 6 vezes na semana } \\
\text { 5-Uma vez ao dia ou mais } \\
\text { freqüente }\end{array}$ & \\
\hline Carne de porco & $\rightarrow$ & \\
\hline Lingüiça & $\rightarrow$ & \\
\hline Aves & $\rightarrow$ & \\
\hline Peixe & $\rightarrow$ & \\
\hline Arroz & $\rightarrow$ & \\
\hline Feijão & $\rightarrow$ & \\
\hline Macarrão & $\rightarrow$ & \\
\hline Bolo & $\rightarrow$ & \\
\hline Refrigerante "normal" & $\rightarrow$ & \\
\hline Refrigerante dietético & $\rightarrow$ & \\
\hline Suco de fruta natural & $\rightarrow$ & \\
\hline Suco industrial "normal & $\rightarrow$ & \\
\hline Suco industrial dietético & $\rightarrow$ & \\
\hline
\end{tabular}

\begin{tabular}{|c|c|c|}
\hline \multicolumn{3}{|l|}{ 5. Consumo de Álcool } \\
\hline Variável & Legenda & Codificação \\
\hline Você toma bebida alcoólica? & 1-Sim; 2Não; 3-Não respondeu & \\
\hline \multicolumn{3}{|c|}{$\begin{array}{l}\text { Com que freqüência você toma bebidas de álcool? } \\
\text { Opções: }\end{array}$} \\
\hline Nunca & & 1 \\
\hline Uma vez por mês ou menos & & 2 \\
\hline $\begin{array}{l}\text { Duas a quatro vezes por mês (ou uma vez por } \\
\text { semana) }\end{array}$ & & 3 \\
\hline Duas a três vezes por semana & & 4 \\
\hline Quatro ou mais vezes por semana & & 5 \\
\hline Nenhuma das respostas & & 99 \\
\hline $\begin{array}{l}\text { Listar três bebidas predominantemente } \\
\text { consumidas conforme a ordem abaixo: }\end{array}$ & \multicolumn{2}{|c|}{$\begin{array}{r}\text { Opções: } \\
\text { 4-Vinho; 2-Uísque; 3-Cachaça; } \\
\\
\text { 4-Champanhe; 9-Licor; } 10 \text { - Outras } \\
\text { 8-Cerveja; 6-Chopp 7-Conhaque; }\end{array}$} \\
\hline $1^{\text {a }}$ mais consumida: & $\mathrm{R} .=$ & \\
\hline $2^{\mathrm{a}}$ mais consumida: & $\mathrm{R} .=$ & \\
\hline $3^{\mathrm{a}}$ mais consurda: & $\mathrm{R} .=$ & \\
\hline \multicolumn{3}{|c|}{$\begin{array}{l}\text { Nas ocasiões em que bebe, quantas doses, copos ou garrafas o Sr. ou Sra. costuma tomar? } \\
\text { Opções: }\end{array}$} \\
\hline 1 ou 2 doses & & 1 \\
\hline 3 ou 4 doses & & 2 \\
\hline 5 ou 6 doses & & 3 \\
\hline 7 a 9 doses & & 4 \\
\hline 10 ou mais doses & & 5 \\
\hline Nenhuma das respostas & & 99 \\
\hline \multicolumn{3}{|c|}{$\begin{array}{l}\text { Com que freqüência você toma cinco ou mais doses em uma ocasião? } \\
\text { Opções: }\end{array}$} \\
\hline Nunca & & 1 \\
\hline Menos de 1 vez por mês & & 2 \\
\hline Uma vez ao mês & & 3 \\
\hline Uma vez por semana & & 4 \\
\hline Todos os dias ou quase todos os dias & & 5 \\
\hline Nenhuma das respostas & & 99 \\
\hline
\end{tabular}




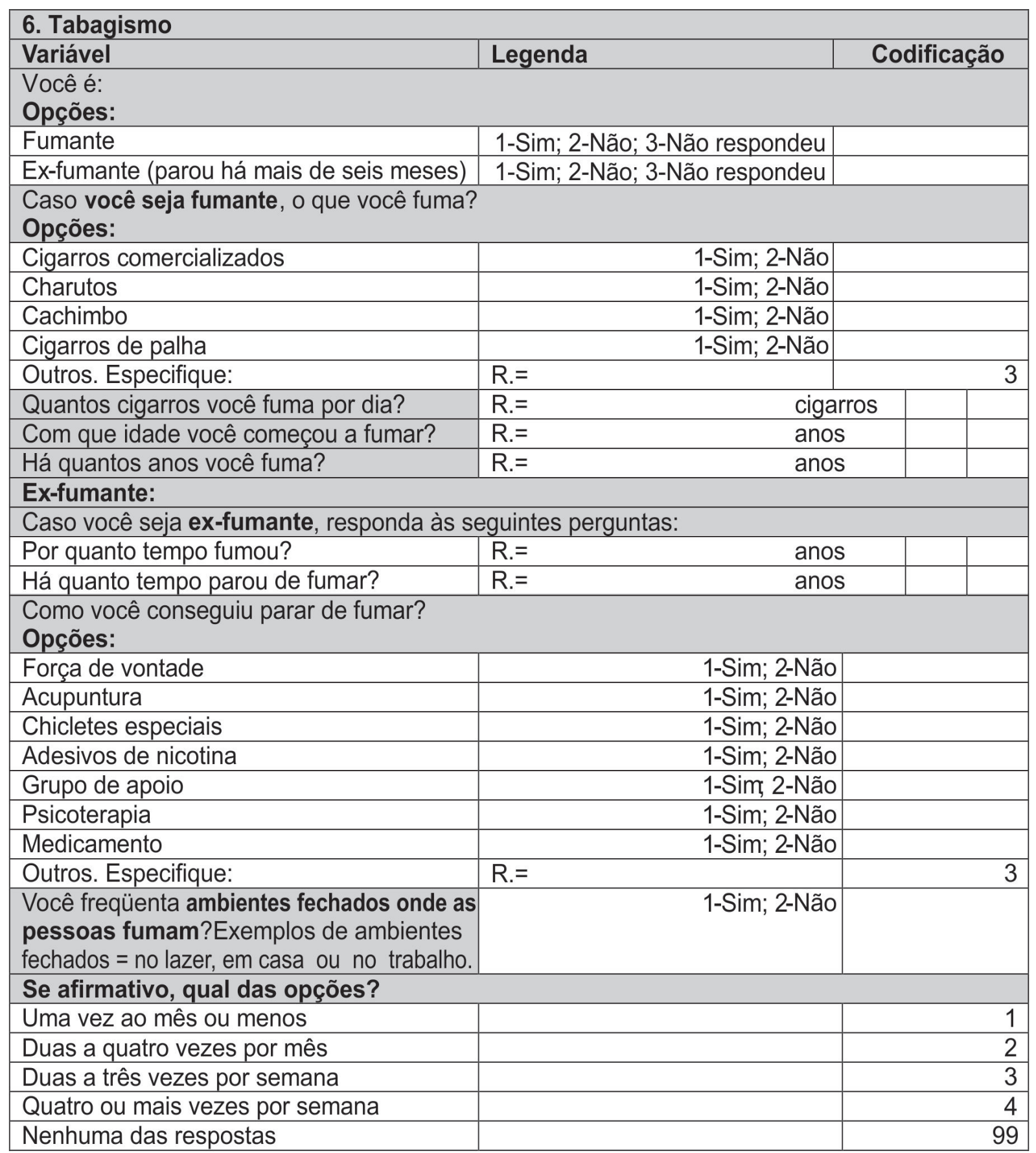

\begin{tabular}{|l|l|}
\hline 7. Índice de Massa Corporal - IMC & Registro \\
\hline Variável & \\
\hline Peso & \\
\hline Altura & \\
\hline Cálculo IMC & \\
\hline
\end{tabular}

IMC = peso $/(\text { altura })^{2}$ 


\begin{tabular}{|c|c|c|}
\hline \multicolumn{3}{|c|}{ 8. Recursos de Assistência à Saúde/Saneamento Básico } \\
\hline Variável & Legenda & Codificação \\
\hline $\begin{array}{l}\text { Local possui centro de saúde } \\
\text { comunitária? }\end{array}$ & 1- Sim; 2-Não; 3-Não sei & \\
\hline Existe sede do Centro de Saúde? & 1- Sim; 2-Não; 3-Não sei & \\
\hline $\begin{array}{l}\text { Local possui Programa Saúde da } \\
\text { Família/Família Saudável? }\end{array}$ & 1- Sim; 2-Não; 3-Não sei & \\
\hline $\begin{array}{l}\text { O Programa Saúde da Família/Familia } \\
\text { Saudável está visitando as casas? }\end{array}$ & 1- Sim; 2-Não; 3-Não sei & \\
\hline $\begin{array}{l}\text { Existe Sistema de Referência e } \\
\text { Contrareferência? }\end{array}$ & 1- Sim; 2-Não; 3-Não sei & \\
\hline $\begin{array}{l}\text { Este Sistema de Referência e Contra } \\
\text { referência funciona? }\end{array}$ & 1- Sim; 2-Não; 3-Não sei & \\
\hline \multicolumn{3}{|c|}{$\begin{array}{l}\text { Quais desses profissionais que vou citar atuam no Programa Saúde da Família/Família Saudável? } \\
\text { (Referir quantidade de cada profissional) } \\
\text { Opções: }\end{array}$} \\
\hline Médicos & 1- Sim; 2- Não; 3-Não sei $\rightarrow$ Quantidade: & \\
\hline Enfermeiros & 1- Sim; 2- Não; 3-Não sei $\rightarrow$ Quantidade: & \\
\hline Cirurgiões dentistas & 1- Sim; 2- Não; 3-Não sei $\rightarrow$ Quantidade: & \\
\hline Técnicos de enfermagem & 1- Sim; 2- Não; 3-Não sei $\rightarrow$ Quantidade: & \\
\hline Auxiliares de enfermagem & 1- Sim; 2- Não; 3-Não sei $\rightarrow$ Quantidade: & \\
\hline Técnicos de higiene dental & 1- Sim; 2- Não; 3-Não sei $\rightarrow$ Quantidade: & \\
\hline Auxiliares de consultório dental & 1- Sim; 2- Não; 3-Não sei $\rightarrow$ Quantidade: & \\
\hline Agentes comunitários de saúde & 1- Sim; 2- Não; 3-Não sei $\rightarrow$ Quantidade: & \\
\hline \multicolumn{3}{|l|}{ Outros recursos: } \\
\hline Local possui água encanada? & 1- Sim; 2-Não; 3-Não sei & \\
\hline Local possui água tratada? & 1- Sim; 2-Não; 3-Não sei & \\
\hline Local possui água de poço? & 1- Sim; 2-Não; 3-Não sei & \\
\hline Local possui rede de esgotos? & 1- Sim; 2-Não; 3-Não sei & \\
\hline Local possui fossa séptica? & 1- Sim; 2-Não; 3-Não sei & \\
\hline Local possui rede elétrica? & 1- Sim; 2-Não; 3-Não sei & \\
\hline Local possui ruas pavimentadas? & 1- Sim; 2-Não; 3-Não sei| & \\
\hline $\begin{array}{l}\text { Quando você adoece, o que você faz? } \\
\text { A que você recorre? }\end{array}$ & R. $=$ & \\
\hline Para você, o que é saúde? & $\mathrm{R} .=$ & \\
\hline $\begin{array}{l}\text { Quais as palavras que vêm à sua mente } \\
\text { quando se fala em saúde? }\end{array}$ & R. $=$ & \\
\hline
\end{tabular}




\begin{tabular}{|c|c|c|}
\hline \multicolumn{3}{|l|}{ 9. Freqüência da Biblioteca } \\
\hline Variável & Legenda & Codificação \\
\hline Por que você está aqui na biblioteca? & $\begin{array}{l}1 \text { - Acesso digital } \\
2 \text { - Estudar para concursos } \\
3 \text { - Estudar para vestibulares } \\
4 \text { - Estudos convencionais } \\
\text { - - Leitura } \\
\text { 6 - Reunião de grupos } \\
7 \text { - Outros: } \\
\quad \text { Quais? }\end{array}$ & \\
\hline $\begin{array}{l}\text { Com que freqüência você utiliza a } \\
\text { biblioteca? }\end{array}$ & $\begin{array}{l}\text { 1- Raras vezes ou nunca } \\
2 \text { - Uma ou poucas vezes ao mês } \\
\text { - } 1 \text { vez na semana } \\
\text { 4- } 2 \text { a } 4 \text { vezes na semana } \\
\text { - Diariamente }\end{array}$ & \\
\hline
\end{tabular}

OBRIGADO PELA SUA VALIOSA COLABORAÇÃO! 


\section{Anexo 6}

\section{Produção Literária que Integrou o Kit de Apoio à Intervenção Proposta}


6.1 - Coleção para gente grande: Cuidando dos Dentes 6.2 - Coleção para gente grande: Cuidando da Higiene 6.3 - Coleção para gente grande: Como se Organizar 6.4 - Coleção maçã verde: A festa dos dentes 6.5 - Coleção maçã verde: Isadora e a turma do banho 6.6 - Coleção maçã verde: Cada coisa no lugar certo 

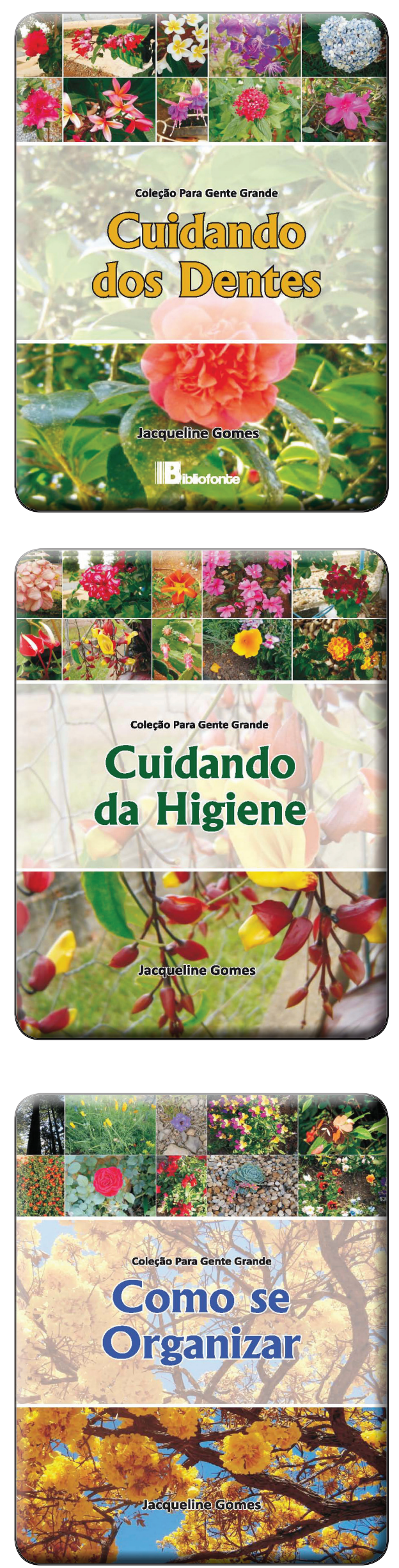
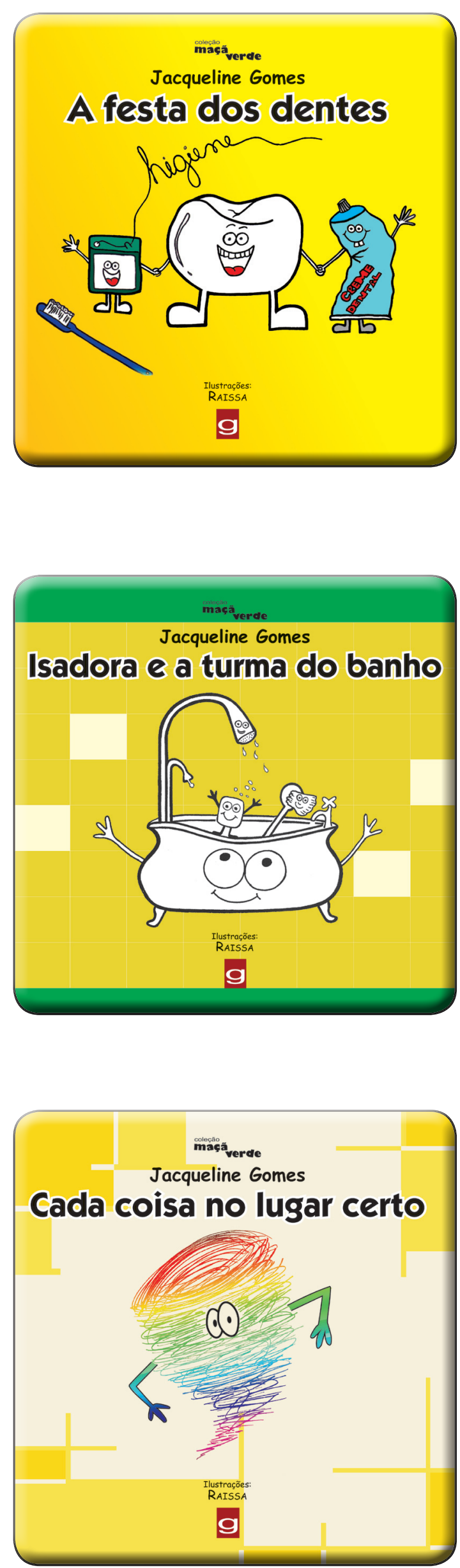


\section{Anexo 7}

Demo do Vídeo Produzido para Integrar o Kit de Apoio à Intervenção 


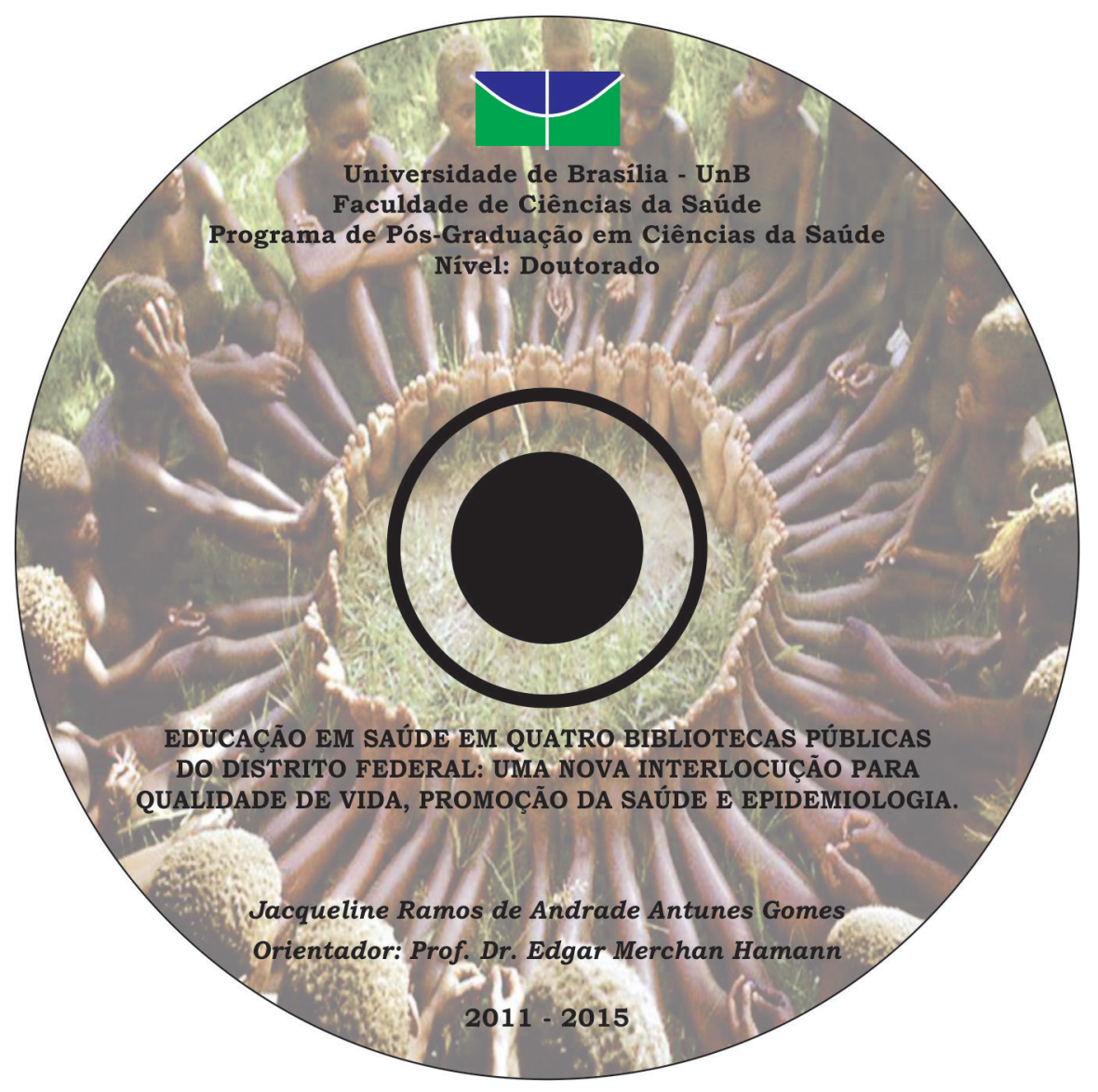




\section{Anexo 8}

\section{Orientações para \\ Cálculos do WHOQOL - Bref}


WHOQOL-BREF

INTRODUCTION, ADMINISTRATION, SCORING

AND GENERIC VERSION OF THE ASSESSMENT

Field Trial Version

December 1996

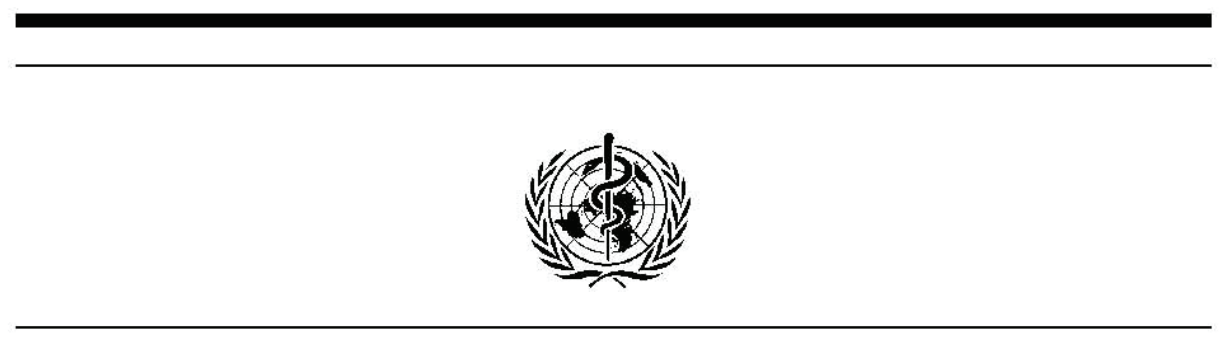

PROGRAMME ON MENTAL HEALTH

WORLD HEALTH ORGANIZATION GENEVA 
This manual was drafted by Alison Harper on behalf of the WHOQOL group. The WHOQOL group comprises a coordinating group, collaborating investigators in each of the field centres and a panel of consultants. Dr J. Orley directs the project. He has been assisted in this by Professor M. Power, Dr W. Kuyken, Professor N. Sartorius, Dr M. Bullinger and Dr A. Harper. The field centres involved in initial piloting of the WHOQOL were: Professor $\mathrm{H}$. Herrman, Dr H. Schofield and Ms B. Murphy, University of Melbourne, Australia; Professor Z. Metelko, Professor S. Szabo and Mrs M. Pibernik-Okanovic, Institute of Diabetes, Endocrinology and Metabolic Diseases and Department of Psychology, Faculty of Philosophy, University of Zagreb, Croatia; Dr N. Quemada and Dr A. Caria, INSERM, Paris, France; Dr S. Rajkumar and Mrs Shuba Kumar, Madras Medical College, India; Dr S. Saxena and Dr K. Chandiramani, All India Institute of Medical Sciences, New Delhi, India; Dr M. Amir and Dr D. Bar-On, Ben-Gurion University of the Negev, Beer-Sheeva, Israel; Dr Miyako Tazaki, Department of Science, Science University of Tokyo, Japan and Dr Ariko Noji, Department of Community Health Nursing, St Luke's College of Nursing, Japan; Dr G. van Heck and Mrs J. De Vries, Tilburg University, The Netherlands; Professor J. Arroyo Sucre and Professor L. PicardAmi, University of Panama, Panama; Professor M. Kabanov, Dr A. Lomachenkov and Dr G. Burkovsky, Bekhterev Psychoneurological Research Institute, St. Petersburg, Russia; Dr R. Lucas Carrasco, University of Barcelona, Spain; Dr Yooth Bodharamik and Mr Kitikorn Meesapya, Institute of Mental Health, Bangkok, Thailand; Dr S. Skevington, University of Bath, United Kingdom; Professor D. Patrick, Ms M. Martinand, Ms D. Wild, University of Washington, Seattle, USA and; Professor W. Acuda and Dr J. Mutambirwa, University of Zimbabwe, Harare, Zimbabwe.

New centres using the field version of the WHOQOL-100 are: Dr S. Bonicato, FUNDONAR, Fundacion Oncologica Argentina, Argentina; Dr A.E. Molzahn, University of Victoria, Canada; Dr G. Yongping, St Vincent s Hospital, Victoria, Australia; Dr G. Page, University of Quebec at Rimouski, Canada; Professor J. Fang, Sun Yat-Sen University of Medical Sciences, People s Republic of China; Dr M. Fleck, University of the State of Rio Grande do Sul, Brazil; Professor M.C. Angermeyer, Dr R. Kilian, Universitätsklinikum Klinik und Poliklinik für Psychiatrie, Leipzig, Germany, Mr Kwok Fai Leung, Hospital Authority, Hong Kong; Dr B.R. Hanestad, University of Bergen, Norway; Dr M.H. Mubbashar, Rawalpindi General Hospital, Pakistan; Dr J. Harangozo, Semelweis University of Medicine, Budapest \& Dr L. Kullman, National Institute of Mental Rehabilitation, Budapest, Hungary; Professor I. Wiklund, Health Economics \& Quality of Life, Astra Hässle AB, Sweden; Dr C. Fidaner, Dr Behçet Uz Paediatric Hospital, Balçova/Izmir, Turkey, Dr G. de Girolamo, Servizio Salute Mentale USL 27, Italy, Professor P. Bech, Frederiksborg General Hospital, Denmark; Dr R.S. Pippalla, Howard University, College of Pharmacy and Pharmaceutical Sciences, Washington, DC, USA and Dr H. Che Ismail, School of Medical Sciences, Kelantan, Malaysia.

\author{
Further information can be obtained from: \\ Dr John Orley \\ Programme on Mental Health \\ World Health Organization \\ CH-1211 Geneva 27, Switzerland
}


This document is not issued to the general public, and all rights are reserved by $t$ Health Organization (WHO). This document may not be reviewed, abstracted, reproduced, translated, referred to in bibliographical matter or cited, in part or i without the prior written permission of WHO. No part of this document may be : retrieval system or transmitted in any form by any means - electronic, mechanical without the prior written permission of WHO. The WHOQOL Group, Programme Health, WHO, CH-1211 Geneva 27, Switzerland. 


\section{WHOQOL-BREF \\ Introduction, Administration, Scoring and Generic Version of the Assessment}

\section{Introduction}

The WHOQOL-100 quality of life assessment was developed by the WHOQOL Group with fifteen international field centres, simultaneously, in an attempt to develop a quality of life assessment that would be applicable cross-culturally. The development of the WHOQOL-100, has been detailed elsewhere (i.e. Orley \& Kuyken, 1994; Szabo, 1996; WHOQOL Group 1994a, 1994b, 1995). This document gives a conceptual background to the WHOQOL definition of quality of life and describes the development of the WHOQOL-BREF, an abbreviated version of the WHOQOL-100. It also includes a generic English language version of the WHOQOL-BREF, instructions for administering and scoring, and proposed uses for this short form of the WHOQOL.

\section{Rationale for the development of the WHOQOL-100}

WHO's initiative to develop a quality of life assessment arose for a number of reasons. In recent years there has been a broadening in focus in the measurement of health, beyond traditional health indicators such as mortality and morbidity (e.g. World Bank, 1993; WHO, 1991), to include measures of the impact of disease and impairment on daily activities and behaviour (e.g. Sickness Impact Profile; Bergner, Bobbitt, Carter et al, 1981), perceived health measures (e.g. Nottingham Health Profile; Hunt, McKenna and McEwan, 1989) and disability / functional status measures (e.g. the MOS SF-36, Ware et al, 1993). These measures, whilst beginning to provide a measure of the impact of disease, do not assess quality of life per se, which has been aptly described as "the missing measurement in health" (Fallowfield, 1990). Second, most measures of health status have been developed in North America and the UK, and the translation of these measures for use in other settings is time-consuming, and unsatisfactory for a number of reasons (Sartorius and Kuyken, 1994; Kuyken, Orley, Hudelson and Sartorius, 1994). Third, the increasingly mechanistic model of medicine, concerned only with the eradication of disease and symptoms, reinforces the need for the introduction of a humanistic element into health care. By calling for quality of life assessments in health care, attention is focused on this aspect of health, and resulting interventions will pay increased attention to this aspect of patients' well-being. WHO's initiative to develop a quality of life assessment arises from a need for a genuinely international measure of quality of life and a commitment to the continued promotion of an holistic approach to health and health care.

\section{Steps in the development of the WHOQOL-100}

The WHOQOL-100 development process consisted of several stages. These are explained in brief within this document. For a detailed description, the reader is referred to the WHOQOL Group (1994a, $1994 \mathrm{~b}$, in preparation). In the first stage, concept clarification involved establishing an agreed upon definition of quality of life and an approach to international quality of life assessment.

Quality of life is defined as individuals' perceptions of their position in life in the context of the culture and value systems in which they live and in relation to their goals, expectations, standards and concerns.

This definition reflects the view that quality of life refers to a subjective evaluation which is embedded in a cultural, social and environmental context. Because this definition of quality of life focuses upon respondents' "perceived" quality of life, it is not expected to provide a means of measuring in any 
WHOQOL-BREF - INSTRUCTIONS

Page 6

detailed fashion symptoms, diseases or conditions, but rather the effects of disease and health interventions on quality of life. As such, quality of life cannot be equated simply with the terms "health status", "life style", "life satisfaction", "mental state" or "well-being". The recognition of the multi-dimensional nature of quality of life is reflected in the WHOQOL-100 structure.

In the second stage of development, exploration of the quality of life construct within 15 culturally diverse field centres was carried out to establish a list of areas/facets that participating centres considered relevant to the assessment of quality of life. This involved a series in meetings of focus groups which included health professionals, patients and well subjects. A maximum of six specific items for exploring each proposed facet were generated by each centre's focus group. To enable the collaboration to be genuinely international the 15 field centres were selected world-wide to provide differences in level of industrialisation, available health services, and other markers relevant to the measurement of quality of life (e.g. role of the family, perception of time, perception of self, dominant religion)

In the third stage of development, questions from each centre were assembled into a global pool. After clustering semantically equivalent questions, 236 items covering 29 facets were included in a final assessment. Pilot work involved administration of this standardised assessment to at least 300 respondents within each centre.

Following field testing in these 15 centres, 100 items were selected for inclusion in the WHOQOL-100 Field Trial Version. These included four items for each of 24 facets of quality of life, and four items relating to the 'overall quality of life and general health' facet (see Table 1). The method by which these 100 items were selected is fully documented elsewhere (The WHOQOL Group, in preparation). The WHOQOL-100 Field Trial Version is currently being tested in new centres world-wide (these centres are outlined on page 6 of this document). The initial conceptual framework for the WHOQOL-100 proposed that the 24 facets relating to quality of life should be grouped into 6 domains. Recent analysis of available data, using structural equation modelling, has shown a four domain solution to be more appropriate. For a more detailed explanation of this, the reader is referred to The WHOQOL Group (in preparation). The WHOQOL-BREF is therefore based on a four domain structure (see Table 1). 


\section{Table 1 - WHOQOL-BREF domains}

\begin{tabular}{||l|l||}
\hline \hline Doma in & Facets incorporated with in doma ins \\
\hline \hline 1. Physical health & $\begin{array}{l}\text { Activities of daily living } \\
\text { Dependence on medicinal substances and medical aids } \\
\text { Energy and fatigue } \\
\text { Mobility } \\
\text { Pain and discomfort } \\
\text { Sleep and rest } \\
\text { Work Capacity }\end{array}$ \\
\hline 2. Psychological & $\begin{array}{l}\text { Bodily image and appearance } \\
\text { Negative feelings } \\
\text { Positive feelings } \\
\text { Self-esteem } \\
\text { Spirituality / Religion / Personal beliefs } \\
\text { Thinking, learning, memory and concentration }\end{array}$ \\
\hline 3. Social relationships & $\begin{array}{l}\text { Personal relationships } \\
\text { Social support } \\
\text { Sexual activity }\end{array}$ \\
\hline 4. Environment & $\begin{array}{l}\text { Financial resources } \\
\text { Freedom, physical safety and security } \\
\text { Health and social care: accessibility and quality } \\
\text { Home environment } \\
\text { Opportunities for acquiring new information and skills } \\
\text { Participation in and opportunities for recreation / leisure activities } \\
\text { Physical environment (pollution / noise / traffic / climate) } \\
\text { Transport }\end{array}$ \\
\hline \hline
\end{tabular}

\section{Development of the WHOQOL-BREF}

The WHOQOL-100 allows detailed assessment of each individual facet relating to quality of life. In certain instances however, the WHOQOL-100 may be too lengthy for practical use. The WHOQOLBREF Field Trial Version has therefore been developed to provide a short form quality of life assessment that looks at Domain level profiles, using data from the pilot WHOQOL assessment and all available data from the Field Trial Version of the WHOQOL-100. Twenty field centres situated within eighteen countries have included data for these purposes (see Table 2). The WHOQOL-BREF contains a total of 26 questions. To provide a broad and comprehensive assessment, one item from each of the 24 facets contained in the WHOQOL-100 has been included. In addition, two items from the Overall quality of Life and General Health facet have been included. 
WHOQOL-BREF - INSTRUCTIONS

Page 8

\section{Table 2 - Centres included in development of the WHOQOL-BREF}

\begin{tabular}{||l|l|}
\hline \hline $\begin{array}{l}\text { Centres in the pilot version } \\
\text { of the WHOQOL }\end{array}$ & $\begin{array}{l}\text { Centres in the field trial of } \\
\text { the WHOQOL-100 }\end{array}$ \\
\hline Bangkok, Thailand & Bangkok, Thailand \\
Beer Sheva, Israel & Beer Sheva, Israel \\
Madras, India & Madras, India \\
Melbourne, Australia & Melbourne, Australia \\
New Delhi, India & New Delhi, India \\
Panama City, Panama & Panama City, Panama \\
Seattle, USA & Seattle, USA \\
Tilburg, The Netherlands & Tilburg, The Netherlands \\
Zagreb, Croatia & Zagreb, Croatia \\
Tokyo, Japan & Tokyo, Japan \\
Harare, Zimbabwe & Harare, Zimbabwe \\
Barcelona, Spain & Barcelona, Spain \\
Bath, UK & Bath, UK \\
St Petersburg, Russia & Hong Kong \\
Paris, France & Leipzig, Germany \\
& Mannheim, Germany \\
& La Plata, Argentina \\
& Port Alegre, Brazil \\
\hline
\end{tabular}

The WHOQOL-BREF is available in 19 different languages. The appropriate language version, and permission for using it, can be obtained from The WHOQOL Group, Programme on Mental Health, World Health Organisation, CH-1211 Geneva 27, Switzerland. Under no circumstances should the WHOQOL-BREF be used without consultation with The WHOQOL Group. A methodology has been developed for new centres wishing to develop a further language version of the WHOQOL-100 or the WHOQOL-BREF. This can be obtained from The WHOQOL Group, Programme on Mental Health, World Health Organisation, CH-1211, Geneva 27, Switzerland.

Questions should appear in the order in which they appear in the example WHOQOL-BREF provided within this document, with instructions and headers unchanged. Questions are grouped by response format. The equivalent numbering of questions between the WHOQOL-BREF and the WHOQOL-100 is given in the example version of the WHOQOL-BREF to enable easy comparison between responses to items on the two versions. The WHOQOL-100 field test permitted centres to include national items or facets that were thought to be important in assessing quality of life. Where centres wish to include additional national items or modules to the WHOQOL-BREF, these should be included on a separate sheet of paper and not scattered amongst the existing 26 items. There are three reasons for this:

1) To control for item order effects which could occur and change item meaning.

2) The WHOQOL-BREF represents an agreed upon core set of international items.

3) The WHOQOL-BREF is likely to be used where quality of life is amongst one of several parameters being assessed. Therefore additional national information can be obtained by including additional modules and measures

\section{Administration of the WHOQOL-BREF}


For any new centre not previously involved in either the development or field testing of the WHOQOL-100, the procedure being followed to field test the WHOQOL-BREF should be identical to that used to field test the WHOQOL-100. The instrument should be piloted on at least 300 people. This figure is based on the required numbers of respondents needed for analysis of pilot data. The sample of respondents to whom the assessment should be administered ought to be adults, with 'adult' being culturally defined. While stratified samples are not essential, a sampling quota should apply with regard to:

$$
\begin{array}{lll}
- & \text { Age } & (50 \%=<45 \text { years, } 50 \%=45+\text { years }) \\
\text { - } & \text { Sex } & (50 \%=\text { male, } 50 \%=\text { female }) \\
\text { - } & \text { Health status } & (250 \text { persons with disease or impairment; } 50 \text { well persons })
\end{array}
$$

With respect to persons with disease or impairment, this group should contain a cross-section of people with varied levels of quality of life. One way of attempting this would be to include some people with quite severe and disabling chronic diseases, some people in contact with health facilities for more transient conditions, possibly some attending a family practitioner, and others who are in contact with the health service for reasons that are not likely to impinge upon their quality of life to any great extent. By sampling patients from a cross-section of primary care settings, hospitals and community care settings this could most likely be achieved.

The WHOQOL-BREF should be self-administered if respondents have sufficient ability: otherwise, interviewer-assisted or interview-administered forms should be used. Standardised instructions, given on the second page of the WHOQOL-BREF example assessment, should be read out to respondents in instances where the assessment is interviewer-administered.

For centres who have already participated in the development and field testing of the WHOQOL100 , the above option of testing the WHOQOL-BREF is preferred, but not imperative where specific studies of patient groups are planned.

\section{Frame of reference and time frame}

A time frame of two weeks is indicated in the assessment. It is recognised that different time frames may be necessary for particular uses of the instrument in subsequent stages of work. For example, in the assessment of quality of life in chronic conditions, such as arthritis, a longer time frame such as four weeks may be preferable. Furthermore, the perception of time is different within different cultural settings and therefore changing the time scale may be appropriate.

\section{Proposed uses of the WHOQOL-100 and the WHOQOL-BREF}

It is anticipated that the WHOQOL assessments will be used in broad-ranging ways. They will be of considerable use in clinical trials, in establishing baseline scores in a range of areas, and looking at changes in quality of life over the course of interventions. It is expected that the WHOQOL assessments will also be of value where disease prognosis is likely to involve only partial recovery or remission, and in which treatment may be more palliative than curative.

For epidemiological research, the WHOQOL assessments will allow detailed quality of life data to be gathered on a particular population, facilitating the understanding of diseases, and the development 
WHOQOL-BREF - INSTRUCTIONS

Page 10

of treatment methods. The international epidemiological studies that would be enabled by instruments such as the WHOQOL-100 and the WHOQOL-BREF will make it possible to carry out multi-centre quality of life research, and to compare results obtained in different centres. Such research has important benefits, permitting questions to be addressed which would not be possible in single site studies (Sartorius and Helmchen, 1981). For example, a comparative study in two or more countries on the relationship between health care delivery and quality of life requires an assessment yielding cross-culturally comparable scores. Sometimes accumulation of cases in quality of life studies, particularly when studying rare disorders, is helped by gathering data in several settings. Multi-centre collaborative studies can also provide simultaneous multiple replications of a finding, adding considerably to the confidence with which findings can be accepted.

In clinical practice the WHOQOL assessments will assist clinicians in making judgements about the areas in which a patient is most affected by disease, and in making treatment decisions. In some developing countries, where resources for health care may be limited, treatments aimed at improving quality of life through palliation, for example, can be both effective and inexpensive (Olweny, 1992). Together with other measures, the WHOQOL-BREF will enable health professionals to assess changes in quality of life over the course of treatment.

It is anticipated that in the future the WHOQOL-100 and the WHOQOL-BREF will prove useful in health policy research and will make up an important aspect of the routine auditing of health and social services. Because the instrument was developed cross-culturally, health care providers, administrators and legislators in countries where no validated quality of life measures currently exist can be confident that data yielded by work involving the WHOQOL assessments will be genuinely sensitive to their setting.

\section{Scoring the WHOQOL-BREF}

The WHOQOL-BREF (Field Trial Version) produces a quality of life profile. It is possible to derive four domain scores. There are also two items that are examined separately: question 1 asks about an individual's overall perception of quality of life and question 2 asks about an individual's overall perception of their health. The four domain scores denote an individual's perception of quality of life in each particular domain. Domain scores are scaled in a positive direction (i.e. higher scores denote higher quality of life). The mean score of items within each domain is used to calculate the domain score. Mean scores are then multiplied by 4 in order to make domain scores comparable with the scores used in the WHOQOL-100. Explicit instructions for checking and cleaning data, and for computing domain scores, are given in Table 3. A method for the manual calculation of individual scores is given on page 1 of the WHOQOL-BREF assessment form. The method for converting raw scores to transformed scores when using this method is given in Table 4, on page 11 of these instructions. The first transformation method converts scores to range between 4-20, comparable with the WHOQOL-100. The second transformation method converts domain scores to a $0-100$ scale.

Where more than $20 \%$ of data is missing from a assessment, the assessment should be discarded (see Step 4 in Table 3). Where an item is missing, the mean of other items in the domain is substituted. Where more than two items are missing from the domain, the domain score should not be calculated (with the exception of domain 3 , where the domain should only be calculated if $\leq 1$ item is missing).

Any national items should be scored separately from the core 26 item of the BREF. During the analysis the performance of any national items will be examined for possible use in alter national studies. At this stage of field testing national and core items must not be mixed in administration or scoring of the BREF. 
An SPSS syntax file that automatically checks, recodes data and computes domain scores may be obtained from Professor Mick Power, Department of Psychiatry, Royal Edinburgh Hospital, Morningside Park, Edinburgh, EH10 5HF (email: mj@srv2.med.ed.ac.uk; fax: + 131447 6860) 
WHOQOL-BREF - INSTRUCTIONS

Page 12

Table 3 - Steps for checking and cleaning data and computing domain scores

\begin{tabular}{|c|c|c|}
\hline & Steps & $\begin{array}{l}\text { SPSS syntax for carrying out data } \\
\text { checking, cleaning and computing total } \\
\text { scores }\end{array}$ \\
\hline 1. & $\begin{array}{l}\text { Check all } 26 \text { items from } \\
\text { assessment have a range of } 1-5\end{array}$ & $\begin{array}{l}\text { RECODE Q1 Q2 Q3 Q4 Q5 Q6 Q7 Q8 Q9 Q10 Q11 Q12 Q13 Q14 } \\
\text { Q15 Q16 Q17 Q18 Q19 Q20 Q21 Q22 Q23 Q24 Q25 Q26 (1=1) } \\
\text { (2=2) (3=3) (4=4) (5=5) (ELSE=SYSMIS). } \\
\text { (This recodes all data outwith the range } 1-5 \text { to system missing). }\end{array}$ \\
\hline 2. & $\begin{array}{l}\text { Reverse } 3 \text { negatively phrased } \\
\text { items }\end{array}$ & $\begin{array}{l}\text { RECODE Q3 Q4 Q26 }(1=5)(2=4)(3=3)(4=2)(5=1) \text {. } \\
\text { (This transforms negatively framed questions to positively framed } \\
\text { questions) }\end{array}$ \\
\hline 3. & Compute domain scores & $\begin{array}{l}\text { COMPUTE DOM1=MEAN.6(Q3,Q4,Q10,Q15,Q16,Q17,Q18)*4. } \\
\text { COMPUTE DOM2=MEAN.5(Q5,Q6,Q7,Q11,Q19,Q26)*4. } \\
\text { COMPUTE DOM3=MEAN.2(Q20,Q21,Q22)*4. } \\
\text { COMPUTE DOM4=MEAN.6(Q8,Q9,Q12,Q13,Q14,Q23,Q24,Q25)*4. } \\
\text { (These equations calculate the domain scores. A11 scores are } \\
\text { multiplied by } 4 \text { so as to be directly comparable with scores derived } \\
\text { from the WHOQOL-100. The '.6' in 'mean.6' specifies that } 6 \text { items } \\
\text { must be endorsed for the domain score to be calculated). }\end{array}$ \\
\hline 4. & $\begin{array}{l}\text { Delete cases with }>20 \% \text { missing } \\
\text { data }\end{array}$ & $\begin{array}{l}\text { COUNT TOTAL=Q1 TO Q26 ( } 1 \text { THRU 5). } \\
\text { (This command creates a new column 'total'. 'Total' contains a count } \\
\text { of the WHOQOL-100 items with the values } 1-5 \text { that have been } \\
\text { endorsed by each subject. The 'Q1 TO Q26' means that consecutive } \\
\text { columns from 'Q1', the first item, to 'Q26', the last item, are included } \\
\text { in the count. It therefore assumes that data is entered in the order } \\
\text { given in the assessment). } \\
\text { FILTER OFF. } \\
\text { USE ALL. } \\
\text { SELECT IF (TOTAL }>21 \text { ). } \\
\text { EXECUTE. } \\
\text { (This second command selects only those cases where 'total', the total } \\
\text { number of items completed, is greater or equal to } 80 \% \text {. It deletes the } \\
\text { remaining cases from the data set). }\end{array}$ \\
\hline 5. & Check domain scores & $\begin{array}{l}\text { DESCRIPTIVES } \\
\text { VARIABLES=DOM1 DOM2 DOM } 3 \text { DOM4 } \\
\text { /STATISTICS=MEAN STDDEV MIN MAX. } \\
\text { (Running descriptives should display values of all domain scores } \\
\text { within the range } 4-20 \text { ). }\end{array}$ \\
\hline 6. & Save data set & Save data set with a new file name so that the original remains intact. \\
\hline
\end{tabular}


Table 4 - Method for converting raw scores to transformed scores

\begin{tabular}{|c|c|c|}
\hline \multicolumn{3}{|c|}{ DOMAIN 1} \\
\hline \multirow[t]{2}{*}{$\begin{array}{l}\text { Raw } \\
\text { Score }\end{array}$} & \multicolumn{2}{|c|}{$\begin{array}{l}\text { Trasnformed } \\
\text { scores }\end{array}$} \\
\hline & $4-20$ & $0-100$ \\
\hline 7 & 4 & 0 \\
\hline 8 & 5 & 6 \\
\hline 9 & 5 & 6 \\
\hline 10 & 6 & 13 \\
\hline 11 & 6 & 13 \\
\hline 12 & 7 & 19 \\
\hline 13 & 7 & 19 \\
\hline 14 & 8 & 25 \\
\hline 15 & 9 & 31 \\
\hline 16 & 9 & 31 \\
\hline 17 & 10 & 38 \\
\hline 18 & 10 & 38 \\
\hline 19 & 11 & 44 \\
\hline 20 & 11 & 44 \\
\hline 21 & 12 & 50 \\
\hline 22 & 13 & 56 \\
\hline 23 & 13 & 56 \\
\hline 24 & 14 & 63 \\
\hline 25 & 14 & 63 \\
\hline 26 & 15 & 69 \\
\hline 27 & 15 & 69 \\
\hline 28 & 16 & 75 \\
\hline 29 & 17 & 81 \\
\hline 30 & 17 & 81 \\
\hline 31 & 18 & 88 \\
\hline 32 & 18 & 88 \\
\hline 33 & 19 & 94 \\
\hline 34 & 19 & 94 \\
\hline 35 & 20 & 100 \\
\hline
\end{tabular}

\begin{tabular}{||l|l|l||}
\hline \hline \multicolumn{2}{|||}{ DOMAIN 3 } \\
\hline $\begin{array}{c}\text { Raw } \\
\text { score }\end{array}$ & \multicolumn{2}{|c|}{$\begin{array}{c}\text { Transformed } \\
\text { scores }\end{array}$} \\
\hline & $4-20$ & $0-100$ \\
\hline \hline 3 & 4 & 0 \\
\hline 4 & 5 & 6 \\
\hline 5 & 7 & 19 \\
\hline 6 & 8 & 25 \\
\hline 7 & 9 & 31 \\
\hline 8 & 11 & 44 \\
\hline 9 & 12 & 50 \\
\hline 10 & 13 & 56 \\
\hline 11 & 15 & 69 \\
\hline 12 & 16 & 75 \\
\hline 13 & 17 & 81 \\
\hline 14 & 19 & 94 \\
\hline 15 & 20 & 100 \\
\hline \hline
\end{tabular}

\begin{tabular}{|c|c|c|}
\hline \multicolumn{3}{|c|}{ DOMAIN 4} \\
\hline \multirow[t]{2}{*}{$\begin{array}{l}\text { Raw } \\
\text { score }\end{array}$} & \multicolumn{2}{|c|}{$\begin{array}{c}\text { Transformed } \\
\text { scores }\end{array}$} \\
\hline & $4-20$ & $0-100$ \\
\hline 8 & 4 & 0 \\
\hline 9 & 5 & 6 \\
\hline 10 & 5 & 6 \\
\hline 11 & 6 & 13 \\
\hline 12 & 6 & 13 \\
\hline 13 & 7 & 19 \\
\hline 14 & 7 & 19 \\
\hline 15 & 8 & 25 \\
\hline 16 & 8 & 25 \\
\hline 17 & 9 & 31 \\
\hline 18 & 9 & 31 \\
\hline 19 & 10 & 38 \\
\hline 20 & 10 & 38 \\
\hline 21 & 11 & 44 \\
\hline 22 & 11 & 44 \\
\hline 23 & 12 & 50 \\
\hline 24 & 12 & 50 \\
\hline 25 & 13 & 56 \\
\hline 26 & 13 & 56 \\
\hline 27 & 14 & 63 \\
\hline 28 & 14 & 63 \\
\hline 29 & 15 & 69 \\
\hline 30 & 15 & 69 \\
\hline 31 & 16 & 75 \\
\hline 32 & 16 & 75 \\
\hline 33 & 17 & 81 \\
\hline 34 & 17 & 81 \\
\hline 35 & 18 & 88 \\
\hline 36 & 18 & 88 \\
\hline 37 & 19 & 94 \\
\hline 38 & 19 & 94 \\
\hline 39 & 20 & 100 \\
\hline 40 & 20 & 100 \\
\hline
\end{tabular}

\section{References}

\begin{tabular}{|c|c|c|}
\hline \multicolumn{3}{|c|}{ DOMAIN 2} \\
\hline \multirow[t]{2}{*}{$\begin{array}{l}\text { Raw } \\
\text { score }\end{array}$} & \multicolumn{2}{|c|}{$\begin{array}{l}\text { Trasnformed } \\
\text { scores }\end{array}$} \\
\hline & $4-20$ & $0-100$ \\
\hline 6 & 4 & 0 \\
\hline 7 & 5 & 6 \\
\hline 8 & 5 & 6 \\
\hline 9 & 6 & 13 \\
\hline 10 & 7 & 19 \\
\hline 11 & 7 & 19 \\
\hline 12 & 8 & 25 \\
\hline 13 & 9 & 31 \\
\hline 14 & 9 & 31 \\
\hline 15 & 10 & 38 \\
\hline 16 & 11 & 44 \\
\hline 17 & 11 & 44 \\
\hline 18 & 12 & 50 \\
\hline 19 & 13 & 56 \\
\hline 20 & 13 & 56 \\
\hline 21 & 14 & 63 \\
\hline 22 & 15 & 69 \\
\hline 23 & 15 & 69 \\
\hline 24 & 16 & 75 \\
\hline 25 & 17 & 81 \\
\hline 26 & 17 & 81 \\
\hline 27 & 18 & 88 \\
\hline 28 & 19 & 94 \\
\hline 29 & 19 & 94 \\
\hline 30 & 20 & 100 \\
\hline
\end{tabular}

Bergner, M., Bobbitt, R.A., Carter, W.B. et al. (1981). The Sickness Impact Profile: Development and final revision of a health status measure. Medical Care, 19, 787-805. 
MSA/MNH/PSF $/ 97.6$

Page 14

Fallowfield, L. (1990). The Quality of Life: The Missing Measurement in Health Care. Souvenir Press.

Hunt, S.M., McKenna, S.P. and McEwan, J. (1989). The Nottingham Health Profile. Users Manual. Revised edition.

Kuyken, W., Orley, J., Hudelson, P. and Sartorius, N. (1994). Quality of life assessment across cultures. International Journal of Mental Health, 23 (2), 5-27.

Olweny, C. L. M. (1992). Quality of life in developing countries. Joumal of Palliative Care, $\underline{8}$, 25-30.

Sartorius, N. and Helmchen, H. (1981). Aims and implementation of multi-centre studies. Modern Problems of Pharmacopsychiatry, 16, 1-8.

Sartorius, N. and Kuyken, W. (1994). Translation of health status instruments. In J. Orley and W. Kuyken (Eds). Quality of Life Assessment: International Perspectives. Heidelberg: Springer Verlag.

Szabo, S. (1996). The World Health Organisation Quality of Life (WHOQOL) Assessment Instrument. In Quality of Life and Pharmaeconomics in Clinical Trials (2nd edition, Edited by Spilker B.). Lippincott-Raven Publishers, Philadelphia, New York.

The WHOQOL Group. The World Health Organization Quality of Life assessment (WHOQOL): position paper from the World Health Organization. Soc. Sci. Med., 41, 1403, 1995.

Ware, J. E., Snow, K., K., Kosinski, M. and Gandek, B. (1993). SF-36 Health Survey: Manual and Interpretation Guide. New England Medical Center, MA, USA.

World Bank. (1993). World Development Report: Investing in Health. New York: Oxford University Press.

World Health Organization. (1991). World Health Statistics Annual. Geneva: WHO.

The WHOQOL Group. (1994a). Development of the WHOQOL: Rationale and current status. International Journal of Mental Health, 23 (3), 24-56.

The WHOQOL Group. (1994b). The development of the World Health Organization quality of life assessment instrument (the WHOQOL). In J. Orley and W. Kuyken (Eds) Quality of Life Assessment: International Perspectives. Heidelberg: Springer Verlag.

The WHOQOL Group. (In preparation). The World Health Organisation Quality of Life Assessment (WHOQOL): Development and General Psychometric Properties.

m:k...miscellwhoqolbrefinst 


\section{WHO/MSA/MNH/PSF $/ 97.4$ \\ Engl ish only}

\section{WHOQOL-BREF}

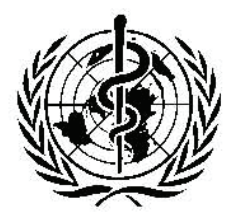

\section{PROGRAMME ON MENTAL HEALTH \\ WORLD HEALTH ORGANIZATION \\ GENEVA}

For office use only

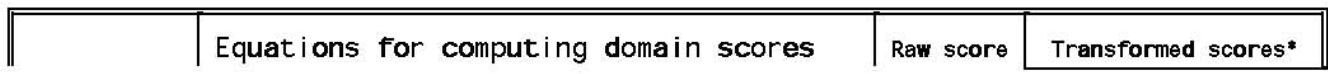

\begin{tabular}{|c|c|c|c|c|}
\hline Domain 1 & $\begin{array}{l}(6-\mathrm{Q} 3)+(6-\mathrm{Q} 4)+\mathrm{Q} 10+\mathrm{Q} 15+\mathrm{Q} 16+\mathrm{Q} 17+\mathrm{Q} 18 \\
\square+\square+\square+\square+\square+\square+\square\end{array}$ & $=$ & $4-20$ & $0-100$ \\
\hline Domain 2 & $\begin{array}{l}\mathrm{Q} 5+\mathrm{Q} 6+\mathrm{Q} 7+\mathrm{Q} 11+\mathrm{Q} 19+(6-\mathrm{Q} 26) \\
\square+\square+\square+\square+\square+\square\end{array}$ & $=$ & & \\
\hline Domain 3 & $\begin{array}{l}\mathrm{Q} 20+\mathrm{Q} 21+\mathrm{Q} 22 \\
\square+\square+\square\end{array}$ & $=$ & & \\
\hline Domain 4 & $\begin{array}{l}\mathrm{Q} 8+\mathrm{Q} 9+\mathrm{Q} 12+\mathrm{Q} 13+\mathrm{Q} 14+\mathrm{Q} 23+\mathrm{Q} 24+\mathrm{Q} 25 \\
\square+\square+\square+\square+\square+\square+\square+\square\end{array}$ & $=$ & & \\
\hline
\end{tabular}

* Please see Table 4 on page 10 of the manual, for converting raw scores to transformed scores.

This document is not issued to the general public, and all rights are reserved by the World Health Organization (WHO). The document may not be reviewed, abstracted, quoted, reproduced or translated, in part or in whole, without the prior written permission of WHO. No part of this document may be stored in a retrieval system or transmitted in any form or by any means electronic, mechanical or other - without the prior written permission of WHO. 
MSA/MNH/PSF $/ 97.6$

Page 16

\section{ABOUT YOU}

Before you begin we would like to ask you to answer a few general questions about yourself: by circling the correct answer or by filling in the space provided.

What is your gender?

What is you date of birth?

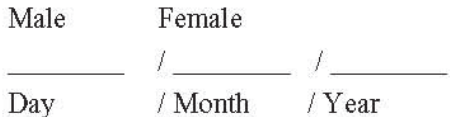

What is the highest education you received?

None at all

Primary school

Secondary school

Tertiary

What is your marital status?

$\begin{array}{ll}\text { Single } & \text { Separated } \\ \text { Married } & \text { Divorced } \\ \text { Living as married } & \text { Widowed }\end{array}$

Are you currently ill?

Yes No

If something is wrong with your health what do you think it is?

illness/ problem

\section{Instructions}

This assessment asks how you feel about your quality of life, health, or other areas of your life. Please answer all the questions. If you are unsure about which response to give to a question, please choose the one that appears most appropriate. This can often be your first response.

Please keep in mind your standards, hopes, pleasures and concerns. We ask that you think about your life in the last two weeks. For example, thinking about the last two weeks, a question might ask:

\begin{tabular}{||l|l|c|c|c|c|c||}
\hline \hline $\begin{array}{l}\text { Do you get the kind of support from } \\
\text { others that you need? }\end{array}$ & 1 & Not at all & Not much & Moderately & A great deal \\
4 & 3 & 5 \\
\hline
\end{tabular}

You should circle the number that best fits how much support you got from others over the last two weeks. So you would circle the number 4 if you got a great deal of support from others as follows.

\begin{tabular}{|c|c|c|c|c|c|}
\hline & Not at all & Not much & Moderately & A great deal & Completely \\
\hline $\begin{array}{l}\text { Do you get the kind of support from } \\
\text { others that you need? }\end{array}$ & 1 & 2 & 3 & 4 & 5 \\
\hline
\end{tabular}

You would circle number 1 if you did not get any of the support that you needed from others in the last two weeks. 
Please read each question, assess your feelings, and circle the number on the scale for each question that gives the best answer for you.

\begin{tabular}{||l|c|c|c|c|c|c||}
\hline \hline & & Very poor & Poor & $\begin{array}{c}\text { Neither } \\
\text { poor nor } \\
\text { good }\end{array}$ & Good Very good \\
\hline $1(\mathrm{G} 1)$ & How would you rate your quality of life? & 1 & 2 & 3 & 4 & 5 \\
\hline
\end{tabular}

\begin{tabular}{||l|l|c|c|c|c|c||}
\hline \hline & $\begin{array}{c}\text { Very } \\
\text { dissatisfied }\end{array}$ & Dissatisfied & $\begin{array}{c}\text { Neither } \\
\text { satisfied nor } \\
\text { dissatisfied }\end{array}$ & Satisfied & Very \\
satisfied \\
\hline $2(\mathrm{G} 4)$ & How satisfied are you with your health? & 1 & 2 & 3 & 4 & 5 \\
\hline \hline
\end{tabular}

The following questions ask about how much you have experienced certain things in the last two weeks.

\begin{tabular}{|c|c|c|c|c|c|c|}
\hline & & Not at all & A little & $\begin{array}{l}\text { A moderate } \\
\text { amount }\end{array}$ & Very much & $\begin{array}{l}\text { An extreme } \\
\text { amount }\end{array}$ \\
\hline 3 (F1.4) & $\begin{array}{l}\text { To what extent do you feel that physical } \\
\text { pain prevents you from doing what you } \\
\text { need to do? }\end{array}$ & 1 & 2 & 3 & 4 & 5 \\
\hline $4(\mathrm{~F} 11.3)$ & $\begin{array}{l}\text { How much do you need any medical } \\
\text { treatment to function in your daily life? }\end{array}$ & 1 & 2 & 3 & 4 & 5 \\
\hline $5(\mathrm{~F} 4.1)$ & How much do you enjoy life? & 1 & 2 & 3 & 4 & 5 \\
\hline $6(\mathrm{~F} 24.2)$ & $\begin{array}{l}\text { To what extent do you feel your life to } \\
\text { be meaningful? }\end{array}$ & 1 & 2 & 3 & 4 & 5 \\
\hline
\end{tabular}

\begin{tabular}{||l|l|c|c|c|c|c||}
\hline \hline & & Not at all & A little & $\begin{array}{c}\text { A moderate } \\
\text { amount }\end{array}$ & Very much & Extremely \\
\hline 7 (F5.3) & How well are you able to concentrate? & 1 & 2 & 3 & 4 & 5 \\
\hline 8 (F16.1) & How safe do you feel in your daily life? & 1 & 2 & 3 & 4 & 5 \\
\hline 9 (F22.1) & $\begin{array}{l}\text { How healthy is your physical } \\
\text { environment? }\end{array}$ & 1 & 2 & 3 & 4 & 5 \\
\hline
\end{tabular}

The following questions ask about how completely you experience or were able to do certain things in the last two weeks.

\begin{tabular}{|c|c|c|c|c|c|c|}
\hline & & Not at all & A little & Moderately & Mostly & Completely \\
\hline $10(\mathrm{~F} 2.1)$ & $\begin{array}{l}\text { Do you have enough energy for } \\
\text { everyday life? }\end{array}$ & 1 & 2 & 3 & 4 & 5 \\
\hline 11 (F7.1) & $\begin{array}{l}\text { Are you able to accept your bodily } \\
\text { appearance? }\end{array}$ & 1 & 2 & 3 & 4 & 5 \\
\hline 12 (F18.1) & $\begin{array}{l}\text { Have you enough money to meet your } \\
\text { needs? }\end{array}$ & 1 & 2 & 3 & 4 & 5 \\
\hline $13(\mathrm{~F} 20.1)$ & $\begin{array}{l}\text { How available to you is the information } \\
\text { that you need in your day-to-day life? }\end{array}$ & 1 & 2 & 3 & 4 & 5 \\
\hline $14(\mathrm{~F} 21.1)$ & $\begin{array}{l}\text { To what extent do you have the } \\
\text { opportunity for leisure activities? }\end{array}$ & 1 & 2 & 3 & 4 & 5 \\
\hline
\end{tabular}

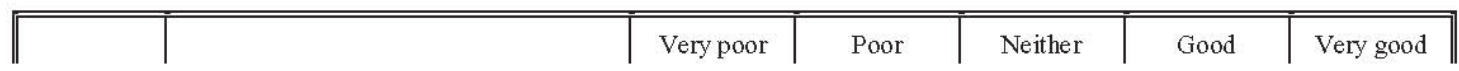




\begin{tabular}{||l|l|c|c|c|c|c||}
\hline \hline & & & & $\begin{array}{c}\text { poor nor } \\
\text { good }\end{array}$ & \\
\hline 15 (F9.1) & How well are you able to get around? & 1 & 2 & 3 & 4 & 5 \\
\hline
\end{tabular}

The following questions ask you to say how good or satisfied you have felt about various aspects of your life over the last two weeks.

\begin{tabular}{||l|l|c|c|c|c|c||}
\hline \hline & & $\begin{array}{c}\text { Very } \\
\text { dissatisfied }\end{array}$ & Dissatisfied & $\begin{array}{c}\text { Neither } \\
\text { satisfied nor } \\
\text { dissatisfied }\end{array}$ & Satisfied & Very \\
satisfied
\end{tabular}

The following question refers to how often you have felt or experienced certain things in the last two weeks.

\begin{tabular}{||l|l|c|c|c|c|c||}
\hline \hline 26 (F8.1) & $\begin{array}{l}\text { How often do you have negative feelings } \\
\text { such as blue mood, despair, anxiety, } \\
\text { depression? }\end{array}$ & 1 & 2 & 3 & 4 & Quite often \\
\hline
\end{tabular}

Did someone help you to fill out this form?

How long did it take to fill this form out?. 


\section{Anexo 9}

Carta e Bilhete do Senador da República Cristovam Buarque 
SENADO FEDERAL

Gabinete do Senador Cristovam Buarque

Ao Magnífico Senhor

IVAN MARQUES DE TOLEDO CAMARGO

REITOR DA UNIVERSIDADE DE BRASILIIA

Campus Universitário Darcy Ribeiro

70910-900 Brasilia-DF

Magnífico Reitor,

Com os meus cordiais cumprimentos e com muita satisfação, dirijome a Vossa Magnificência com o objetivo precípuo de solicitar providencias para implementação da emenda parlamentar $n^{0} 20690006$, de minha autoria junto a LOA 2014 , no valor de $R \$ 300.000,00$ (trezentos mil reais), destinada a realização do projeto de leitura e uso da informação como estratégias para despertar nos usuários das bibliotecas públicas do Distrito Federal, especialmente os alunos do ensino fundamental, a percepção de auto-cuidado, saúde e qualidade de vida: formação e qualificação de dirigentes e usuários.

O referido projeto é de relevante importância em face dos inúmeros benefícios que trará para as comunidades contempladas, assim como, será fértil campo de pesquisa acadêmica de múltiplas ciências. Ademais, contribuirá, sobremaneira, como instrumento para a promoção da saúde em espaços diversos do cenário formal, ampliando o potencial transformador da informação disponibilizada nas bibliotecas públicas e, consequentemente, na qualidade de vida dos indivíduos.

Ressalto que o referido projeto pertence ao Programa de PósGraduação em Ciências da Saúde da Faculdade de Ciências da Saúde, da UnB.

Atenciosamente,

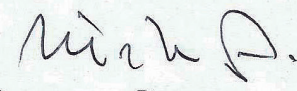

CRISTOVAM BUARQUE

Senador da República 


\section{Taequelime:}

Que brum ner as carti-

thas linalar que usce tey. Pare

bèns prela producap, tanto

a qualitade, unanto a

qualidace.

$$
\frac{\text { obrigato }}{\operatorname{linh} \ln _{19 / 2 / 16 .}}
$$

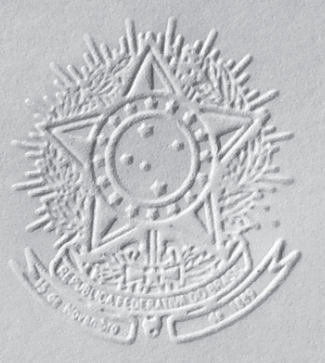

SENADO FEDEAL

CRIOTOVAM BUAROUE

जENADOR 


\section{Anexo 10}

\section{Certificado do Curso de Dinamização e Uso da Biblioteca Pública fornecido aos Participantes}




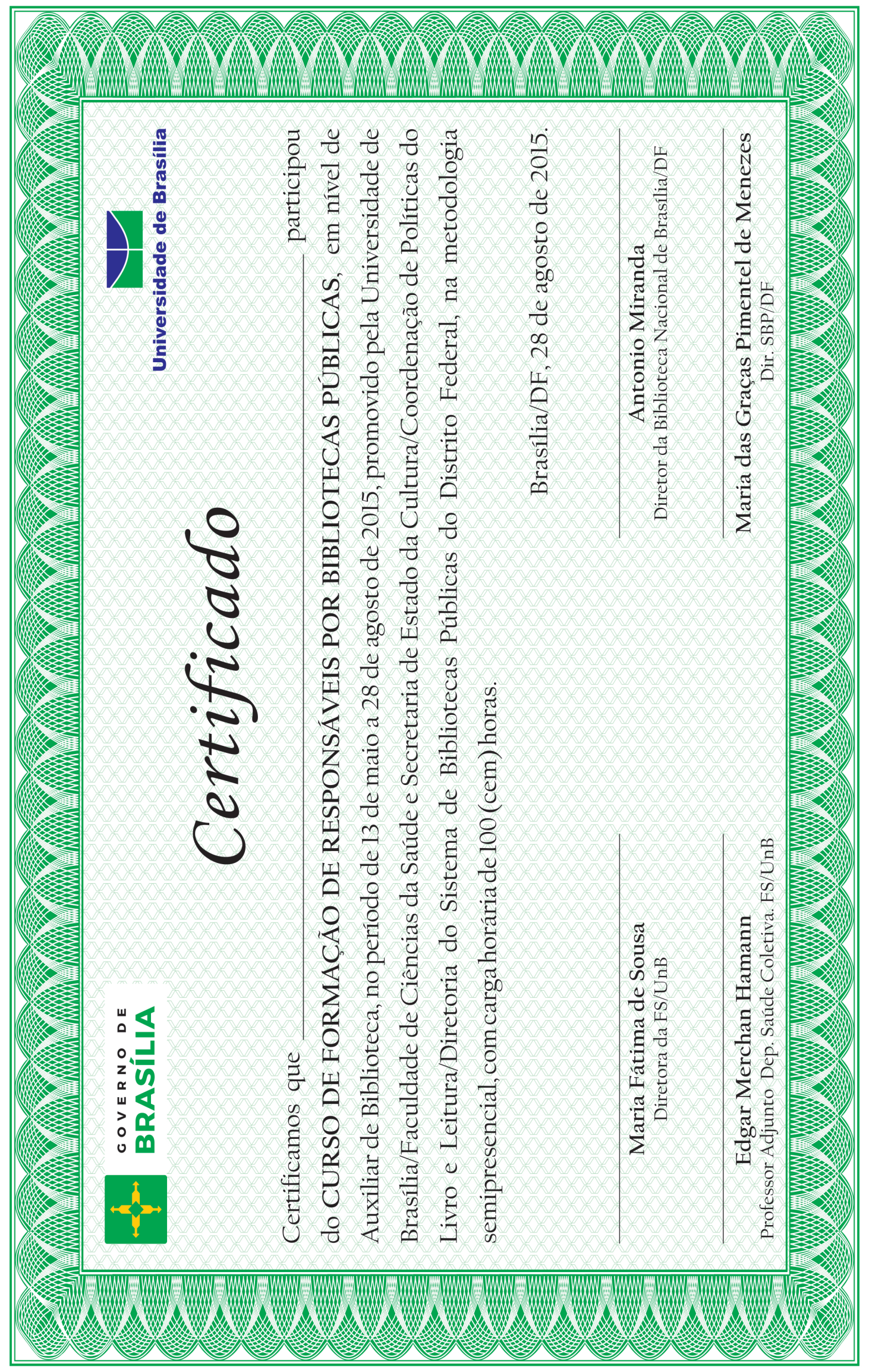




\section{Anexo 11}

\section{Lista de Presenças na Reunião no Centro de Orientação Sócioeducativa - COSE do Recanto das Emas}




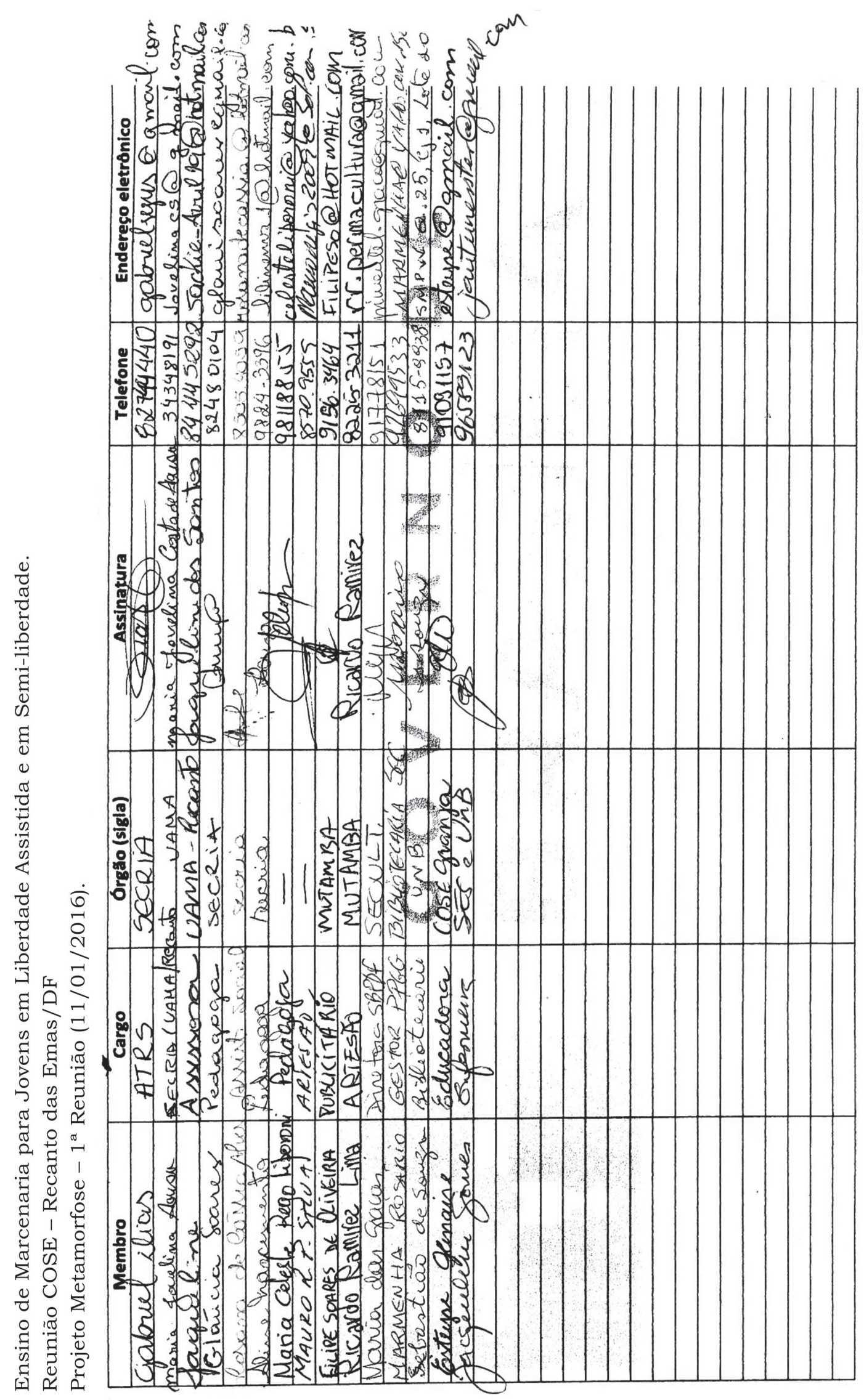




\section{Anexo 12}

Certificado de Agradecimento 


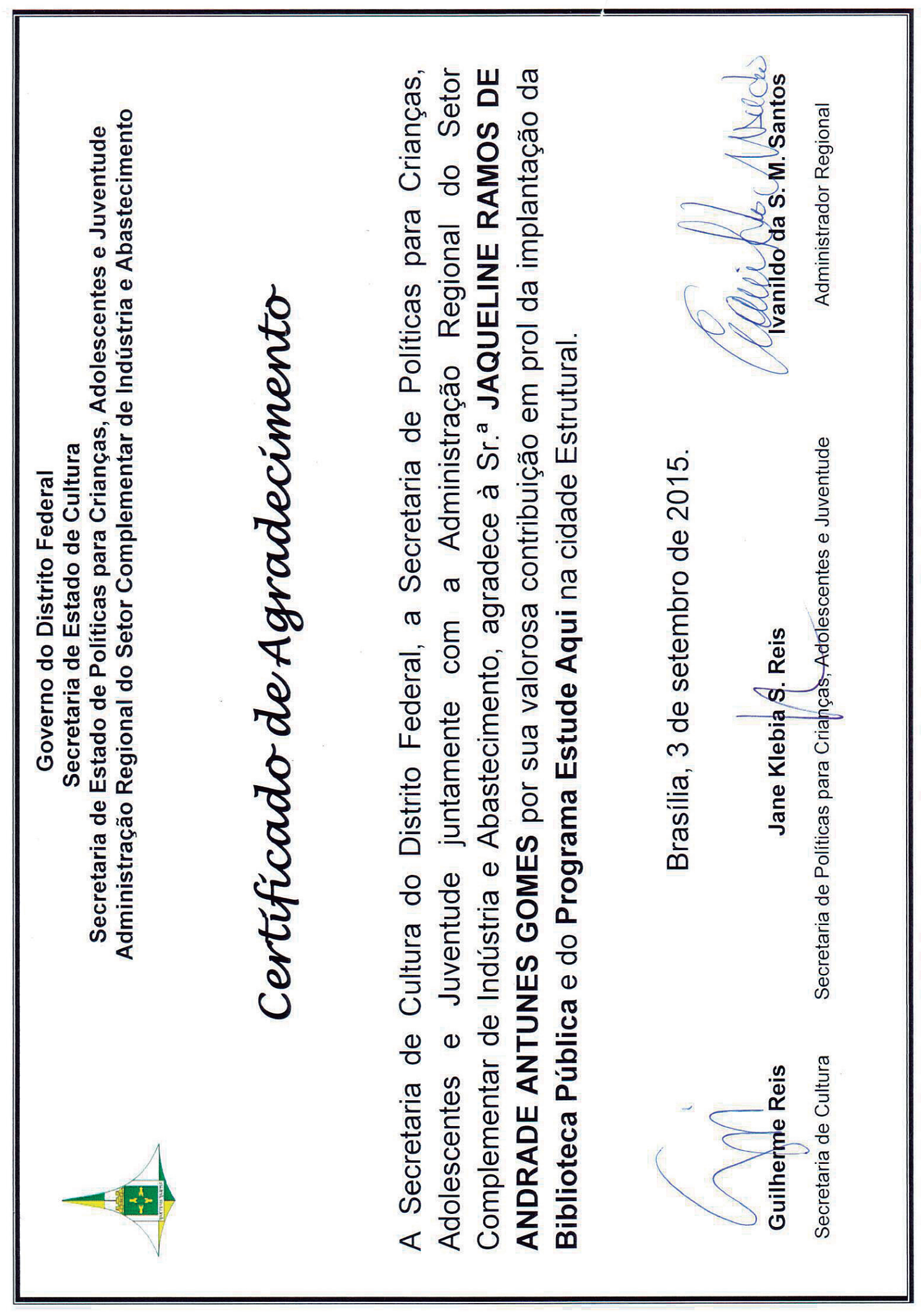




\section{Anexo 13}

\section{Cálculos para os \\ Cruzamentos das Tabelas}


Tabelas com os cruzamentos feitos no Epi info para o DoMínIo 1

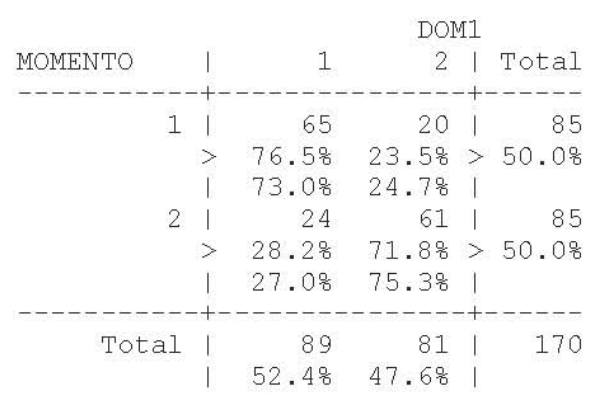

Single Table Analysis

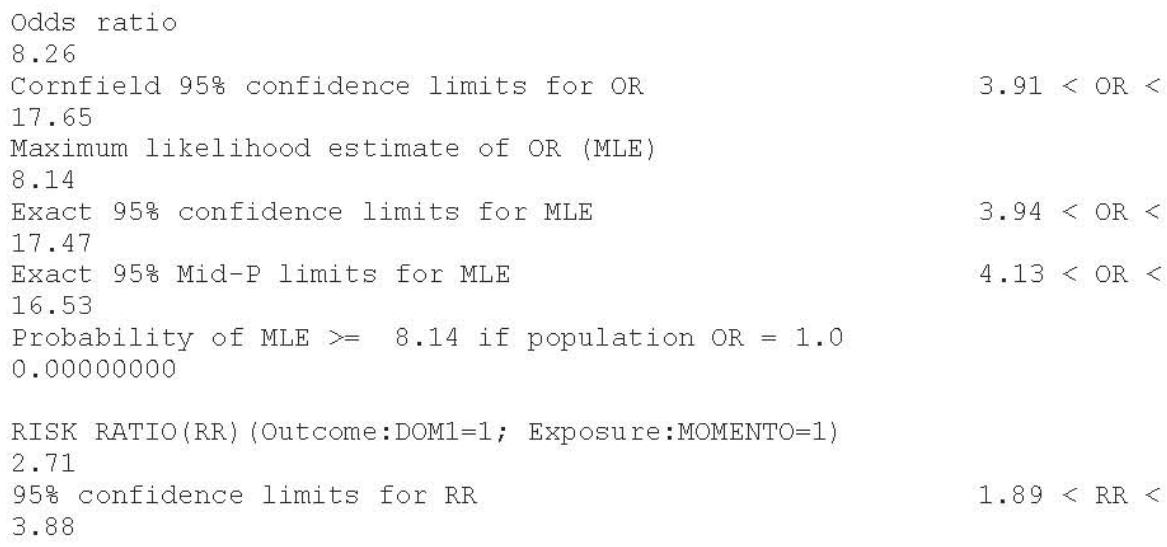




\begin{tabular}{r|rrrr}
1 & 35 & 14 & 49 \\
& $>$ & 71.48 & 28.68 & $>50.08$ \\
2 & 68.68 & 29.88 & \\
2 & 16 & 33 & 49 \\
& $>$ & 32.78 & 67.38 & $>50.08$ \\
& $\mid$ & 31.48 & 70.28 & \\
-0.09 & 51 & 47 & 98
\end{tabular}

Single Table Analysis

Odds ratio

Stratum 1

5.16

Cornfield 95\% confidence limits for oR

$1.99<\mathrm{OR}<$

13.58

Maximum likelihood estimate of OR (MLE)

5.06

Exact $95 \%$ confidence limits for MLE

13.37

Exact 95\% Mid-P limits for MLE

12.32

Probability of MLE $>=5.06$ if population $\mathrm{OR}=1.0$

0.00011683

RISK RATIO(RR) (Outcome:DOMI=1; Exposure: MOMENTO=1)

2.19

95\% confidence limits for RR

3.39

Ignore risk ratio if case control study

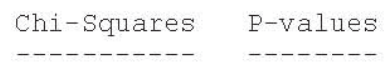

Uncorrected: $\quad 14.76 \quad 0.00012214<---$

Mantel-Haenszel: $\quad 14.61 \quad 0.00013230<---$

Yates corrected: $\quad 13.25 \quad 0.00027308<---$

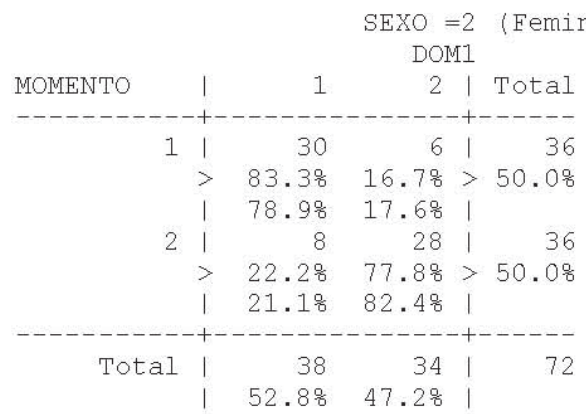

Single Table Analysis

Stratum 2 
Odds ratio

17.50

Cornfield 95\% confidence limits for OR

$4.69<\mathrm{OR}<$

Maximum likelihood estimate of OR (MLE)

16.57

Exact 95\% confidence limits for MLE

68.01

Exact 95\% Mid-P limits for MLE

58.42

Probability of $\mathrm{MLE}>=16.57$ if population $\mathrm{OR}=1.0$

0.00000016

RISK RATIO(RR) (Outcome:DOMl=1; Exposure:MOMENTO=1

3.75

95\% confidence limits for RR

7.03

Ignore risk ratio if case control study

$4.77<\mathrm{OR}<$

$5.31<\mathrm{OR}<$

$2.00<\mathrm{RR}<$

\section{Chi-Squares P-values}

$\begin{array}{lll}\text { Uncorrected: } & 26.97 & 0.00000021<--- \\ \text { Mantel-Haenszel: } & 26.60 & 0.00000025<--- \\ \text { Yates corrected: } & 24.58 & 0.00000071<---\end{array}$

*t Summary of 2 Tables With Non-Zero margins $\star *$ $\mathrm{N}=170$

Mantel-Haenszel Summary Chi Square

37.29

P value

0.00000000

Mantel-Haenszel Summary Chi Square (uncorrected)

39.18

P value

0.00000000

Crude OR

SUMMARY ODDS RATIO

8.26

Mantel-Haenszel weighted odds ratio

7.94

958 Conf limits for M-H OR (Robins, Greenland, Breslow) $4.01<$ OR <

15.72

Maximum likelihood estimate of OR (MLE)

8.02

Exact $95 \%$ confidence limits for MLE

17.15

Exact $95 \%$ Mid-P limits for MLE

16.23

Probability of $\mathrm{MLE}>=8.02$ if population $\mathrm{OR}=1.0$

0.00000000 
Chi Square for evaluation of interaction

2.70

P value

0.10048867

Test does not suggest that ORs differ by stratum (interaction)

If Crude and Summary values are similar, confounding is small.

In the absence of interaction and confounding, crude, unstratified analysis (MOMENTO $x$ DOM1) may be used.

SUMMARY RISK RATIO (RR)

(Ignore if Case-Control Study)

Crude RR without stratification

2.71

Summary RR of (DOMI=1) for (MOMENTO=1)

2.71

95\% confidence limits for RR

$1.89<\mathrm{RR}<$

3.88

Chi Square for evaluation of interaction

1.90

P value

0.16825781

Test does not suggest that RRs differ by stratum (interaction)

If Crude and Summary values are similar, confounding is small.

In the absence of interaction and confounding, crude, unstratified analysis (MOMENTO $x$ DOMl) may be used.

** End of Stratified Analysis *t

$\ldots$

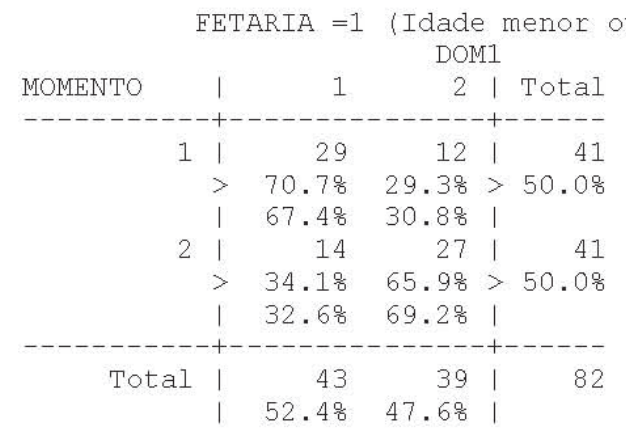

Single Table Analysis

Stratum 1

odds ratio

4.66

Cornfield $95 \%$ confidence limits for OR

$1.65<\mathrm{OR}<$

13.42

Maximum likelihood estimate of OR (MLE)

4.57 
Exact 95\% confidence limits for MLE

13.19

Exact 95\% Mid-P limits for MLE

12.00

Probability of MLE $>=4.57$ if population $O R=1.0$

0.00089204

RISK RATIO(RR) (Outcome:DOM1=1; Exposure:MOMENTO=1)

2.07

95\% confidence limits for $R R$

3.31

Ignore risk ratio if case control study

$$
\text { Chi-Squares P-values }
$$

$\begin{array}{lrl}\text { Uncorrected: } & 11.00 & 0.00091024<--- \\ \text { Mantel-Haenszel: } & 10.87 & 0.00097860<--- \\ \text { Yates corrected: } & 9.58 & 0.00196304<---\end{array}$

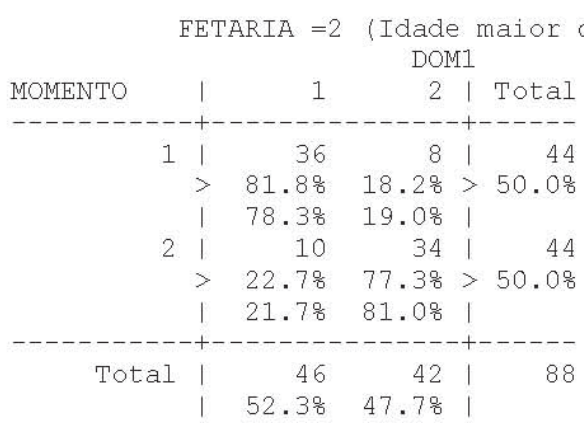

Single Table Analysis

Stratum 2

Odds ratio

15.30

Cornfield 95\% confidence limits for OR

51.10

Maximum likelihood estimate of OR (MLE)

14.68

Exact 95\% confidence limits for MLE

49.82

Exact 95\% Mid-P limits for MLE

44. 14

Probability of MLE $>=14.68$ if population $\mathrm{OR}=1.0$

0.00000002

RISK RATIO(RR) (Outcome:DOM1=1; Exposure:MOMENTO=1)

3.60

95\% confidence limits for RR

6.32

Ignore risk ratio if case control study
$1.67<\mathrm{OR}<$

$1.81<\mathrm{OR}<$

$1.30<R R<$ 


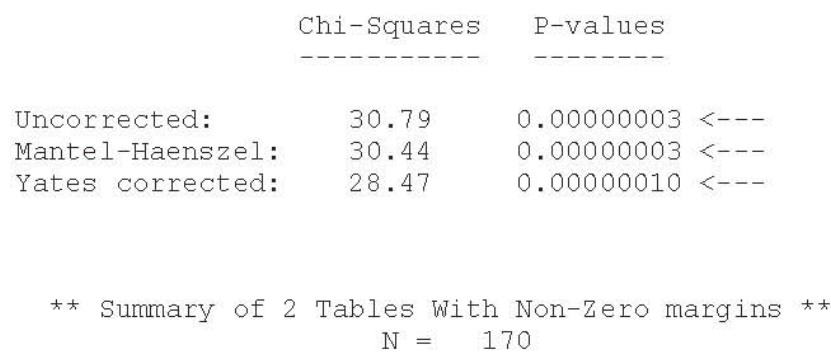

Mantel-Haenszel Summary Chi Square

37.29

P value

0.00000000

Mantel-Haenszel Summary Chi Square (uncorrected)

39.17

P value

0.00000000

Crude OR

SUMMARY ODDS RATIO

8.26

Mantel-Haenszel weighted odds ratio

7.93

95\% conf limits for M-H OR (Robins, Greenland, Breslow) $4.01<$ OR

15.70

Maximum likelihood estimate of OR (MLE)

8.02

Exact 95\% confidence limits for MLE

17.14

Exact $95 \%$ Mid-P limits for MLE

16.23

Probability of MLE $>=8.02$ if population $\mathrm{OR}=1.0$

0.00000000

Chi Square for evaluation of interaction

2.78

P value

0.09551619

Test does not suggest that ORs differ by stratum (interaction)

If Crude and Summary values are similar, confounding is small.

In the absence of interaction and confounding, crude, unstratified analysis (MOMENTO $x$ DOMl) may be used.

SUMMARY RISK RATIO (RR)

(Ignore if Case-Control Study)

Crude RR without stratification

2.71

Summary RR of (DOM1 $=1$ ) for (MOMENTO $=1$ )

2.71

$95 \%$ confidence limits for RR

$1.89<\mathrm{RR}<$

3.88 
Chi Square for evaluation of interaction

2.19

P value

0.13886553

Test does not suggest that RRs differ by stratum (interaction)

If Crude and Summary values are similar, confounding is small.

In the absence of interaction and confounding, crude, unstratified analysis (MOMENTO x DOM1) may be used.

** End of Stratified Analysis **

** Beginning Stratified Analysis ** 
Tabelas com os cruzamentos feitos no Epi info para o DoMínIo 2

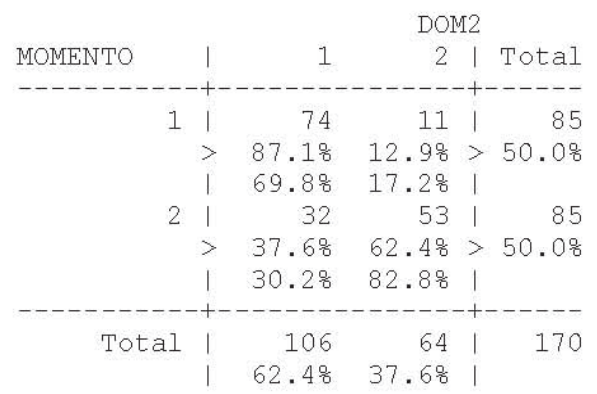

Single Table Analysis

Odds ratio

11.14

Cornfield $95 \%$ confidence limits for OR

$4.83<\mathrm{OR}<$

26.26

Maximum likelihood estimate of OR (MLE)

10.96

Exact $95 \%$ confidence limits for MLE

26.45

Exact $95 \%$ Mid-P limits for MLE

24.60

Probability of MLE $>=10.96$ if population $O R=1.0$

0.00000000

RISK RATIO(RR) (Outcome:DOM2=1; Exposure :MOMENTO=1)

2.31

95\% confidence limits for RR

3.08

Ignore risk ratio if case control study

$\begin{array}{lcc} & \text { Chi-Squares } & \text { P-values } \\ & & \\ & & \\ \text { Uncorrected: } & 44.20 & 0.00000000<--- \\ \text { Mantel-Haenszel: } & 43.94 & 0.00000000<--- \\ \text { Yates corrected: } & 42.12 & 0.00000000<---\end{array}$

** Beginning Stratified Analysis **

$4.89<\mathrm{OR}<$

$5.17<\mathrm{OR}<$

$1.74<\mathrm{RR}<$

$\ldots$

SEXO $=1 \quad$ (Masculino)

DOM2

\begin{tabular}{l|lr|r} 
MOMENTO & 1 & 2 & Total
\end{tabular} 


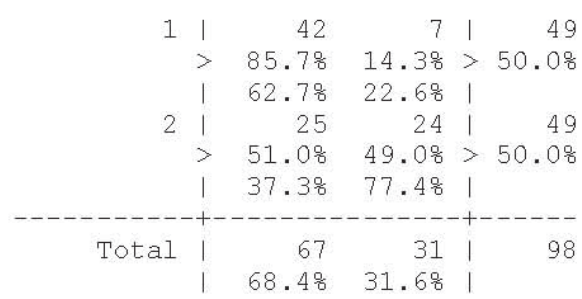

Single Table Analysis

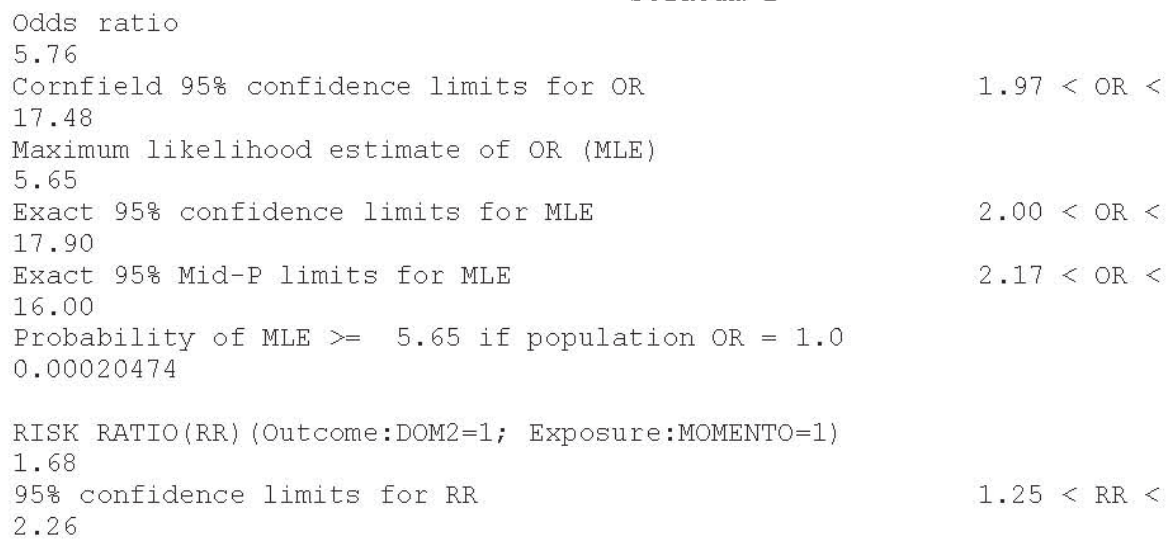

Stratum 2 
Odds ratio

33.14

Cornfield 95\% confidence limits for OR

$7.53<\mathrm{OR}<$

$164.22 *$

* May be inaccurate

Maximum likelihood estimate of OR (MLE)

30.74

Exact 95\% confidence limits for MLE

161.49

Exact 95\% Mid-P limits for MLE

132.50

Probability of $\mathrm{MLE}>=30.74$ if population $\mathrm{OR}=1.0$

0.00000000

RISK RATIO(RR) (Outcome:DOM2=1; Exposure: MOMENTO=1)

4.57

$95 \%$ confidence limits for RR

8.98

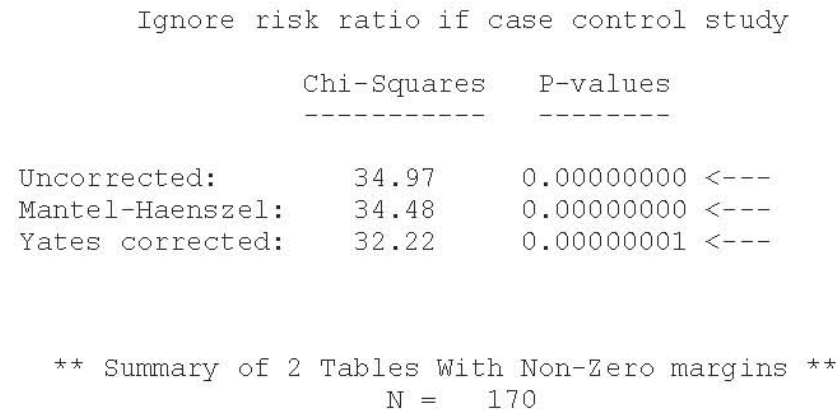

Mantel-Haenszel Summary Chi Square

42.51

P value

0.00000000

Mantel-Haenszel Summary Chi Square (uncorrected)

44.61

P value

0.00000000

SUMMARY ODDS RATIO

Crude OR

11.14

Mantel-Haenszel weighted odds ratio

10.66

95\% conf limits for M-H OR (Robins, Greenland, Breslow) $4.96<$ OR <

22.92

Maximum likelihood estimate of OR (MLE)

11.71

Exact $95 \%$ confidence limits for MLE

29.10

Exact $95 \%$ Mid-P limits for MLE

$7.69<\mathrm{OR}<$

$8.69<\mathrm{OR}<$

26.96

Probability of MLE $>=11.71$ if population $O R=1.0$

0.00000000 
Chi Square for evaluation of interaction

4.33

P value

0.03741089

Test suggests that ORs differ by stratum (interaction)

If Crude and Summary values are similar, confounding is small.

In the absence of interaction and confounding, crude, unstratified analysis (MOMENTO $x$ DOM2) may be used.

SUMMARY RISK RATIO (RR)

(Ignore if Case-Control Study)

Crude $R R$ without stratification

2. 31

Summary RR of (DOM2=1) for (MOMENTO=1)

2.31

95\% confidence limits for RR

3.08

Chi Square for evaluation of interaction

7.08

P value

0.00779712

Test suggests that RRs differ by stratum (interaction)

If Crude and Summary values are similar, confounding is small.

In the absence of interaction and confounding, crude, unstratified analysis (MOMENTO $x$ DOM2) may be used.

t* End of Stratified Analysis $t \star$

$\ldots$

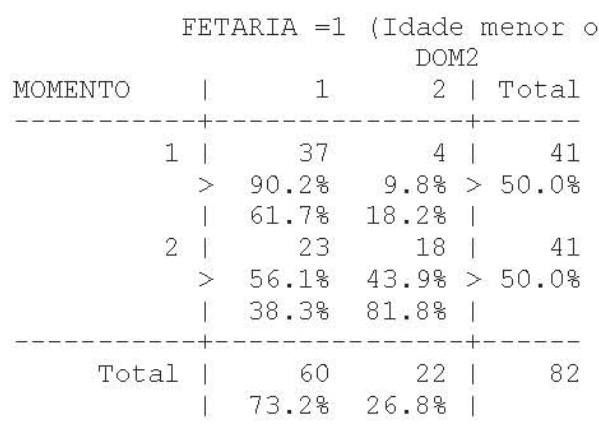

Single Table Analysis

odds ratio

Stratum 1

7.24

Cornfield $95 \%$ confidence limits for OR

$1.93<\mathrm{OR}<$

$29.51 *$

*May be inaccurate 
Maximum likelihood estimate of OR (MLE)

7.06

Exact $95 \%$ confidence limits for MLE

$1.99<\mathrm{OR}<$

32.32

Exact 95\% Mid-P limits for MLE

$2.22<\mathrm{OR}<$

27.04

Probability of MLE $>=7.06$ if population OR $=1.0$

0.00045859

RISK RATIO(RR) (Outcome:DOM2=1; Exposure :MOMENTO=1)

1.61

95\% confidence limits for RR

2.15

Ignore risk ratio if case control study

$$
\text { Chi-Squares P-values }
$$

$\begin{array}{lll}\text { Uncorrected: } & 12.18 & 0.00048415<--- \\ \text { Mantel-Haenszel: } & 12.03 & 0.00052428<--- \\ \text { Yates corrected: } & 10.50 & 0.00119472<---\end{array}$

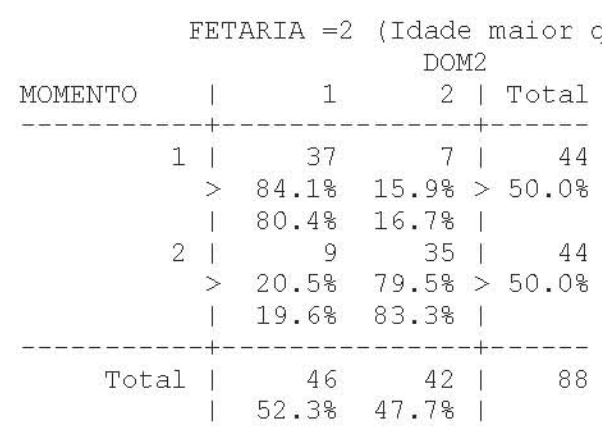

Single Table Analysis

Odds ratio

Stratum 2

20.56

Cornfield 95\% confidence limits for oR

73.45

Maximum likelihood estimate of OR (MLE)

19.58

Exact $95 \%$ confidence limits for MLE

71.39

Exact $95 \%$ Mid-P limits for MLE

62.49

Probability of $\mathrm{MLE}>=19.58$ if population $\mathrm{OR}=1.0$

0.00000000

RISK RATIO(RR) (Outcome:DOM2=1; Exposure: MOMENTO=1)

4.11

95\% confidence limits for RR

$1.21<\mathrm{RR}<$

7.47

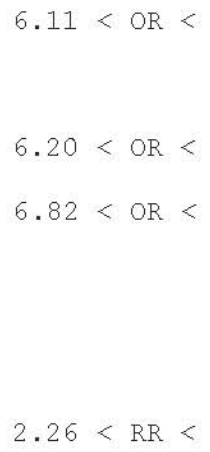




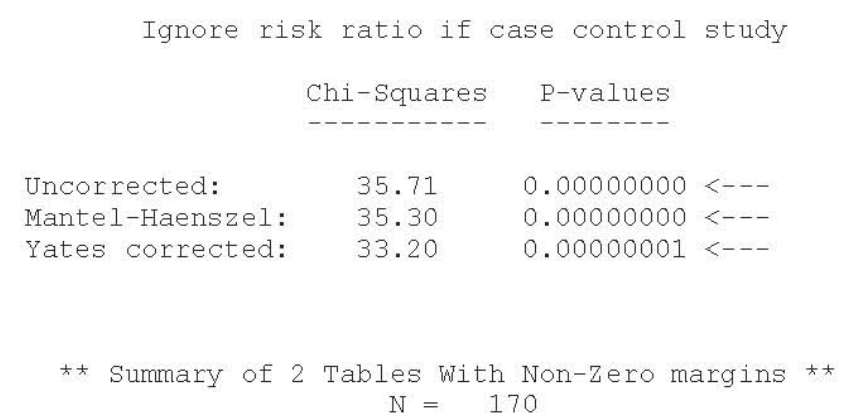

Mantel-Haenszel Summary Chi Square

43.66

P value

0.00000000

Mantel-Haenszel Summary Chi Square (uncorrected)

45.81

P value

0.00000000

SUMMARY ODDS RATIO

Crude OR

11.14

Mantel-Haenszel weighted odds ratio

12.43

95ㅁ conf limits for M-H OR (Robins, Greenland, Breslow) $5.53<$ OR <

27.91

Maximum likelihood estimate of OR (MLE)

13.06

Exact 95\% confidence limits for MLE

33.81

Exact 95\% Mid-P limits for MLE

31.13

Probability of MLE $>=13.06$ if population $\mathrm{OR}=1.0$

0.00000000

Chi Square for evaluation of interaction

1.59

P value

0.20753128

Test does not suggest that ORs differ by stratum (interaction)

If Crude and Summary values are similar, confounding is small.

In the absence of interaction and confounding, crude, unstratified analysis (MOMENTO x DOM2) may be used.

SUMMARY RISK RATIO (RR)

(Ignore if Case-Control Study)

Crude RR without stratification

2.31

Summary RR of (DOM2=1) for (MOMENTO=1)

2.31

958 confidence limits for $R R$

$1.74<\mathrm{RR}<$

3.07 
Chi Square for evaluation of interaction

7.69

P value

0.00553801

Test suggests that RRs differ by stratum (interaction)

If Crude and Summary values are similar, confounding is small.

In the absence of interaction and confounding, crude, unstratified analysis (MOMENTO $x$ DOM2) may be used.

** End of Stratified Analysis **

** Beginning stratified Analysis * 
Tabelas com os cruzamentos feitos no Epi info para o DoMínIo 3

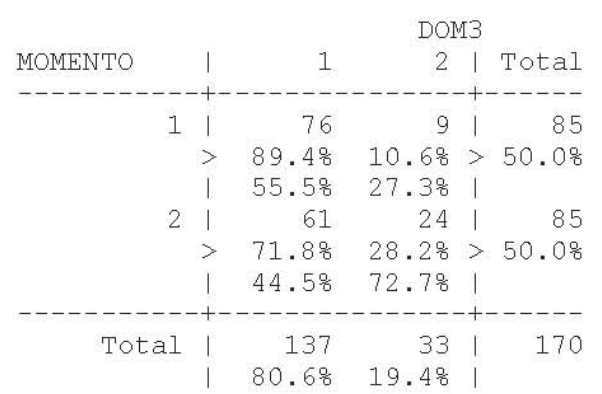

Single Table Analysis

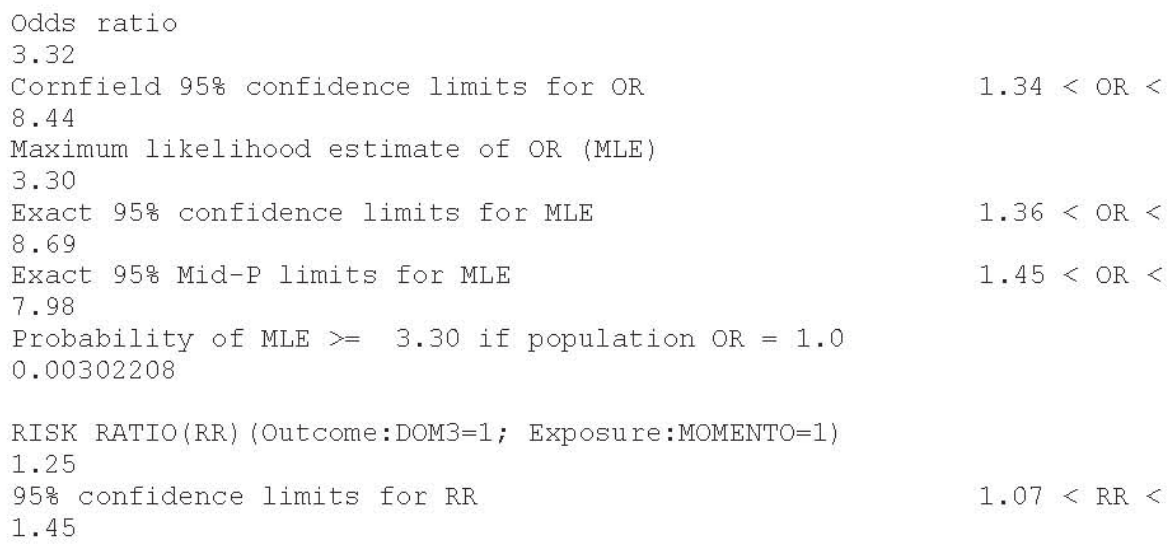

Ignore risk ratio if case control study

$\begin{array}{lcc} & \text { Chi-Squares } & \text { P-values } \\ & & \\ & & \\ \text { Uncorrected: } & 8.46 & 0.00362939<--- \\ \text { Mantel-Haenszel: } & 8.41 & 0.00373009<--- \\ \text { Yates corrected: } & 7.37 & 0.00663191<---\end{array}$

** Beginning Stratified Analysis **

$\cdots$

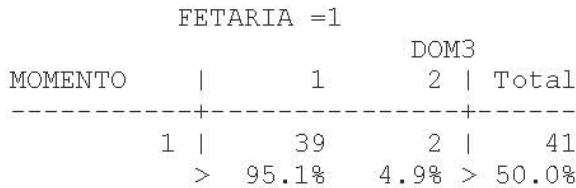




\begin{tabular}{|c|c|c|c|}
\hline & 51.38 & $33.3 \%$ & 1 \\
\hline 2 & 37 & 4 & 41 \\
\hline & $90.2 \%$ & $9.8 \%$ & $>50.0 \%$ \\
\hline & $48.7 \%$ & $66.7 \%$ & 1 \\
\hline Total & 76 & 6 & 82 \\
\hline & $92.7 \%$ & 7.38 & I \\
\hline
\end{tabular}

Single Table Analysis

odds ratio

Stratum 1

2.11

Cornfield $95 \%$ confidence limits for oR

$0.30<\mathrm{OR}<$

$18.04^{*}$

*May be inaccurate

Maximum likelihood estimate of OR (MLE)

2.09

Exact 95\% confidence limits for MLE

24.40

Exact 95\% Mid-P limits for MLE

17.14

Probability of MLE $>=2.09$ if population $\mathrm{OR}=1.0$

0.33773845

RISK RATIO(RR) (Outcome:DOM3=1; Exposure :MOMENTO=1)

1.05

95\% confidence limits for RR

1.19

Ignore risk ratio if case control study

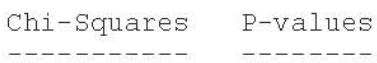

$\begin{array}{lll}\text { Uncorrected: } & 0.72 & 0.39637419 \\ \text { Mantel-Haenszel: } & 0.71 & 0.39926914 \\ \text { Yates corrected: } & 0.18 & 0.67152405\end{array}$

Fisher exact: 1-tailed P-value: 0.3377384

2-tailed P-value: 0.6754769

An expected value is less than 5; recommend Fisher exact results.

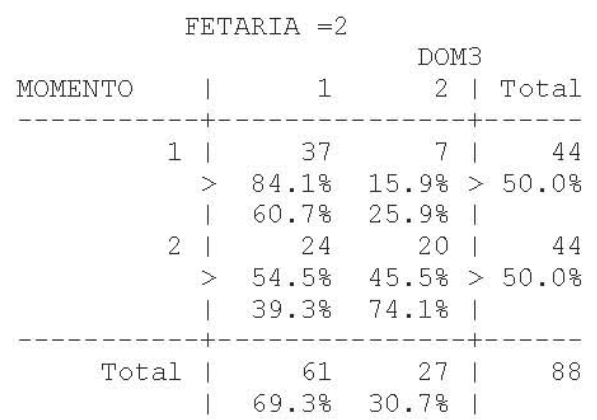




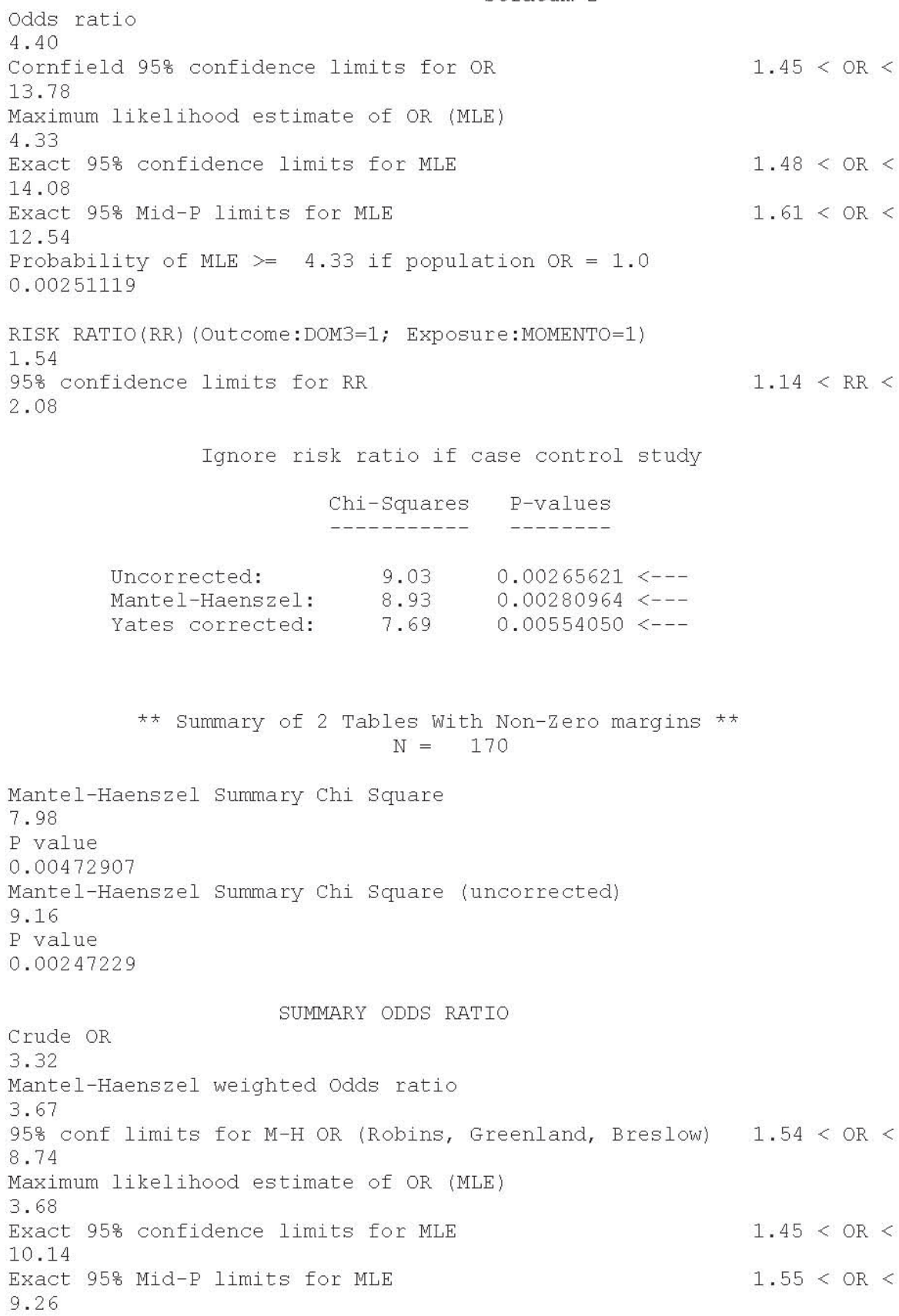


Probability of MLE $>=3.68$ if population $\mathrm{OR}=1.0$

0.00205719

Chi Square for evaluation of interaction

0.51

P value

0.47503188

Test does not suggest that ORs differ by stratum (interaction)

If Crude and Summary values are similar, confounding is small.

In the absence of interaction and confounding, crude, unstratified analysis (MOMENTO x DOM3) may be used.

SUMMARY RISK RATIO (RR)

(Ignore if Case-Control Study)

Crude RR without stratification

1.25

Summary RR of (DOM3=1) for (MOMENTO=1)

1.25

95\% confidence limits for RR

1.44

$1.08<\mathrm{RR}<$

Chi Square for evaluation of interaction

5.33

$\mathrm{P}$ value

0.02096931

Test suggests that RRs differ by stratum (interaction)

If Crude and Summary values are similar, confounding is small.

In the absence of interaction and confounding, crude, unstratified analysis (MOMENTO $x$ DOM3) may be used.

* End of Stratified Analysis *ᄎ

** Beginning Stratified Analysis **

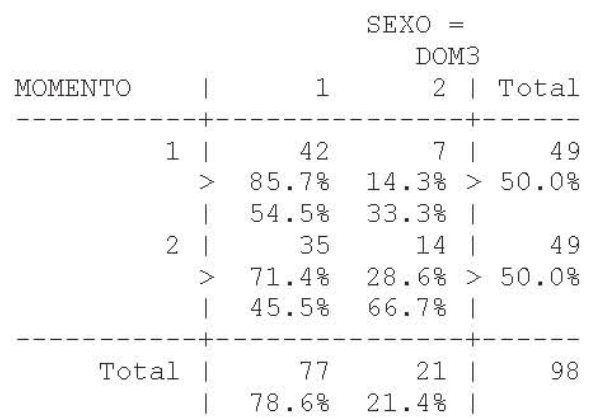

Single Table Analysis

Stratum 1

Odds ratio

2.40

Cornfield 95\% confidence limits for OR

1.00000

7.55

$0.78<\mathrm{OR}<$ 


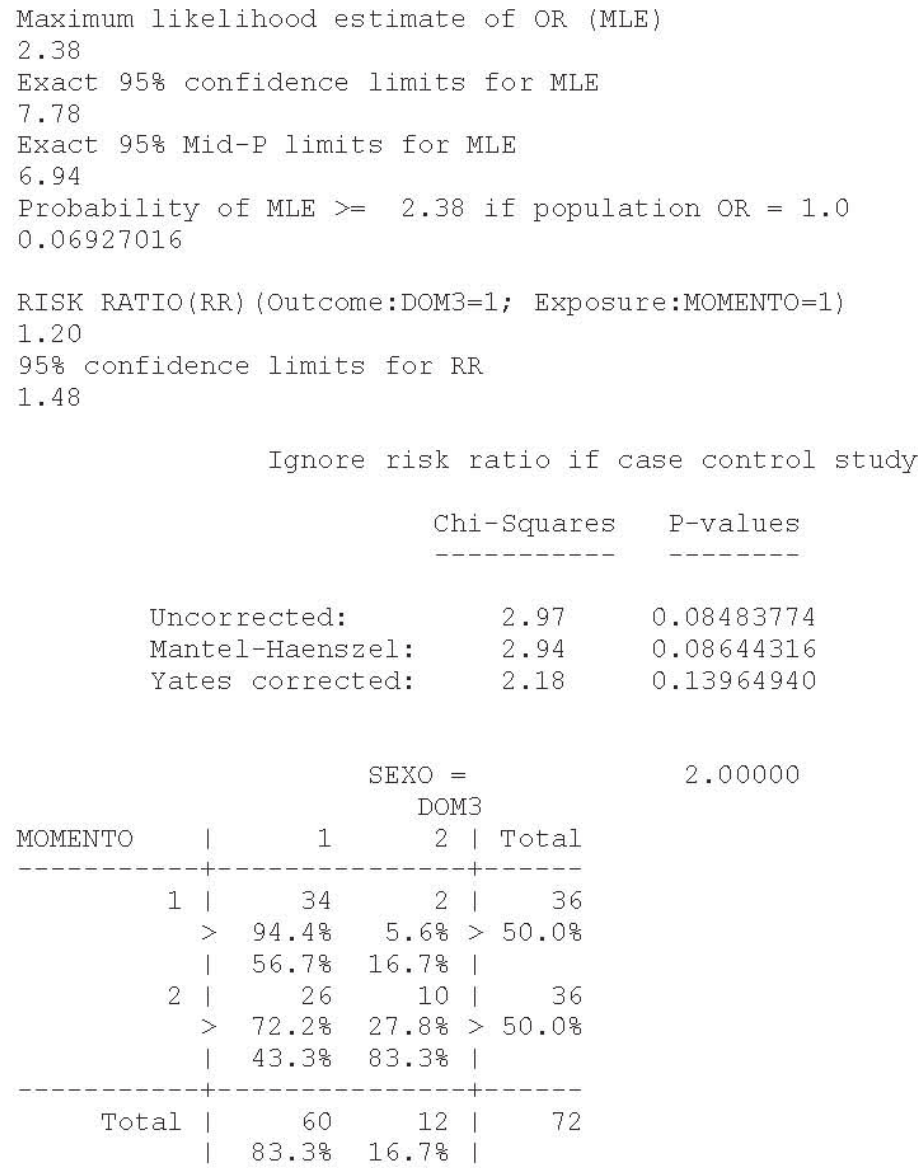


95\% confidence limits for RR

1.63

Ignore risk ratio if case control study

$\begin{array}{lcc} & \text { Chi-Squares } & \text { P-values } \\ & & \\ & & \\ \text { Uncorrected: } & 6.40 & 0.01141204<--- \\ \text { Mantel-Haenszel: } & 6.31 & 0.01199836<--- \\ \text { Yates corrected: } & 4.90 & 0.02685670<--- \\ \text { ** Summary of } 2 \text { Tables With Non-Zero margins ** } & \mathrm{N}=170\end{array}$

Mantel-Haenszel Summary Chi Square

7.31

P value

0.00685549

Mantel-Haenszel Summary Chi Square (uncorrected)

8.39

P value

0.00376856

SUMMARY ODDS RATIO

Crude OR

3.32

Mantel-Haenszel weighted odds ratio

3.33

95\% conf limits for M-H OR (Robins, Greenland, Breslow) $1.44<$ OR <

7.70

Maximum likelihood estimate of OR (MLE)

3.29

Exact $95 \%$ confidence limits for MLE

8.66

Exact $95 \%$ Mid-P limits for MLE

$1.36<\mathrm{OR}<$

7.96

Probability of MLE $>=3.29$ if population $O R=1.0$

0.00305007

Chi square for evaluation of interaction

1.07

P value

0.29985707

Test does not suggest that ORs differ by stratum (interaction)

If Crude and Summary values are similar, confounding is small.

In the absence of interaction and confounding, crude, unstratified

analysis (MOMENTO x DOM3) may be used.

SUMMARY RISK RATIO (RR)

(Ignore if Case-Control Study)

Crude RR without stratification

1.25

Summary RR of (DOM3=1) for (MOMENTO=1)

1. 25 
Chi Square for evaluation of interaction

0.31

P value

0.57812850

Test does not suggest that RRs differ by stratum (interaction)

If Crude and Summary values are similar, confounding is small.

In the absence of interaction and confounding, crude, unstratified

analysis (MOMENTO x DOM3) may be used.

** End of Stratified Analysis ** 
Tabelas com os cruzamentos feitos no Epi info para o DOMÍNIO 4

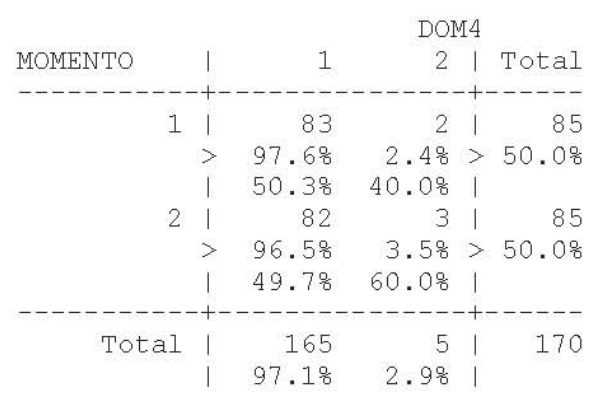

Single Table Analysis

odds ratio

1.52

Cornfield $95 \%$ confidence limits for oR

$13.57^{*}$

'May be inaccurate

Maximum likelihood estimate of OR (MLE)

1.51

Exact 95\% confidence limits for MLE

18.57

Exact $95 \%$ Mid-P limits for MLE

13.02

Probability of MLE $>=1.51$ if population $\mathrm{OR}=1.0$

0.50000000

RISK RATIO(RR) (Outcome:DOM4=1; Exposure: MOMENTO=1)

1.01

95\% confidence limits for RR

1.07

Ignore risk ratio if case control study

\begin{tabular}{|c|c|c|}
\hline & $\begin{array}{l}\text { Chi-Squares } \\
---------\end{array}$ & $\begin{array}{l}\text { P-values } \\
-------\end{array}$ \\
\hline Uncorrected: & 0.21 & 0.64987274 \\
\hline Mantel-Haenszel: & 0.20 & 0.65083543 \\
\hline Yates corrected: & 0.00 & 1.00000000 \\
\hline isher exact: & $\begin{array}{l}\text {-tailed P-va } \\
\text {-tailed P-va }\end{array}$ & $\begin{array}{l}\text { e: } 0.5000000 \\
\text { e: } 1.0000000\end{array}$ \\
\hline
\end{tabular}

An expected value is less than 5; recommend Fisher exact results.

** Beginning Stratified Analysis **

$\cdots$ 


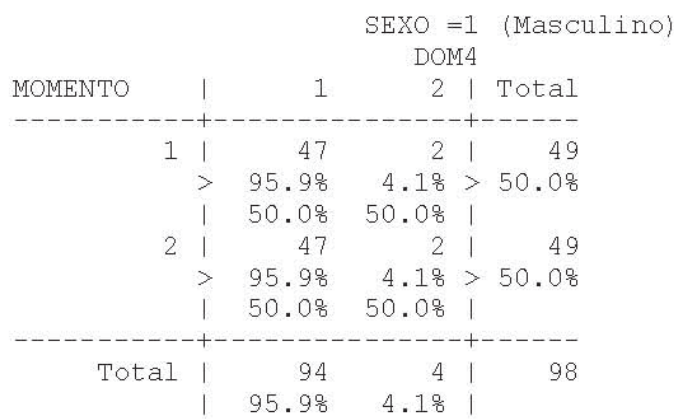

Single Table Analysis

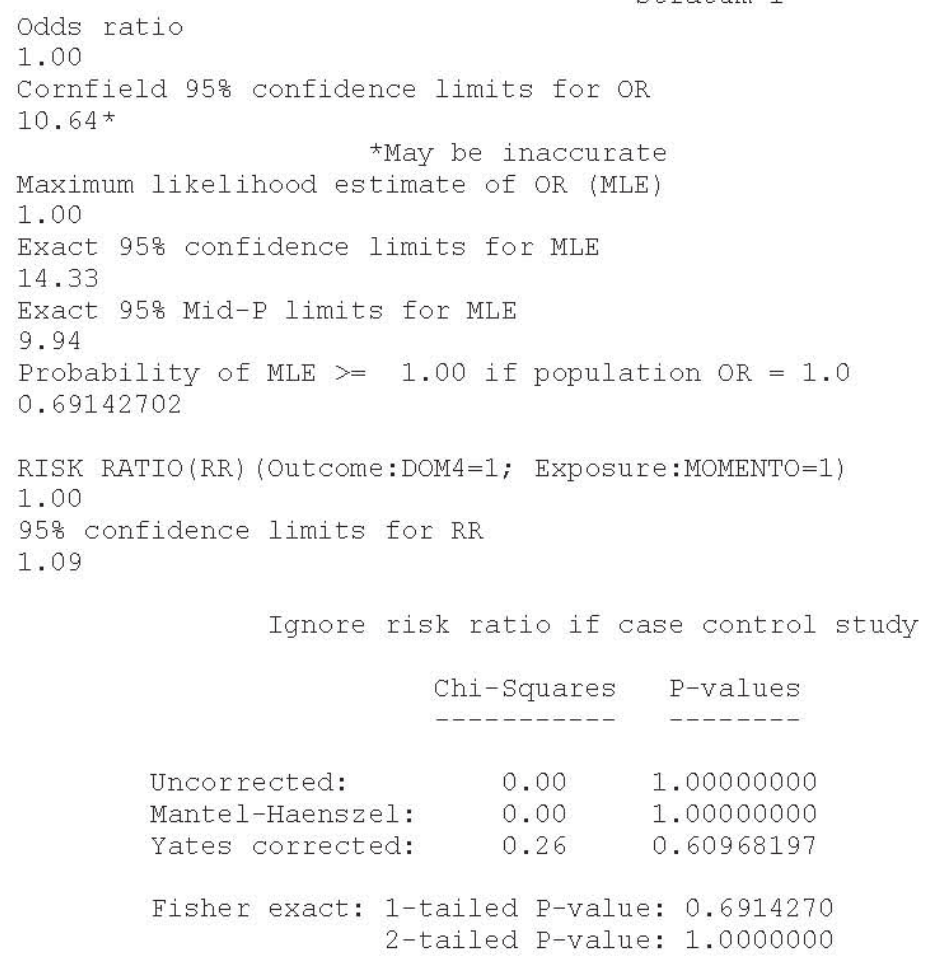

$\begin{array}{lcc} & \text { Chi-Squares } & \text { P-values } \\ & 0.00 & 1.00000000 \\ \text { Uncorrected: } & 0.00 & 1.00000000 \\ \text { Mantel-Haenszel: } & 0.26 & 0.60968197 \\ \text { Yates corrected: } & & \\ \text { Fisher exact: } & \text { 1-tailed P-value: } 0.6914270 \\ & \text { 2-tailed P-value: } & 1.0000000\end{array}$

An expected value is less than 5; recommend Fisher exact results.

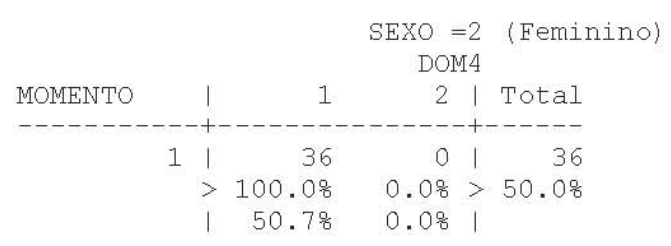




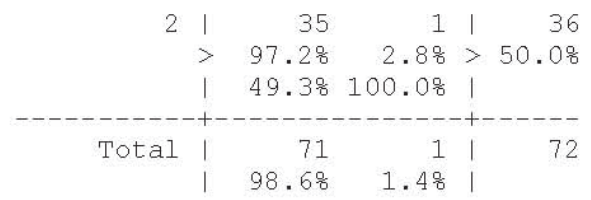

Single Table Analysis

Odds ratio

Stratum 2

??????

Maximum likelihood estimate of OR (MLE)

??????

Exact 95\% confidence limits for MLE $\quad 0.03<0 R<$

??????

Exact $95 \%$ Mid-P limits for MLE

$0.05<\mathrm{OR}<$

Probability of MLE >= ????? if population $\mathrm{OR}=1.0$

0.50000000

RISK RATIO(RR) (Outcome:DOM4=1; Exposure: MOMENTO=1)

1.03

95\% confidence limits for RR

1.09

Ignore risk ratio if case control study

$\begin{array}{lcc} & \text { Chi-Squares } & \text { P-values } \\ & 1.01 & 0.31392630 \\ \text { Uncorrected: } & 1.00 & 0.31731051 \\ \text { Mantel-Haenszel: } & 0.00 & 1.00000000 \\ \text { Yates corrected: } & & \\ \text { Fisher exact: } 1 \text {-tailed P-value: } 0.5000000 \\ \text { 2-tailed P-value: } 1.0000000\end{array}$

An expected value is less than 5; recommend Fisher exact results.

** Summary of 2 Tables With Non-Zero margins **

$$
\mathrm{N}=170
$$

Mantel-Haenszel Summary Chi Square

0.00

P value

1.00000000

Mantel-Haenszel Summary Chi square (uncorrected)

0.21

P value

0.65065606

Crude OR

SUMMARY ODDS RATIO

1.52

Mantel-Haenszel weighted odds ratio

1.52 


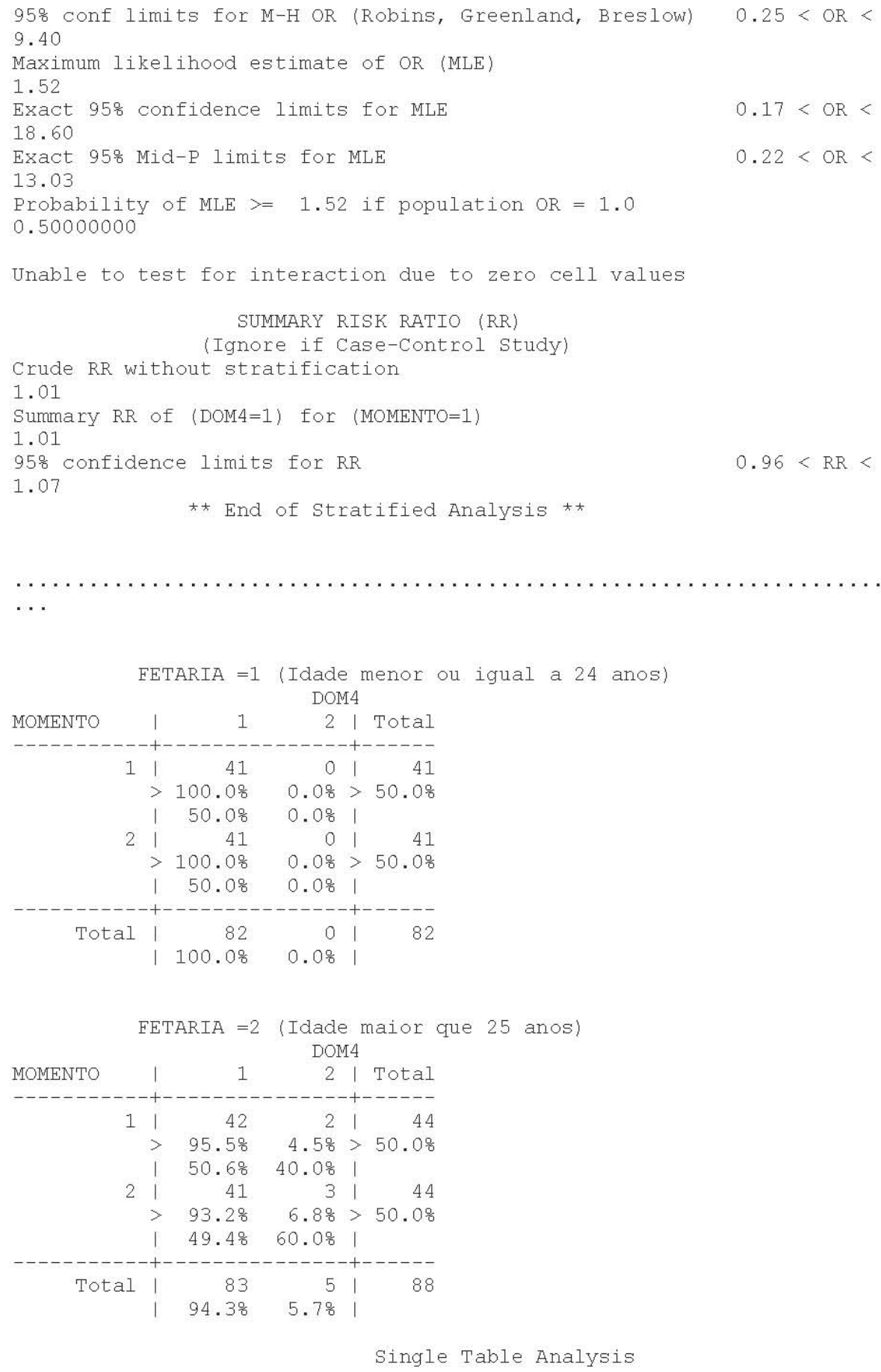




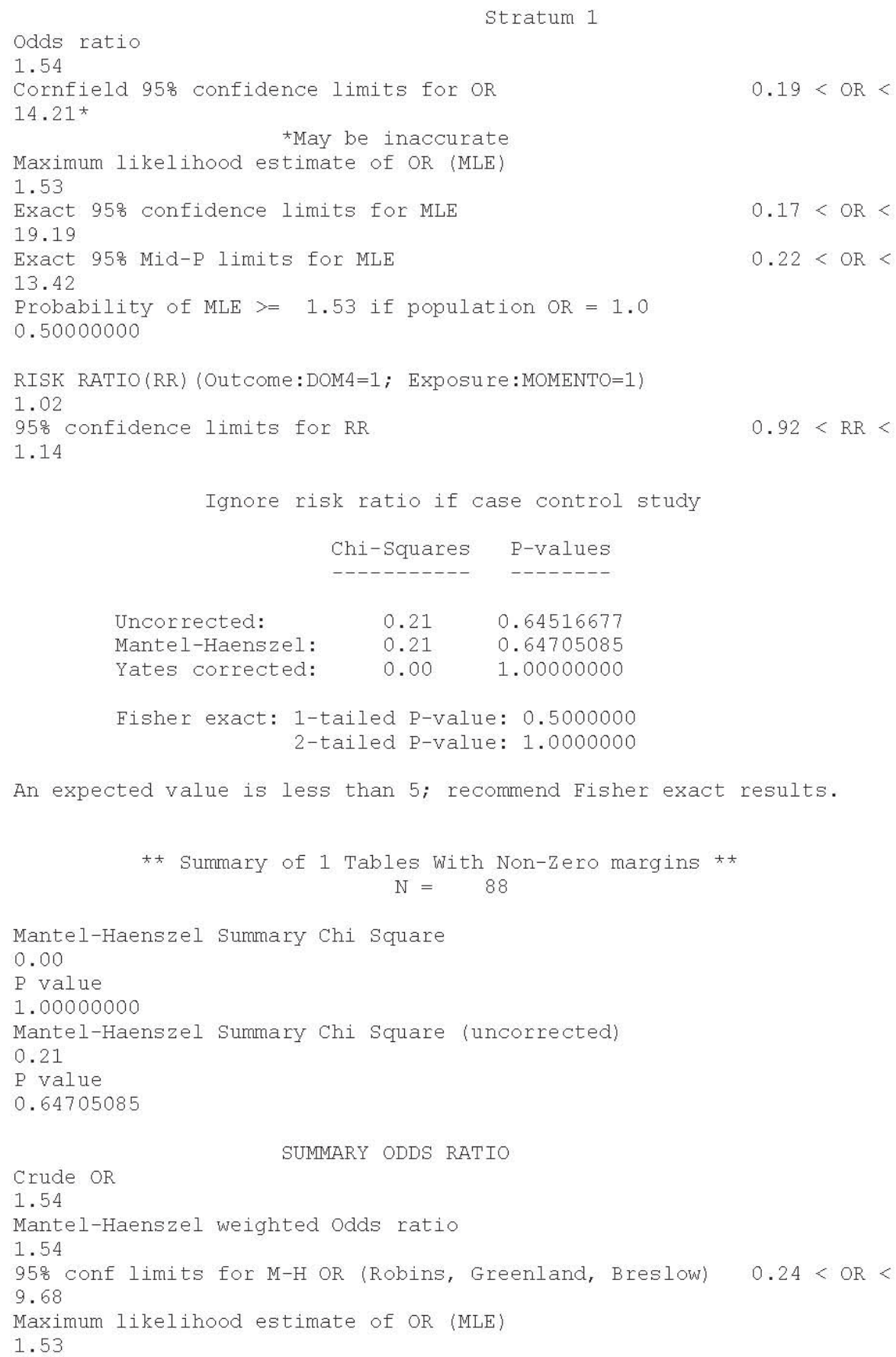


Exact 95\% confidence limits for MLE

19.19

Exact 95\% Mid-P limits for MLE

13.42

Probability of MLE $>=1.53$ if population $\mathrm{OR}=1.0$

0.50000000

SUMMARY RISK RATIO (RR)

(Ignore if Case-Control Study)

Crude RR without stratification

1.02

Summary RR of (DOM4=1) for (MOMENTO=1)

1.02

95: confidence limits for RR

1.14

** End of Stratified Analysis **

** Beginning Stratified Analysis **
$0.17<\mathrm{OR}<$

$0.22<\mathrm{OR}<$

$0.92<\mathrm{RR}<$ 


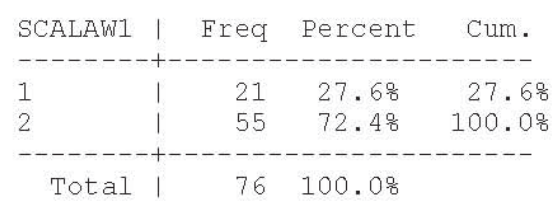

$\begin{array}{rrrrrr}\text { Total } & \text { Sum } & \text { Mean } & \text { Variance } & \text { Std Dev } & \text { Std Err } \\ 76 & 131 & 1.724 & 0.203 & 0.450 & 0.052 \\ & & & & & \\ \text { Minimum } & 258 \text { ile } & \text { Median } & 75 \% \text { ile } & \text { Maximum } & \text { Mode } \\ 1.000 & 1.000 & 2.000 & 2.000 & 2.000 & 2.000\end{array}$

Student's "t", testing whether mean differs from zero. $\mathrm{T}$ statistic $=33.382, \mathrm{df}=75 \mathrm{p}$-value $=0.00000$

\begin{tabular}{|c|c|c|c|}
\hline & & & \\
\hline SCALAW1 & | & 1. & 2. | Total \\
\hline-------- & & -- & -----+----- \\
\hline 1 & | & 6 & $15 \mid$ \\
\hline & $>$ & $28.6 \%$ & $71.48>27.68$ \\
\hline & | & $25.0 \%$ & $28.88 \quad \mid$ \\
\hline 2 & | & 18 & $37 \mid 55$ \\
\hline & $>$ & $32.7 \%$ & $67.38>72.48$ \\
\hline & | & $75.0 \%$ & $71.28 \quad \mid$ \\
\hline---- & + & ---- & -----+----- \\
\hline Total & | & 24 & $52 \mid$ \\
\hline & | & $31.6 \%$ & $68.48 \quad \mid$ \\
\hline
\end{tabular}

Single Table Analysis

Odds ratio

0.82

Cornfield 95\% confidence limits for OR

$0.23<\mathrm{OR}<$

2.81

Maximum likelihood estimate of OR (MLE)

0.82

Exact $95 \%$ confidence limits for MLE

2.74

Exact $95 \%$ Mid-P limits for MLE

2.47

Probability of $\operatorname{MLE}<=0.82$ if population $\mathrm{OR}=1.0$

0.47734714

RISK RATIO(RR) (Outcome:SEXO=1.; Exposure:SCALAW1=1)

0.87

95\% confidence limits for RR

1.90

Ignore risk ratio if case control study

$\begin{array}{cc}\text { Chi-Squares } & \text { P-values } \\ 0.12 & 0.72743641\end{array}$




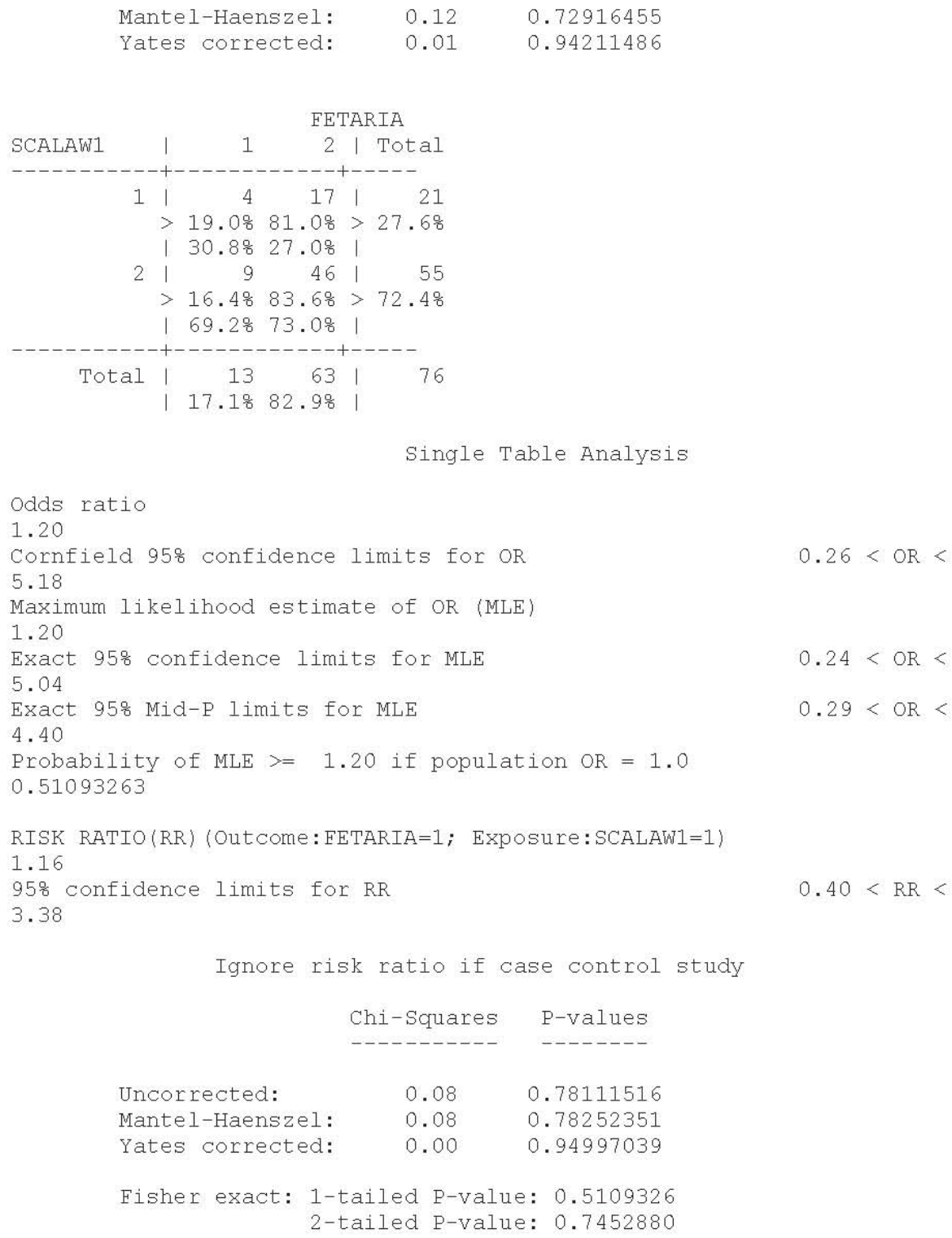

$\begin{array}{lcc} & \begin{array}{c}\text { Chi-Squares } \\ \text { Uncorrected: }\end{array} & \begin{array}{l}\text { P-values } \\ -------\end{array} \\ \text { Mantel-Haenszel: } & 0.08 & 0.78111516 \\ \text { Yates corrected: } & 0.00 & 0.78252351 \\ \text { Fisher exact: } & 0.94997039 \\ & & \\ \text { 2-tailed P-value: } & 0.5109326 \\ & \end{array}$

An expected value is less than 5; recommend Fisher exact results.

Current selection: RENDAPESSO $<$.

\begin{tabular}{r|rrrr} 
& & \multicolumn{3}{c}{ RP } \\
SCALAW1 & | & 1 & 2 & Total \\
-1 & | & 4 & 10 & 14 \\
& $>$ & 28.68 & 71.48 & $>29.28$
\end{tabular}




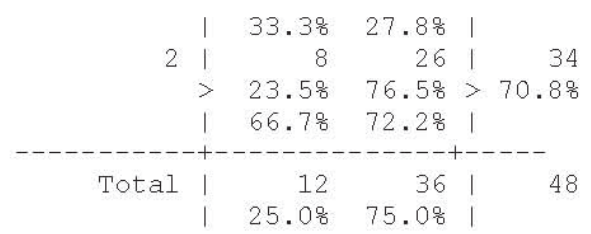

Single Table Analysis

odds ratio

1.30

Cornfield 95\% confidence limits for oR

$0.25<\mathrm{OR}<$

6.51

Maximum likelihood estimate of OR (MLE)

1.29

Exact $95 \%$ confidence limits for MLE

6.29

Exact 95\% Mid-P limits for MLE

5.35

Probability of MLE $>=1.29$ if population $O R=1.0$

0.48931550

RISK RATIO(RR) (Outcome:RP=1; Exposure: SCALAW1=1)

1.21

95\% confidence limits for RR

3.39

Ignore risk ratio if case control study

$\begin{array}{lcc} & \text { Chi-Squares } & \text { P-values } \\ & 0.13 & 0.71385818 \\ \text { Uncorrected: } & 0.13 & 0.71672462 \\ \text { Mantel-Haenszel: } & 0.00 & 1.00000000 \\ \text { Yates corrected: } & & \\ \text { Fisher exact: } & \text { 1-tailed P-value: } 0.4893155 \\ \text { 2-tailed P-value: } & 0.7259558\end{array}$

An expected value is less than 5; recommend Fisher exact results.

Current selection: RENDAFAMIL $<>$.

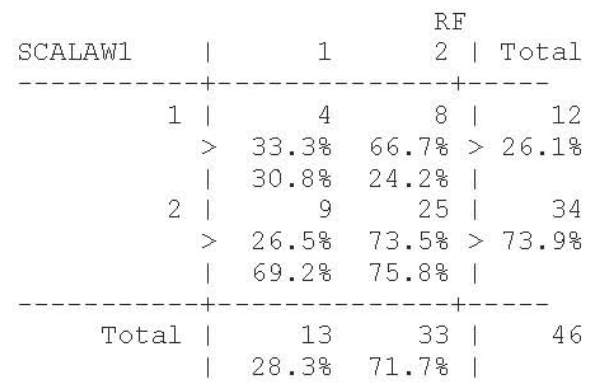

Single Table Analysis 


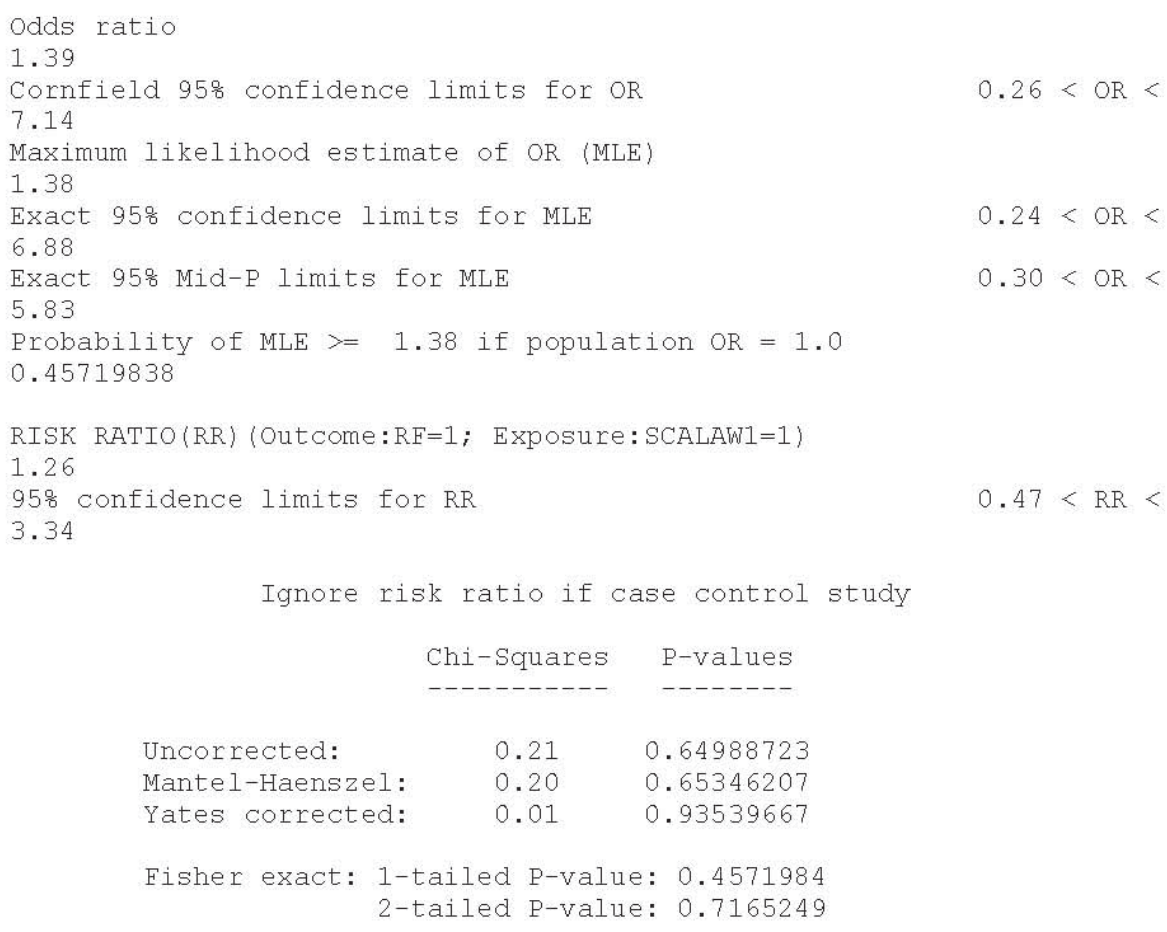

$\begin{array}{lcc} & \text { Chi-Squares } & \text { P-values } \\ & & \\ & & \\ \text { Uncorrected: } & 0.21 & 0.64988723 \\ \text { Mantel-Haenszel: } & 0.20 & 0.65346207 \\ \text { Yates corrected: } & 0.01 & 0.93539667 \\ \text { Fisher exact: } 1 \text {-tailed P-value: } & 0.4571984 \\ & \text { 2-tailed P-value: } 0.7165249\end{array}$

An expected value is less than 5; recommend Fisher exact results.

\begin{tabular}{|c|c|c|c|c|c|}
\hline & & & & ESCO & LA \\
\hline SCALAW1 & & I & 1 & 21 & Total \\
\hline & & & & -----+- & \\
\hline & 1 & I & 5 & 16 & 21 \\
\hline & & $>$ & $23.8 \%$ & $76.28>$ & 27.68 \\
\hline & & । & $29.4 \%$ & 27.18 & \\
\hline & 2 & I & 12 & 43 & 55 \\
\hline & & $>$ & $21.8 \%$ & $78.28>$ & $72.4 \%$ \\
\hline & & । & 70.68 & $72.98 \quad$ & \\
\hline-- & & & ----- & ------+- & --- \\
\hline & & & 17 & 59 & 76 \\
\hline & & & $22.4 \%$ & 77.68 & \\
\hline
\end{tabular}

Single Table Analysis

Odds ratio

1.12

Cornfield 95\% confidence limits for OR

$0.28<\mathrm{OR}<$

4.25

Maximum likelihood estimate of OR (MLE)

1.12

Exact $95 \%$ confidence limits for MLE

4.13

Exact 95\% Mid-P limits for MLE

3.66 
Probability of MLE $>=1.12$ if population $\mathrm{OR}=1.0$

0.53778806

RISK RATIO(RR) (Outcome:ESCOLA=1; Exposure:SCALAW1=1)

1.09

$95 \%$ confidence limits for $\mathrm{RR}$

$0.44<\mathrm{RR}<$

2.72

Ignore risk ratio if case control study

\begin{tabular}{|c|c|c|}
\hline & Chi-Squares & $\begin{array}{l}\text { P-values } \\
-------\end{array}$ \\
\hline Uncorrected: & 0.03 & 0.85221613 \\
\hline Mantel-Haenszel: & 0.03 & 0.85318049 \\
\hline Yates corrected: & 0.01 & 0.90329938 \\
\hline
\end{tabular}

An expected value is less than 5; recommend Fisher exact results.

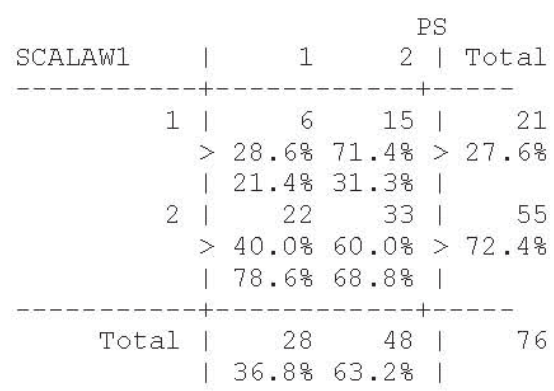

Single Table Analysis

Odds ratio

0.60

Cornfield 95\% confidence limits for oR

$0.17<\mathrm{OR}<$

2.02

Maximum likelihood estimate of OR (MLE)

0.60

Exact $95 \%$ confidence limits for MLE

1.97

Exact $95 \%$ Mid-P limits for MLE

1.78

Probability of MLE $<=0.60$ if population $\mathrm{OR}=1.0$

0.25774446

RISK RATIO(RR) (Outcome: $\mathrm{PS}=1$; Exposure: SCALAW1=1)

0.71

95\% confidence limits for RR

$0.34<\mathrm{RR}<$

1.51

Ignore risk ratio if case control study

$$
\text { Chi-Squares P-values }
$$




$\begin{array}{lll}\text { Uncorrected: } & 0.85 & 0.35568777 \\ \text { Mantel-Haenszel: } & 0.84 & 0.35887199 \\ \text { Yates corrected: } & 0.43 & 0.51071517\end{array}$




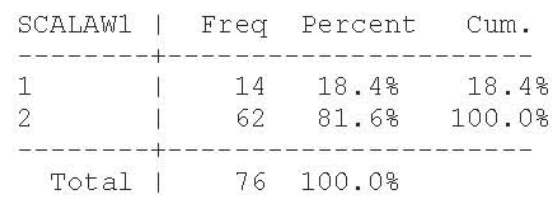

$\begin{array}{rrrrrr}\text { Total } & \text { Sum } & \text { Mean } & \text { Variance } & \text { Std Dev } & \text { Std Err } \\ 76 & 138 & 1.816 & 0.152 & 0.390 & 0.045 \\ & & & & & \\ \text { Minimum } & 258 \text { ile } & \text { Median } & 758 \text { ile } & \text { Maximum } & \text { Mode } \\ 1.000 & 2.000 & 2.000 & 2.000 & 2.000 & 2.000\end{array}$

Student's "t", testing whether mean differs from zero. $\mathrm{T}$ statistic $=40.565, \mathrm{df}=75 \mathrm{p}$-value $=0.00000$

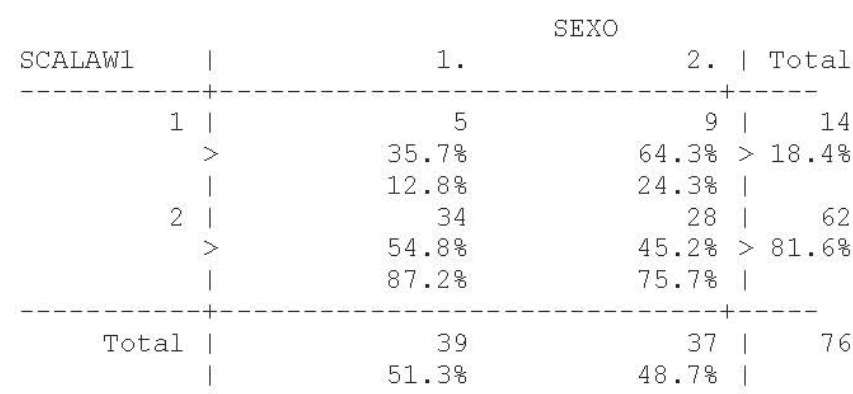

Single Table Analysis

odds ratio

0.46

Cornfield $95 \%$ confidence limits for oR

1.75

Maximum likelihood estimate of OR (MLE)

0.46

Exact $95 \%$ confidence limits for MLE

1.75

Exact $95 \%$ Mid-P limits for MLE

1.54

Probability of $\mathrm{MLE}<=0.46$ if population $\mathrm{OR}=1.0$

0.15948605

RISK RATIO(RR) (Outcome: $\mathrm{SEXO}=1$. ; Exposure: SCALAW1=1)

0.65

95\% confidence limits for RR

1.36

$0.11<\mathrm{OR}<$

$0.11<\mathrm{OR}<$

$0.13<\mathrm{OR}<$

$0.31<R R<$

Ignore risk ratio if case control study

Chi-Squares P-values 


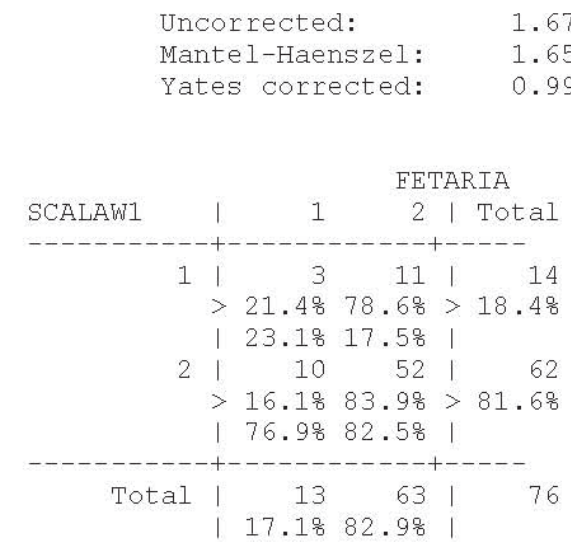

Single Table Analysis

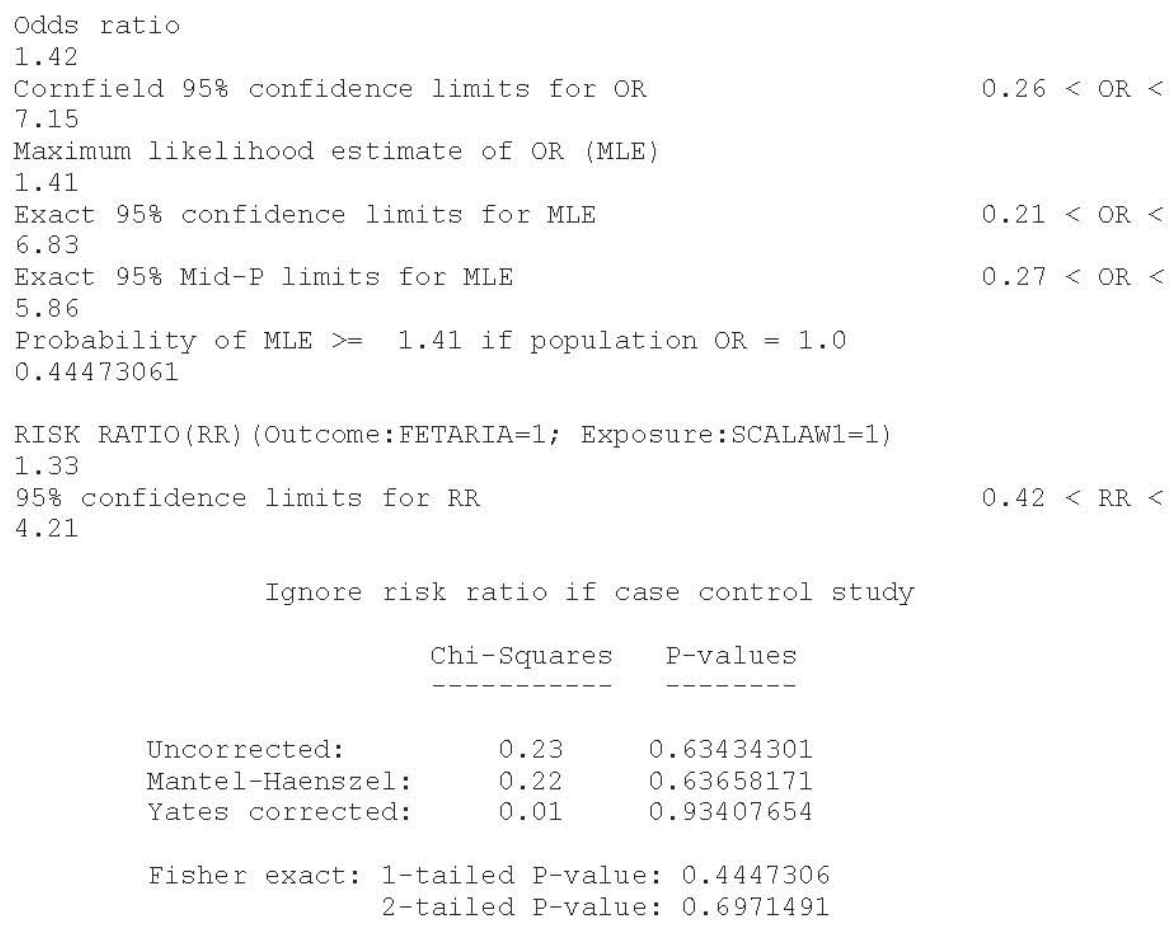

An expected value is less than 5; recommend Fisher exact results.

Current selection: RENDAPESSO $<>$.

\begin{tabular}{r|ccc} 
& \multicolumn{3}{c}{$\mathrm{RP}$} \\
SCALAW1 & 1 & 2 | Total \\
-1 & 11 & 3 & 14
\end{tabular}




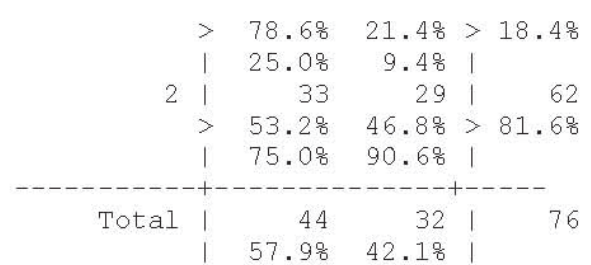

Single Table Analysis

odds ratio

3.22

Cornfield $95 \%$ confidence limits for oR

$0.72<\mathrm{OR}<$

$16.47^{\text {* }}$

*May be inaccurate

Maximum likelihood estimate of OR (MLE)

3.18

Exact $95 \%$ confidence limits for MLE

19.45

Exact 95\% Mid-P limits for MLE

15.39

Probability of MLE $>=3.18$ if population $\mathrm{OR}=1.0$

0.07315602

RISK RATIO(RR) (Outcome:RP=1; Exposure: SCALAW1=1)

1.48

95\% confidence limits for RR

2.11

Ignore risk ratio if case control study

$\begin{array}{lcc} & \text { Chi-Squares } & \text { P-values } \\ & & \\ & 3.01 & 0.08276288 \\ \text { Uncorrected: } & 2.97 & 0.08481189 \\ \text { Mantel-Haenszel: } & 2.06 & 0.15122581 \\ \text { Yates corrected: } & 2.06\end{array}$

Current selection: RENDAFAMIL $<>$.

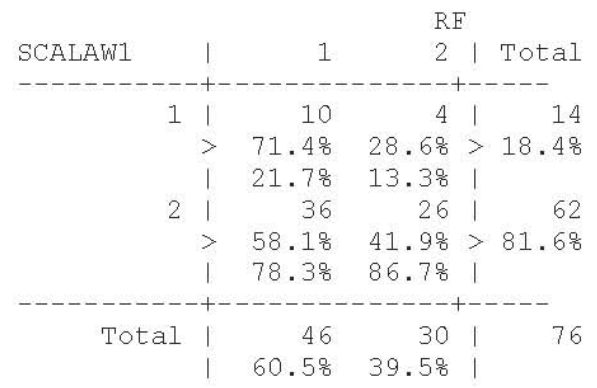

Single Table Analysis 


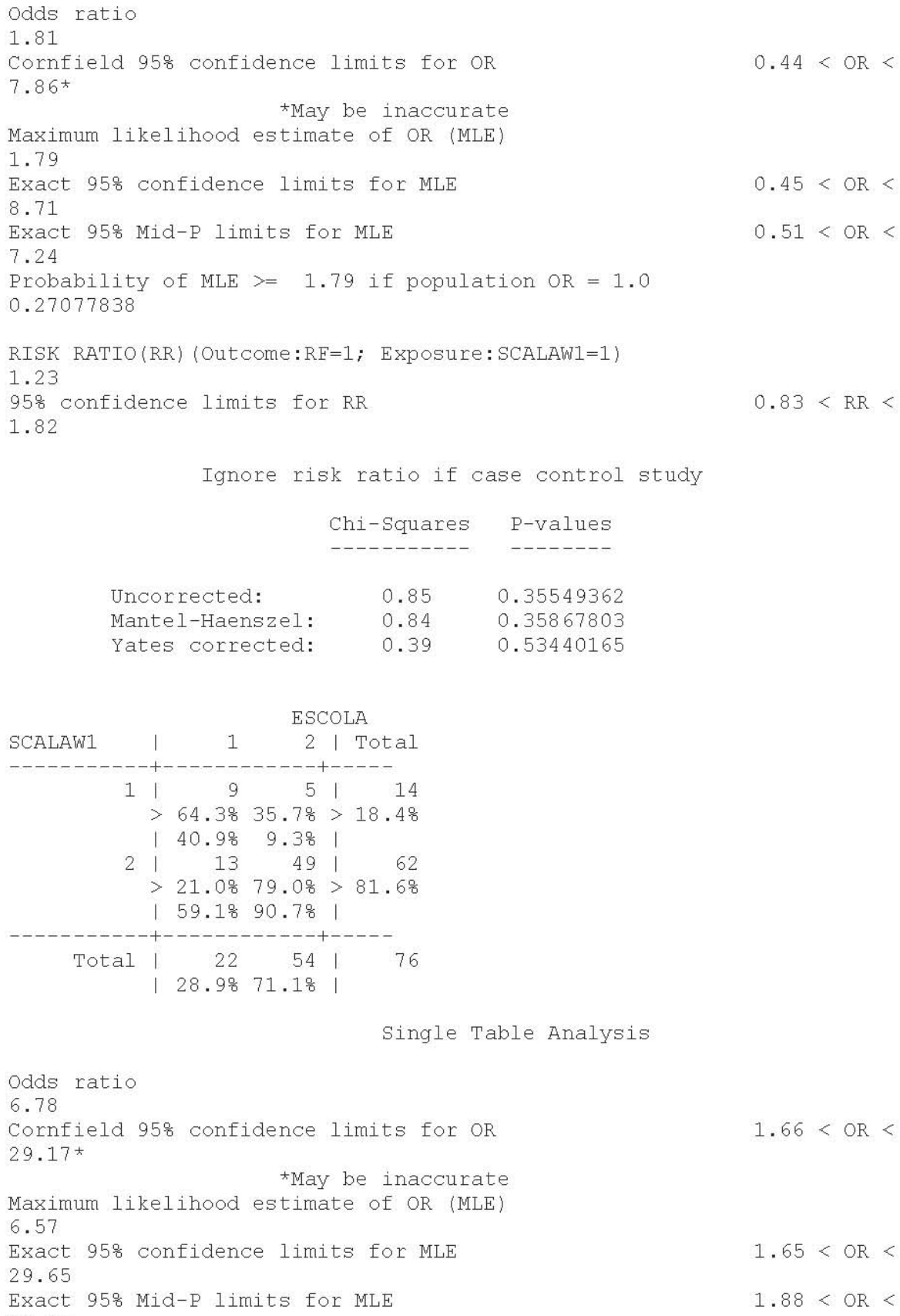

$0.44<\mathrm{OR}<$

$0.45<\mathrm{OR}<$

$0.51<\mathrm{OR}<$

$0.83<\mathrm{RR}<$

$1.66<\mathrm{OR}<$

$1.65<\mathrm{OR}<$

$1.88<\mathrm{OR}<$ 
RISK RATIO(RR) (Outcome:ESCOLA=1; Exposure: SCALAW1=1)

3.07

95\% confidence limits for RR

$1.65<\mathrm{RR}<$

5.71

Ignore risk ratio if case control study

$\begin{array}{lcc} & \text { Chi-Squares } & \text { P-values } \\ & & \\ & & \\ \text { Uncorrected: } & 10.42 & 0.00124682<--- \\ \text { Mantel-Haenszel: } & 10.28 & 0.00134294<--- \\ \text { Yates corrected: } & 8.42 & 0.00371121<--- \\ \text { Fisher exact: } & \text { 1-tailed P-value: } 0.0026133<--- \\ & \text { 2-tailed P-value: } 0.0026133<---\end{array}$

An expected value is less than 5; recommend Fisher exact results.

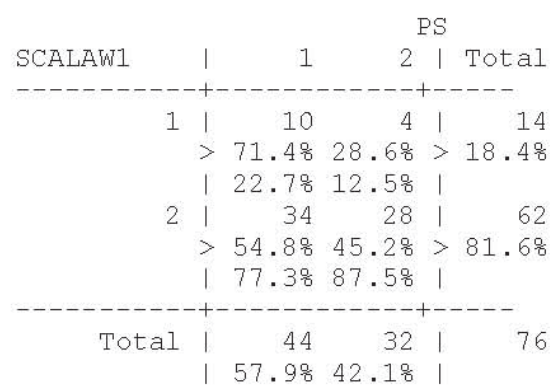

Single Table Analysis

odds ratio

2.06

Cornfield 95\% confidence limits for OR

$0.51<\mathrm{OR}<$

$8.95^{\star}$

*May be inaccurate

Maximum likelihood estimate of OR (MLE)

2.04

Exact 958 confidence limits for MLE

9.89

Exact $95 \%$ Mid-P limits for MLE

8.23

Probability of MLE $>=2.04$ if population $\mathrm{OR}=1.0$

0.20298475

RISK RATIO(RR) (Outcome:PS=1; Exposure: SCALAW1=1)

1.30

95\% confidence limits for RR

$0.87<\mathrm{RR}<$

1.95

Ignore risk ratio if case control study

Chi-Squares P-values 
$\begin{array}{lll}\text { Uncorrected: } & 1.29 & 0.25614293 \\ \text { Mantel-Haenszel: } & 1.27 & 0.25929487\end{array}$

Yates corrected: $\quad 0.70 \quad 0.40321425$ 


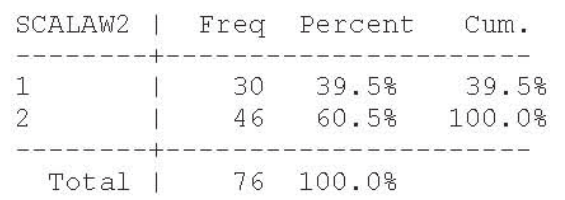

$\begin{array}{rrrrrr}\text { Total } & \text { Sum } & \text { Mean } & \text { Variance } & \text { Std Dev } & \text { Std Err } \\ 76 & 122 & 1.605 & 0.242 & 0.492 & 0.056 \\ & & & & & \\ \text { Minimum } & 258 \text { ile } & \text { Median } & 758 \text { ile } & \text { Maximum } & \text { Mode } \\ 1.000 & 1.000 & 2.000 & 2.000 & 2.000 & 2.000\end{array}$

Student's "t", testing whether mean differs from zero. $\mathrm{T}$ statistic $=28.441, \mathrm{df}=75 \mathrm{p}$-value $=0.00000$

\begin{tabular}{|c|c|c|c|}
\hline & & & \\
\hline SCALAW2 & । & 1. & 2. I Total \\
\hline 1 & | & 10 & 201 \\
\hline & $>$ & 33.38 & $66.78>39.5 \%$ \\
\hline & । & $41.7 \%$ & $38.58 \quad \mid$ \\
\hline 2 & i & 14 & 32 \\
\hline & $>$ & 30.48 & $69.68>60.5 \%$ \\
\hline & । & 58.38 & $61.5 \% \quad \mid$ \\
\hline Total & | & 24 & 52 | \\
\hline & । & 31.68 & $68.4 \% \quad \mid$ \\
\hline
\end{tabular}

Single Table Analysis

Odds ratio

1.14

Cornfield $95 \%$ confidence limits for oR

3.45

Maximum likelihood estimate of OR (MLE)

1.14

Exact 95\% confidence limits for MLE

3.40

Exact $95 \%$ Mid-P limits for MLE

3.09

Probability of MLE $>=1.14$ if population $\mathrm{OR}=1.0$

0.49204249

RISK RATIO(RR) (Outcome: $\mathrm{SEXO}=1$. ; Exposure: SCALAW2=1)

1.10

95\% confidence limits for RR

$0.38<\mathrm{OR}<$

2.14

Ignore risk ratio if case control study

Chi-Squares P-values 


\begin{tabular}{r|rr|r} 
& 58.38 & 61.18 & \\
-1 & 12 & 36 & 48 \\
Total & 25.08 & 75.08 &
\end{tabular}

Single Table Analysis

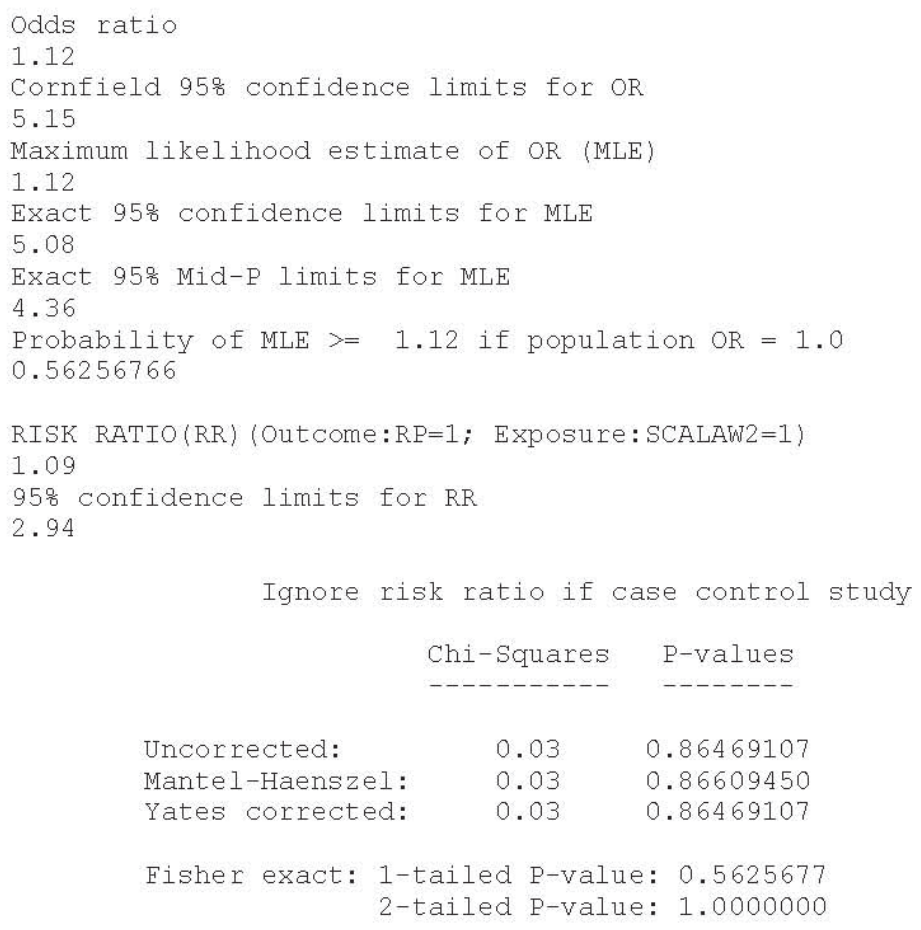

$\begin{array}{lcc} & \text { Chi-Squares } & \text { P-values } \\ & & ------ \\ \text { Uncorrected: } & 0.03 & 0.86469107 \\ \text { Mantel-Haenszel: } & 0.03 & 0.86609450 \\ \text { Yates corrected: } & 0.03 & 0.86469107\end{array}$

Fisher exact: 1-tailed P-value: 0.5625677 2-tailed P-value: 1.0000000

An expected value is less than 5; recommend Fisher exact results.

Current selection: RENDAFAMIL $<>$.

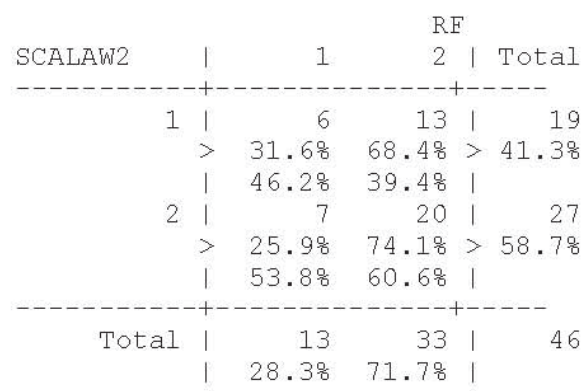

Single Table Analysis

Odds ratio

1.32 
Cornfield 95\% confidence limits for OR

$0.30<\mathrm{OR}<$

Maximum likelihood estimate of OR (MLE)

1.31

Exact 95\% confidence limits for MLE

5.79

Exact 95\% Mid-P limits for MLE

4.97

Probability of MLE $>=1.31$ if population $\mathrm{OR}=1.0$

0.46214223

RISK RATIO(RR) (Outcome:RF=1; Exposure: SCALAW2=1)

1.22

95\% confidence limits for RR

3.05

$0.29<\mathrm{OR}<$

$0.34<\mathrm{OR}<$

$0.49<\mathrm{RR}<$

Ignore risk ratio if case control study

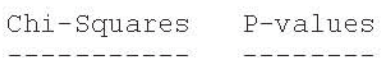

Uncorrected:

$0.18 \quad 0.67502178$

Mantel-Haenszel:

0.17

0.67837349

Yates corrected:

0.01

0.93087446

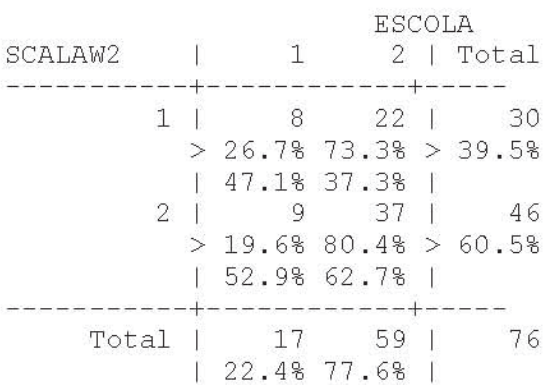

Single Table Analysis

odds ratio

1.49

Cornfield 95\% confidence limits for OR

5.11

Maximum likelihood estimate of OR (MLE)

1.49

Exact $95 \%$ confidence limits for MLE

5.08

Exact $95 \%$ Mid-P limits for MLE

4.53

Probability of MLE $>=1.49$ if population $\mathrm{OR}=1.0$

0.32549876

RISK RATIO(RR) (Outcome: ESCOLA=1; Exposure: SCALAW2=1)

1.36

95\% confidence limits for $R R$

3.14
$0.44<\mathrm{OR}<$

$0.43<\mathrm{OR}<$

$0.48<\mathrm{OR}<$

$0.59<\mathrm{RR}<$ 
Ignore risk ratio if case control study

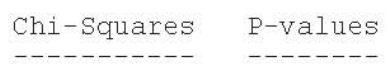

$\begin{array}{lll}\text { Uncorrected: } & 0.53 & 0.46772989 \\ \text { Mantel-Haenszel: } & 0.52 & 0.47067309 \\ \text { Yates corrected: } & 0.20 & 0.65660990\end{array}$

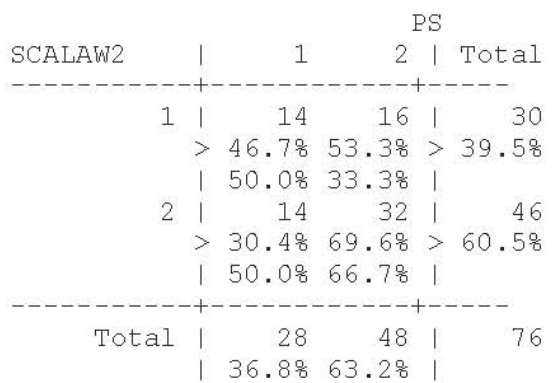

Single Table Analysis

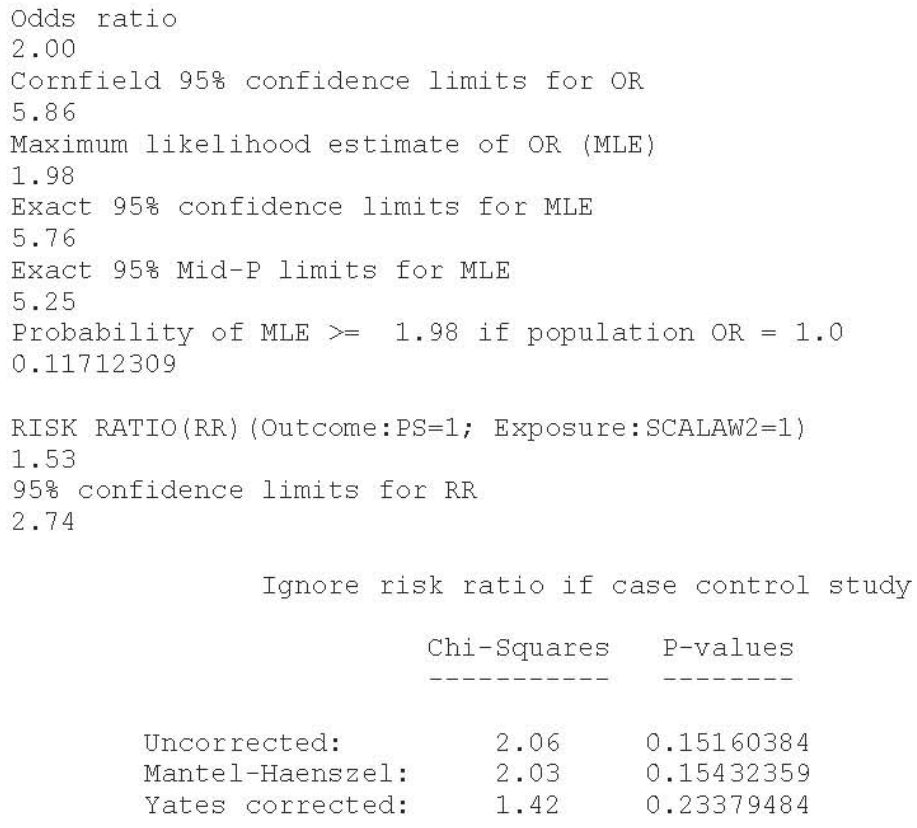

$\begin{array}{cc}\text { Chi-Squares } & \text { P-values } \\ 2.06 & 0.15160384 \\ 2.03 & 0.15432359 \\ 1.42 & 0.23379484\end{array}$




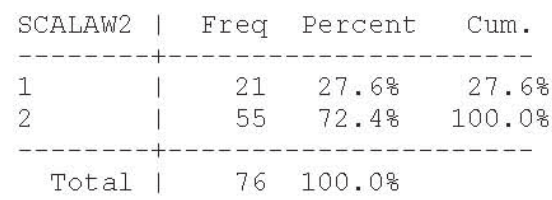

$\begin{array}{rrrrrr}\text { Total } & \text { Sum } & \text { Mean } & \text { Variance } & \text { Std Dev } & \text { Std Err } \\ 76 & 131 & 1.724 & 0.203 & 0.450 & 0.052 \\ & & & & & \\ \text { Minimum } & 258 \text { rile } & \text { Median } & 75 \% \text { ile } & \text { Maximum } & \text { Mode } \\ 1.000 & 1.000 & 2.000 & 2.000 & 2.000 & 2.000\end{array}$

Student's "t", testing whether mean differs from zero. $\mathrm{T}$ statistic $=33.382, \mathrm{df}=75 \mathrm{p}$-value $=0.00000$

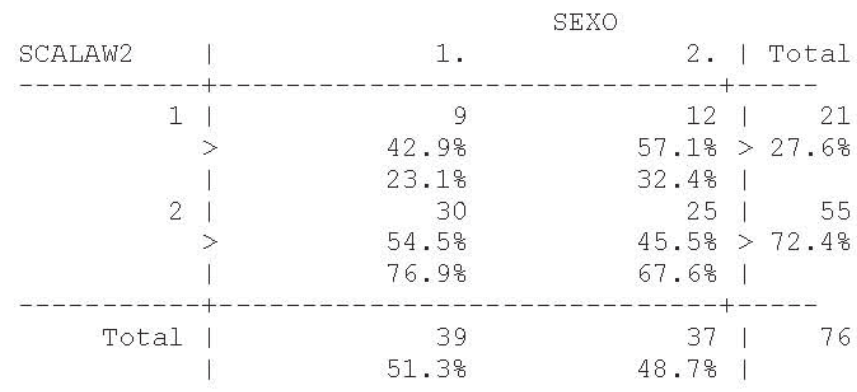

Single Table Analysis

odds ratio

0.63

Cornfield 95\% confidence limits for OR

1. 95

Maximum likelihood estimate of OR (MLE)

0.63

Exact 95\% confidence limits for MLE

1.93

Exact 95\% Mid-P limits for MLE

1.75

Probability of $\mathrm{MLE}<=0.63$ if population $\mathrm{OR}=1.0$

0.25634777

RISK RATIO(RR) (Outcome: SEXO=1.; Exposure: SCALAW2=1)

0.79

95\% confidence limits for RR

1.36

$0.20<\mathrm{OR}<$

$0.20<\mathrm{OR}<$

$0.22<\mathrm{OR}<$

$0.45<\mathrm{RR}<$

Ignore risk ratio if case control study

$$
\text { Chi-Squares P-values }
$$




$\begin{array}{lll}\text { Uncorrected: } & 0.83 & 0.36196596 \\ \text { Mantel-Haenszel: } & 0.82 & 0.36514338 \\ \text { Yates corrected: } & 0.43 & 0.51245506\end{array}$

Yates corrected: $\quad 0.43-0.51245506$

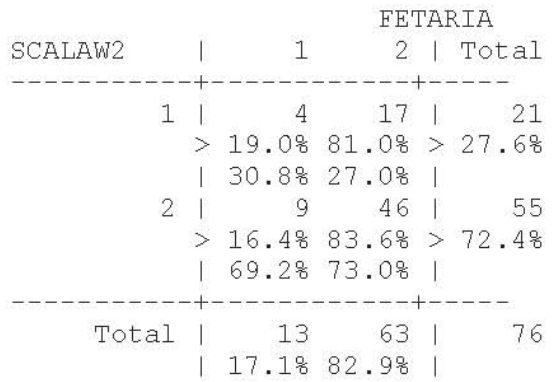

Single Table Analysis

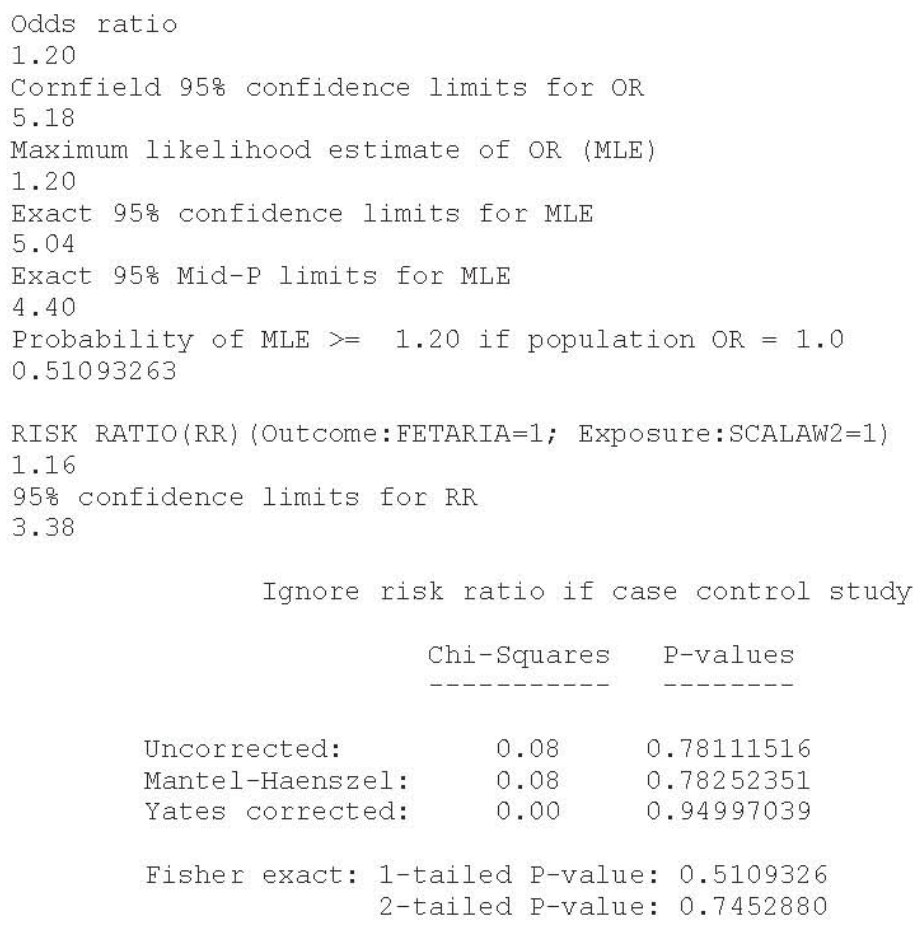

An expected value is less than 5; recommend Fisher exact results.

Current selection: RENDAPESSO $<>$.

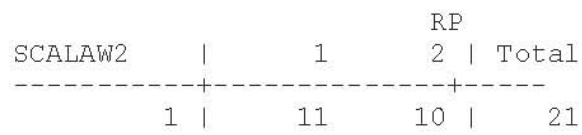




$\begin{array}{rrrrrr} & > & 52.48 & 47.68 & >27.68 \\ 2 & \mid & 25.08 & 31.38 & \\ & > & 60.08 & 22 & 50.08 \\ & \mid & 75.08 & 68.88 & 72.48 \\ -0 & 44 & 32 & 76 \\ \text { Total } & & 48 & \\ & 57.98 & 42.18 & \end{array}$

Single Table Analysis

odds ratio

0.73

Cornfield $95 \%$ confidence limits for oR

$0.23<\mathrm{OR}<$

2.29

Maximum likelihood estimate of OR (MLE)

0.74

Exact $95 \%$ confidence limits for MLE

2.30

Exact $95 \%$ Mid-P limits for MLE

2.07

Probability of $\mathrm{MLE}<=0.74$ if population $\mathrm{OR}=1.0$

0.36444786

RISK RATIO(RR) (Outcome:RP=1; Exposure: SCALAW2=1)

0.87

95\% confidence limits for RR

1.38

Ignore risk ratio if case control study

$\begin{array}{lcc} & \text { Chi-Squares } & \text { P-values } \\ & & ----- \\ \text { Uncorrected: } & 0.36 & 0.54745028 \\ \text { Mantel-Haenszel: } & 0.36 & 0.55009732 \\ \text { Yates corrected: } & 0.12 & 0.73249405\end{array}$

Current selection: RENDAFAMIL $<>$.

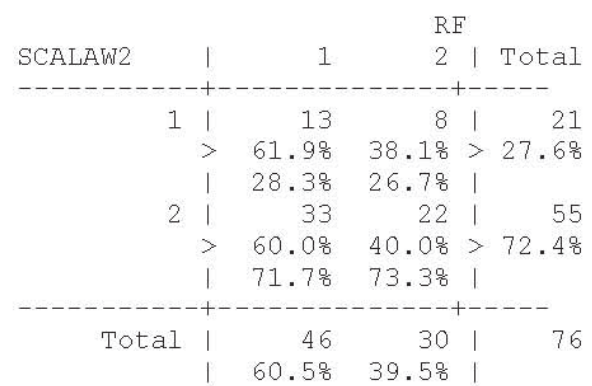

Single Table Analysis

Odds ratio

1.08 
Cornfield 95\% confidence limits for OR

3.48

Maximum likelihood estimate of OR (MLE)

1.08

Exact 95\% confidence limits for MLE

3.55

Exact $95 \%$ Mid-P limits for MLE

3.17

Probability of $\mathrm{MLE}>=1.08$ if population $\mathrm{OR}=1.0$

0.54718416

RISK RATIO(RR) (Outcome:RF=1; Exposure: $\operatorname{SCALAW2=1}$

1.03

95\% confidence limits for $R R$

1.54

Ignore risk ratio if case control study

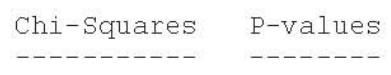

$\begin{array}{lll}\text { Uncorrected: } & 0.02 & 0.87925445 \\ \text { Mantel-Haenszel: } & 0.02 & 0.88004541 \\ \text { Yates corrected: } & 0.01 & 0.91202617\end{array}$

Yates corrected: $\quad 0.01 \quad 0.91202617$

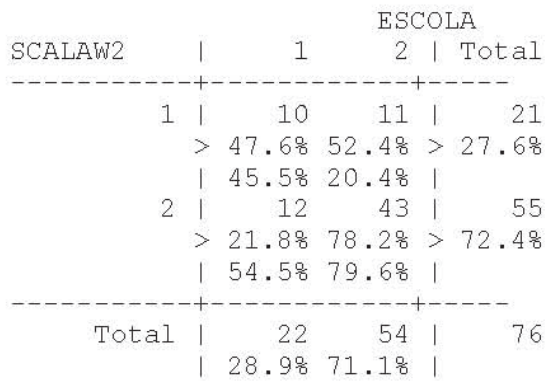

Single Table Analysis

Odds ratio

3.26

Cornfield $95 \%$ confidence limits for oR

11.02

Maximum likelihood estimate of OR (MLE)

3.20

Exact 95\% confidence limits for MLE

10.77

Exact $95 \%$ Mid-P limits for MLE

9. 61

Probability of MLE $>=3.20$ if population $\mathrm{OR}=1.0$

0.02848517

RISK RATIO(RR) (Outcome: ESCOLA=1; Exposure: SCALAW2=1)

2.18

95\% confidence limits for RR

4.27
$0.34<\mathrm{OR}<$

$0.35<O R<$

$0.38<\mathrm{OR}<$

$0.69<R R<$
$0.98<\mathrm{OR}<$

$0.97<\mathrm{OR}<$

$1.08<\mathrm{OR}<$

$1.11<\mathrm{RR}<$ 
Ignore risk ratio if case control study

$$
\text { Chi-Squares P-values }
$$

Uncorrected: $\quad 4.92 \quad 0.02656796<---$

Mantel-Haenszel: $\quad 4.85 \quad 0.02758289$

Yates corrected: $\quad 3.74 \quad 0.05299032$

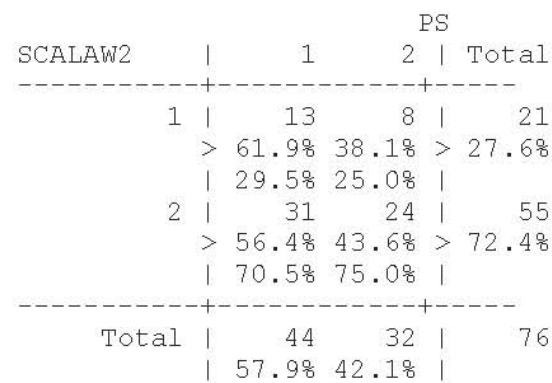

Single Table Analysis

Odds ratio

1.26

Cornfield 95\% confidence limits for $O R$

$0.40<\mathrm{OR}<$

4.03

Maximum likelihood estimate of OR (MLE)

1.25

Exact $95 \%$ confidence limits for MLE

4.10

Exact $95 \%$ Mid-P limits for MLE

3.66

Probability of MLE $>=1.25$ if population $\mathrm{OR}=1.0$

0.43203348

RISK RATIO(RR) (Outcome:PS=1; Exposure: SCALAW2=1)

1.10

958 confidence limits for RR

1.65

Ignore risk ratio if case control study

\begin{tabular}{|c|c|c|}
\hline & Chi-Squares & P-values \\
\hline Uncorrected: & 0.19 & 0.66173680 \\
\hline Mantel-Haenszel: & 0.19 & 0.66383204 \\
\hline Yates corrected: & 0.03 & 0.85892632 \\
\hline
\end{tabular}




\begin{tabular}{|c|c|c|c|c|c|}
\hline & & & MOME & ENT & \\
\hline D1TS0100 & | & 1 & 2 & | & Total \\
\hline - & & -1 & --+ & - & -- \\
\hline 44 & | & 1 & 0 & | & 1 \\
\hline & $>$ & 100.08 & 0.08 & $>$ & $0.6 \%$ \\
\hline & | & 1.28 & 0.08 & | & \\
\hline 50 & | & 6 & 0 & i & 6 \\
\hline & $>$ & $100.0 \%$ & 0.08 & $>$ & $3.5 \%$ \\
\hline & | & $7.1 \%$ & $0.0 \%$ & 1 & \\
\hline 56 & | & 6 & 1 & 1 & 7 \\
\hline & $>$ & 85.78 & 14.38 & $>$ & 4.18 \\
\hline & | & 7.18 & 1.28 & 1 & \\
\hline 63 & | & 28 & 3 & i & 31 \\
\hline & $>$ & 90.38 & $9.7 \%$ & $>$ & $18.2 \%$ \\
\hline & | & 32.98 & 3.58 & 1 & \\
\hline 69 & i & 24 & 20 & 1 & 44 \\
\hline & $>$ & 54.58 & $45.5 \%$ & $>$ & 25.98 \\
\hline & | & 28.28 & 23.58 & 1 & \\
\hline 75 & 1 & 8 & 28 & i & 36 \\
\hline & $>$ & $22.2 \%$ & $77.8 \%$ & $>$ & $21.2 \%$ \\
\hline & । & $9.4 \%$ & 32.98 & 1 & \\
\hline 81 & | & 7 & 26 & 1 & 33 \\
\hline & $>$ & $21.2 \%$ & $78.8 \%$ & $>$ & $19.4 \%$ \\
\hline & । & 8.28 & 30.68 & 1 & \\
\hline 88 & | & 4 & 6 & | & 10 \\
\hline & $>$ & 40.08 & $60.0 \%$ & $>$ & $5.9 \%$ \\
\hline & | & 4.78 & 7.18 & 1 & \\
\hline 94 & | & 1 & 1 & 1 & 2 \\
\hline & $>$ & $50.0 \%$ & 50.08 & $>$ & 1.28 \\
\hline & | & $1.2 \%$ & $1.2 \%$ & I & \\
\hline Total & 1 & 85 & 85 & I & 170 \\
\hline & & $50.0 \%$ & 50.08 & I & \\
\hline
\end{tabular}

\begin{tabular}{|c|c|c|c|c|c|}
\hline MOMENTO & Obs & Total & Mean & Variance & Std Dev \\
\hline 1 & 85 & 5713 & 67.212 & 94.121 & 9.702 \\
\hline 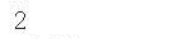 & 85 & 6453 & 75.918 & 44.672 & 6.684 \\
\hline Difference & & & -8.706 & & \\
\hline $\begin{array}{l}\text { MOMENTO } \\
\text { Mode }\end{array}$ & Minimum & 258ile & Median & 758 ile & Maximum \\
\hline 1 & 44.000 & 63.000 & 69.000 & 69.000 & 94.000 \\
\hline $\begin{array}{l}63.000 \\
2\end{array}$ & 56 مח 50 & 690 & 750 & 810 & 40 \\
\hline 75.000 & 0.00 & 09.000 & & 01.000 & 94.000 \\
\hline
\end{tabular}

$\begin{array}{lrrrrrr}\text { Variation } & \text { SS } & \text { df } & \text { MS } & \text { F statistic } & \text { p-value } & \text { t-value } \\ \text { Between } & 3221.176 & 1 & 3221.176 & 46.417 & 0.000000 & 6.813001 \\ \text { Within } & 11658.612 & 168 & 69.396 & & & \\ \text { Total } & 14879.788 & 169 & & & \end{array}$

Bartlett's test for homogeneity of variance 
Bartlett's chi square $=11.335$ deg freedom $=1$ p-value $=$
0.000760

Bartlett's Test shows the variances in the samples to differ. Use non-parametric results below rather than ANOVA.

Mann-Whitney or Wilcoxon Two-Sample Test (Kruskal-Wallis test for two groups)

Kruskal-Wallis H (equivalent to Chi square) $=41.962$

$\begin{array}{rr}\text { Degrees of freedom }= & 1 \\ \mathrm{p} \text { value }= & 0.000000\end{array}$ 


\begin{tabular}{|c|c|c|c|c|c|}
\hline & & & MOME & ENT & \\
\hline D2TS0100 & | & 1 & 2 & | & Total \\
\hline$-\ldots$ & & -- & --+ & - & -- \\
\hline 31 & | & 1 & 0 & | & 1 \\
\hline & $>$ & 100.08 & 0.08 & $>$ & 0.68 \\
\hline & | & 1.28 & 0.08 & | & \\
\hline 38 & i & 2 & 0 & i & 2 \\
\hline & $>$ & $100.0 \%$ & 0.08 & $>$ & $1.2 \%$ \\
\hline & | & $2.4 \%$ & $0.0 \%$ & 1 & \\
\hline 44 & । & 8 & 1 & 1 & 9 \\
\hline & $>$ & 88.98 & 11.18 & $>$ & 5.38 \\
\hline & | & 9.48 & 1.28 & | & \\
\hline 50 & i & 10 & 3 & i & 13 \\
\hline & $>$ & 76.98 & $23.1 \%$ & $>$ & 7.68 \\
\hline & | & $11.8 \%$ & 3.58 & | & \\
\hline 56 & | & 27 & 4 & I & 31 \\
\hline & $>$ & 87.18 & 12.98 & $>$ & 18.28 \\
\hline & | & $31.8 \%$ & 4.78 & 1 & \\
\hline 63 & | & 10 & 7 & i & 17 \\
\hline & $>$ & $58.8 \%$ & $41.2 \%$ & $>$ & $10.0 \%$ \\
\hline & | & $11.8 \%$ & 8.28 & 1 & \\
\hline 69 & i & 16 & 17 & i & 33 \\
\hline & $>$ & $48.5 \%$ & 51.58 & $>$ & $19.4 \%$ \\
\hline & 1 & 18.88 & $20.0 \%$ & | & \\
\hline 75 & | & 5 & 17 & | & 22 \\
\hline & $>$ & 22.78 & 77.38 & $>$ & $12.9 \%$ \\
\hline & | & 5.98 & 20.08 & 1 & \\
\hline 81 & | & 6 & 33 & 1 & 39 \\
\hline & $>$ & 15.48 & $84.6 \%$ & $>$ & $22.9 \%$ \\
\hline & I & 7.18 & $38.8 \%$ & | & \\
\hline 88 & | & 0 & 2 & I & 2 \\
\hline & $>$ & $0.0 \%$ & 100.08 & $>$ & $1.2 \%$ \\
\hline & | & $0.0 \%$ & $2.4 \%$ & 1 & \\
\hline 94 & | & 0 & 1 & 1 & 1 \\
\hline & $>$ & 0.08 & 100.08 & $>$ & $0.6 \%$ \\
\hline & | & $0.0 \%$ & 1.28 & I & \\
\hline Total & 1 & 85 & 85 & I & 170 \\
\hline & & $50.0 \%$ & 50.08 & I & \\
\hline
\end{tabular}

$\begin{array}{lrrrrr}\text { MOMENTO } & \text { Obs } & \text { Total } & \text { Mean } & \text { Variance } & \text { Std Dev } \\ 1 & 85 & 5066 & 59.600 & 124.195 & 11.144 \\ 2 & 85 & 6250 & 73.529 & 90.514 & 9.514 \\ \text { Difference } & & & -13.929 & & \\ \text { MOMENTO } & \text { Minimum } & 258 \text { ile } & \text { Median } & 758 \text { ile } & \text { Maximum } \\ \begin{array}{l}\text { Mode } \\ 1 \\ 56.000\end{array} & 31.000 & 56.000 & 56.000 & 69.000 & 81.000 \\ 2 & & & & & \\ 81.000 & 44.000 & 69.000 & 75.000 & 81.000 & 94.000\end{array}$

ANOVA

(For normally distributed data only)

Variation SS df MS F statistic p-value t-value 


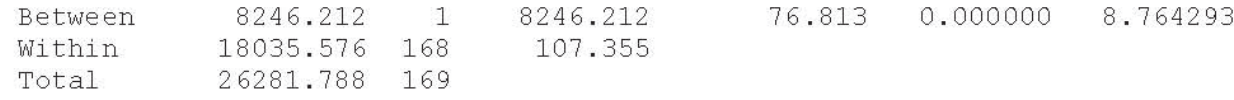

Total 26281.788 169

Bartlett's test for homogeneity of variance

Bartlett's chi square $=2.081$ deg freedom $=1 \quad \mathrm{p}$-value $=$ 0.149188

The variances are homogeneous with $95 \%$ confidence.

If samples are also normally distributed, ANOvA results can be

used.

Mann-Whitney or Wilcoxon Two-Sample Test (Kruskal-Wallis test for two groups)

Kruskal-Wallis $\mathrm{H}$ (equivalent to Chi square) $=\quad 54.549$

$\begin{array}{rr}\text { Degrees of } \mathrm{freedom}= & 1 \\ \mathrm{p} \text { value }= & 0.000000\end{array}$ 


\begin{tabular}{|c|c|c|c|c|c|}
\hline & & & MOM & ENT & \\
\hline D3TS0100 & | & 1 & 2 & 1 & Total \\
\hline--1 & & -- & -- & +- & -1 \\
\hline 25 & | & 12 & 0 & 1 & 12 \\
\hline & $>$ & 100.08 & 0.08 & $>$ & 7.58 \\
\hline & | & 15.08 & 0.08 & | & \\
\hline 31 & i & 11 & 3 & i & 14 \\
\hline & $>$ & 78.68 & $21.4 \%$ & $>$ & $8.8 \%$ \\
\hline & । & $13.8 \%$ & $3.8 \%$ & 1 & \\
\hline 44 & i & 8 & 5 & i & 13 \\
\hline & $>$ & $61.5 \%$ & $38.5 \%$ & $>$ & $8.1 \%$ \\
\hline & । & $10.0 \%$ & 6.38 & | & \\
\hline 50 & i & 34 & 9 & i & 43 \\
\hline & $>$ & 79.18 & 20.98 & $>$ & $26.9 \%$ \\
\hline & । & $42.5 \%$ & 11.38 & 1 & \\
\hline 56 & i & 1 & 5 & i & 6 \\
\hline & $>$ & 16.78 & $83.3 \%$ & $>$ & $3.8 \%$ \\
\hline & | & 1.38 & 6.38 & | & \\
\hline 69 & i & 5 & 34 & i & 39 \\
\hline & $>$ & $12.8 \%$ & $87.2 \%$ & $>$ & $24.4 \%$ \\
\hline & | & $6.3 \%$ & $42.5 \%$ & 1 & \\
\hline 75 & | & 7 & 13 & | & 20 \\
\hline & $>$ & $35.0 \%$ & 65.08 & $>$ & $12.5 \%$ \\
\hline & । & $8.8 \%$ & $16.3 \%$ & 1 & \\
\hline 81 & | & 0 & 1 & | & 1 \\
\hline & $>$ & $0.0 \%$ & $100.0 \%$ & $>$ & $0.6 \%$ \\
\hline & | & 0.08 & $1.3 \%$ & | & \\
\hline 94 & 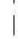 & 1 & 9 & i & 10 \\
\hline & $>$ & $10.0 \%$ & $90.0 \%$ & $>$ & 6.38 \\
\hline & । & 1.38 & 11.38 & I & \\
\hline 100 & | & 1 & 1 & | & \\
\hline & $>$ & $50.0 \%$ & $50.0 \%$ & $>$ & $1.3 \%$ \\
\hline & | & $1.3 \%$ & 1.38 & 1 & \\
\hline Total & & 80 & 80 & | & 160 \\
\hline & & $50.0 \%$ & 50.08 & 1 & \\
\hline
\end{tabular}

\begin{tabular}{|c|c|c|c|c|c|}
\hline MOMENTO & Obs & Total & Mean & Variance & Std Dev \\
\hline 1 & 80 & 3813 & 47.663 & 278.150 & 16.678 \\
\hline 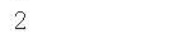 & 80 & 5391 & 67.388 & 234.696 & 15.320 \\
\hline Difference & & & -19.725 & & \\
\hline $\begin{array}{l}\text { MOMENTO } \\
\text { Mode }\end{array}$ & Minimum & 25\%ile & Median & 758 ile & Maximum \\
\hline $\begin{array}{l}1 \\
50.000\end{array}$ & 25.000 & 31.000 & 50.000 & 50.000 & 100.000 \\
\hline $\begin{array}{l}2 \\
69.000\end{array}$ & 31.000 & 56.000 & 69.000 & 75.000 & 100.000 \\
\hline
\end{tabular}

$\begin{array}{lrrrrrr}\text { Variation } & \text { SS } & \text { df } & \text { MS } & \text { F statistic } & \text { p-value } & \text { t-value } \\ \text { Between } & 15563.025 & 1 & 15563.025 & 60.693 & 0.000000 & 7.790553 \\ \text { Within } & 40514.875 & 158 & 256.423 & & & \\ \text { Total } & 56077.900 & 159 & & & \end{array}$


Bartlett's test for homogeneity of variance

Bartlett's chi square $=0.566$ deg freedom $=1 \quad \mathrm{p}$-value $=$ 0.451995

The variances are homogeneous with 95\% confidence. used.

If samples are also normally distributed, ANOVA results can be

Mann-Whitney or Wilcoxon Two-Sample Test (Kruskal-Wallis test for two groups)

Kruskal-Wallis $\mathrm{H}$ (equivalent to Chi square) $=44.082$

$\begin{array}{rr}\text { Degrees of freedom }= & 1 \\ & \end{array}$




\begin{tabular}{|c|c|c|c|c|c|}
\hline & & & MOME & ENT & \\
\hline D4TS0100 & | & 1 & 2 & | & Total \\
\hline-- & + & - & --+ & - & -- \\
\hline 25 & 1 & 1 & 0 & 1 & 1 \\
\hline & $>$ & 100.08 & 0.08 & $>$ & $0.6 \%$ \\
\hline & | & 1.28 & 0.08 & | & \\
\hline 31 & i & 9 & 1 & i & 10 \\
\hline & $>$ & $90.0 \%$ & $10.0 \%$ & $>$ & 5.98 \\
\hline & 1 & 10.68 & $1.2 \%$ & 1 & \\
\hline 38 & 1 & 38 & 5 & 1 & 43 \\
\hline & $>$ & $88.4 \%$ & 11.68 & $>$ & $25.3 \%$ \\
\hline & | & 44.78 & 5.98 & 1 & \\
\hline 44 & i & 12 & 9 & i & 21 \\
\hline & $>$ & 57.18 & 42.98 & $>$ & $12.4 \%$ \\
\hline & 1 & 14.18 & 10.68 & 1 & \\
\hline 50 & i & 12 & 19 & i & 31 \\
\hline & $>$ & 38.78 & 61.38 & $>$ & 18.28 \\
\hline & i & 14.18 & 22.48 & 1 & \\
\hline 56 & i & 6 & 21 & i & 27 \\
\hline & $>$ & $22.2 \%$ & $77.8 \%$ & $>$ & $15.9 \%$ \\
\hline & 1 & $7.1 \%$ & 24.78 & 1 & \\
\hline 63 & 1 & 3 & 18 & 1 & 21 \\
\hline & $>$ & $14.3 \%$ & $85.7 \%$ & $>$ & $12.4 \%$ \\
\hline & 1 & $3.5 \%$ & $21.2 \%$ & 1 & \\
\hline 69 & i & 2 & 9 & | & 11 \\
\hline & $>$ & 18.28 & $81.8 \%$ & $>$ & $6.5 \%$ \\
\hline & 1 & 2.48 & $10.6 \%$ & 1 & \\
\hline 75 & i & 1 & 2 & i & 3 \\
\hline & $>$ & 33.38 & $66.7 \%$ & $>$ & $1.8 \%$ \\
\hline & I & $1.2 \%$ & $2.4 \%$ & I & \\
\hline 88 & 1 & 1 & 1 & I & \\
\hline & $>$ & $50.0 \%$ & 50.08 & $>$ & 1.28 \\
\hline & 1 & $1.2 \%$ & $1.2 \%$ & 1 & \\
\hline Total & I & $\begin{array}{r}85 \\
50.0 \%\end{array}$ & $\begin{array}{r}85 \\
50.08\end{array}$ & I & 170 \\
\hline
\end{tabular}

\begin{tabular}{|c|c|c|c|c|c|}
\hline MOMENTO & Obs & Total & Mean & Variance & Std Dev \\
\hline 1 & 85 & 3702 & 43.553 & 116.179 & 10.779 \\
\hline 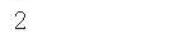 & 85 & 4736 & 55.718 & 99.610 & 9.980 \\
\hline Difference & & & -12.165 & & \\
\hline $\begin{array}{l}\text { MOMENTO } \\
\text { Mode }\end{array}$ & Minimum & 25\%ile & Median & 758 ile & Maximum \\
\hline $\begin{array}{l}1 \\
38.000\end{array}$ & 25.000 & 38.000 & 38.000 & 50.000 & 88.000 \\
\hline 2 & 31.000 & 50.000 & 56.000 & 63.000 & 88.000 \\
\hline
\end{tabular}

$\begin{array}{lrrrrrr}\text { Variation } & \text { SS } & \text { df } & \text { MS } & \text { F statistic } & \text { p-value } & \text { t-value } \\ \text { Between } & 6289.153 & 1 & 6289.153 & 58.290 & 0.000000 & 7.634787 \\ \text { Within } & 18126.235 & 168 & 107.894 & & & \\ \text { Total } & 24415.388 & 169 & & & \end{array}$


Bartlett's test for homogeneity of variance

Bartlett's chi square $=0.494$ deg freedom $=1 \quad \mathrm{p}$-value $=$ 0.482255

The variances are homogeneous with 95\% confidence. used.

If samples are also normally distributed, ANOvA results can be

Mann-Whitney or Wilcoxon Two-Sample Test (Kruskal-Wallis test for two groups)

Kruskal-Wallis $\mathrm{H}$ (equivalent to Chi square) $=51.782$

$\begin{array}{lr}\text { Degrees of freedom }= & 1 \\ & \end{array}$ 